\title{
Isolation and characterisation of thirteen pterosins and pterosides from bracken (Pteridium aquilinum (L.) Kuhn) rhizome
}

Rizgar Hassan Mohammad, Mohammad Nur e-Alam, Martina Lahmann, Ifat Parveen Shah, Graham J. Tizzard, Simon J. Coles, Mark Fowler, Alex F. Drake, Derren Heyes, Vera Thoss*

Thirteen previously undescribed pterosins and pterosides were isolated from bracken rhizomes in north of Wales. Their structures were elucidated using NMR spectroscopic and high resolution FT-ICR-MS data.
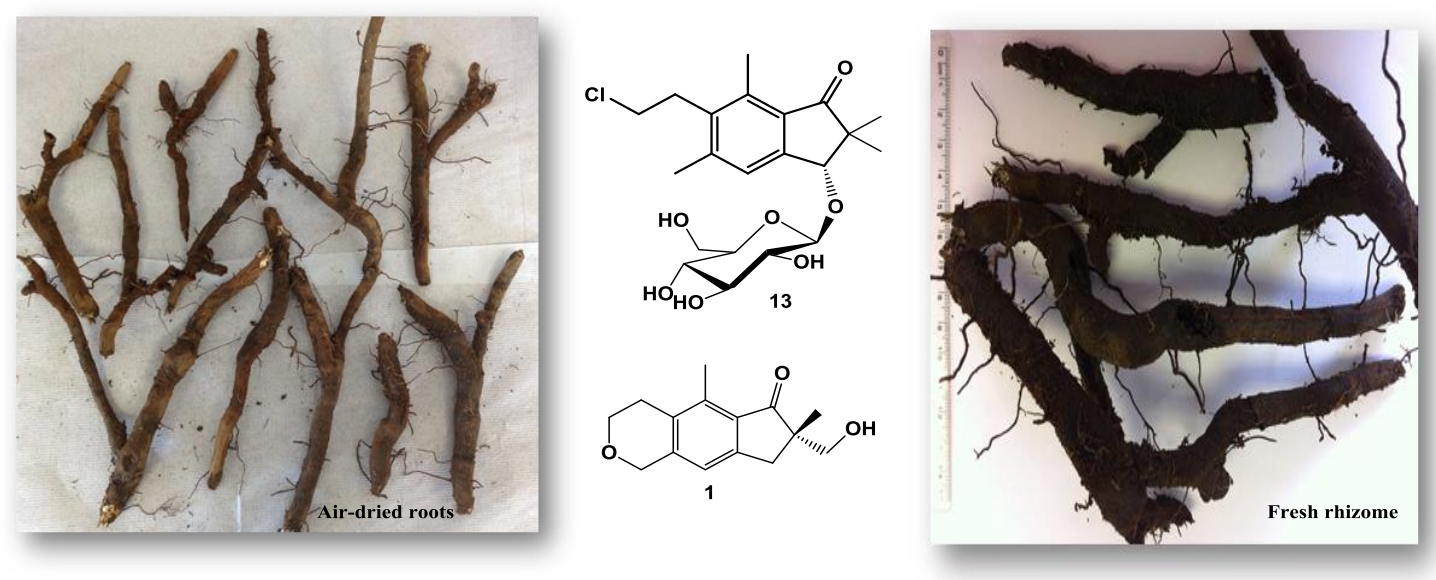

\section{Isolation and characterisation of 13 pterosins and pterosides from bracken (Pteridium aquilinum (L.) Kuhn) rhizome}

Rizgar Hassan Mohammad ${ }^{\mathrm{a}}$, Mohammad Nur-e-Alam ${ }^{\mathrm{a}, \mathrm{b}}$, Martina Lahmann ${ }^{\mathrm{a}}$, Ifat Parveen ${ }^{\mathrm{c}}$, Graham J. Tizzard ${ }^{\mathrm{d}}$, Simon J. Coles ${ }^{\mathrm{d}}$, Mark Fowler ${ }^{\mathrm{e}}$, Alex F. Drake ${ }^{\mathrm{f}}$, Derren Heyes ${ }^{\mathrm{g}}$, Vera $\operatorname{Thoss}^{\mathrm{a}, *}$

\footnotetext{
a School of Chemistry, Bangor University, Bangor LL57 2UW, United Kingdom

${ }^{b}$ Department of Pharmacognosy, College of Pharmacy, King Saud University, P.O. Box 2457, Riyadh 11451, Saudi Arabia
} 
${ }^{c}$ IBERS, Aberystwyth University, Penglais, Aberystwyth SY23 3DA, UK

${ }^{\mathrm{d}}$ UK National Crystallography Service, School of Chemistry, University of Southampton, University Road, Southampton SO17 1BJ, United Kingdom

${ }^{\text {e }}$ Strategic Science Group, Unilever R\&D, Colworth Science Park, Bedford, MK44 1LQ, UK

${ }^{\mathrm{f}}$ Biomolecular Spectroscopy Centre, Pharmaceutical Optical \& Chiroptical Spectroscopy Facility, King's College London, The Wolfson Wing, WWB10 Hodgkin Building, Guy's Campus, London SE1 1UL, UK

g Manchester Institute of Biotechnology, University of Manchester, 131 Princess St, Manchester M1 7DN

*Corresponding Author vera.thoss@bangor.ac.uk

\section{ABSTRACT}

Systematic phytochemical investigations of the underground rhizome of Pteridium aquilinum (L.) Kuhn (Dennstaedtiaceae) afforded thirty-five pterosins and pterosides. By detailed analysis of one- and two-dimensional nuclear magnetic resonance spectroscopy, circular dichroism (CD) and high-resolution mass spectrometric data, thirteen previously undescribed pterosins and pterosides have been identified. Interestingly, for the first time $12-O-\beta$-D-glucopyranoside substituted pterosins, rhedynosides $\mathrm{C}$ and $\mathrm{D}$, and the sulfate-containing pterosin, rhedynosin $\mathrm{H}$, alongside the two known compounds, histiopterosin A and ( $2 S$ )-pteroside A2, were isolated from the rhizomes of subsp. aquilinum of bracken. In addition, six-membered cyclic ether pterosins and pterosides, rhedynosin A and rhedynoside A, are the first examples of this type of pterosinsesquiterpenoid. Additionally, the three previously reported compounds (rhedynosin I, (2S)-2hydroxymethylpterosin $\mathrm{E}$ and (2S)-12-hydroxypterosin A) were obtained for the first time from plants as opposed to mammalian metabolic products. Single crystal X-ray diffraction analysis was applied to the previously undescribed compounds $(2 R)$-rhedynoside $\mathrm{B},(2 R)$-pteroside $\mathrm{B}$ and $(2 S)$-pteroside $\mathrm{K}$, yielding the first crystal structures for pterosides, and three known pterosins, (2S)-pterosin A, trans-pterosin C and cis-pterosin C. Rhedynosin C is the only example of the cyclic lactone pterosins with a keto group at position C-14. Six selected pterosins $((2 S)$-pterosin A, $(2 R)$-pterosin B and trans-pterosin C) and associated glycosides $((2 S)$-pteroside A, $(2 R)$ pteroside $\mathrm{B}$ and pteroside $\mathrm{Z}$ ) were assessed for their anti-diabetic activity using an intestinal glucose uptake assay; all were found to be inactive at $300 \mu \mathrm{M}$.

Keywords: Pteridium aquilinum; Dennstaedtiaceae; Bracken Pterosins; Pterosides; Norsesquiterpenes; Sesquiterpenoids; Pterosins A and B; Circular Dichroism, SGLT1 and GLUT2 Transporters 


\section{Introduction}

One of the most widely distributed vascular plant species in the world is bracken (Pteridium aquilinum (L.) Kuhn). In the UK, $P$. aquilinum subsp. aquilinum comprises the majority of bracken, with a dense coverage estimated at $4782 \mathrm{~km}^{2}$ (dense) or $17000 \mathrm{~km}^{2}$ (presence), representing $7 \%$ of the land area in the UK, including sparse bracken (Pakeman et al., 1996). This corresponds to 1.1 - 5 Gigatonne (Gt) of plant material above ground and 5 - $20 \mathrm{Gt}$ of rhizome biomass (dry weight, calculated from data in (Marrs and Watt, 2006)). Bracken has long been recognised for its potential pharmaceutical uses and its toxicity. Furthermore, bracken has been used medicinally as an anthelminthic agent (Marrs and Watt, 2006). Bracken crosiers have been eaten as a delicacy in Japan and Brazil. The rhizome has been used as a source of starch (AlonsoAmelot and Avendano, 2002; Madeja et al., 2009).

Phytochemical studies of bracken are most often concerned with the norsesquiterpene glycoside ptaquiloside, because of its established carcinogenicity (Fenwick, 1988; Hirono, 1986). Research has been concentrated on the quantification of this compound in the plant (Alonso-Amelot et al., 1992; Rasmussen et al., 2003) and in biological samples, such as urine, milk and plasma (Aranha et al., 2014). Ptaquiloside is unstable due to the presence of a spirocyclopropane moiety. The main degradation product of ptaquiloside is pterosin B (Hirono, 1986). Other pterosins have been isolated from different subsp. of Pteridium aquilinum (Fukuoka et al., 1978; Kuraishi et al., 1985; Murakami et al., 1980; Sengupta et al., 1976; Tanaka et al., 1982; Yoshihira et al., 1971). Pterosins are sesquiterpenoids and their structures are derivatives of 1-indanone. They are biosynthesised in all parts of the bracken, including fronds and rhizomes (Hikino et al., 1976; Kigoshi et al., 1989). Bracken has historically been associated with incidents of livestock poisoning (Hopkins, 1990; Vetter, 2009) resulting in many mechanistic studies on distinct pterosins and their biological targets. For example, pterosin B was found to inhibit the Gram-positive bacterium Bacillus subtilis at minimum inhibitory concentration (MIC) of $30 \mu \mathrm{g} \mathrm{ml}^{-1}$ (Kobayashi et al., 1975). Pterosins B, F, H, I, O, Z and V showed cytotoxic effects on Paramecium caudatum and caused abnormal development of sea urchin embryos but did not inhibit DNA synthesis (Kobayashi and Koshimizu, 1980). Pterosin $\mathrm{Z}$ is a potent relaxant to smooth muscle $\left(\mathrm{EC}_{50}=1.3 \pm 0.1 \mu \mathrm{M}\right)$ (Sheridan et al., 1999). In addition, the interaction of bracken extract with vitamin $C$ in human submandibular and oral epithelial cell lines has been assessed (Campos-da-Paz et al., 2008) and the dependency of the biological effect of bracken extract in different cell assays has been evaluated (Almeida Santos et al., 2006). Anti-diabetic activity has also been associated with pterosins (Hsu et al., 2014), and studies using distinct pterosins, methanolic extracts of bracken have been used to investigate glycophenotypic alterations in mice gastric mucosa (Gomes et al., 2012).

The toxicity of North Wales bracken, 'Rhedyn' in the Welsh language, to cattle has been studied previously (Potter, D.M., Baird, 2000; Yamada et al., 2007). Recently, a traditional phytochemical investigation of bracken rhizomes using various analytical techniques led to the isolation of thirteen novel compounds (1-13) (Figs. 1 \& 2), together with twenty two known compounds: rhedynosin I (14), $(2 S)$-pterosin A (15), $(2 R)$-pterosin B (16), $(2 R, 3 R)$-pterosin C (trans-pterosin C) (17), (2S, 3R)-pterosin C (cis-pterosin C) (18), (3S)-pterosin D (19), (2R)-pterosin E (20), (2R)pterosin F (21), $(2 S, 3 S)$-pterosin J (22), (2S)-pterosin K (23), (2S)-pterosin N (24), (2S)-pterosin $\mathrm{P}$ (25), pterosin Z (26), (2S)-2-hydroxymethylpterosin E (27), histiopterosin A (28), (2S)-12hydroxypterosin A (29), (2S)-pteroside A (30), (2R)-pteroside B (31), (3S)-pteroside D (32), pteroside Z (33), (2S)-pteroside A2 (34) and (2S)-pteroside K (35), of which compounds 14 and 27-29 are identified for the first time from the genus Pteridium which belongs to Dennstaedtiaceae 
family (Figs. 1-3). Herein described are the isolation and structural elucidation of these compounds.

\section{Results and Discussion:}

The underground parts (rhizomes) of bracken (Pteridium aquilinum (L.) Kuhn) were air-dried, chopped and then extracted with chloroform. More than twenty sesquiterpenoid constituents have been identified with UV absorption spectra profiles in the 340 to $205 \mathrm{~nm}$ region characteristic of 1-indanone derivatives (Fukuoka et al., 1978; Kuraishi et al., 1985; Murakami et al., 1980; Yoshihira et al., 1971). The chloroform extract was repeatedly subjected to thin-layer, normalphase column, and automated reversed phase flash chromatography to afford thirty five compounds (1-35). One- and two-dimensional NMR experiments combined with mass spectrometry were used to identify thirteen novel natural products (1-13) (Supplementary Information 1) belonging to the sesquiterpenoid family. The structures of twenty two previously reported pterosins and pterosides 14, 27, 29 (Lee et al., 2012), 15-18, 30-33, 35 (Kuroyanagi et al., 1979), 19-25 (Fukuoka et al., 1978), 26 (Kuraishi et al., 1985; Tanaka et al., 1982), 28 (Murakami et al., 1980), 34 (Castillo et al., 2003) were determined by the comparison of their spectroscopic data with those reported in the literature (Figs. 1-3). The structures of compound 1$\mathbf{1 3}$ are shown in Figs. $1 \& 2$ and their ${ }^{1} \mathrm{H}$ and ${ }^{13} \mathrm{C}$ data is listed in Tables 1-4.

X-ray crystallography remains the definitive tool to determine the absolute configuration but requires the existence of good crystals. Circular Dichroism (CD) is a technique that can be used to assign the absolute configuration in solution with less than $1 \mathrm{mg}$ of compound (Warnke and Furche, 2012). However, CD is only reliable for the determination of absolute configuration if chromophores are in close spatial proximity allowing for exciton coupling. Unfortunately, this is not the case with the compounds discussed here. In the past, sector rules (eg octant rules) were invoked in order to assign the absolute configuration of compounds composed of a chromophore in a dissymmetric environment. However, such rules are now considered with scepticism. Nevertheless, careful pair-wise comparison of the $\mathrm{CD}$ of compounds with identical chromophore cores (Fig. 4) and similar dissymmetric environments enables correlation. Unfortunately, the large perturbing influence of a glycosyl-residue in the structure can hamper comparison with glucosefree compounds.

The UV and CD spectra in the $380 \mathrm{~nm}$ to $260 \mathrm{~nm}$ region associated with the keto group $\mathrm{n} \rightarrow \pi^{*}$ transition can be deceptively complex. The electron transitions primarily observed in an UV spectrum produce fairly straightforward spectral data. However, the presence of vibronic effects (coincidental change of vibrational and electronic energy levels) may add complexity to the signal, e.g., in form of additional shoulders. The corresponding CD spectra obey different selection rules. The $C D$ associated with the $n \rightarrow \pi^{*}$ transition may mimic the absorption spectrum and be relatively plain or may be fine structured indicating the importance of particular vibronic progressions. In the series outlined here, compound 1, 14, 15, 23, 27, 29 and 30 present CDs with vibronic fine structure, while compounds 2, 7, 34, 35 render relatively featureless spectra. Comparison of the CD spectra with X-ray data or published CD data (Kuroyanagi et al, 1979) revealed that the stereogenic centre in the core aglycone (Fig. 4) of all compounds 1, 2, 7, 14, 15, 23, 27, 29, 30, 34, 35 can be assigned as $2 S$. 


\subsection{Structural Elucidation}

Compound 1 was obtained as a yellow powder and its molecular formula was established as $\mathrm{C}_{15} \mathrm{H}_{18} \mathrm{O}_{3}$ based on the positive mode quasi-molecular ion peak at $\mathrm{m} / z 247.1330[\mathrm{M}+\mathrm{H}]^{+}$(calcd for $\mathrm{C}_{15} \mathrm{H}_{19} \mathrm{O}_{3}, 247.1334$ ) showing 7 degrees of unsaturation. The UV absorbance maxima at 211, 258 and $306 \mathrm{~nm}$ were consistent with 1-indanone derivatives. The IR absorption bands at 3014, 1605, 3418 and $1704 \mathrm{~cm}^{-1}$ indicated the presence of aromatic $\mathrm{C}-\mathrm{H}, \mathrm{C}=\mathrm{C}$, hydroxyl and carbonyl groups, respectively, which concur with the presence of a 1-indanone skeleton (Fukuoka et al., 1978; Kuroyanagi et al., 1979).

The full assignment of ${ }^{1} \mathrm{H}$ and ${ }^{13} \mathrm{C}$ NMR resonances was deduced from ${ }^{1} \mathrm{H}-{ }^{1} \mathrm{H}$ COSY, DEPTQ, HSQC and HMBC analysis (Tables 1 \& 4, Fig. 5 and Supplementary Information 1). The signals for all protonated carbons were assigned by analysis of the DEPTQ and HSQC spectra to establish the connectivity. The ${ }^{1} \mathrm{H}$ NMR spectrum of 1 shows signals of one secondary methyl $\left[\delta_{\mathrm{H}} 2.56(3 \mathrm{H}\right.$, $\mathrm{s}, \mathrm{H}-15)]$, one tertiary methyl $\left[\delta_{\mathrm{H}} 1.23(3 \mathrm{H}, \mathrm{s}, \mathrm{H}-10)\right]$, two methylenes $\left[\delta_{\mathrm{H}} 2.77,3.06(2 \mathrm{H}, \mathrm{d}, J=\right.$ $17.5 \mathrm{~Hz}, \mathrm{H}-3)$ and $2.76(2 \mathrm{H}, \mathrm{t}, J=5.9 \mathrm{~Hz}, \mathrm{H}-13)]$, three oxygenated methylenes $\left[\delta_{\mathrm{H}} 3.62,3.78\right.$ $(2 \mathrm{H}, \mathrm{d}, J=10.8 \mathrm{~Hz}, \mathrm{H}-11), 4.80(2 \mathrm{H}, \mathrm{s}, \mathrm{H}-12)$ and $4.01(2 \mathrm{H}, \mathrm{td}, J=1.3,5.9,11.8 \mathrm{~Hz}, \mathrm{H}-14)]$ and one methine $\left[\delta_{\mathrm{H}} 6.93(1 \mathrm{H}, \mathrm{s}, \mathrm{H}-4)\right]$ signal in the aromatic region. The DEPTQ spectrum, in combination with HSQC and HMBC data, displays 15 carbon resonances, including two quaternary methyls at $\delta_{\mathrm{C}} 21.1(\mathrm{C}-10)$ and $\delta_{\mathrm{C}} 13.1$ (C-15), five methylenes (including three oxygenated carbons), one methine at $\delta_{\mathrm{C}} 120.0$ (C-4) and seven quaternary carbons. As three of the 7 degrees of unsaturation are accounted for by a tricyclic system of $\mathbf{1}$, the remaining 4 degrees of unsaturation require 4 double bonds. The key HMBC correlations are shown in Fig. 5. In the HMBC spectrum, the signals at $\delta_{\mathrm{H}} 2.77$ and $3.06(2 \mathrm{H}, \mathrm{d}, J=17.5 \mathrm{~Hz}, \mathrm{H}-3)$ shows correlations with $\delta_{\mathrm{C}} 50.9(\mathrm{C}-2), \delta_{\mathrm{C}} 138.2(\mathrm{C}-7), \delta_{\mathrm{C}} 131.3(\mathrm{C}-8), \delta_{\mathrm{C}} 151.0(\mathrm{C}-9), \delta_{\mathrm{C}} 21.1(\mathrm{C}-10)$ and $\delta_{\mathrm{C}} 68.3(\mathrm{C}-$ 11). $\delta_{\mathrm{H}} 4.80(2 \mathrm{H}, \mathrm{s}, \mathrm{H}-12)$ displays correlations with $\delta_{\mathrm{C}} 120.0(\mathrm{C}-4), \delta_{\mathrm{C}} 142.1(\mathrm{C}-5), \delta_{\mathrm{C}} 131.8(\mathrm{C}-$ 6) and $\delta_{\mathrm{C}} 65.6(\mathrm{C}-14) . \delta_{\mathrm{H}} 2.76(2 \mathrm{H}, \mathrm{t}, J=5.9 \mathrm{~Hz}, \mathrm{H}-13)$ exhibits correlations with $\delta_{\mathrm{C}} 142.1(\mathrm{C}-5)$, $\delta_{\mathrm{C}} 131.8(\mathrm{C}-6)$ and $\delta_{\mathrm{C}} 138.2(\mathrm{C}-7) . \delta_{\mathrm{H}} 4.01(2 \mathrm{H}, \mathrm{td}, J=1.3,5.9,11.8 \mathrm{~Hz}, \mathrm{H}-14)$ reveals correlations with $\delta_{\mathrm{C}} 131.8(\mathrm{C}-6), 68.8(\mathrm{C}-12)$ and $\delta_{\mathrm{C}} 25.8(\mathrm{C}-13) . \delta_{\mathrm{H}} 3.62,3.78(2 \mathrm{H}, \mathrm{d}, J=10.8 \mathrm{~Hz}, \mathrm{H}-11)$ is correlated with $\delta_{\mathrm{C}} 210.5(\mathrm{C}-1), \delta_{\mathrm{C}} 50.9(\mathrm{C}-2), \delta_{\mathrm{C}} 37.1(\mathrm{C}-3)$ and $\delta_{\mathrm{C}} 21.1(\mathrm{C}-10)$. The latter correlations confirmed the position of the hydroxymethylene $\left(\mathrm{CH}_{2} \mathrm{OH}\right)$ group at $\mathrm{C}-2$. Other connectivities shown in this spectrum are: $\delta_{\mathrm{H}} 6.93(1 \mathrm{H}, \mathrm{s}, \mathrm{H}-4)$ with $\mathrm{C}-3, \mathrm{C}-6 \& \mathrm{C}-12, \delta_{\mathrm{H}} 1.23$ $(3 \mathrm{H}, \mathrm{s}, \mathrm{H}-10)$ with $\mathrm{C}-1, \mathrm{C}-2, \mathrm{C}-3 \& \mathrm{C}-11$ and $\delta_{\mathrm{H}} 2.56(3 \mathrm{H}, \mathrm{s}, \mathrm{H}-15)$ with $\mathrm{C}-6, \mathrm{C}-7 \& \mathrm{C}-8$. The presence of an ether link was assigned to be between positions $\mathrm{C}-12$ and $\mathrm{C}-14$ as their proton and carbon chemical shifts appeared at the low field region due to the deshielding influence of the oxygen atom. This was further confirmed with the HMBC spectrum that showed the correlations from $\mathrm{H}-12\left(\delta_{\mathrm{H}} 4.80\right)$ to $\mathrm{C}-14\left(\delta_{\mathrm{C}} 65.6\right)$ and from $\mathrm{H}-14\left(\delta_{\mathrm{H}} 4.01\right)$ to $\mathrm{C}-12\left(\delta_{\mathrm{C}} 68.8\right)$. The $J$-coupling systems were confirmed by COSY data that displays couplings between signals: $\delta_{\mathrm{H}} 2.76 \& \delta_{\mathrm{H}} 4.01$, $\delta_{\mathrm{H}} 2.77 \& \delta_{\mathrm{H}} 3.06$, and $\delta_{\mathrm{H}} 3.62 \& \delta_{\mathrm{H}} 3.78$, respectively.

The CD spectrum of 1 shows a vibronic $n \rightarrow \pi^{*}$ transition (Fig. 6) which concurs with C-2 having $2 S$ configuration. The observed transitions for the assignment of the absolute stereochemistry were based on the comparison of CD spectra of $\mathbf{1}$ with X-ray crystallography data of $\mathbf{1 5}$ (Fig. 7) and the CD interpretation provided for $\mathbf{1 5}$ by Kuroyanagi et al., 1979. Based on the above analysis, the structure of this compound was determined as a new natural product and named rhedynosin A (1). Its physical and spectroscopic features were consistent with the proposed structure in Fig. 1. 
Compound 2 was isolated as a white powder exhibiting negative optical rotation ( $[\alpha]_{D}^{24.2}-26.07$ ( $c$ $0.33, \mathrm{MeOH})$ ). The IR spectrum showed absorption bands in the region 1602, 1692 and $3369 \mathrm{~cm}^{-}$ ${ }^{1}$ attributable to the aromatic ring, carbonyl and hydroxyl groups, respectively. UV spectrum absorption maxima were observed at 304 (log ع 2.99), 259 (log ع 3.92) and $216(\log \varepsilon 4.27) \mathrm{nm}$. The molecular formula, $\mathrm{C}_{21} \mathrm{H}_{28} \mathrm{O}_{8}$, of 2 was determined by the quasi-molecular ion peak at $\mathrm{m} / \mathrm{z}$ : $409.1865\left([\mathrm{M}+\mathrm{H}]^{+}\right.$, calcd. 409.1862) in the FT-ICR-MS spectrum (Fig. S14, SI1). Compound 2 exhibited ${ }^{1} \mathrm{H}$ and ${ }^{13} \mathrm{C}$ NMR data closely resembling to those of $\mathbf{1}$. Comparison of the UV, IR and NMR spectroscopic data of $\mathbf{2}$ (Tables 1 and 4) with those of rhedynosin A (1) showed the following differences, the main one being the presence of an additional hexose sugar moiety having a signal for an anomeric- $\mathrm{H}$ at $\delta_{\mathrm{H}} 4.21(\mathrm{~d}, J=7.8 \mathrm{~Hz})$ and remaining sugar proton signals at $\delta_{\mathrm{H}}$ 3.03-3.78. The ${ }^{13} \mathrm{C}$ NMR spectrum of 2 contained an anomeric carbon signal of a hexose moiety at $\delta_{\mathrm{C}} 104.7$ and signals for the remaining five sugar carbons at $\delta_{\mathrm{C}} 62.7-78.1$, which were in good agreement with those reported for glucoside compounds (Fukuoka et al., 1983). This indicated that compound 2 was a glycoside of compound $\mathbf{1}$. The coupling constant $(J=7.8 \mathrm{~Hz})$ is consistent with trans ${ }^{3} J_{\mathrm{H}-\mathrm{H}}$, showing that it is a $\beta$-hexoside and that the adjacent proton on the sugar is axial in the chair conformation of the pyranose ring. The $8.9 \mathrm{~Hz}$ trans-diaxial coupling between $\mathrm{H}-2^{\prime}$ and $\mathrm{H}-3^{\prime}$ indicates an equatorial $\mathrm{OH}$ at $\mathrm{C}-3^{\prime}$. Thus, the sugar must be glucose or galactose. Since the ${ }^{1} \mathrm{H}$ NMR signals for $\mathrm{H}-3^{\prime}$ and $\mathrm{H}-4^{\prime}$ overlap in the spectrum of $\mathbf{2}$, a sample was peracetylated forming the tetraacetate. The introduction of the electron withdrawing groups shifts the signals for the ring protons $\mathrm{H}-2^{\prime}, \mathrm{H}-3^{\prime}, \mathrm{H}-4^{\prime}$ and $\mathrm{H}-6^{\prime}$ downfield and resolves them clearly (method and spectra in SI1). The $J_{\mathrm{H} 3^{\prime}, \mathrm{H} 4^{\prime}}$ coupling was determined to be $c a$. $8 \mathrm{~Hz}$. This value is consistent with a trans-diaxial relationship between these protons in the chair conformation of the hexopyranose. Three trans-diaxial relationships derived from the ring protons of a pyranose are indicating a glucosyl residue. To our knowledge, no L-glucose has been reported being isolated from a plant source yet. Thus, it is most likely that this glycosyl residue belongs to the D-series. Carbon resonances at $\delta_{\mathrm{C}} 104.7,78.1,77.9,74.9,71.5$ and 62.7 in the ${ }^{13} \mathrm{C}$ NMR spectrum (Table 4) provided further evidence for the presence of a glucopyranyl residue. The linkage position of the sugar moiety to $\mathrm{C}-11$ of the aglycone was confirmed by an HMBC experiment, which shows correlations between the anomeric resonance $\mathrm{H}-1^{\prime}(\delta 4.21)$ and $\mathrm{C}-11(\delta 75.0)$, and between $\mathrm{H}-11$ $\left(\delta 4.13\right.$ and 3.48) and the anomeric carbon $\mathrm{C}-1^{\prime}(\delta 104.7)$. The $\mathrm{CD}$ spectrum shows a plain positive $\mathrm{n} \rightarrow \pi^{*}$ component at $\sim 330 \mathrm{~nm}$ that can be correlated with the configuration at C-2 being $2 S$ (Kuroyanagi et al., 1979). Based upon the above evidence, the structure of $\mathbf{2}$ was identified as rhedynosin A 11-O- $\beta$-D-glucoside and named rhedynoside A (Fig. 1).

A new natural product, compound $\mathbf{3}$, was isolated as a yellow powder with an accurate mass similar to $\mathbf{1}$ at $\mathrm{m} / z 247.0967[\mathrm{M}+\mathrm{H}]^{+}$, consistent with a molecular formula of $\mathrm{C}_{14} \mathrm{H}_{15} \mathrm{O}_{4}$ and 8 degrees of unsaturation. The IR bands were due to a hydroxyl, carbonyl and aromatic carboncarbon double bond observed at 3419, 1715 and $1603 \mathrm{~cm}^{-1}$, respectively. The ${ }^{1} \mathrm{H}$ NMR spectrum (Table 1) of $\mathbf{3}$ closely resembles that of $\mathbf{1}$ but the ${ }^{13} \mathrm{C}$ NMR (HMBC) data, displays only 14 carbon resonances instead of the 15 signals that appear in the spectrum of $\mathbf{1}$. These signals were ascribed to three methylenes, two methyls, one methine, six quaternary carbons and two carbonyl groups (Tables 1 \& 4). The major difference in the NMR data for compound $\mathbf{3}$ is the absence of a methylene signal at $\delta_{\mathrm{H}} 4.80\left(\mathrm{CH}_{2}-12,{ }^{1} \mathrm{H} \mathrm{NMR}\right)$ and the appearance of a quaternary carbon at $\delta_{\mathrm{C}}$ $165.0\left({ }^{13} \mathrm{C} \mathrm{NMR}\right)$ corresponding to an ester, thus indicating that the methylene group $\left(\mathrm{CH}_{2}-12\right)$ of $\mathbf{1}$ is oxidised to a carbonyl in 3. This interpretation explains the downfield shift $\left(\delta_{\mathrm{H}} 8.05\right)$ of the methine signal (H-4) due to the influence of the carbonyl at position $\mathrm{C}-12$. The HMBC spectrum 
confirmed the location of the carbonyl group. Furthermore, in the HMBC experiment strong correlations were observed from both proton signals at $\delta_{\mathrm{H}} 8.05(\mathrm{H}-4) \& 4.55(\mathrm{H}-14)$ to the carbon signal at $\delta_{\mathrm{C}} 165.0(\mathrm{C}-12)$. The other significant difference was the absence of $\mathrm{CH}_{2}$ signals at $\delta_{\mathrm{H}}$ 3.78 and $\delta_{\mathrm{H}} 3.62\left(\mathrm{CH}_{2}-11\right)$ in the ${ }^{1} \mathrm{H}$ NMR spectrum. The ${ }^{13} \mathrm{C}$ NMR spectrum showed that the methylene signal from $\mathrm{C}-11$ was absent and that the signal for $\mathrm{C}-2$ had moved downfield to $\delta_{\mathrm{C}}$ 78.0, showing the presence of an oxygen. While CD spectra were obtained for $\mathbf{3}$, the absolute stereochemistry was not assignable as there was neither an X-ray reference with hydroxyl substitution on C-2 nor a previous literature report of a CD spectrum of a compound with a suitable chromophore core. Compound $\mathbf{3}$ was identified as a previously unreported natural product and named rhedynosin B (Fig. 1).

Compound 4 was obtained as a white powder with an optical rotation $[\alpha]_{D}^{24.2}+3.76$. The negative mode mass spectrum showed a molecular ion peak at $m / z$ 245.0821 [M-H] ${ }^{-}$, compatible with the molecular formula of $\mathrm{C}_{14} \mathrm{H}_{13} \mathrm{O}_{4}$. In the IR spectrum, strong bands at $v_{\max } 1703$ and $3428 \mathrm{~cm}^{-1}$ were indicative of carbonyl and hydroxyl groups, respectively. The maximum UV absorbances of 4 appeared at 214, 258 and $306 \mathrm{~nm}$, in agreement with 1-indanone compounds (Tanaka et al., 1982; Yoshihira et al., 1971). Analysis of the NMR and MS spectral data showed that $\mathbf{4}$ is structural similar to 3. The major differences were detected by NMR experiments, for example the presence of two isolated methylene signals at $\delta_{\mathrm{H}} 5.40(2 \mathrm{H}, \mathrm{s}, \mathrm{H}-12)$ and $\delta_{\mathrm{H}} 3.83(2 \mathrm{H}, \mathrm{s}, \mathrm{H}-13)$ which appear as singlets and thus indicated that the carbonyl group was at position $14 \mathrm{in} \mathbf{4}$. The chemical shift for $\mathrm{CH}_{2}-12\left(\delta_{\mathrm{H}} 5.40\right)$ also indicated a very electron-deficient environment, consistent with $\mathrm{ArCH}_{2} \mathrm{OC}=\mathrm{O}$. The $\mathrm{HMBC}$ spectrum confirmed the assignments and connectivities, and also shows a cross peak between $\mathrm{H}-12\left(\delta_{\mathrm{H}} 5.40\right)$ and $\mathrm{C}-14\left(\delta_{\mathrm{C}} 173.5\right)$. The data provided further evidence for the carbonyl being present at the $\mathrm{C}-14$ position. Thus, the structure of 4 was identified as a new compound, named rhedynosin $\mathrm{C}$ (Fig. 1). However, the absolute configuration in $\mathrm{C}-2$ remains undetermined.

Compound 5 was obtained as a yellow solid. In the positive mode spectrum, pseudo-molecular ion peaks at $\mathrm{m} / z 269.0941$ and $\mathrm{m} / z 271.0912[\mathrm{M}+\mathrm{H}]^{+}$in the ratio 3:1, indicate the presence of one chlorine atom and suggested a molecular formula of $\mathrm{C}_{14} \mathrm{H}_{18} \mathrm{ClO}_{3}$. The IR spectrum showed major absorption bands at $3418 \mathrm{~cm}^{-1}(\mathrm{OH}), 1714 \mathrm{~cm}^{-1}(\mathrm{C}=\mathrm{O})$ and 1602 and $1447 \mathrm{~cm}^{-1}$ (aromatic $\mathrm{C}=\mathrm{C}$ ). The UV spectrum exhibits UV signals at 212, 215 and $303 \mathrm{~nm}$. The ${ }^{1} \mathrm{H}$ NMR data (Table 1) of 5 indicates a penta-substituted benzene ring with a single aromatic proton signal at $\delta_{\mathrm{H}} 7.39$ $(1 \mathrm{H}, \mathrm{s})$. Two coupled methylene groups at $\delta_{\mathrm{H}} 3.21(2 \mathrm{H}, \mathrm{t}, J=8.0 \mathrm{~Hz})$ and $\delta_{\mathrm{H}} 3.62(2 \mathrm{H}, \mathrm{t}, J=8.0$ $\mathrm{Hz}$ ) indicate an $\mathrm{ArCH}_{2} \mathrm{CH}_{2} \mathrm{X}$ system, with the chemical shift of the latter triplet suggesting that $\mathrm{X}$ $=\mathrm{Cl}$. The remaining ${ }^{1} \mathrm{H}$ NMR signals were in agreement with a pterosin-type structure (Fukuoka et al., 1978; Kovganko et al., 2004; Kuraishi et al., 1985; Tanaka et al., 1982). The ${ }^{13} \mathrm{C}$ NMR data of 5 (Table 4) shows fourteen distinct carbon environments, confirming the presence of a pentasubstituted aromatic ring, including a low-field signal at $\delta_{\mathrm{C}} 208.9 \mathrm{ppm}(\mathrm{C}=\mathrm{O})$ assigned as the $\mathrm{C}-1$ of a pterosin-type sesquiterpene skeleton. The HMBC proton-carbon correlations confirmed a pterosin $\mathrm{K}$ side chain, a 2-chloroethyl group $\left(\mathrm{CH}_{2} \mathrm{CH}_{2} \mathrm{Cl}\right)$ attached to $\mathrm{C}-6$ of benzene ring. A singlet methylene signal at $\delta_{\mathrm{H}} 4.84$ was assigned as the hydroxymethylene $\left(\mathrm{CH}_{2} \mathrm{OH}\right)$ group attached to C-5 of the benzene ring. All assignments were confirmed by HMBC correlations and 5 was thus identified as rhedynosin D (Fig. 1). However, the absolute configuration in C-2 remains undetermined. 
Compound 6 was obtained as an off-white powder and its molecular formula was determined from the positive mode FT-ICR-MS to be $\mathrm{C}_{15} \mathrm{H}_{19} \mathrm{O}_{4}\left(\mathrm{~m} / \mathrm{z} 263.1280[\mathrm{M}+\mathrm{H}]^{+}\right.$, calcd 263.1283). The UV, IR, and NMR data of $\mathbf{6}$ were very similar to histiopterosin A (28) (Murakami et al., 1980). Two carbonyl resonances were evident in the ${ }^{13} \mathrm{C}$ NMR spectrum, with the ketone signal at $\delta_{\mathrm{C}} 211.6$ and a carboxylic acid signal at $\delta_{\mathrm{C}} 175.3$. In the ${ }^{1} \mathrm{H}$ NMR spectrum of $\mathbf{6}$, an additional methyl signal is present, which was shown to be connected to $\mathrm{C}-2$ by HMBC. Thus, two magnetically inequivalent methyl groups are attached to C-2, which resonate as singlets at $\delta_{\mathrm{H}} 1.05$ and $\delta_{\mathrm{H}}$ 1.19.The application of CD spectroscopy to compound 6 showed a non-vibronic $n \rightarrow \pi *$ transition which was compared to the CD spectrum for 19 reported by Kuroyanagi et al., 1979 and assigned the configuration as $S$ on C-3. Therefore, the structure of $\mathbf{6}$ was confirmed as rhedynosin E (Fig. $1)$.

Compound $\mathbf{8}$ was obtained as a yellow gum. In the FT-ICR-MS, 8 gave the same molecular formula as $5\left(\mathrm{C}_{14} \mathrm{H}_{17} \mathrm{ClO}_{3}\right)$. The UV spectrum showed absorption bands at 218, 260 and $299 \mathrm{~nm}$. The IR, NMR and MS data of $\mathbf{8}$ were similar to those of $\mathbf{5}$, with detailed exceptions which allowed identification of $\mathbf{8}$. Differences were found in the NMR signals for the C-12 and C-13 positions for these two compounds. The ${ }^{1} \mathrm{H}$ NMR spectrum of $\mathbf{8}$ showed a methyl group resonating at $\delta_{\mathrm{H}}$ 2.55 that gave a proton-carbon correlation to the carbon resonating at $\delta_{\mathrm{C}} 22.0$ in the HSQC spectrum and by HMBC this was assigned as C-12. A methine group, resonating at $\delta_{\mathrm{H}} 5.45(1 \mathrm{H}$, $\mathrm{dd}, J=5.2,8.7 \mathrm{~Hz}$ ), that gave proton-carbon correlation to the carbon resonating at $\delta_{\mathrm{C}} 71.4$ in the HSQC spectrum, was assigned as the C-13. This suggested that the hydroxy group, which had been at $\mathrm{C}-12$ in $\mathbf{5}$, was in position $\mathrm{C}-13$ in $\mathbf{8}$. Compound $\mathbf{8}$ was thus identified as rhedynosin $\mathrm{G}$ (Fig. 1). However, the absolute configuration in C-2 remains undetermined.

Compound 7 was obtained as a pale yellow crystalline powder. In the accurate mass spectrum, 7 gave the molecular formula $\mathrm{C}_{15} \mathrm{H}_{19} \mathrm{ClO}_{3}$, suggesting an additional methylene group when compared to 8. The UV, IR and NMR data were similar to those of $\mathbf{8}$. However, the additional methylene group was evident from the NMR data of 7, with two geminally coupled doublets $\delta_{\mathrm{H}}$ $3.79(1 \mathrm{H}, \mathrm{d}, J=10.7 \mathrm{~Hz})$ and $\delta_{\mathrm{H}} 3.59(1 \mathrm{H}, \mathrm{d}, J=10.7 \mathrm{~Hz})$, correlating through one-bond with a new carbon signal at $\delta_{\mathrm{C}} 68.1$. The chemical shifts indicated that this new methylene was attached to the oxygen and thus the hydroxymethylene group was in position $\mathrm{C}-2$. On the basis of the above mentioned evidence, the structure of 7 was confirmed as rhedynosin F (Fig. 1). CD spectroscopy allowed a $2 S$ assignment of configuration.

Compound 9 was isolated as an off-white powder and its mass spectrum in the negative ion mode showed a molecular ion peak at $\mathrm{m} / z 297.0802[\mathrm{M}-\mathrm{H}]^{-}$corresponding to a molecular formula of $\mathrm{C}_{14} \mathrm{H}_{17} \mathrm{O}_{5} \mathrm{~S}$ (calcd as 297.0797). The UV, IR, and NMR data of 9 were very similar to those of pterosin B (16) (Fig. 3). This molecular formula suggested that the primary alcohol of $\mathbf{1 6}$ had been sulfated. This was confirmed by a downfield shift of the ${ }^{1} \mathrm{H}$ NMR resonance for the adjacent $\mathrm{CH}_{2}$ $\left(\mathrm{CH}_{2}-14\right)$ to $\delta_{\mathrm{H}} 4.05$. Sulfated monoesters are common in marine natural products (McKee et al., 1994; Uddin et al., 2011). Compound 9 and 12 were subjected to CD spectroscopy, however, no significant spectra were observed and it is hypothesised that $\mathbf{9}$ and $\mathbf{1 2}$ racemised due to the presence of an acidic proton in the $\alpha$-position to the carbonyl group. The structure of $\mathbf{9}$ was confirmed by full analysis of the data as rhedynosin $\mathrm{H}$ (Fig. 1). 
Compound 10, obtained as a white crystalline product, exhibited a molecular ion peak at $\mathrm{m} / z$ $415.1527[\mathrm{M}+\mathrm{H}]^{+}$in the mass spectrum and correlated to the molecular formula $\mathrm{C}_{20} \mathrm{H}_{28} \mathrm{ClO}_{7}$ (calcd as 415.1523). The UV, IR, and NMR data for $\mathbf{1 0}$ was very similar to that reported for pterosin F (21) (Fukuoka et al., 1978; Kuroyanagi et al., 1979), except for the presence of a sugar moiety in $\mathbf{1 0}$ which was connected to the aglycone through C-2, as determined by the HMBC experiment. Careful study of the coupling constants around the hexopyranose in the ${ }^{1} \mathrm{H}$ NMR spectrum suggested that the sugar was a glucose; $J_{1^{\prime}, 2^{\prime}}=7.8 \mathrm{~Hz}, J_{2^{\prime}, 3^{\prime}}=8.0 \mathrm{~Hz}$ and $J_{3^{\prime}, 4^{\prime}}=8.9 \mathrm{~Hz}$, consistent with trans-diaxial arrangements of these protons. X-ray crystallography confirmed $\mathbf{1 0}$ as rhedynoside $\mathrm{B}$ and assigned the configuration at C-2 as $R$ (Figs. $2 \& 8$ ).

Compound 11 was obtained as an off-white crystalline powder. In the FT-ICR-MS, 11 was shown to have the molecular formula $\mathrm{C}_{21} \mathrm{H}_{29} \mathrm{ClO}_{7}$, with a molecular mass $14 \mathrm{Da}$ higher than 10 . The UV, IR and NMR data of 11 were similar to those of pterosin H (Hayashi et al., 1972; Padwa et al., 1996; Tanaka et al., 1982) with the exception that $\mathbf{1 1}$ contained a sugar moiety. Of particular interest was a pair of geminally coupled doublets in the ${ }^{1} \mathrm{H}$ NMR spectrum at $\delta_{\mathrm{H}} 5.11(1 \mathrm{H}, \mathrm{d}, J=$ $12.4 \mathrm{~Hz})$ and $\delta_{\mathrm{H}} 4.78(1 \mathrm{H}, \mathrm{d}, J=12.4 \mathrm{~Hz})$. These signals gave a one-bond $\mathrm{H}-\mathrm{C}$ correlation with the ${ }^{13} \mathrm{C}$ NMR signal at $\delta_{\mathrm{C}} 70.2$. The chemical shifts corresponded to an $\mathrm{ArCH}_{2} \mathrm{O}$ system. An HMBC experiment assigned this carbon signal being connected to $\mathrm{C}-12$. Moreover, the HMBC also linked the sugar to this methylene. The ${ }^{1} \mathrm{H}$ NMR spectrum of $\mathbf{1 1}$ confirmed the sugar as a hexopyranoside and identified the configuration of the glycosidic bond as $\beta$, with $J_{1^{\prime}, 2^{\prime}}=7.7 \mathrm{~Hz}$ (also suggesting that the sugar was glucose or galactose). Peracetylation of the sugar separated the ${ }^{1} \mathrm{H}$ NMR signals of the sugar sufficiently to provide a full diastereomeric assignment of the sugar as glucose (see the discussion for $\mathbf{2}$ above). On the basis of this evidence, compound $\mathbf{1 1}$ was identified as rhedynoside C (Fig. 1).

Compound 12, a novel natural product, was obtained as a yellow powder with the negative optical rotation $[\alpha]_{D}^{24.6}-0.643(c 0.33, \mathrm{MeOH})$. In the FT-ICR-MS, 12 gave a quasi-molecular ion peak at $m / z, 413.1374$ [M-H] $]^{-}$, appropriate for a molecular formula $\mathrm{C}_{20} \mathrm{H}_{26} \mathrm{ClO}_{7}$ (calcd as 413.1367), and indicating that it was an isomer of 10. The UV, IR and NMR data of $\mathbf{1 2}$ were broadly similar to those of $\mathbf{1 0}$ except that the point of attachment of the sugar was clearly different. As for 11, a diastereotopic methylene group was observed in the NMR spectra at $\delta_{\mathrm{H}} 5.10(1 \mathrm{H}, \mathrm{d}, J=12.3 \mathrm{~Hz})$ $\& 4.78(1 \mathrm{H}, \mathrm{d}, J=12.3 \mathrm{~Hz})$ and $\delta \mathrm{C} 70.2$. Using the same rationale as for determination of the location of the sugar as for 11, HMBC data confirmed that the sugar was attached through a glycosidic linkage to $\mathrm{C}-12$. Examination of the ${ }^{1} \mathrm{H}$ NMR coupling constants for protons around the hexopyranose in native and peracetylated forms demonstrated that it was $\beta$-linked glucose. Also notable was the presence of only one methyl group at $\mathrm{C}-2, \delta_{\mathrm{H}} 1.25(3 \mathrm{H}, \mathrm{d}, J=7.2 \mathrm{~Hz})$, with the ${ }^{13} \mathrm{C}$ NMR signal for C-2 now reported as a methine. The structure of $\mathbf{1 2}$ was thus established as rhedynoside D (Fig. 1). However, the absolute configuration in C-2 remains undetermined.

Compound 13 was isolated as an off-white crystalline powder. Its molecular formula, $\mathrm{C}_{21} \mathrm{H}_{29} \mathrm{ClO}_{7}$, was deduced from the FT-ICR-MS, indicating that it was another isomer of 11. The UV, IR and NMR data for the aglycone of $\mathbf{1 3}$ were very similar to those of (3R)-hydroxypterosin H (Tanaka et al., 1982) indicating that it has the same structure in the aglycone part. A NOESY study of compound 13 showed through-space correlations between $\mathrm{H}-1^{\prime}$ and $\mathrm{H}-3^{\prime}$ and between $\mathrm{H}-\mathrm{1}^{\prime}$ and $\mathrm{H}-$ $5^{\prime}$, confirming that these three protons are all axial and that the sugar is glucose. Singlet signals for three methyl groups were evident in the ${ }^{1} \mathrm{H}$ NMR spectrum, with $\mathrm{HMBC}$ confirming that two methyl signals ( $\delta_{\mathrm{H}} 1.28$ and $\left.\delta_{\mathrm{H}} 1.09\right)$ formed a geminal pair. The third ( $\left.\delta_{\mathrm{H}} 2.49\right)$ was in an ArMe 
environment and was confirmed by HMBC data to correspond to $\mathrm{C}-12$. The signal for $\mathrm{H}-3$ was identified as being at $\delta_{\mathrm{H}} 4.85$, appropriate to ArCHO. HMBC correlations from $\mathrm{H}-3\left(\delta_{\mathrm{H}} 4.85, \mathrm{~s}\right)$ to $\mathrm{C}-1^{\prime}\left(\delta_{\mathrm{C}} 105.9\right)$, and from $\mathrm{H}-1^{\prime}\left(\delta_{\mathrm{H}} 4.58, \mathrm{~d}, J=7.7 \mathrm{~Hz}\right)$ to $\mathrm{C}-3\left(\delta_{\mathrm{C}} 86.10\right)$ evidence that the glycosyl residue is connected through C-3 (Fig. S113, Supplementary Information 1). The application of CD spectroscopy to compound $\mathbf{1 3}$ shows a non-vibronic $n \rightarrow \pi^{*}$ transition which is opposite to the transition observed for $\mathbf{6}$. Based on the comparison of CD data of $\mathbf{1 3}$ to that for $\mathbf{1 9}$ reported by Kuroyanagi et al., 1979, $\mathbf{1 3}$ was assigned the $R$ configuration in C-3. The reported compounds, 13-chloro-spelosin 3-O- $\beta$-D-glucopyranoside (Chen et al., 2015) and $(2 R, 3 R)$ pterosin L 3- $O$ - $\beta$-D-glucopyranoside (Chen et al., 2008), whose ${ }^{1} \mathrm{H}$ and ${ }^{13} \mathrm{C}$ NMR data are very similar to compound $\mathbf{1 3}$, also show $R$ configuration in C-3. As a result of these observations, 13 was identified as rhedynoside E (Fig. 1).

\subsection{Structural Relationships between New and Known Pterosins and Pterosides}

Rhedynoside B (10) is the first example of a pteroside bearing the glucose moiety at the position $\mathrm{C}-2$ and hence being directly attached to the five membered ring in $\alpha$-position to the keto group. In addition, this is also the first report of glycosylation at $\mathrm{C}-12$ with the $12-O-\beta$-D-glucopyranoside substituted pterosins: rhedynosides C (11) and D (12). Most previously reported pterosides have had the sugar moiety at the following positions: C-11, for example, pterosides A2 and $\mathrm{K}$ (Castillo et al., 2003; Kuroyanagi et al., 1979); C-14, such as pterosides A, B, C, D, P and Z (Hikino et al., 1972, 1971; Kuroyanagi et al., 1979) or C-3, e.g. ( $2 R, 3 R)$-pterosin L 3-O- $\beta$-D-glucopyranoside (Chen et al., 2008) and (2S, 3S)-pterosin C 3-O- $\beta$-D-glucoside (wallichoside) (Sengupta et al., 1976). Furthermore, rhedynosin A (1) and rhedynoside A (2) are novel compounds, being the first examples of a six-membered cyclic ether containing pterosin and pteroside.

For the first time rhedynosin C (4) was isolated from the rhizomes of P. aquilinun (L.) Kuhn, as a new cyclic lactone pterosin with a keto group at position C-14. However, another cyclic lactone pterosin, $(S)$-12-hydroxy-2-hydroxymethylpterosin E 14, 12-lactone, with one extra methylene has been reported as a metabolic product of $(2 S)$-pterosin A in rat urine via oral administration (100 $\mathrm{mg} / \mathrm{kg}$ ) (Lee et al., 2012). Other metabolites of (2S)-pterosin A were compounds 14, 27 and 29, which we isolated for the first time from plant material. We hence suggest rhedynosin I as common name for compound 14. Moreover, $(2 S)$-pteroside A2 and histiopterosin A are being reported for the first time from the rhizomes of subsp. aquilinum of bracken fern, as they have previously been isolated from the young fronds of P. aquilinum (L.) Kuhn var. caudatum (syn Pteridium caudatum L. Maxon) (Castillo et al., 2003) and Histiopteris incisa (Murakami et al., 1980), respectively. More interestingly, a novel sulfated-pterosin, rhedynosin $\mathrm{H}(\mathbf{9})$, was isolated from belowground rhizomes of $P$. aquilinum (L.) Kuhn. Previously, $(2 R, 3 S)$-sulfated pterosin C and $(2 S, 3 S)$-sulfated pterosin $\mathrm{C}$ have been reported from the aerial parts of Acrostichum aureum (Uddin et al., 2011).

The absolute stereochemistry of the novel compound rhedynoside B (10) was determined by single crystal X-ray diffraction analysis (Figs. $2 \&$ 8, and SI2). The CD spectrum of $\mathbf{1 5}$ exhibited negative and positive vibronic components associated with the $n \rightarrow \pi^{*}$ transition in the range of $320-360 \mathrm{~nm}$ (Fig. 6). Thus, compound 15 was assigned $2 S$ configuration (Kuroyanagi et al., 1979) and confirmed by X-ray diffraction (Fig. 7). The $n \rightarrow \pi^{*}$ CD components of compounds $\mathbf{1 7}$ and $\mathbf{1 8}$ exhibit a strong negative Cotton effect around $330 \mathrm{~nm}$ (Fig. 9) which is in agreement with the reported CD data and thus, the configurations of $\mathbf{1 7}$ and $\mathbf{1 8}$ were determined to be $2 R, 3 R$ and $2 S$, $3 R$ (Kuroyanagi et al., 1979). Again, X-ray diffraction confirmed this (Fig. 7). X-ray data for the two known pterosides ( $\mathbf{3 1}$ and $\mathbf{3 5}$ ) confirmed the absolute configuration determined previously by 
CD, i.e. (2R)-pteroside B (31) and (2S)-pteroside K (35) (Fukuoka et al., 1978; Kuroyanagi et al., 1979; Ng and McMorris, 1984) (Figs. 2 \& 7, SI2, and deposited with the Cambridge Crystallographic Data Centre).

The pterosins and pterosides isolated from bracken rhizomes showed surprising structural diversity, which even encompassed chloride and sulphate substituents. The biosynthesis of pterosin B is thought to be derived from the sesquiterpenoid biosynthetic pathway established by using the incorporation of radiolabelled mevalonate. Specifically Hikino et al. (1976) suggested pterosin B (16) to be derived from mevalonic acid via farnesyl pyrophosphate and humulene. It is hypothesised that at least compounds $\mathbf{9}$ and $\mathbf{1 2}$ derive from ptaquiloside degradation in planta as the major ptaquiloside degradation product, pterosin $\mathrm{B}(\mathbf{1 6})$, originates from a nucleophilic addition of present nucleophiles. The less abundant nucleophiles in planta $\mathrm{Cl}^{-}$and $\mathrm{SO}_{4}{ }^{2-}$ can also act by a similar mechanism to yield the chlorinated rhedynosins $(\mathbf{5}, \mathbf{7}$ and $\mathbf{8})$ and rhedynosides (1013). Their presence in crude rhizome extracts, using $\mathrm{MeOH}$ and $\mathrm{Et}_{2} \mathrm{O}$ instead of chloroform, was confirmed by HPLC/ESI-MS ${ }^{n}$ analysis. Both negative molecular ions (427 and $429 \mathrm{Da}$ ) of compounds 11, 13 and 35 showed a constant neutral loss of 162 Da to give ions at $m / z, 265$ and 267, respectively, which corresponded to the loss of an $O$-linked hexose moiety (glucose) (Felipe et al., 2014; Levandi et al., 2014; Qu et al., 2004; Scholz et al., 2005) (Figs. SD1-4, Supplementary Data 2). The presence of only one sulfated metabolite amongst the group of reported pterosins is rather a degradation product than a compound of biosynthetic origin. The other reported sulfated pterosins (Uddin et al., 2011) occurred as both trans and cis isomers at C2-C3, which also suggests their origin from degradation of ptaquiloside rather than through direct biosynthesis (Yamada et al., 2007). Similarly, cis and trans motifs at C2-C3 were identified in compounds $\mathbf{1 7}$ and $\mathbf{1 8}$ (Figs. $2 \& 7$ ). The C-2 position adjacent to the keto group readily epimerises if there is simply a methyl substituent. Unfortunately, at this stage it was not possible to assign the absolute configurations for compounds $9, \mathbf{1 2}, \mathbf{1 6}, \mathbf{2 0}, \mathbf{2 1}, \mathbf{2 5}$, and $\mathbf{3 1}$. A hydroxymethyl group at C-2 is apparently optically stable as in compounds 1, 2, 7, 14, 15, 23, 27, 29, 30, 34 and 35. Epimerisation may well be inhibited through intermolecular hydrogen bonding in these compounds (Kuroyanagi et al., 1979).

\subsection{Biological Activity Assessment}

Hsu et al. (2014) patented the use of pterosins and pterosides, including 86 distinct compounds of natural and synthetic origin. Their biological activity for treating diabetes and obesity was investigated predominantly with pterosin A but claimed for all described compounds. On this basis we were particularly interested whether pterosins or pterosides were more active. Hence a selection of pterosins (15 - 17) and their associated pterosides (30, 31 and 33) were assessed for their anti-diabetic activity using an intestinal glucose uptake assay in vitro, specifically seeking inhibitors of the SGLT1 and GLUT2 transporters. However, no compound was active at $300 \mu \mathrm{M}$ (more details can be found in the Supplementary Data 2) in contrast to activity reported by Hsu et al. (2014). However, Hsu et al. (2014) studied the antidiabetic activity for extracts of bracken against STZ-induced disease in mice at $100 \mathrm{mg} / \mathrm{Kg} / \mathrm{d}$ for 14 days by activating GLUT4. Thus, the discrepancy could have multiple origins, including the dosing schedule and activity in the latter assay through a mechanism other than through SGLT1 and GLUT2 transporters. 


\section{Conclusion}

This study describes the successful isolation and identification of 35 pterosin-type sesquiterpenoids from the rhizome of Pteridium aquilinum (L.) Kuhn, including eight new pterosins (1 \& 3-9) and five new pterosides $(2 \&$ 10-13). Their chemical structures were elucidated by $1 \mathrm{D}$ and $2 \mathrm{D}$ NMR spectroscopic analysis. The absolute configuration were also determined for five compounds by using either single crystal X-ray diffraction (10) or CD spectroscopy (15, 31, 35) or both techniques $(\mathbf{1 7}, \mathbf{1 8})$. In addition, $C D$ spectroscopy yielded the absolute configuration for $1,2,6,7$, and 13. To the best of our knowledge, rhedynosides $C(\mathbf{1 1})$ and $D(\mathbf{1 2})$ are the first reported glucosides with the glucose moiety on the $\mathrm{C}-12$ of the aglycone. In addition, one previously unreported sulfate-containing pterosin, rhedynosin $\mathrm{H}(\mathbf{9})$, together with two other reported compounds, histiopterosin A (28) and (2S)-pteroside A2 (34), were isolated for the first time from the rhizomes of bracken, subsp. aquilinum. Furthermore, compounds $\mathbf{1}$ and $\mathbf{2}$ have a relatively rare aglycone, containing a six-membered cyclic ether.

\section{Experimental}

\subsection{General experimental procedures:}

1D and 2D NMR spectra were recorded on a Bruker Avance (DRX) instrument (Bruker BioSpin Group, Germany) (400 or $500 \mathrm{MHz}$ ) NMR spectrometer in $\mathrm{CD}_{3} \mathrm{OD}, \mathrm{CDCl}_{3}$, or $\left(\mathrm{CD}_{3}\right)_{2} \mathrm{CO}$ with TMS as internal standard. Ultra-high mass accuracy analysis was performed on a Nano-Flow (Triversa Nanomate; Advion biosciences limited, Norfolk, UK) linear trap quadrupole Fourier Transformation Ion Cyclotron Resonance Mass Spectrometry Ultra (FT-ICR-MS), where ultra refers to the high sensitivity ICR cell. Samples were reconstituted in $100 \mu \mathrm{L}$ of HPLC grade MeOH / ultra-pure water (7:3). Samples were vortexed, and were centrifuged for $4 \mathrm{~min}$, at 13,000 rpm at a temperature of $0{ }^{\circ} \mathrm{C} .20 \mu \mathrm{L}$ of supernatant was then transferred to a clean well on a 128 -well plate. $13 \mu \mathrm{L}$ of sample was injected by the nano-flow injection system, with a $5 \mu \mathrm{L}$ aliquot being delivered to the ICR cell. Gas pressure was maintained at 0.5 psi with an applied voltage of 1.5 $\mathrm{kV}$ to maintain a consistent current of 60-120 nA. When operating in narrow SIM mode, the resolution was 100,000 and the scan window $30 \mathrm{~m} / \mathrm{z}$. Each scan window was acquired in $60 \mathrm{~s}$.

Specific rotations were acquired using ADP 440+ Polarimeter (Bellingham + Stanley Ltd). IR spectra were recorded on a PerkinElmer Spectrum 100 FT-IR Spectrometer using NaCl disc, and the samples were prepared as a solution. Column chromatography (CC) used silica gel (LC60A 40-63 MICRON, Germany). UV spectra were recorded on PerkinElmer (Singapore) Lambda 35 UV/VIS Spectrometer.

$\mathrm{CD}$ spectra for the compounds were recorded at $25{ }^{\circ} \mathrm{C}$ using a Chirascan $\mathrm{CD}$ spectrometer (Applied Photophysics Ltd). Samples $(\sim 1 \mathrm{mg} / \mathrm{ml})$ were measured in methanol using a $1 \mathrm{~mm}$ pathlength quartz cuvette. Data were recorded every $0.5 \mathrm{~nm}$ between $280 \mathrm{~nm}$ and $400 \mathrm{~nm}$ with a $1 \mathrm{~nm}$ spectral bandwidth and an integration time of 2 seconds per data point.

Chromatographic profiling, method development and assessment of purity of isolated pterosins and pterosides from each fraction of bracken rhizome chloroform extract were performed using a Dionex UltiMate 3000 HPLC system from Thermo Scientific equipped with Binary gradient pump, Autosampler and diode array detector (DAD) monitoring 190-400 nm (UV-VIS detector). 
Chromatographic analysis of each fraction was achieved using reverse phase analytical column, $250 \times 4.6 \mathrm{~mm}$, packed with Spherisil ODS-2 (C18), $5 \mu \mathrm{m}$ as a stationary phase. Different ratios of two mobile phases of $\mathrm{MeOH}-\mathrm{H}_{2} \mathrm{O}$ and $\mathrm{ACN}-\mathrm{H}_{2} \mathrm{O}$ (acidified with $0.1 \%$ formic acid) at a flow rate of $1.0 \mathrm{~mL} / \mathrm{min}$ at $40{ }^{\circ} \mathrm{C}$ were used to obtain high resolution chromatograms. Ultraviolet detection was set at $254 \mathrm{~nm}$. The Chromeleon 7 Software was used to control gradient setting, data acquisition and auto-sampler.

The Reveleris ${ }^{\circledR}$ Flash Chromatography system was used for purification of pterosins and pterosides. The samples were pre-adsorbed onto silica gel and subsequently run on the Reveleris ${ }^{\circledR}$ $\mathrm{C} 18(40 \mu \mathrm{m}, 12 \mathrm{~g})$ column for $64 \mathrm{~min}$ using two different solvent systems, $\mathrm{MeOH}-\mathrm{H}_{2} \mathrm{O}$ and ACN$\mathrm{H}_{2} \mathrm{O}$ (acidified with $0.1 \%$ formic acid), at a flow rate of $18 \mathrm{~mL} / \mathrm{min}$. The peaks were visualised and recorded with UV-Vis (254 $\mathrm{nm}$ and $280 \mathrm{~nm}$ ) and ELSD detectors.

Preparative TLC was conducted using glass plates pre-coated with silica gel (TLC Silica gel 60 $\mathrm{F}_{254}$, Germany, $1.0 \mathrm{~mm}$ thickness, $20 \times 20 \mathrm{~cm}$ ). Mixture of chloroform extract fractions were applied to TLC plates using suitable solvent systems. These compounds were visualized using UV-light and / or phosphomolybdic acid (PMA).

Single crystal X-ray diffraction data were collected either on a Rigaku AFC11 quarter chi goniometer equipped with an enhanced sensitivity (HG) Saturn944+ detector mounted at the window of $007 \mathrm{HF}$ copper rotating anode generator with Varimax optics (cis-pterosin C, transpterosin $\mathrm{C}$ and (2S)-pterosin A), or on a Rigaku AFC12 goniometer equipped with an enhanced sensitivity (HG) Saturn724+ detector mounted at the window of an FR-E+ SuperBright molybdenum rotating anode generator with VHF Varimax optics (70 $\mu \mathrm{m}$ focus) $((2 R)$-pteroside $\mathrm{B}$, (2S)-pteroside $\mathrm{K}$ and rhedynoside B). Rigaku CrystalClear (Rigaku Corporations, The Woodlands, Texas, USA) was used to record images. Data integration was carried out using Agilent CrysAlisPro (Agilent- Technologies UK Ltd). (cis-pterosin C, trans-pterosin C, $(2 S)$ pterosin A and rhedynoside B) or Rigaku CrystalClear ( $(2 R)$-pteroside B, $(2 S)$-pteroside $\mathrm{K})$. The structures were solved by charge-flipping methods using SUPERFLIP (Palatinus and Chapuis, 2007) and refined on $\mathrm{F}_{\mathrm{o}}{ }^{2}$ by full-matrix least squares refinement using SHELXL-2014 (Sheldrick, 2008). All non-hydrogen atoms were refined with anisotropic displacement parameters. Hydrogen atoms were added at calculated positions and refined using a riding model with isotropic displacement parameters based on the equivalent isotropic displacement parameter (Ueq) of the parent atom. The structures were deposited on the Cambridge Structural Database with the deposition numbers CCDC 1050917, 1050918, 1050920, 1406891,1418452 and 1418453.

In order to confirm the presence of isolated chlorinated compounds, bracken rhizomes $(10 \mathrm{~g}$, dry weight) were extracted with $100 \mathrm{ml}$ of methanol and ethyl acetate, and the extracts were analysed by reverse-phase HPLC using photodiode array detection with and without electrospray ionisation-ion trap mass spectrometry (HPLC/ESI-MS ${ }^{n}$ ) (more details are in the SI2).

\subsection{Plant material}

The bracken rhizomes $(11.8 \mathrm{~kg})$ were collected from Llanberis in Wales $\mathrm{N} 53^{\circ} 07^{\prime}$ and $\mathrm{W} 04^{\circ} 08^{\prime}$, on 21 February 2013. They were confirmed as Pteridium aquilinum (L.) Kuhn by Nigel Brown. A voucher specimen was deposited at Treborth Botanical Garden, Bangor. 


\subsection{Extraction and isolation}

The air-dried chopped bracken rhizomes $(3.45 \mathrm{~kg})$ were macerated with chloroform $(14 \mathrm{~L})$ at room temperature for $3 \times 24 \mathrm{~h}$. After filtration, the organic solvent was reduced under pressure to give the crude extract $(7.1 \mathrm{~g})$ which was pre-adsorbed onto silica gel and subjected to $\mathrm{CC}$ using $\mathrm{CHCl}_{3-}$ $\mathrm{MeOH}$ mixture with increasing polarity $(100: 0 \rightarrow 0: 100)$ to give thirteen fractions (BR1-BR13). From these fractions, 13 new compounds $(\mathbf{1}, 6.0 \mathrm{mg} ; \mathbf{2}, 11.0 \mathrm{mg} ; \mathbf{3}, 5.8 \mathrm{mg} ; \mathbf{4}, 2.6 \mathrm{mg} ; \mathbf{5}, 4.5 \mathrm{mg}$; 6, $6.0 \mathrm{mg} ; \mathbf{7}, 4.1 \mathrm{mg} ; \mathbf{8}, 13.0 \mathrm{mg}, \mathbf{9}, 3.0 \mathrm{mg} ; \mathbf{1 0}, 11.6 \mathrm{mg} ; \mathbf{1 1}, 3.2 \mathrm{mg} ; \mathbf{1 2}, 9.1 \mathrm{mg}$, and 13, $3.8 \mathrm{mg}$ ) and 22 known compounds (14, $6.0 \mathrm{mg} ; \mathbf{1 5}, 160.0 \mathrm{mg} ; \mathbf{1 6}, 110.0 \mathrm{mg} ; \mathbf{1 7}, 18.0 \mathrm{mg} ; \mathbf{1 8}, 20.0 \mathrm{mg} ; \mathbf{1 9}$, $60.0 \mathrm{mg} ; \mathbf{2 0}, 17.0 \mathrm{mg} ; \mathbf{2 1}, 10.0 \mathrm{mg} ; \mathbf{2 2}, 5.0 \mathrm{mg} ; \mathbf{2 3}, 3.0 \mathrm{mg} ; \mathbf{2 4}, 15.4 \mathrm{mg} ; \mathbf{2 5}, 4.0 \mathrm{mg} ; \mathbf{2 6}, 14.0 \mathrm{mg}$; 27, $14.7 \mathrm{mg}$; 28, $3.0 \mathrm{mg}$; 29, $4.0 \mathrm{mg} ; \mathbf{3 0}, 10.2 \mathrm{mg}$; 31, $203.0 \mathrm{mg} ; \mathbf{3 2}$, $4.9 \mathrm{mg} ; 33$, $47.0 \mathrm{mg} ; \mathbf{3 4}, 4.2$ $\mathrm{mg}$ and $\mathbf{3 5}, 30.0 \mathrm{mg}$ ) were isolated as the following:

Preparative TLC was applied to purify fraction BR1 $(25.0 \mathrm{mg})$ using $n$-hexane-acetone (1:9) to give $21(10.0 \mathrm{mg})$. Fraction BR2 (350 mg) was further chromatographed on a silica gel column eluting with gradient of $n$-hexane-EtOAc $(100: 0 \rightarrow 45: 55)$ to obtain five sub-fractions (BR2ABR2E). Sub-fraction BR2A (170.0 mg) was subjected to RP-FC using a gradient elution of ACN$\mathrm{H}_{2} \mathrm{O}(35-45 \%, 1 \mathrm{~h})$ to give $20(17.0 \mathrm{mg}) ; 22(5.0 \mathrm{mg}) ; \mathbf{2 3}(3.0 \mathrm{mg})$ and $\mathbf{2 6}(14.0 \mathrm{mg})$. Sub-fractions BR2B (130.0 mg), BR2D (20.0 mg) and BR2E (10 mg) were each subjected to preparative TLC using $n$-hexane-EtOAc (4:6), EtOAc and $\mathrm{MeOH}-\mathrm{Et}_{2} \mathrm{O}$ (1:49) to give 16 (110.0 mg), 14 (6.0 mg) and $4(2.6 \mathrm{mg})$, respectively. Sub-fraction BR2C (22 $\mathrm{mg})$ was purified using preparative TLC (diethyl ether) to afford compounds $\mathbf{1}(6.0 \mathrm{mg})$ and $\mathbf{3}(5.8 \mathrm{mg})$. Fractions BR3 (128.9 $\mathrm{mg}$ ) and BR4 (37 mg) were purified separately by preparative TLC using $n$-hexane-acetone (1:1 and 6:4) to afford $\mathbf{8}(13.0 \mathrm{mg})$ and $\mathbf{7}(4.1 \mathrm{mg})$, respectively. Preparative TLC (diethyl ether) was applied to fraction BR5 (109 $\mathrm{mg})$ to afford $5(4.5 \mathrm{mg})$ and $24(15.4 \mathrm{mg})$. Fraction BR6 (375 $\mathrm{mg})$ was fractionated by applying it on RP-FC with an isocratic gradient elution $\left(20-20 \%, \mathrm{ACN}-\mathrm{H}_{2} \mathrm{O}, 1 \mathrm{~h}\right)$ to give 15 (160.0 mg) and 19 (60.0 mg). Fraction BR7 (600 mg) was resolved by a silica gel CC eluted with gradients of $n$-hexane-EtOAc and EtOAc-MeOH with increasing polarity, respectively, to yield four sub-fractions (BR7A-BR7D). Sub-fraction BR7A (51.5 mg) was chromatographed on RP-FC using a gradient elution of $\mathrm{ACN}-\mathrm{H}_{2} \mathrm{O}(20-23 \%, 1 \mathrm{~h})$ to afford 6 (6.0 $\mathrm{mg}$ ) and 27 (14.7 mg). RP-FC was applied on sub-fraction BR7B (33.0 mg) using ACN-H $\mathrm{H}_{2} \mathrm{O}(20-$ $23 \%, 1 \mathrm{~h})$ as a gradient elution to obtain $\mathbf{2 8}(3.0 \mathrm{mg})$. Sub-fraction BR7C (242.0 $\mathrm{mg})$ was subjected to RP-FC using a gradient elution of $\mathrm{ACN}-\mathrm{H}_{2} \mathrm{O}(20-23 \%, 1 \mathrm{~h})$ to obtain four main fractions (BR7C1-BR7C4), and then the second peak (BR7C2) (38 mg) was further chromatographed on RP-FC using a gradient elution of $\mathrm{ACN}-\mathrm{H}_{2} \mathrm{O}(06-06-10-11 \%, 2 \mathrm{~h})$ to afford $\mathbf{1 7}(16.5 \mathrm{mg})$ and $\mathbf{1 8}$ $(19.5 \mathrm{mg})$. Sub-fraction BR7D $(97.0 \mathrm{mg})$ was resolved on RP-FC using a gradient elution of ACN$\mathrm{H}_{2} \mathrm{O}(15-20 \%, 1 \mathrm{~h})$ to give 25 (4.0 mg). Fraction BR8 (119.7 mg) was subjected to RP-FC using a gradient elution of $\mathrm{MeOH}-\mathrm{H}_{2} \mathrm{O}(40-50 \%, 1 \mathrm{~h})$ to give $\mathbf{1 0}(11.6 \mathrm{mg})$ and $\mathbf{2 9}(4.0 \mathrm{mg})$. Fraction BR9 $\left(110 \mathrm{mg}\right.$ ) was separated with RP-FC using a gradient elution of $\mathrm{MeOH}-\mathrm{H}_{2} \mathrm{O}(40-50 \%, 1 \mathrm{~h})$ to obtain four sub-fractions (BR9A-BR9D). Sub-fractions BR9A, BR9B and BR9D gave 11 (3.2 $\mathrm{mg}), \mathbf{1 2}(9.1 \mathrm{mg})$ and $\mathbf{3 5}(30.0 \mathrm{mg})$, respectively. The purification of sub-fraction BR9C (15.0 mg) on RP-FC using gradient elution (25-30\% ACN-H $\left.\mathrm{H}_{2} \mathrm{O}, 1 \mathrm{~h}\right)$ yielded $\mathbf{1 3}$ (3.8 mg). Fraction BR11 (261.7 mg) was resolved on RP-FC using $\mathrm{MeOH}-\mathrm{H}_{2} \mathrm{O}(40-50 \%, 1 \mathrm{~h}$ ) as a mobile phase to obtain $\mathbf{2}(11.0 \mathrm{mg}), \mathbf{3 1}(203.0 \mathrm{mg})$ and $\mathbf{3 3}(47.0 \mathrm{mg})$. Fraction BR13 (200 mg) was further fractionated by applying it to RP-FC with a gradient elution $\left(10-25 \% \mathrm{ACN}-\mathrm{H}_{2} \mathrm{O}, 1 \mathrm{~h}\right)$ to obtain four subfractions (BR13A-BR13D). Compounds $32(4.9 \mathrm{mg}), \mathbf{3 0}(10.2 \mathrm{mg})$ and $\mathbf{3 4}(4.2 \mathrm{mg})$ were obtained 
from sub-fractions BR13A, BR13B and BR13C, respectively, while sub-fraction BR13D (30 mg) was re-subjected to RP-FC using a gradient elution (40-50\% $\mathrm{ACN}-\mathrm{H}_{2} \mathrm{O}, 1 \mathrm{~h}$ ) to afford 9 (3.0 mg).

\subsection{Physico-chemical parameters of the new compounds}

Rhedynosin A (1); Yellow powder; $[\alpha]_{D}^{24}-4.31\left(c 0.33, \mathrm{CHCl}_{3}\right) ; \mathrm{UV}(\mathrm{MeOH}) \lambda_{\max } \mathrm{nm}(\log \varepsilon)$ : 211 (4.16), 241 (3.77), 258 (3.85), 306 (2.99); IR (film) $v_{\max }$ 3418, 3014, 2928, 1704, 1605, 1446, 1380, 1048, 755, $666 \mathrm{~cm}^{-1}$; for ${ }^{1} \mathrm{H}$ and ${ }^{13} \mathrm{C}$ NMR spectroscopic data, see Tables $1 \&$ 4; FT-ICRMS $m / z, 247.1330[\mathrm{M}+\mathrm{H}]^{+}$(calcd for $\mathrm{C}_{15} \mathrm{H}_{19} \mathrm{O}_{3}, 247.1334$ ).

Rhedynoside A (2): White powder; $[\alpha]_{D}^{24.2}-26.07$ ( $c$ 0.33, MeOH); UV (MeOH) $\lambda_{\max } \mathrm{nm}(\log$ ع): 216 (4.27), 259 (3.92), 304 (2.99); IR (film) $v_{\max }$ 3369, 2927, 1692, 1602, 1444, 1378, 1075, $918 \mathrm{~cm}^{-1}$; for ${ }^{1} \mathrm{H}$ and ${ }^{13} \mathrm{C}$ NMR spectroscopic data, see Tables 1 \& 4; FT-ICR-MS $\mathrm{m} / \mathrm{z} 409.1865$ $[\mathrm{M}+\mathrm{H}]^{+}$(calcd for $\mathrm{C}_{21} \mathrm{H}_{29} \mathrm{O}_{8}, 409.1862$ ).

Rhedynosin B (3): Yellow powder; $[\alpha]_{D}^{24}-12.78\left(c\right.$ 0.33, $\left.\mathrm{CHCl}_{3}\right)$; UV $(\mathrm{MeOH}) \lambda_{\max } \mathrm{nm}(\log$ $\varepsilon): 209$ (4.31), 260 (3.96), 313 (3.09); IR (film) $v_{\max }$ 3419, 3018, 2926, 1715, 1603, 1446, 1379, 1290, 1196, 1096, 985, 856, 754, $666 \mathrm{~cm}^{-1}$; for ${ }^{1} \mathrm{H}$ and ${ }^{13} \mathrm{C}$ NMR spectroscopic data, see Tables 1 \& 4; FT-ICR-MS m/z 247.0967 [M+H] ${ }^{+}$(calcd for $\mathrm{C}_{14} \mathrm{H}_{15} \mathrm{O}_{4}, 247.0970$ ).

Rhedynosin C (4): White powder; $[\alpha]_{D}^{24.2}+3.76(c 0.33, \mathrm{MeOH}) ; \mathrm{UV}(\mathrm{MeOH}) \lambda_{\max } \mathrm{nm}(\log \varepsilon)$ : 214 (3.24), 242 (2.97), 258 (2.94), 306 (2.51); IR (film) $v_{\max }$ 3428, 2924, 1703, 1608 1458, 1379, 1260, 1034, $800 \mathrm{~cm}^{-1}$; for ${ }^{1} \mathrm{H}$ and ${ }^{13} \mathrm{C}$ NMR spectroscopic data, see Tables 1 \& 4; FT-ICR-MS $\mathrm{m} / z$ $245.0821[\mathrm{M}-\mathrm{H}]^{-}\left(\right.$calcd for $\left.\mathrm{C}_{14} \mathrm{H}_{13} \mathrm{O}_{4}, 245.0814\right)$.

Rhedynosin D (5): Yellow solid; $[\alpha]_{D}^{24}-19.12\left(c 0.33, \mathrm{CHCl}_{3}\right)$; UV (MeOH) $\lambda_{\max } \mathrm{nm}(\log \varepsilon)$ : 215 (4.13), 259 (3.75), 303 (2.76); IR (film) $v_{\max } 3418,2925,1714,1602,1447,1379,1093,855$, 756, $666 \mathrm{~cm}^{-1}$; for ${ }^{1} \mathrm{H}$ and ${ }^{13} \mathrm{C}$ NMR spectroscopic data, see Tables 1 \& 4; FT-ICR-MS $\mathrm{m} / \mathrm{z}$ $269.0941[\mathrm{M}+\mathrm{H}]^{+}$(calcd for $\mathrm{C}_{14} \mathrm{H}_{18}{ }^{35} \mathrm{ClO}_{3}, 269.0944$ ).

Rhedynosin E (6): Off-white powder; $[\alpha]_{D}^{24.2}-14.94$ ( $c$ 0.33, MeOH); UV (MeOH) $\lambda_{\max } \mathrm{nm}(\log$ ع): 217 (4.35), 258 (4.02), 295 (3.13); IR (film) $v_{\max }$ 3419, 2932, 1699, 1600, 1465, 1382, 1203, 1099, 995, $884 \mathrm{~cm}^{-1}$; for ${ }^{1} \mathrm{H}$ and ${ }^{13} \mathrm{C}$ NMR spectroscopic data, see Tables 2 \& 4; FT-ICR-MS $\mathrm{m} / \mathrm{z}$ 263.1280 [M+H] $]^{+}$(calcd for $\mathrm{C}_{15} \mathrm{H}_{19} \mathrm{O}_{4}, 263.1283$ ).

Rhedynosin F (7): Light yellow crystalline powder; $[\alpha]_{D}^{24}+15.36\left(c 0.33, \mathrm{CHCl}_{3}\right)$; UV (MeOH) $\lambda_{\max } \mathrm{nm}(\log \varepsilon): 219$ (4.27), 259 (3.87), 298 (2.92); IR (film) $v_{\max }$ 3417, 2929, 1698, 1598, 1455, 1379, 1223, 1042, 923, 859, $755 \mathrm{~cm}^{-1}$; for ${ }^{1} \mathrm{H}$ and ${ }^{13} \mathrm{C}$ NMR spectroscopic data, see Tables 2 \& 4; FT-ICR-MS $m / z 283.1098[\mathrm{M}+\mathrm{H}]^{+}$(calcd for $\mathrm{C}_{15} \mathrm{H}_{20}{ }^{35} \mathrm{ClO}_{3}, 283.1101$ ).

Rhedynosin G (8): Yellow gum; $[\alpha]_{D}^{24.2}+4.04\left(c\right.$ 0.33, MeOH); UV (MeOH) $\lambda_{\max } \mathrm{nm}(\log \varepsilon)$ : 218 (4.34), 260 (3.97), 299 (3.03); IR (film) $v_{\max }$ 3405, 2929, 1705, 1599, 1447, 1378, 1217, 1094, 983, 887, $751 \mathrm{~cm}^{-1}$; for ${ }^{1} \mathrm{H}$ and ${ }^{13} \mathrm{C}$ NMR spectroscopic data, see Tables 2 \& 4; FT-ICR-MS $\mathrm{m} / z$ 269. $0941[\mathrm{M}+\mathrm{H}]^{+}$(calcd for $\left.\mathrm{C}_{14} \mathrm{H}_{18}{ }^{35} \mathrm{ClO}_{3}, 269.0944\right)$. 
Rhedynosin H (9): Off-white powder; $[\alpha]_{D}^{24}-28.049$ ( $c$ 0.33, $\left.\mathrm{CHCl}_{3}\right)$; UV (MeOH) $\lambda$ max $\mathrm{nm}$ ( $\log \varepsilon$ ): 217 (4.71), 258 (4.37), 303 (3.55); IR (film) $v_{\max }$ 2919, 1704, 1601, 1456, 1377, 1325, 1221, 1129, 1020, 970, 885, 756, $702 \mathrm{~cm}^{-1}$; for ${ }^{1} \mathrm{H}$ and ${ }^{13} \mathrm{C}$ NMR spectroscopic data, see Tables 2 \& 4; FT-ICR-MS m/z 297. $0802[\mathrm{M}-\mathrm{H}]^{-}$(calcd for $\mathrm{C}_{14} \mathrm{H}_{17} \mathrm{O}_{5} \mathrm{~S}, 297.0797$ ).

Rhedynoside B (10): White crystalline compound; $[\alpha]_{D}^{24.2}-10.82(c 0.33, \mathrm{MeOH}) ; \mathrm{UV}(\mathrm{MeOH})$ $\lambda_{\max } \mathrm{nm}(\log \varepsilon): 219$ (4.48), 263 (4.12), 304 (3.11), nm; IR (film) $v_{\max } 3391,2926,1703,1601$ $1451,1376,1327,1227,1074,918,872 \mathrm{~cm}^{-1}$; for ${ }^{1} \mathrm{H}$ and ${ }^{13} \mathrm{C}$ NMR spectroscopic data, see Tables 3 \& 4; FT-ICR-MS $m / z$ 415.1527 [M+H $]^{+}$(calcd for $\mathrm{C}_{20} \mathrm{H}_{28}{ }^{35} \mathrm{ClO}_{7}, 415.1523$ ).

Rhedynoside C (11): Off-white crystalline powder; $[\alpha]_{D}^{24.6}-0.488$ ( $c$ 0.33, MeOH); UV (MeOH) $\lambda_{\max } \mathrm{nm}(\log \varepsilon): 216$ (4.43), 257 (3.98), 303 (2.93); IR (film) $v_{\max }$ 3391, 2927, 1699, 1601, 1440, 1379, 1326, 1077, 918, $888 \mathrm{~cm}^{-1}$; for ${ }^{1} \mathrm{H}$ and ${ }^{13} \mathrm{C}$ NMR spectroscopic data, see Tables 3 \& 4; FTICR-MS $m / z, 427.1530[\mathrm{M}-\mathrm{H}]^{-}$(calcd for $\mathrm{C}_{21} \mathrm{H}_{28}{ }^{35} \mathrm{ClO}_{7}, 427.1524$ ).

Rhedynoside D (12): Yellow powder; $[\alpha]_{D}^{24.6}-0.643(c 0.33, \mathrm{MeOH}) ; \mathrm{UV}(\mathrm{MeOH}) \lambda_{\max } \mathrm{nm}(\log$ ع): 216 (4.43), 256 (4.01), 303 (2.98); IR (film) $v_{\max }$ 3374, 2928, 1700, 1600, 1440, 1376, 1312, 1163, 1075, 921, $890 \mathrm{~cm}^{-1}$; for ${ }^{1} \mathrm{H}$ and ${ }^{13} \mathrm{C}$ NMR spectroscopic data, see Tables 3 \& 4; FT-ICRMS $m / z 413.1374[\mathrm{M}-\mathrm{H}]^{-}$(calcd for $\mathrm{C}_{20} \mathrm{H}_{26}{ }^{35} \mathrm{ClO}_{7}, 413.1367$ ).

Rhedynoside E (13): Off-white crystalline powder; $[\alpha]_{D}^{24.6}+0.436(c 0.33, \mathrm{MeOH}) ; \mathrm{UV}(\mathrm{MeOH})$ $\lambda_{\max } \mathrm{nm}(\log \varepsilon): 218$ (4.40), 258 (3.92), 300 (2.63); IR (film) $v_{\max }$ 3390, 3018, 2928, 1703, 1599, $1462,1380,1325,1162,1076,898,757 \mathrm{~cm}^{-1}$; for ${ }^{1} \mathrm{H}$ and ${ }^{13} \mathrm{C}$ NMR spectroscopic data, see Tables 3 \& 4; FT-ICR-MS $m / z$ 427.1530 [M-H] ${ }^{-}$(calcd for $\mathrm{C}_{21} \mathrm{H}_{28}{ }^{35} \mathrm{ClO}_{7}, 427.1524$ ).

\section{Acknowledgements}

Vera Thoss, Martina Lahmann and Mohammad Nur-e-Alam acknowledge the European Regional Development Fund through the BEACON project. Rizgar Hassan Mohammad acknowledges funding by the Kurdish Ministry of Higher Education and Scientific Research-Kurdistan Regional Government (MHE-SR-KRG) for his scholarship. Muhammad Yousaf, King Saudi University, Saudi Arabia confirmed previously undescribed compounds. Stephania Christou, Manchester University, UK, measured the specific rotations for the previously unreported compounds. Ana Winters, Aberystwyth University, conducted the HPLC-ESI-MS ${ }^{\mathrm{n}}$ analysis. Kathleen Tailliart, Shon Glyn Jones, David Davenport Hughes, Sam Page and Toby Vye provided technical assistance. An anonymous reviewer and Prof. Michael D. Threadgill (University of Bath) provided useful suggestions to improve the manuscript.

\section{Appendix A. Supplementary data}

Supplementary data associated with this article can be found, in the online version, at website- 


\section{References}

Almeida Santos, M. de F.M., Dórea, J.G., Luna, H., 2006. Bracken-fern extracts can be clastogenic or aneugenic depending on the tissue cell assay. Food Chem. Toxicol. 44, 1845-1848.

Alonso-Amelot, M., Avendano, M., 2002. Human carcinogenesis and bracken fern: A review of the evidence. Curr. Med. Chem. 9, 675-686.

Alonso-Amelot, M.E., Pérez-Mena, M., Calcagno, M.P., Jaimes-Espinoza, R., Castillo, U., 1992. Ontogenic variation of biologically active metabolites of Pteridium aquilinum (L. Kuhn) pterosins $\mathrm{A}$ and $\mathrm{B}$, and ptaquiloside in a bracken population of the tropical Andes. J. Chem. Ecol. 18, 1405-1420.

Aranha, P.C.R., Hansen, H.C.B., Rasmussen, L.H., Strobel, B.W., Friis, C., 2014. Determination of ptaquiloside and pterosin B derived from bracken (Pteridium aquilinum) in cattle plasma, urine and milk. J. Chromatogr. B. Analyt. Technol. Biomed. Life Sci. 951-952, 44-51.

Campos-da-Paz, M., Pereira, L.O., Bicalho, L.S., Dórea, J.G., Poças-Fonseca, M.J., Santos, M. de F.M.A., 2008. Interaction of bracken-fern extract with vitamin $\mathrm{C}$ in human submandibular gland and oral epithelium cell lines. Mutat. Res. 652, 158-163.

Castillo, U.F., Wilkins, A.L., Lauren, D.R., Smith, B.L., Alonso-Amelot, M., 2003. Pteroside A2a new illudane-type sesquiterpene glucoside from Pteridium caudatum L. Maxon, and the spectrometric characterization of caudatodienone. J. Agric. Food Chem. 51, 2559-2564.

Chen, C.-Y., Chiu, F.-Y., Lin, Y., Huang, W.-J., Hsieh, P.-S., Hsu, F.-L., 2015. Chemical constituents analysis and antidiabetic activity validation of four fern species from Taiwan. Int. J. Mol. Sci. 16, 2497-2516.

Chen, Y.-H., Chang, F.-R., Lu, M.-C., Hsieh, P.-W., Wu, M.-J., Du, Y.-C., Wu, Y.-C., 2008. New benzoyl glucosides and cytotoxic pterosin sesquiterpenes from Pteris ensiformis Burm. Molecules 13, 255-266.

Felipe, D., Brambilla, L., Porto, C., Pilau, E., Cortez, D., 2014. Phytochemical analysis of Pfaffia glomerata inflorescences by LC-ESI-MS/MS. Molecules 19, 15720-15734.

Fenwick, G.R., 1988. Bracken (Pteridium aquilinum) — toxic effects and toxic constituents. J. Sci. Food Agric. 46, 147-173.

Fukuoka, M., Kuroyanagi, M., Yoshihira, K., Natori, S., 1978. Chemical and toxicological studies on bracken fern, Pteridium aquilinum var. latiusculum. II. Structures of pterosins, sesquiterpenes having 1-indanone skeleton. Chem. Pharm. Bull. (Tokyo). 26, 2365-2385.

Fukuoka, M., Yoshihira, K., Natori, S., Mihashi, K., Nishi, M., 1983. Carbon-13 nuclear magnetic resonance spectra of pterosin-sesquiterpenes and related indan-1-one derivatives. Chem. Pharm. Bull. (Tokyo). 31, 3113-3128.

Gomes, J., Magalhães, A., Carvalho, A.S., Hernandez, G.E., Papp, S.L., Head, S.R., Michel, V., David, L., Gärtner, F., Touati, E., Reis, C.A., 2012. Glycophenotypic alterations induced by Pteridium aquilinum in mice gastric mucosa: synergistic effect with Helicobacter pylori infection. PLoS One 7, 1-11.

Hayashi, Y., Nishizawa, M., Harita, S., Sakan, T., 1972. Structures and syntheses of hypolepin A, 
B and C, sesquiterpenes from Hypolepis Punctata Mett. Chem. Lett. 375-378.

Hikino, H., Miyase, T., Takemoto, T., 1976. Biosynthesis of pteroside B in Pteridium aquilinum var. Latiusculum, proof of the sesquiterpenoid origin of the pterosides. Phytochemistry (Elsevier) 15, 121-123.

Hikino, H., Takahashi, T., Takemoto, T., 1972. Structure of pteroside A and C, glycosides of Pteridium aquilinum var. latiusculum. Chem. Pharm. Bull. (Tokyo). 20, 210-212.

Hikino, H., Takahashi, T., Takemoto, T., 1971. Structure of pteroside Z and D, glycosides of Pteridium aquilinum var. latiusculum. Chem. Pharm. Bull. (Tokyo). 19, 2424-2425.

Hirono, I., 1986. Carcinogenic principles isolated from bracken fern. Crit. Rev. Toxicol. 17, 1-22.

Hopkins, A., 1990. Bracken (Pteridium aquilinum): Its distribution and animal health implications. Br. Vet. J. 146, 316-326.

Hsu, F.-L., Liu, S.-H., Uang, B.-J., 2014. Use of pterosin compounds for treating diabetes and obesity. U.S. Patent 8633252 B2.

Kigoshi, H., Sawada, A., Imamura, Y., Niwa, H., Yamada, K., 1989. Ptaquilosin, the aglycone of a bracken carcinogen ptaquiloside: Chemical derivation from ptaquiloside and the reactivity. Tetrahedron 45, 2551-2556.

Kobayashi, A., Egawa, H., Koshimizu, K., Mitsui, T., 1975. Antimicrobial constituents in Pteris inaequalis bak. Agric. Biol. Chem. 39, 1851-1856.

Kobayashi, A., Koshimizu, K., 1980. Cytotoxic effects of bracken fern constituents, pterosins, on sea urchin embryos and a ciliate. Agric. Biol. Chem. 44, 393-398.

Kovganko, N. V., Kashkan, Z.N., Krivenok, S.N., 2004. Bioactive compounds of the flora of Belarus. 4. Pterosins A and B from Pteridium aquilinum. Chem. Nat. Compd. 40, 227-229.

Kuraishi, T., Murakami, T., Taniguchi, T., Kobuki, Y., Maehashi, H., Tanaka, N., Saiki, Y., Chen, C., 1985. Chemical and chemotaxonomical studies of ferns. LIV. Pterosin derivatives of the genus Microlepia (Pteridaceae). Chem. Pharm. Bull. (Tokyo). 33, 2305-2312.

Kuroyanagi, M., Fukuoka, M., Yoshihira, K., Natori, S., 1979. Chemical and toxicological studies on bracken fern, Pteridium aquilinum var. latiusculum. III. Further characterization of pterosins and pterosides, sesquiterpenes and the glucosides having 1-indanone skeleton, from the rhizomes. Chem. Pharm. Bull. (Tokyo). 27, 592-601.

Lee, Y.-P., Hsu, F.-L., Kang, J.-J., Chen, C.-K., Lee, S.-S., 2012. Metabolism of (2S)-pterosin A: identification of the phase I and phase II metabolites in rat urine. Drug Metab. Dispos. 40, $1566-1574$.

Levandi, T., Püssa, T., Vaher, M., Ingver, A., Koppel, R., Kaljurand, M., 2014. Principal component analysis of HPLC-MS/MS patterns of wheat ( Triticum aestivum ) varieties. Proc. Est. Acad. Sci. 63, 86-92.

Madeja, J., Harmata, K., Kolaczek, P., Karpinska-Kolaczek, M., Piatek, K., Naks, P., 2009. Bracken (Pteridium aquilinum (L.) Kuhn), Mistletoe (Viscum album (L.)) and Bladder-nut (Staphylea pinnata (L.))-Mysterious Plants with Unusual Applications. Cultural and Ethnobotanical Studies, in: Morel, J.-P., Mercuri, A.M. (Eds.), Plants and Cultural: Seeds of 
the Cultural Heritage of Europe. Edipuglia, pp. 207-215.

Marrs, R.H., Watt, a. S., 2006. Biological flora of the British Isles: Pteridium aquilinum (L.) Kuhn. J. Ecol. 94, 1272-1321.

McKee, T.C., II, J.H.C., Riccio, R., D’Auria, M.V., Iorizzi, M., Minale, L., Moran, R.A., Gulakowski, R.J., McMahon, J.B., 1994. HIV-inhibitory natural products. 11. Comparative studies of sulfated sterols from marine invertebrates. J. Med. Chem. 37, 793-797.

Murakami, T., Satake, T., Ninomiya, K., Iida, H., Yamauchi, K., Tanaka, N., Saiki, Y., Chen, C.M., 1980. Pterosin-derivate aus der familie pteridaceae. Phytochemistry (Elsevier) 19, $1743-$ 1746.

Ng, K.-M.E., McMorris, T.C., 1984. An efficient synthesis of pterosin C and other pterosins. Can. J. Chem. 62, 1945-1953.

Padwa, A., Curtis, E.A., Sandanayaka, V.P., 1996. Generation and cycloaddition behavior of spirocyclic carbonyl ylides. Application to the synthesis of the pterosin family of sesquiterpenes $\uparrow$. J. Org. Chem. 61, 73-81.

Pakeman, R., Marrs, R., Howard, D., Barr, C., Fuller, R., 1996. The bracken problem in Great Britain: Its present extent and future changes. Appl. Geogr. 16, 65-86.

Palatinus, L., Chapuis, G., 2007. SUPERFLIP - a computer program for the solution of crystal structures by charge flipping in arbitrary dimensions. J. Appl. Crystallogr. 40, 786-790.

Potter, D.M., Baird, M.S., 2000. Carcinogenic effects of ptaquiloside in bracken fern and related compounds. Br. J. Cancer 83, 914-920.

Qu, J., Liang, Q., Liang, Q., Luo, G., Wang, Y., 2004. Screening and identification of glycosides in biological samples using energy-gradient neutral loss scan and liquid chromatography tandem mass spectrometry. Anal. Chem. 76, 2239-2247.

Rasmussen, L.H., Kroghsbo, S., Frisvad, J.C., Hansen, H.C.B., 2003. Occurrence of the carcinogenic bracken constituent ptaquiloside in fronds, topsoils and organic soil layers in Denmark. Chemosphere 51, 117-127.

Scholz, K., Dekant, W., Völkel, W., Pähler, A., 2005. Rapid detection and identification of $N$ acetyl- $L$-cysteine thioethers using constant neutral loss and theoretical multiple reaction monitoring combined with enhanced product-ion scans on a linear ion trap mass spectrometer. J. Am. Soc. Mass Spectrom. 16, 1976-1984.

Sengupta, P., Sen, M., Kumar Niyogi, S., Chandra Pakrashi, S., Ali, E., 1976. Isolation and structure of wallichoside, a novel pteroside from Pteris wallichiana. Phytochemistry (Elsevier) 15, 995-998.

Sheldrick, G.M., 2008. A short history of SHELX. Acta Crystallogr. A. 64, 112-122.

Sheridan, H., Frankish, N., Farrell, R., 1999. Smooth muscle relaxant activity of pterosin Z and related compounds. Planta Med. 65, 271-272.

Tanaka, N., Satake, T., Takahashi, A., Mochizuki, M., Murakami, T., Saiki, Y., Yang, J., Chen, C., 1982. Chemical and chemotaxonomical studies of ferns. XXXIX. Chemical studies on the constituents of Pteris bella Tagawa and Pteridium aquilinum subsp. wightianum (Wall) 
Shich. Chem. Pharm. Bull. (Tokyo). 30, 3640-3646.

Uddin, S.J., Jason, T.L.H., Beattie, K.D., Grice, I.D., Tiralongo, E., 2011. (2S,3S)-sulfated pterosin C, a cytotoxic sesquiterpene from the Bangladeshi Mangrove fern Acrostichum aureum. J. Nat. Prod. 74, 2010-2013.

Vetter, J., 2009. A biological hazard of our age: Bracken fern [Pteridium aquilinum (L.) Kuhn] A review. Acta Vet. Hung. 57, 183-196.

Warncke, I. , Furche, F., 2012 Circular dichroism: electronic. Wiley Interdiscipl. Rev.: Comp. Mol. Sc. 2, 150-166

Yamada, K., Ojika, M., Kigoshi, H., 2007. Ptaquiloside, the major toxin of bracken, and related terpene glycosides: chemistry, biology and ecology. Nat. Prod. Rep. 24, 798-813.

Yoshihira, K., Fukuoka, M., Kuroyanagi, M., Natori, S., 1971. 1-Indanone derivatives from bracken, Pteridium aquilinum var. latiusculum. Chem. Pharm. Bull. (Tokyo). 19, 1491-1495. 


\section{Supplementary Information 2 (SI2)}

\section{Isolation and characterisation of thirteen pterosins and pterosides from \\ bracken (Pteridium aquilinum (L.) Kuhn) rhizome}

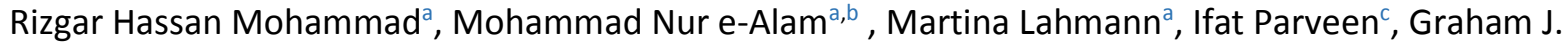
Tizzard $^{d}$, Simon J. Coles ${ }^{d}$, Mark Fowler ${ }^{\mathrm{e}}$, Alex F. Drake ${ }^{\mathrm{f}}$, Derren Heyes ${ }^{\mathrm{g}}$, Vera Thoss ${ }^{\mathrm{a}, *}$

\footnotetext{
a School of Chemistry, Bangor University, Bangor LL57 2UW, United Kingdom

${ }^{b}$ Department of Pharmacognosy, College of Pharmacy, King Saud University, P.O. Box 2457, Riyadh 11451, Saudi Arabia.

c IBERS, Aberystwyth University, Penglais, Aberystwyth SY23 3DA, UK

d UK National Crystallography Service, School of Chemistry, University of Southampton, University Road, Southampton SO17 1BJ, United Kingdom

e Strategic Science Group, Unilever R\&D, Colworth Science Park, Bedford, MK44 1LQ, UK.

${ }^{f}$ Biomolecular Spectroscopy Centre, Pharmaceutical Optical \& Chiroptical Spectroscopy Facility, King's College London, The Wolfson Wing, WWB10 Hodgkin Building, Guy's Campus, London SE1 1UL, UK

g Manchester Institute of Biotechnology, University of Manchester, 131 Princess St, Manchester M1 7DN

*Corresponding Author vera.thoss@bangor.ac.uk
}

\section{Contents:}

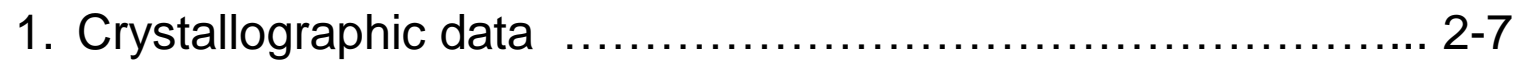

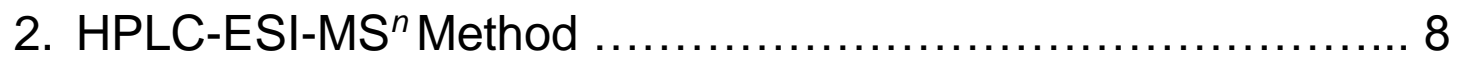

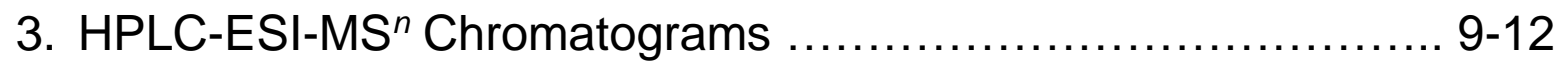

4. Identification of SGLT1 and GLUT2 transporter inhibitors .........13- 


\section{Crystallographic data}

cis-pterosin C

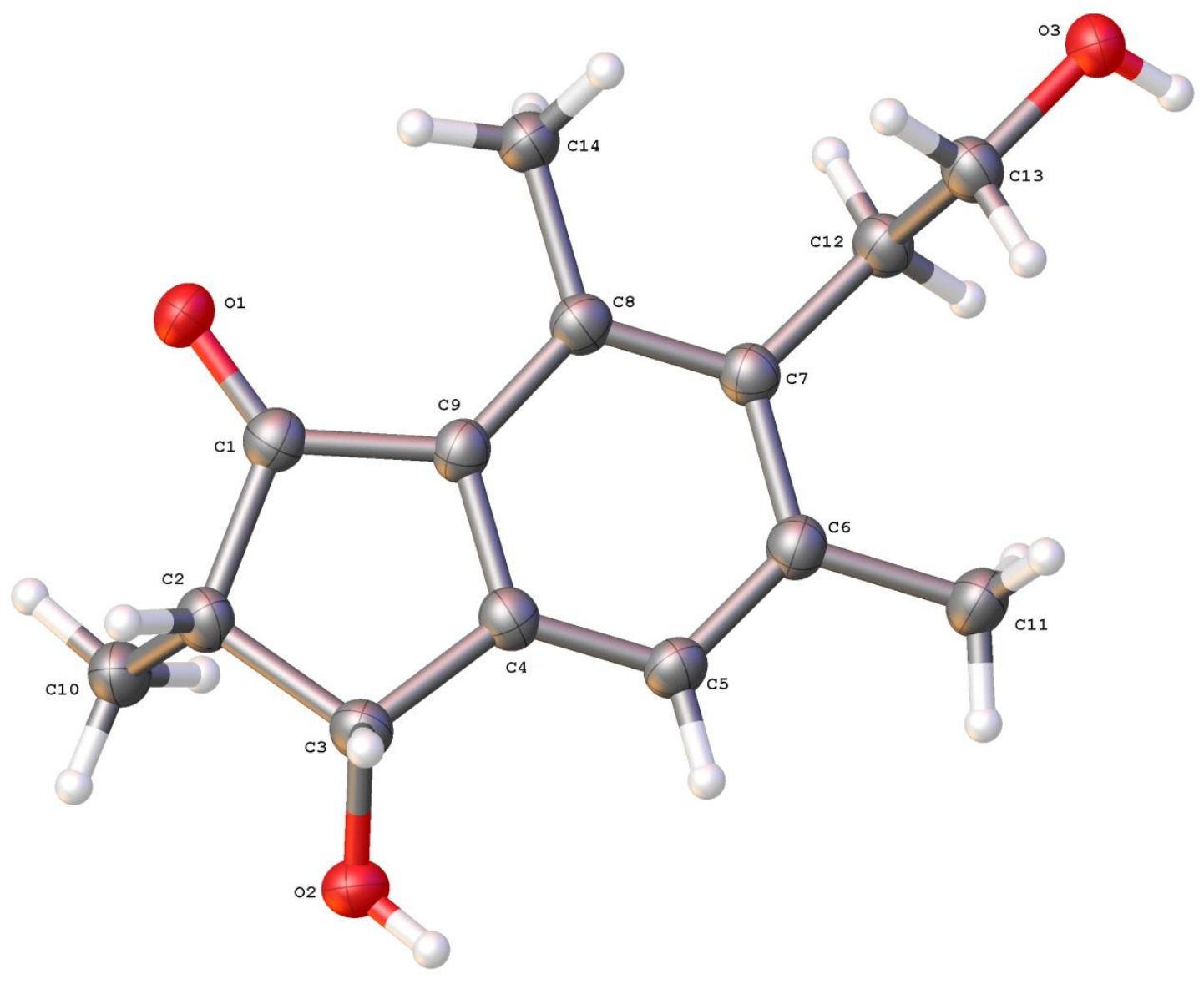

Formula: $\mathrm{C}_{14} \mathrm{H}_{18} \mathrm{O}_{3} ; M_{\mathrm{r}}=234.28$; crystal dimensions: $0.41 \times 0.07 \times 0.04 \mathrm{~mm}$; crystal system: Monoclinic; space group: $P 2_{1} ; a=4.58360(6) \AA ⿻$ 15.93341(16) $\AA, c=8.13657(8) \AA, \alpha=90^{\circ}, \beta=93.1583(10)^{\circ}, \gamma=90^{\circ} ; \mathrm{V}=$ $593.330(11) \AA^{3} ; Z=2 ; \rho_{\text {calcd }}=1.331 \mathrm{Mg} / \mathrm{m}^{3} ; \mu=0.736 \mathrm{~mm}^{-1} ;$ Cu Ka radiation, $\Lambda=1.54184 \AA ; \mathrm{T}=100 \mathrm{~K} ; 2 \Theta_{\max }=138.0^{\circ} ; 20930 / 2179$ measured/independent reflections; $R_{\text {int }}$ : 0.0516; Flack parameter/Hooft parameter $-0.03(9) /-0.12(4) ; R=0.0285, w R=0.0752 ; \Delta \rho_{\max }=0.133 \mathrm{e \AA}^{-3}$, $\Delta \rho_{\min }=-0.121 \mathrm{e}^{-3}$. Colourless lath crystals. CCDC deposition number 1050917. 
trans-pterosin C

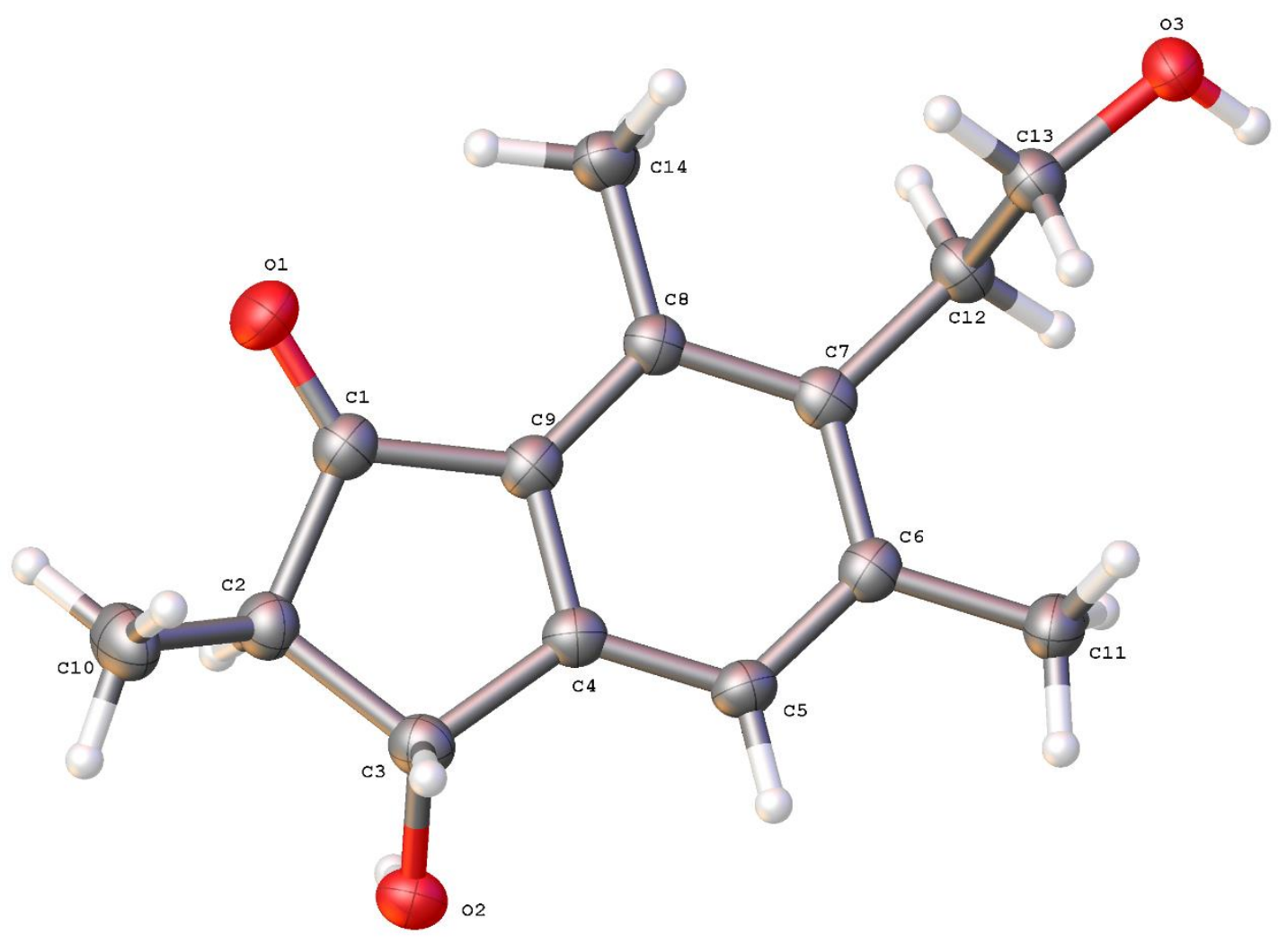

Formula: $\mathrm{C}_{14} \mathrm{H}_{18} \mathrm{O}_{3} ; M_{\mathrm{r}}=234.28$; crystal dimensions: $0.15 \times 0.12 \times 0.10 \mathrm{~mm}$; crystal system: Orthorhombic; space group: $\mathrm{P} 2{ }_{1}{ }_{2}{ }_{1} 2_{1} ; a=7.07508(11) \AA$, $b=$ 11.4381(2) $\AA, c=14.9966(2) \AA, \alpha=90^{\circ}, \beta=90^{\circ}, \gamma=90^{\circ} ; V=1213.61(4) \AA^{3}$; $Z=4 ; \rho_{\text {calcd }}=1.282 \mathrm{Mg} / \mathrm{m}^{3} ; \mu=0.719 \mathrm{~mm}-1 ;$ Cu Ka radiation, $\lambda=1.54184$ $\AA ; \mathrm{T}=100 \mathrm{~K} ; 2 \Theta_{\max }=138.5^{\circ} ; 14992 / 2138$ measured $/$ independent reflections; $R_{\text {int: }}$ 0.0563; Flack parameter/Hooft parameter 0.11(13)/0.05(9); $R=0.0301, w R=0.0779 ; \Delta \rho_{\max }=0.147 \mathrm{e \AA}^{-3}, \Delta \rho_{\min }=-0.119 \mathrm{e}^{-3}$. Colourless plate crystals. CCDC deposition number 1418453. 
(2S)-pterosin A

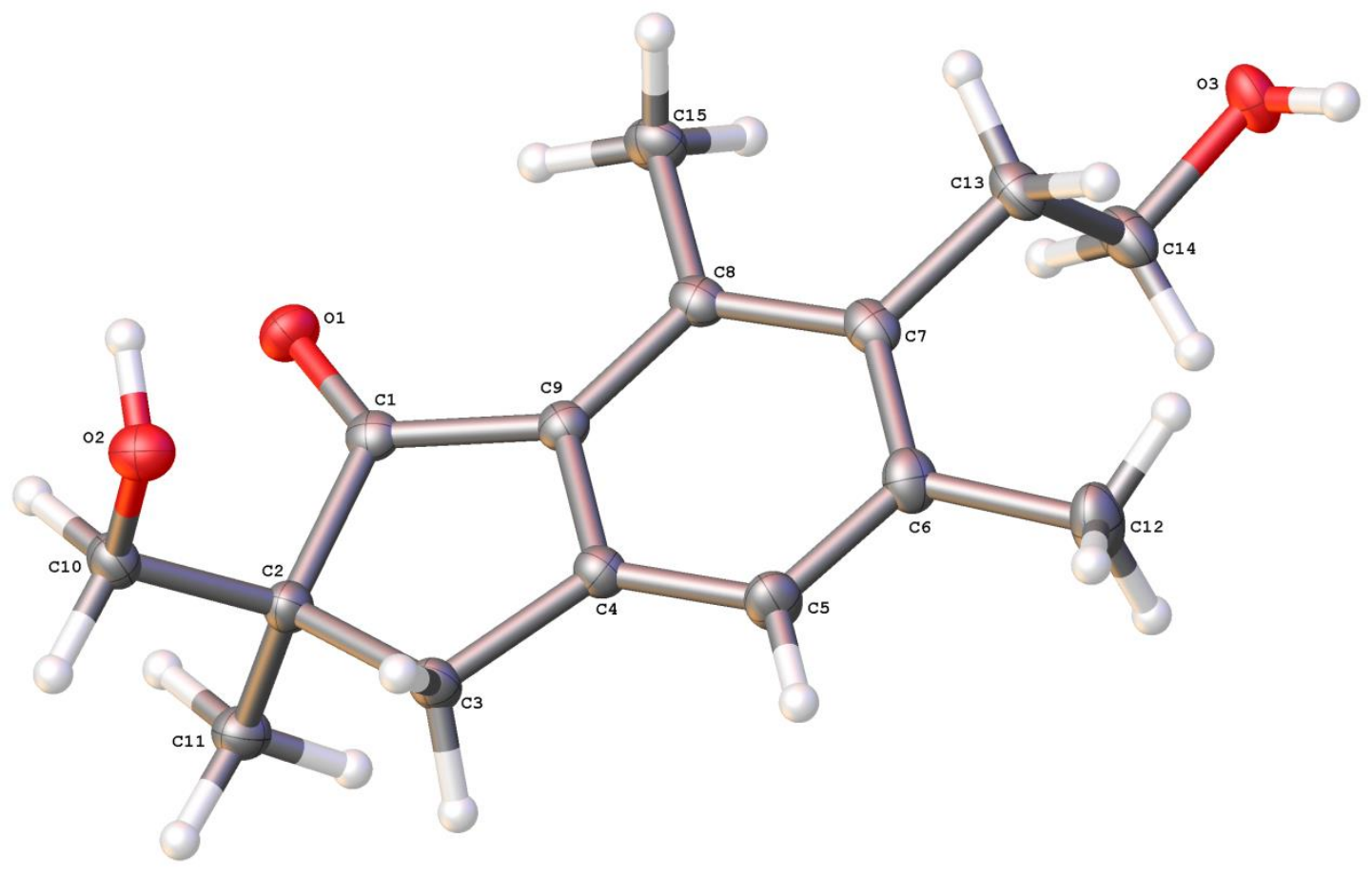

Formula: $\mathrm{C}_{15} \mathrm{H}_{20} \mathrm{O}_{3} ; M_{\mathrm{r}}=248.31$; crystal dimensions: $0.64 \times 0.31 \times 0.06 \mathrm{~mm}$; crystal system: Monoclinic; space group: $P 2{ }_{1} 2_{1} 2_{1} ; a=7.48123(6) \AA, b=$ 8.18005(9) $\AA, c=21.39110(19) \AA, \alpha=90^{\circ}, \beta=90^{\circ}, \gamma=90^{\circ} ; \mathrm{V}=1309.07(2)$ $\AA^{3} ; Z=4 ; \rho_{\text {calcd }}=1.260 \mathrm{Mg} / \mathrm{m}^{3} ; \mu=0.695 \mathrm{~mm}^{-1} ;$ Cu Ka radiation, $\lambda=1.54184$ $\AA ; \quad T=100 \mathrm{~K} ; 2 \Theta_{\max }=137.5^{\circ} ; 13898 / 2395$ measured $/$ independent reflections; $R_{\text {int }}$ : 0.0372; Flack parameter/Hooft parameter 0.09(8)/0.05(3); $R$ $=0.0312, w R=0.0841 ; \Delta \rho_{\max }=0.220 \mathrm{e}^{-3}, \Delta \rho_{\min }=-0.220 \mathrm{e} \AA^{-3}$. Colourless plate crystals. CCDC deposition number 1050918. 


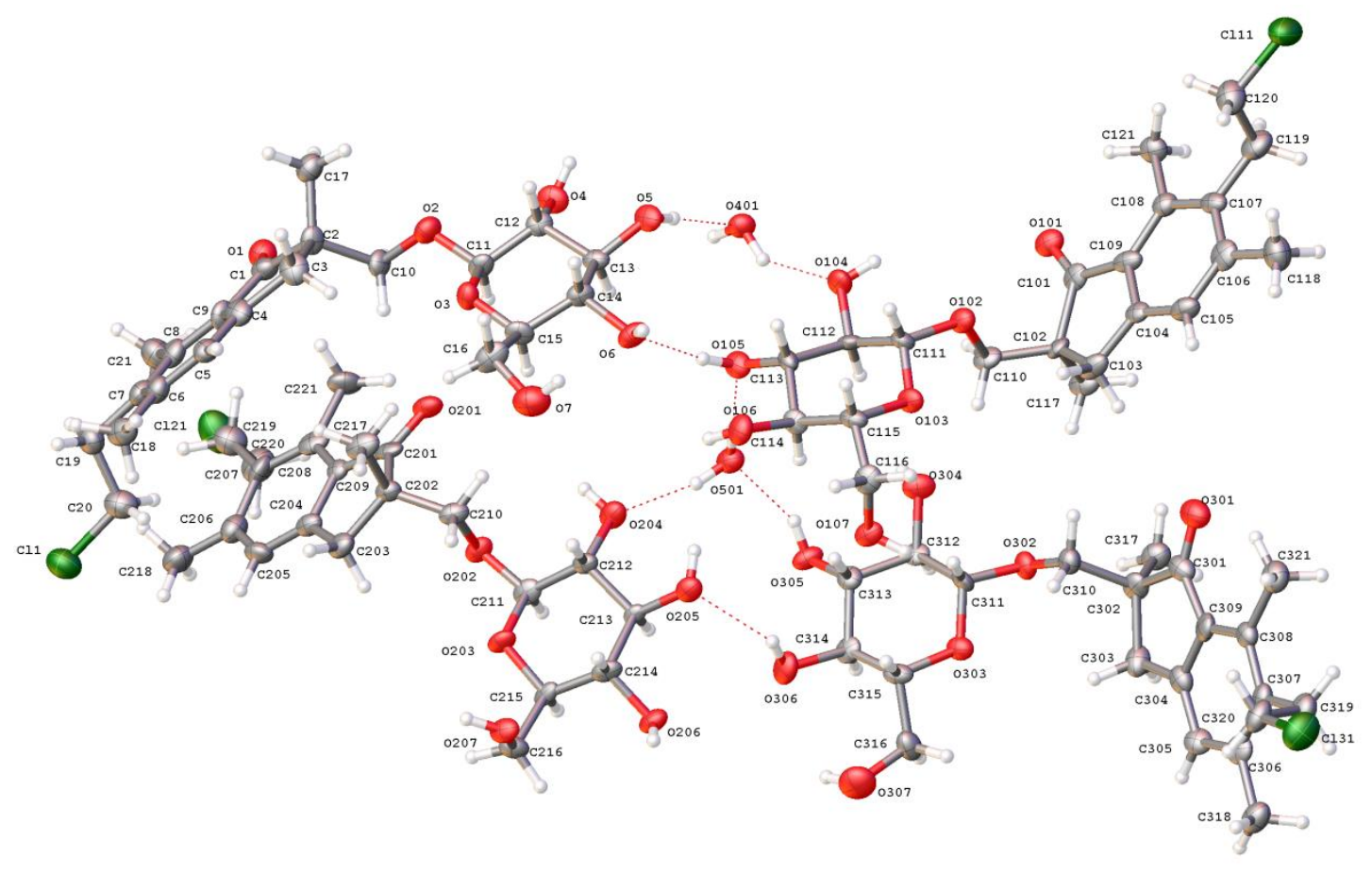

Formula: $\mathrm{C}_{21} \mathrm{H}_{30} \mathrm{ClO}_{7.5} ; M_{\mathrm{r}}=437.90$; crystal dimensions: $0.09 \times 0.07 \times 0.01 \mathrm{~mm}$; crystal system: Triclinic; space group: $P 1 ; a=8.108(4) \AA, b=9.341(4) \AA, c=$ 28.660(12) $\AA, \alpha=81.739(14)^{\circ}, b=88.818(16)^{\circ}, \gamma=89.745(14)^{\circ} ; V=2147.6(17) \AA^{3}$; $Z=4 ; \rho_{\text {calcd }}=1.354 \mathrm{Mg} / \mathrm{m}^{3} ; \mu=0.220 \mathrm{~mm}^{-1} ;$ Mo $K \alpha$ radiation, $\lambda=0.71075 \AA$; $\mathrm{T}=100$ $\mathrm{K} ; 2 \Theta_{\max }=55.3^{\circ} ; 57447 / 19551$ measured/independent reflections; $R_{\text {int: }}$ 0.1941; Flack parameter/Hooft parameter $-0.16(9) / 0.09(8) ; R=0.0995, w R=0.2401 ; \Delta \rho_{\max }$ $=0.843 \mathrm{e}^{-3}, \Delta \rho_{\min }=-0.360 \mathrm{e}^{-3}$. Colourless plate crystals. CCDC deposition number 1050920. 
Rhedynoside B

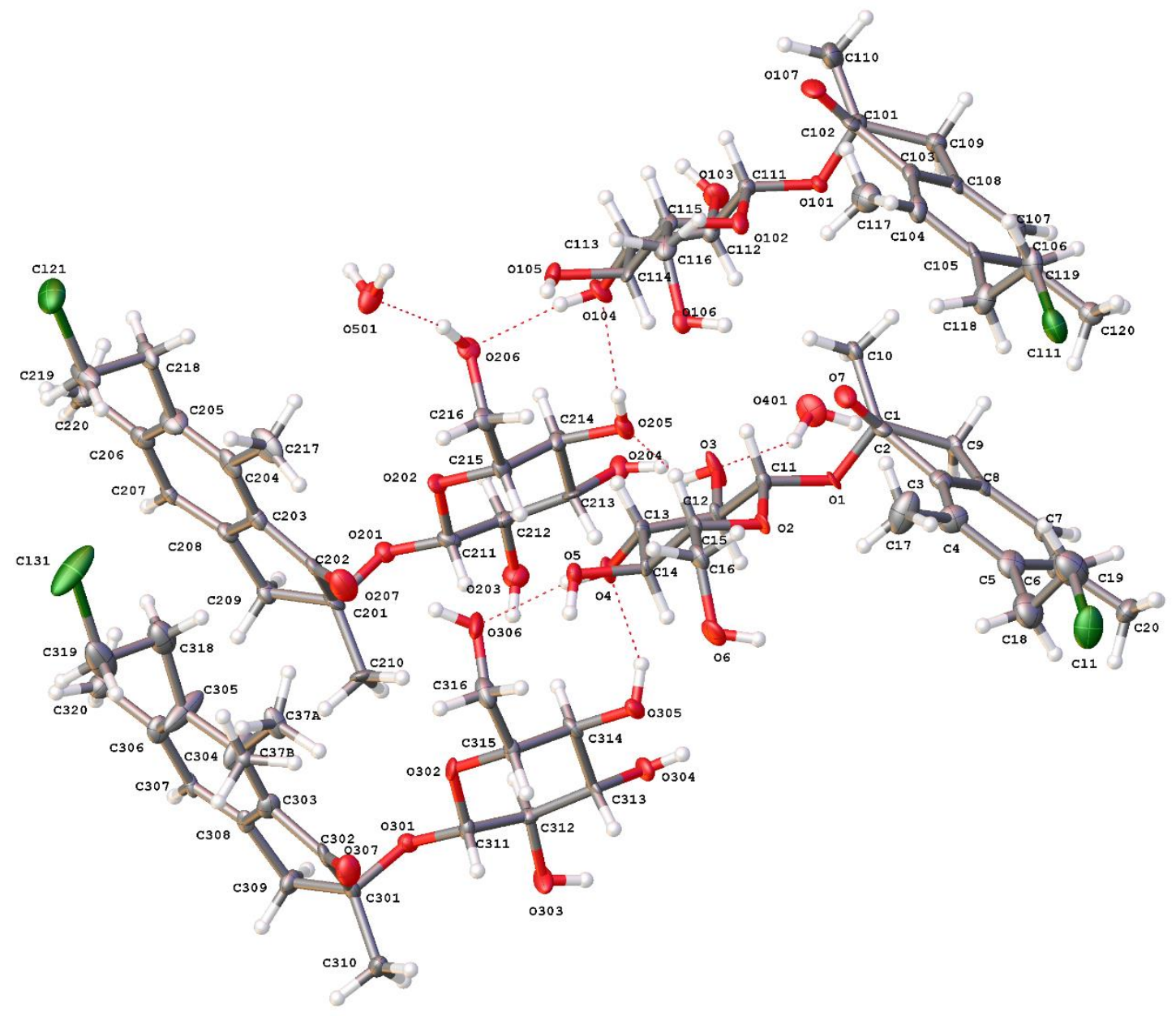

Formula: $\mathrm{C}_{20} \mathrm{H}_{28} \mathrm{ClO}_{7.5} ; M_{\mathrm{r}}=423.87$; crystal dimensions: $0.20 \times 0.08 \times 0.01 \mathrm{~mm}$; crystal system: Monoclinic; space group: $P 2_{1} ; a=8.05004(19) \AA, b=43.4268(10)$ $\AA$, $c=11.4031(3) \AA, \alpha=90^{\circ}, b=90.034(2)^{\circ}, \gamma=90^{\circ} ; \mathrm{V}=3986.38(16) \AA^{3} ; Z=8 ; \rho_{\text {calcd }}$ $=1.413 \mathrm{Mg} / \mathrm{m}^{3} ; \mu=0.235 \mathrm{~mm}^{-1} ;$ Mo $K \alpha$ radiation, $\lambda=0.71075 \AA$ A $;=100 \mathrm{~K} ; 2 \Theta_{\max }=$ $55.3^{\circ} ; 52007 / 18325$ measured/independent reflections; $R_{\text {int }}$ : 0.0382; Flack parameter/Hooft parameter 0.02(2)/0.011(17); $R=0.0691, w R=0.1779 ; \Delta \rho_{\max }=$ $1.383 \mathrm{e}^{-3}, \Delta \rho_{\min }=-0.459 \mathrm{e}^{-3}$. Colourless plate crystals. CCDC deposition number 1406891.

N.B. this structure was refined as a 2-componant twin with the twin law [-1 000 10000 1], BASF 0.520(2) 
(2R)-pteroside $\mathrm{B}$

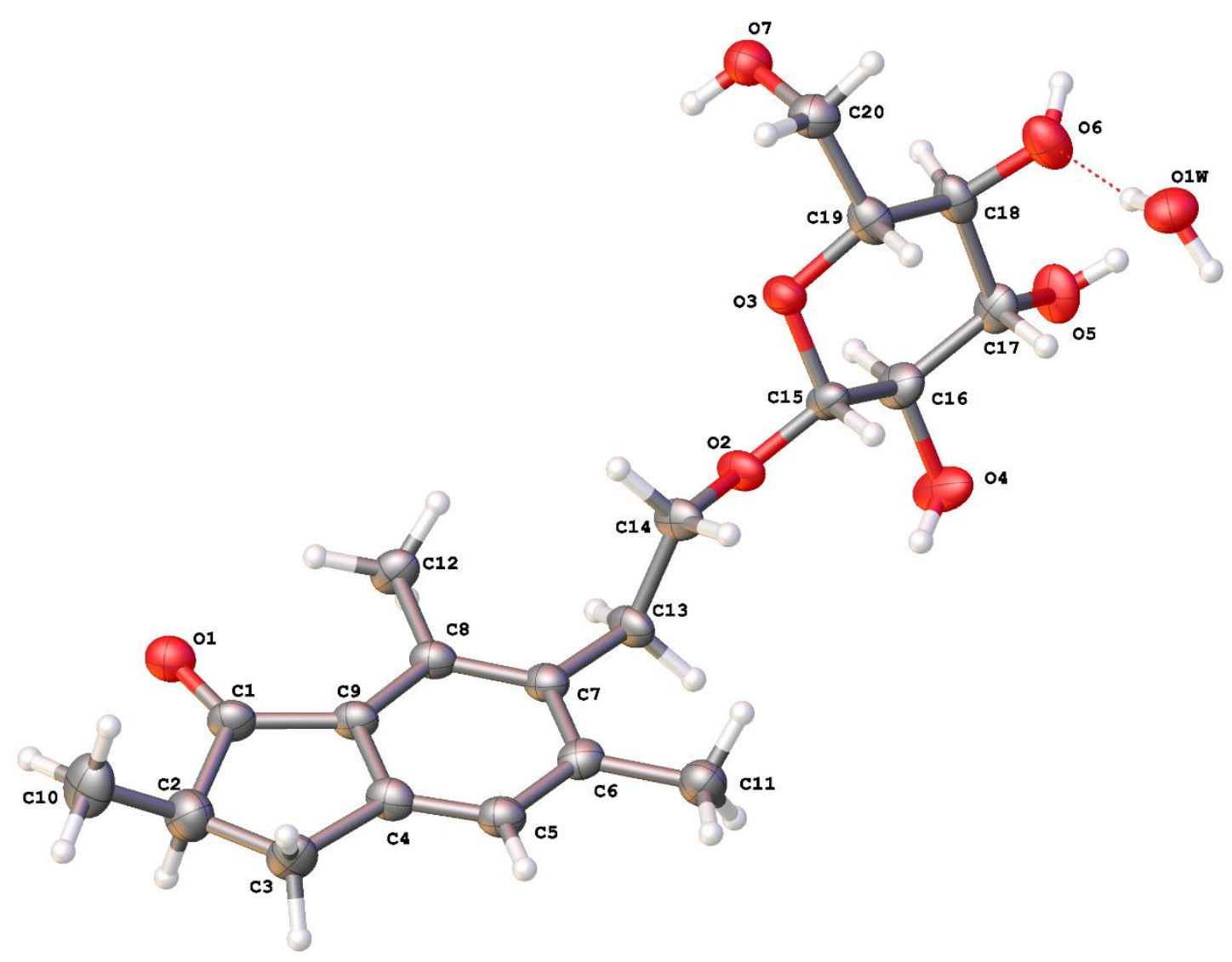

Formula: $\mathrm{C}_{20} \mathrm{H}_{30} \mathrm{O}_{8} ; M_{\mathrm{r}}=398.44$; crystal dimensions: $0.20 \times 0.10 \times 0.02 \mathrm{~mm}$; crystal system: Monoclinic; space group: $P 2_{1} ; a=5.7210(4) \AA$, $b=$ $10.3060(7) \AA, c=16.4249(13) \AA, \alpha=90^{\circ}, \beta=93.254(7)^{\circ}, V=90^{\circ} ; \mathrm{V}=$ $966.87(12) \AA^{3} ; Z=2 ; \rho_{\text {calcd }}=1.369 \mathrm{Mg} / \mathrm{m}^{3} ; \mu=0.879 \mathrm{~mm}^{-1} ; \mathrm{Cu}$ Ka radiation, $\lambda=1.54184 \AA$ 的 $T=100 \mathrm{~K} ; 2 \Theta_{\max }=134.8^{\circ} ; 9102 / 3371$ measured $/$ independent reflections; $R_{\text {int: }}$ 0.0778; Flack parameter/Hooft parameter 0.1(4)/0.3(3); $R=$ $0.0670, w R=0.1803 \Delta \rho_{\max }=0.485 \mathrm{e}^{-3}, \Delta \rho_{\min }=-0.260 \mathrm{e}^{-3}$. Colourless plate crystals. CCDC deposition number 1418452. 


\section{HPLC-ESI-MS ${ }^{n}$ Method}

In order to confirm the presence of chlorinated isolated compounds, bracken rhizomes (10 g, dry weight) were extracted with $100 \mathrm{ml}$ of non-chlorinated organic solvents, methanol and ethyl acetate, and the extracts were analysed by reversephase HPLC with on-line photodiode array detection with and without electrospray ionisation-ion trap mass spectrometry. HPLC/ion trap mass spectrometry (HPLC/ESI-MS ${ }^{n}$ analysis was performed on a Thermo Finnigan LC-MS system (Thermo Electron Corporation, USA) comprising a Finnigan Surveyor PDA Plus detector, a Finnigan LTQ linear ion trap with ESI source and a Waters $\mathrm{C}_{18}$ Nova-Pak column $(4 \mu \mathrm{m}, 3.9 \mathrm{~mm} \times 100 \mathrm{~mm})$. The autosampler tray temperature was maintained at $5^{\circ} \mathrm{C}$ and the column temperature at $30^{\circ} \mathrm{C}$. Sample injection volume was typically $10 \mu \mathrm{L}$, the detection wavelength was set to $210-400 \mathrm{~nm}$ and the flow rate was $1 \mathrm{ml} \mathrm{min}^{-1}$, with $100 \mu \mathrm{L} \mathrm{min}{ }^{-1}$ going to the mass spectrometer. The mobile phase consisted of water:formic acid (A; 100:0.1, v/v) and MeOH:formic acid (B; 100:0.1, v/v). The column was equilibrated with $95 \%$ solvent $A$, and the percentage of B increased linearly to $100 \%$ over 25 min. Ionisation parameters were optimised by infusion of chlorogenic acid standard at a constant rate into the LC flow. Mass spectra were acquired in negative ionisation mode with the following interface and MS parameters: nitrogen sheath gas 30 arbitrary units, nitrogen auxiliary gas 15 units, spray voltage $4 \mathrm{KV}$, capillary temperature $320^{\circ} \mathrm{C}$, capillary voltage $-1 \mathrm{~V}$ 
and tube lens offset $-68 \mathrm{~V}$. MS/MS fragmentation was carried out at normalised collision energy of $35 \%$ and isolation width $2.0(\mathrm{~m} / \mathrm{z})$.

\section{HPLC-ESI-MS ${ }^{n}$ Chromatograms}

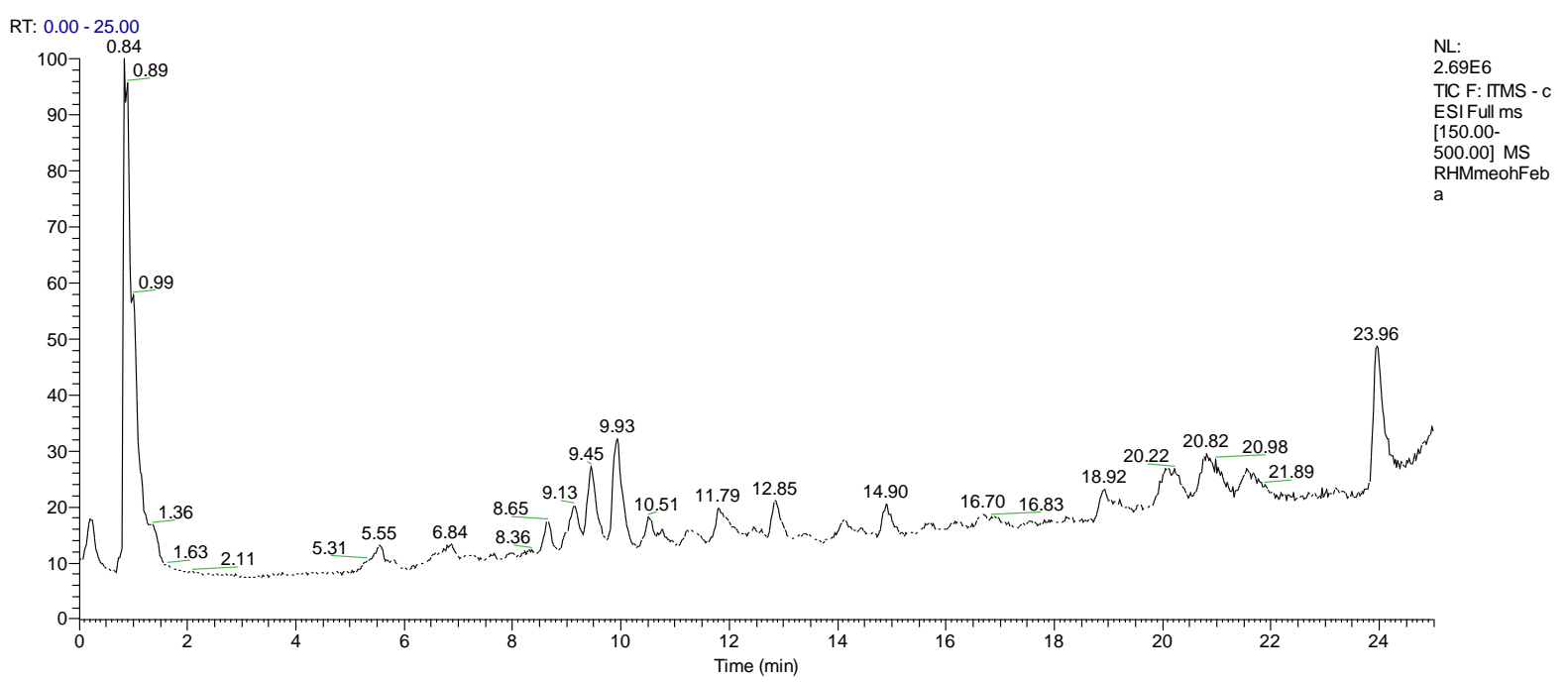

Fig. SD1. Reverse phase HPLC-ESI-MS total ion current (TIC) chromatogram of methanol extract of bracken rhizomes in the negative ion mode.

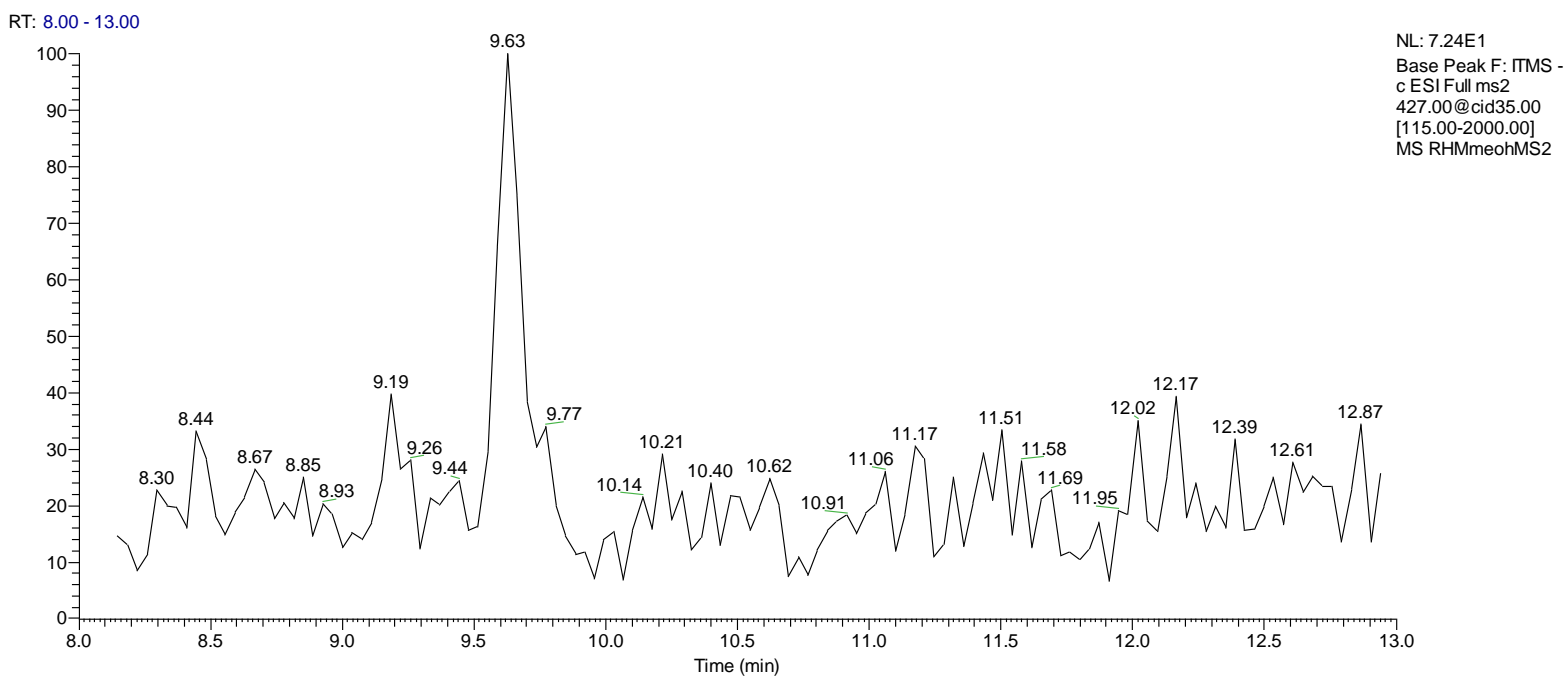

Fig. SD2. HPLC-ESI-MS/MS base peak chromatogram of methanol extract of bracken rhizomes in the negative ion mode. 
RHMmeohMS2 \#1552 RT: 9.15 AV: 1 NL: $1.80 \mathrm{E}$

F: TMS - c ESIFull ms2 427.00@35.00 [115:00-2000.00]

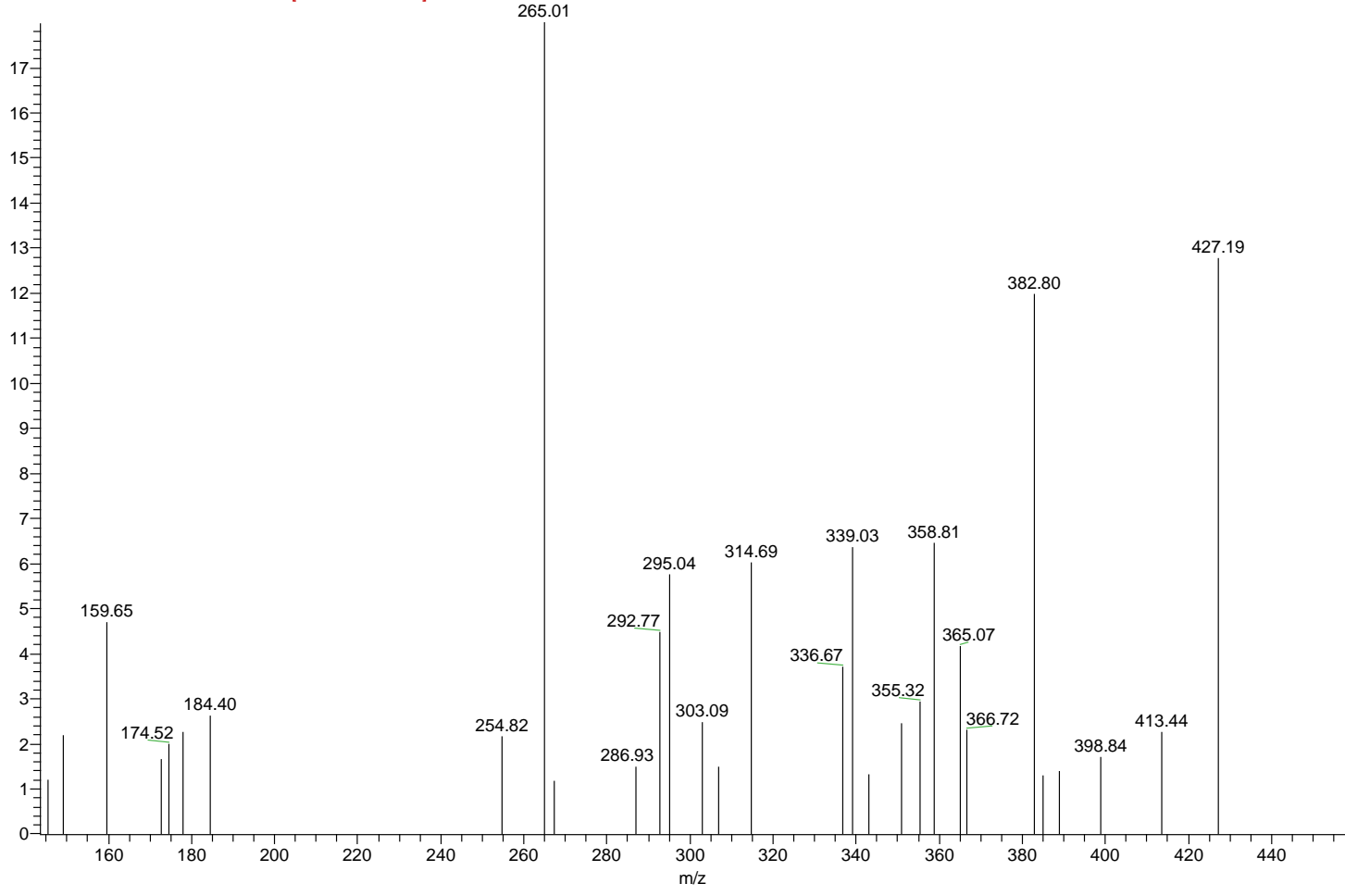

Fig. SD3. HPLC/ESI-MS/MS total ion current (TIC) chromatogram of selected peak (relative retention time $(R R \mathrm{t})$ of $9.15 \mathrm{~min}$ ) of methanol extract of bracken rhizomes in the negative ion mode. 

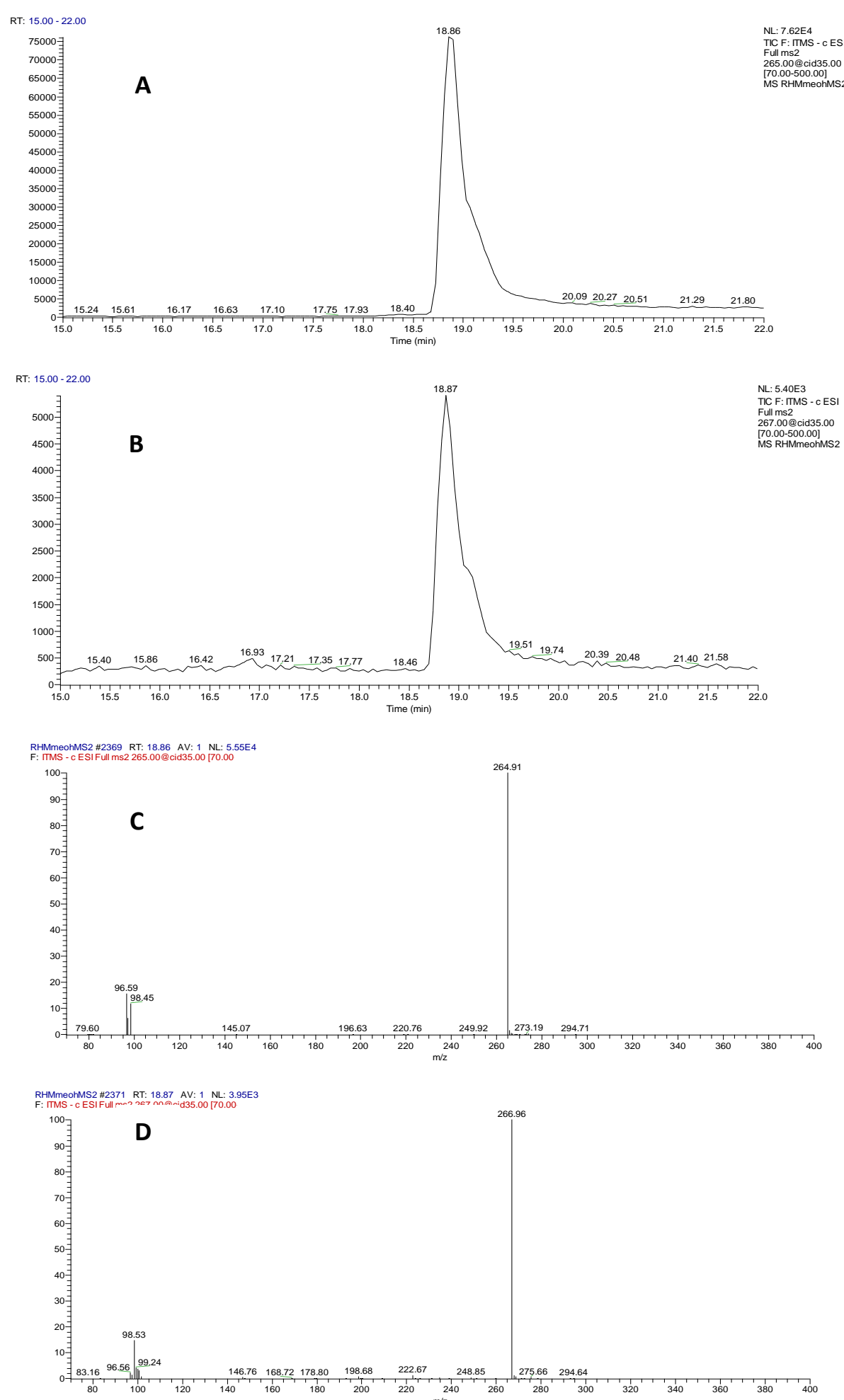

Fig. SD4. Further HPLC/MS/MS identification of the chlorinated compounds (11, 13 and 35) (loss of 162 $\mathrm{amu}$ ) in methanol extract of bracken rhizomes. Total ion current (TIC) of compounds at $R R \mathrm{t}$ of $18.8 \mathrm{~min}$ : (A) with ${ }^{35} \mathrm{Cl}$ isotope; (B) with ${ }^{37} \mathrm{Cl}$ isotope. HPLC/MS/MS spectrum showing [M-H-Glc] ${ }^{-}$(265 amu) in the negative mode at $R R \mathrm{t}$ of $18.8 \mathrm{~min}$ for $(\mathrm{C}){ }^{35} \mathrm{Cl}$-compounds and (D) ${ }^{37} \mathrm{Cl}$-compounds. 
RHMmeohFeba \#729 RT: $9.90 \quad \mathrm{AV}: 1 \mathrm{NI} \cdot 1$ ลวЕ?

F: TMS - c ESI Full ms [150.00-500.00]

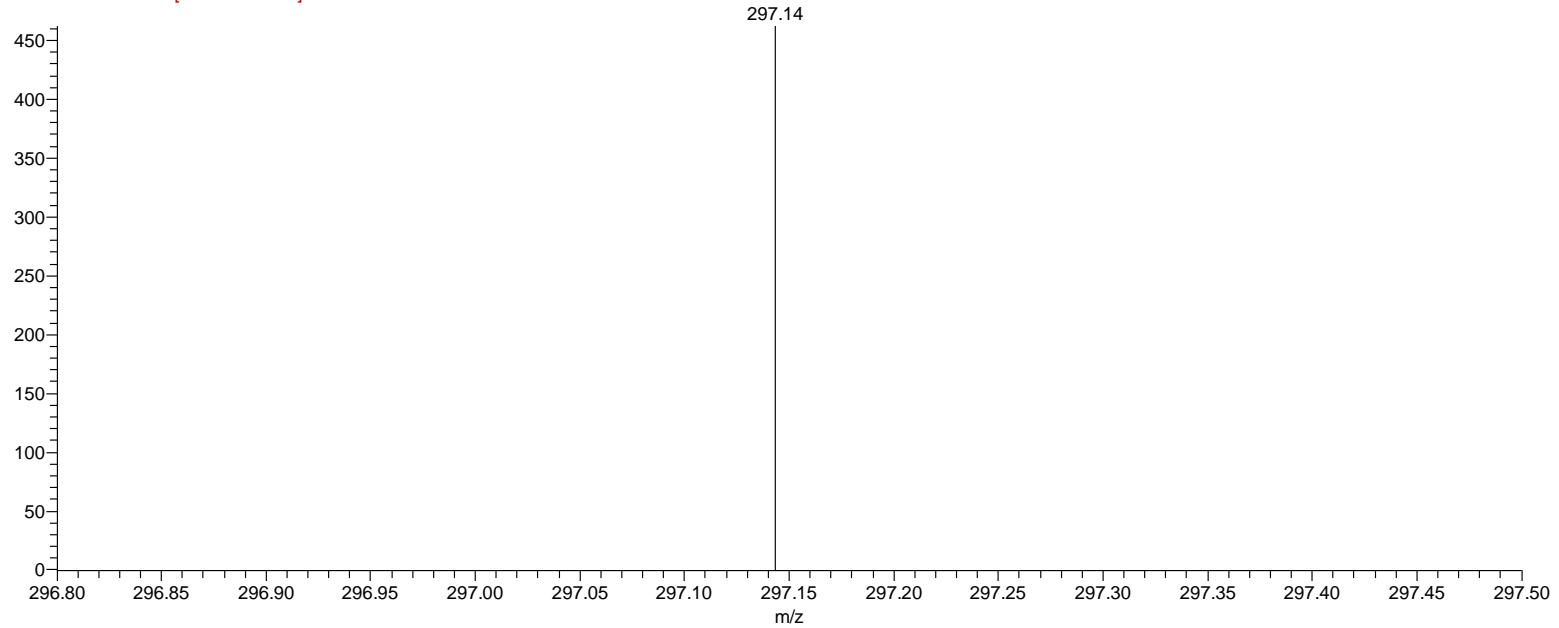

Fig. SD5. HPLC/MS identification of the sulfated-pterosin (9) in methanol extract of bracken rhizomes. HPLC/MS spectrum showing [M-H] $]^{-}(297.14 \mathrm{amu})$ in the negative mode at $R R$ t of 9.90 min for compound (9). 


\section{Identification of SGLT1 and GLUT2 transporter inhibitors}

Routine cell culture - Human epithelial colorectal adenocarcinoma (Caco-2) cells were obtained from the American Type Culture Collection (ATCC) and cultured in Growth Medium consisting of Dulbecco's modified Eagle's medium (containg Glutamax-1, 4.5g/L D-Glucose \& 25mM Hepes (Invitrogen)), 10\% Fetal Bovine Serum (Sigma), 1\% Non-Essential Amino Acids (Invitrogen) \& 1mM Sodium pyruvate (Sigma). The cells were routinely passaged at approximately $80 \%$ confluence using TrypLE ${ }^{\mathrm{TM}}$ Express Stable Trypsin-Like Enzyme (Invitrogen) to detach the cells, and seeded at approximately 114 cells per $\mathrm{mm}^{2}$ in fresh tissue culture flasks. Only cells between the passage numbers 45 and 49 were used for experiments.

Preparation of differentiated Caco-2 cell monolayers - Corning ${ }^{\circledR}$ HTS Transwell ${ }^{\circledR}$ 96 well permeable insert supports (Sigma) were collagen coated with $40 \mu$ l of $50 \mu \mathrm{g} / \mathrm{ml}$ Rat Tail Collagen Type I (BD Biosciences) in 0.02M acetic acid for one hour at room temperature under sterile conditions. The inserts were washed twice in Phosphate Buffered Saline (PBS (Invitrogen)) and the Caco- 2 cells seeded into the inserts at $9.6 \times 10^{5}$ cell $/ \mathrm{ml}(75 \mu \mathrm{l}$ per insert) in Growth Medium and $30 \mathrm{ml}$ of Growth medium added to the feeder plate below. The cells were left to attach to the collagen matrix and form monolayers over $48 \mathrm{hrs}$ at $37^{\circ} \mathrm{C}, 5 \% \mathrm{CO}_{2}$. Both inserts and 
feeder plate were washed in PBS and the cells incubated with BD Entero-STIM ${ }^{\mathrm{TM}}$ Enterocyte Differentiation Medium containing MITO+ ${ }^{\mathrm{TM}}$ Serum Extender solution (both BD Biosciences), $75 \mu \mathrm{l}$ per insert $\& 30 \mathrm{ml}$ in feeder plate, for a further $48 \mathrm{hrs}$ at $37^{\circ} \mathrm{C}, 5 \% \mathrm{CO}_{2}$.

Glucose Transport Inhibitor Cell Screening Assay - Differentiated cell monolayers were washed gently in Dulbecco's Phosphate Buffered Saline containing $\mathrm{CaCl}_{2}$ \& $\mathrm{MgCl}_{2}\left(\mathrm{PBS}(+)\right.$ (Invitrogen) and the inserts transferred to a new Corning ${ }^{\circledR}$ HTS Transwell ${ }^{\circledR}-96$ well receiver plate (Sigma). The cells were incubated with fresh PBS(+) $\left(75 \mu l\right.$ per insert \& $225 \mu \mathrm{l}$ per well) for 60 mins at $37^{\circ} \mathrm{C}, 5 \% \mathrm{CO}_{2}$. The PBS(+) was gently aspirated and replaced with $75 \mu \mathrm{l}$ per insert of either $5 \mathrm{mM}$ D-Glucose (Sigma) \pm test active or $25 \mathrm{mM}$ D-Glucose \pm test active in triplicate and $225 \mu \mathrm{l}$ per well of PBS(+) quickly added to each well. The $5 \mathrm{mM}$ glucose wells and the $45 \mathrm{mM}$ glucose wells were incubated at $37^{\circ} \mathrm{C}, 5 \% \mathrm{CO}_{2}$ for $15 \mathrm{mins}$ and $30 \mathrm{mins}$, respectively. Details of all the actives tested can be found in Table 1 . The cell inserts were transferred to a new receiver plate, the supernatant gently aspirated from the cells and replaced with $100 \mu \mathrm{l}$ of $100 \mu \mathrm{M}$ of Lucifer Yellow (Sigma) solution to confirm the integrity of the monolayers. $225 \mu \mathrm{l}$ of PBS(+) was added to each well and incubated at $37^{\circ} \mathrm{C}, 5 \% \mathrm{CO}_{2}$ for $1 \mathrm{hr}$. The cell inserts were then discarded and the permeability of the membranes to Lucifer Yellow checked by measuring the fluorescence of the 
samples at $485 \mathrm{~nm}$ (excitation) \& 530nm (emission) on a Spectramax Gemini EM fluorescence microplate reader.

Glucose Assay - The amount of glucose transported across the cell monolayers was measured using a glucose assay based on Invitrogen's Amplex Red Glucose/Glucose oxidase Assay Kit. Briefly, $50 \mu \mathrm{l}$ of each unknown sample was transferred to a black sided/clear bottom 96-well plate (Greiner Bio-One) to which $100 \mu \mathrm{l}$ of reaction buffer $(0.5 \mu \mathrm{l} 10 \mathrm{mM}$ Ampliflu Red, $1 \mu \mathrm{l} 10 \mathrm{U} / \mathrm{ml} \mathrm{HRP}, 1 \mu \mathrm{l} 100 \mathrm{U} / \mathrm{ml}$ Glucose Oxidase and 97.5 $\mu$ PBS (all Sigma)) was added. After 10mins incubation at room temperature, the fluorescence of the samples were measured at $530 \mathrm{~nm}$ (excitation) \& 590nm (emission) on a Spectramax Gemini EM fluorescence microplate reader and the glucose concentration extrapolated from a standard curve.

Table 1 - details of the actives tested for SGLT1 and GLUT2 inhibition activity in Caco-2 cells using $5 \mathrm{mM}$ D-glucose for 15 minutes and $25 \mathrm{mM}$ D-glucose for 30 minutes, respectively. The assigned class of transporter inhibited by each active is based on SGLT1 inhibitors having $\geq 20 \%$ inhibition of glucose transport at $5 \mathrm{mM} \mathrm{D-}$ glucose and $\leq 20 \%$ inhibition at $25 \mathrm{mM}$ D-glucose, and GLUT2 inhibitors having $\geq 20 \%$ inhibition at both $5 \mathrm{mM} \& 25 \mathrm{mM}$ D-glucose levels. 


\begin{tabular}{|c|c|c|c|c|c|c|}
\hline \multirow{3}{*}{ Test Active $^{a}$} & \multirow{3}{*}{ Solvent } & \multicolumn{4}{|c|}{$\%$ inhibition of glucose transport } & \multirow{3}{*}{ Class $^{b}$} \\
\hline & & \multicolumn{2}{|c|}{$5 \mathrm{mM}$ Glucose } & \multicolumn{2}{|c|}{ 25mM Glucose } & \\
\hline & & Ave. & S.D. & Ave. & S.D. & \\
\hline Phloridzin & DMSO & 34.81 & 2.64 & 8.42 & 1.42 & SGLT1 \\
\hline Phloretin & DMSO & 83.60 & 0.95 & 76.20 & 3.88 & GLUT2 \\
\hline Pterosin A & DMSO & 6.18 & 6.58 & -2.93 & 1.93 & None \\
\hline Pterosin B & DMSO & 16.80 & 3.09 & 4.38 & 2.61 & None \\
\hline Pterosin C & DMSO & 4.34 & 6.75 & -2.20 & 2.49 & None \\
\hline Pterosin A glucoside & DMSO & -3.41 & 7.81 & -7.64 & 4.12 & None \\
\hline Pterosin B glucoside & DMSO & -1.38 & 5.95 & -6.89 & 2.72 & None \\
\hline Pteroside Z & DMSO & 9.18 & 6.03 & -4.49 & 6.46 & None \\
\hline
\end{tabular}

a - All actives tested at 300uM.

b - Based on SGLT1 inhibitors having $>20 \%$ inhibition at $5 \mathrm{mM}$ (glucose) and $<20 \%$ inhibition at $25 \mathrm{mM}$, and GLUT2 having $>20 \%$ inhibition at both $5 \mathrm{mM} \& 25 \mathrm{mM}$

Table 1 shows the percentage of inhibition of each test active against the transport of glucose across a differentiated Caco-2 cell monolayer. At the lower D-glucose concentration of $5 \mathrm{mM}$, the early transport of glucose across the cell monolayer is predominantly through the apically expressed, high affinity, low capacity SGLT1 glucose transporter. At higher D-glucose concentrations, the SGLT1 transporter becomes saturated and consequently the majority of glucose transport across the monolayer is driven by the low affinity, high capacity GLUT2 transporter that is targeted to the apical membrane only following an initial SGLT1-dependent transport of glucose. The screening cell model, detailed in the methods above, is designed to take advantage of these differences in the optimal conditions for each transporter to identify both SGLT1 and GLUT2 specific inhibitors. While both SGLT1 \& GLUT2 on the apical membrane transport glucose into the enterocyte, GLUT2 is also expressed in the basolateral membrane where it is essential for the transport of glucose out of the cell. Hence, GLUT2 specific inhibitors will not only block the 
apically expressed transporters at high D-glucose concentrations ( $25 \mathrm{mM})$, they will also enter the cell and block the exit of glucose from the enterocyte at low Dglucose concentrations $(5 \mathrm{mM})$. Therefore, to differentiate between inhibition of

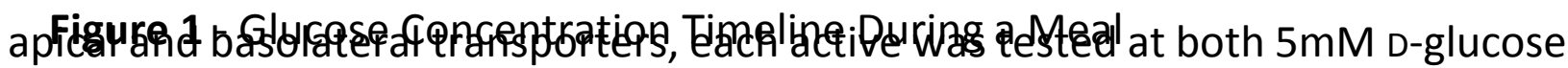
for 15 minutes and $25 \mathrm{mM}$ D-glucose for 30 minutes. Actives were classed as SGLT1 inhibitors if they exhibited a greater than $20 \%$ inhibition of glucose transport at $5 \mathrm{mM}$ D-glucose and a corresponding less than $20 \%$ inhibition at $25 \mathrm{mM}$ D-glucose. Actives that were able to inhibit glucose transport by greater than $20 \%$ in both conditions were classed as GLUT2 specific inhibitors. This approach was qualified through the use of the widely recognised specific inhibitors of both SGLT1 and GLUT2, namely Phloridzin and Phloretin respectively.

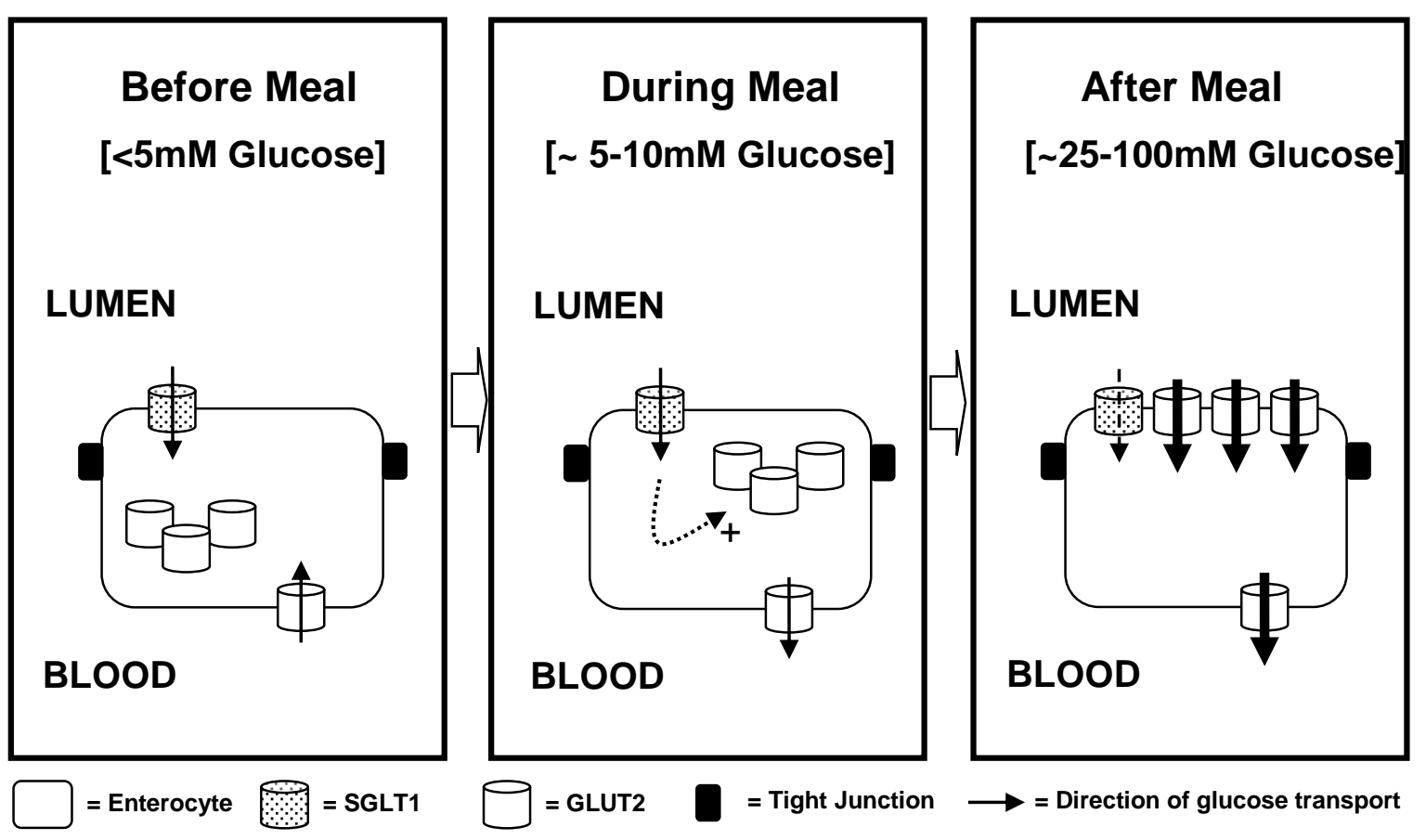


The glucose transport cell model, detailed in the methods above, is a novel in vitro cell system designed to mimic the localised changes in glucose concentration in the small intestine during the consumption of a carbohydrate rich meal (Figure 1) (Kellett \& Brot-Laroche, 2005). Before the meal, the concentration of free glucose in the lumen of the intestine is low $(<5 \mathrm{mM})$ and the apically expressed SGLT1 transporter actively transports any available glucose into the enterocyte. GLUT2 transporters are also active on the basolateral membrane of the enterocyte, transporting glucose from the blood into the cell to maintain cellular metabolism if required. During a meal, the local concentration of glucose begins to increase (5$10 \mathrm{mM}$ ) and is transported from the intestinal lumen by SGLT1 and subsequently into the systemic circulation via GLUT2. As a consequence of this initial glucose transport across the enterocyte, intracellular stores of GLUT2 are mobilised and targeted to the apical membrane. Shortly after the meal, very high local concentrations of glucose occur $(25-100 \mathrm{mM})$ as the carbohydrate content of the meal is broken down into monosaccharides by alpha-glucosidase enzymes located on the apical enterocyte membrane. At these high levels of glucose, the high affinity, low capacity transporter SGLT1 becomes saturated and the majority of glucose transport across the enterocyte is due to the low affinity, high capacity GLUT2 transporters now present in the apical membrane. These localised changes in luminal glucose concentrations are mimicked in vitro through an initial short 
incubation of differentiated Caco-2 cells with a low level of D-glucose ( $5 \mathrm{mM}$ for 15mins) immediately followed by a sustained incubation with a high level of Dglucose (final concentration of $25 \mathrm{mM}$ for $45 \mathrm{mins}$ ).

\section{References:}

Kellett \& Brot-Laroche (2005) Apical GLUT2: a major pathway of intestinal sugar absorption. Diabetes 54(10), 3056-62.

\section{SUPPORTING INFORMATION 1 (SI 1)}

Isolation and characterisation of thirteen pterosins and pterosides from

\section{bracken (Pteridium aquilinum (L.) Kuhn) rhizome}

Rizgar Hassan Mohammad ${ }^{\mathrm{a}}$, Mohammad Nur e-Alam ${ }^{\mathrm{a}, \mathrm{b}}$, Martina Lahmann ${ }^{\mathrm{a}}$, Ifat Parveen ${ }^{\mathrm{c}}$, Graham J. Tizzard ${ }^{\mathrm{d}}$, Simon J. Coles ${ }^{\mathrm{d}}$, Mark Fowler ${ }^{\mathrm{e}}$, Alex F. Drake ${ }^{\mathrm{f}}$, Derren Heyes ${ }^{\mathrm{g}}$, Vera Thoss ${ }^{\mathrm{a}, *}$

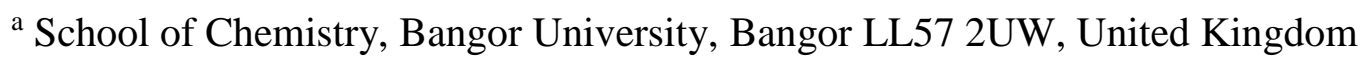

${ }^{\mathrm{b}}$ Department of Pharmacognosy, College of Pharmacy, King Saud University, P.O. Box 2457, Riyadh 11451, Saudi Arabia.

${ }^{\mathrm{c}}$ IBERS, Aberystwyth University, Penglais, Aberystwyth SY23 3DA, UK

${ }^{d}$ UK National Crystallography Service, School of Chemistry, University of Southampton, University Road, Southampton SO17 1BJ, United Kingdom

e Strategic Science Group, Unilever R\&D, Colworth Science Park, Bedford, MK44 1LQ, UK.
} 
${ }^{\mathrm{f}}$ Biomolecular Spectroscopy Centre, Pharmaceutical Optical \& Chiroptical Spectroscopy Facility, King's College London, The Wolfson Wing, WWB10 Hodgkin Building, Guy's Campus, London SE1 1UL, UK

${ }^{\mathrm{g}}$ Manchester Institute of Biotechnology, University of Manchester, 131 Princess St, Manchester M1 7DN

*Corresponding Author vera.thoss@ bangor.ac.uk 


\section{List of Supporting Information:}

Figure S1. ${ }^{1} \mathrm{H}$ NMR $\left(\mathrm{CDCl}_{3}, 400 \mathrm{MHz}\right)$ spectrum of compound $\mathbf{1}$.

Figure S2. DEPTQ NMR $\left(\mathrm{CDCl}_{3}, 100 \mathrm{MHz}\right)$ spectrum of compound 1.

Figure S3. ${ }^{1} \mathrm{H}-{ }^{1} \mathrm{H}$ COSY NMR spectrum of compound 1.

Figure S4. HSQC NMR spectrum of compound 1.

Figure S5. HMBC NMR spectrum of compound 1.

Figure S6. FT-ICR-MS spectrum of compound 1.

Figure S7. UV spectrum of compound 1 in $\mathrm{CH}_{3} \mathrm{OH}$.

Figure S8. FT-IR spectrum of compound 1 in $\mathrm{CHCl}_{3}$.

Figure S9. ${ }^{1} \mathrm{H} \mathrm{NMR}\left(\mathrm{CD}_{3} \mathrm{OD}, 400 \mathrm{MHz}\right)$ spectrum of compound 2.

Figure S10. DEPTQ NMR $\left(\mathrm{CD}_{3} \mathrm{OD}, 100 \mathrm{MHz}\right)$ spectrum of compound 2.

Figure S11. ${ }^{1} \mathrm{H}-{ }^{1} \mathrm{H}$ COSY NMR spectrum of compound 2.

Figure S12. HSQC NMR spectrum of compound 2.

Figure S13. HMBC NMR spectrum of compound 2.

Figure S14. FT-ICR-MS spectrum of compound 2.

Figure S15. UV spectrum of compound 2 in $\mathrm{CH}_{3} \mathrm{OH}$.

Figure S16. FT-IR spectrum of compound 2 in $\mathrm{CH}_{3} \mathrm{OH}$.

Figure S17. ${ }^{1} \mathrm{H}$ NMR $\left(\mathrm{CDCl}_{3}, 400 \mathrm{MHz}\right)$ spectrum of compound 2 after acetylation reaction.

Figure S18. ${ }^{1} \mathrm{H}-{ }^{1} \mathrm{H}$ COSY NMR spectrum of compound 2 after acetylation reaction.

Figure S19. DEPTQ NMR $\left(\mathrm{CDCl}_{3}, 100 \mathrm{MHz}\right)$ spectrum of compound 2 after acetylation reaction.

Figure S20. ${ }^{1} \mathrm{H}$ NMR $\left(\mathrm{CDCl}_{3}, 400 \mathrm{MHz}\right)$ spectrum of compound 3 .

Figure S21. DEPTQ NMR $\left(\mathrm{CDCl}_{3}, 100 \mathrm{MHz}\right)$ spectrum of compound 3.

Figure S22. ${ }^{1} \mathrm{H}-{ }^{1} \mathrm{H}$ COSY NMR spectrum of compound 3.

Figure S23. HSQC NMR spectrum of compound 3.

Figure S24. HMBC NMR spectrum of compound 3.

Figure S25. FT-ICR-MS spectrum of compound 3.

Figure S26. UV spectrum of compound 3 in $\mathrm{CH}_{3} \mathrm{OH}$.

Figure S27. FT-IR spectrum of compound 3 in $\mathrm{CHCl}_{3}$.

Figure S28. ${ }^{1} \mathrm{H}$ NMR $\left(\mathrm{CD}_{3} \mathrm{OD}, 400 \mathrm{MHz}\right)$ spectrum of compound 4.

Figure S29. DEPTQ NMR $\left(\mathrm{CD}_{3} \mathrm{OD}, 100 \mathrm{MHz}\right)$ spectrum of compound 4.

Figure S30. ${ }^{1} \mathrm{H}-{ }^{1} \mathrm{H}$ COSY NMR spectrum of compound 4.

Figure S31. HSQC NMR spectrum of compound 4.

Figure S32. HMBC NMR spectrum of compound 4.

Figure S33. FT-ICR-MS spectrum of compound 4.

Figure S34. UV spectrum of compound 4 in $\mathrm{CH}_{3} \mathrm{OH}$.

Figure S35. FT-IR spectrum of compound 4 in $\mathrm{CH}_{3} \mathrm{OH}$.

Figure S36. ${ }^{1} \mathrm{H}$ NMR $\left(\mathrm{CDCl}_{3}, 400 \mathrm{MHz}\right)$ spectrum of compound 5 .

Figure S37. DEPTQ NMR $\left(\mathrm{CDCl}_{3}, 100 \mathrm{MHz}\right)$ spectrum of compound 5.

Figure S38. ${ }^{13} \mathrm{C} \mathrm{NMR}\left(\mathrm{CDCl}_{3}, 100 \mathrm{MHz}\right)$ spectrum of compound 5 .

Figure S39. ${ }^{1} \mathrm{H}-{ }^{1} \mathrm{H}$ COSY NMR spectrum of compound 5.

Figure S40. HSQC NMR spectrum of compound $\mathbf{5}$.

Figure S41. HMBC NMR spectrum of compound 5.

Figure S42. FT-ICR-MS spectrum of compound 5.

Figure S43. UV spectrum of compound 5 in $\mathrm{CH}_{3} \mathrm{OH}$.

Figure S44. FT-IR spectrum of compound 5 in $\mathrm{CHCl}_{3}$.

Figure S45. ${ }^{1} \mathrm{H} \mathrm{NMR}\left(\mathrm{CD}_{3} \mathrm{OD}, 400 \mathrm{MHz}\right)$ spectrum of compound 6. 
Figure S46. DEPTQ NMR $\left(\mathrm{CD}_{3} \mathrm{OD}, 100 \mathrm{MHz}\right)$ spectrum of compound 6.

Figure $\mathbf{S 4 7} .{ }^{1} \mathrm{H}-{ }^{1} \mathrm{H}$ COSY NMR spectrum of compound 6.

Figure S48. HSQC NMR spectrum of compound 6.

Figure S49. HMBC NMR spectrum of compound 6 .

Figure S50. FT-ICR-MS spectrum of compound 6.

Figure S51. UV spectrum of compound 6 in $\mathrm{CH}_{3} \mathrm{OH}$.

Figure S52. FT-IR spectrum of compound 6 in $\mathrm{CH}_{3} \mathrm{OH}$.

Figure S53. ${ }^{1} \mathrm{H}$ NMR $\left(\mathrm{CDCl}_{3}, 400 \mathrm{MHz}\right)$ spectrum of compound 7.

Figure S54. DEPTQ NMR $\left(\mathrm{CDCl}_{3}, 100 \mathrm{MHz}\right)$ spectrum of compound 7.

Figure S55. ${ }^{13} \mathrm{C}$ NMR $\left(\mathrm{CDCl}_{3}, 100 \mathrm{MHz}\right)$ spectrum of compound 7.

Figure S56. ${ }^{1} \mathrm{H}-{ }^{1} \mathrm{H}$ COSY NMR spectrum of compound 7.

Figure S57. HSQC NMR spectrum of compound 7.

Figure S58. HMBC NMR spectrum of compound 7.

Figure S59. FT-ICR-MS spectrum of compound 7.

Figure S60. UV spectrum of compound 7 in $\mathrm{CH}_{3} \mathrm{OH}$.

Figure S61. FT-IR spectrum of compound 7 in $\mathrm{CHCl}_{3}$.

Figure S62. ${ }^{1} \mathrm{H}$ NMR $\left(\left(\mathrm{CD}_{3}\right)_{2} \mathrm{CO}, 400 \mathrm{MHz}\right)$ spectrum of compound 8 .

Figure S63. DEPTQ NMR $\left(\left(\mathrm{CD}_{3}\right)_{2} \mathrm{CO}, 100 \mathrm{MHz}\right)$ spectrum of compound 8.

Figure S64. ${ }^{1} \mathrm{H}-{ }^{1} \mathrm{H}$ COSY NMR spectrum of compound 8.

Figure S65. HSQC NMR spectrum of compound 8.

Figure S66. HMBC NMR spectrum of compound 8.

Figure S67. FT-ICR-MS spectrum of compound 8.

Figure S68. UV spectrum of compound 8 in $\mathrm{CH}_{3} \mathrm{OH}$.

Figure S69. FT-IR spectrum of compound 8 in $\mathrm{CH}_{3} \mathrm{OH}$.

Figure S70. ${ }^{1} \mathrm{H}$ NMR $\left(\mathrm{CD}_{3} \mathrm{OD}, 500 \mathrm{MHz}\right)$ spectrum of compound 9.

Figure S71. DEPTQ NMR (CD $\left.{ }_{3} \mathrm{OD}, 125 \mathrm{MHz}\right)$ spectrum of compound 9.

Figure S72. HMBC NMR spectrum of compound 9.

Figure S73. FT-ICR-MS spectrum of compound 9.

Figure S74. UV spectrum of compound 9 in $\mathrm{CH}_{3} \mathrm{OH}$.

Figure S75. FT-IR spectrum of compound 9 in $\mathrm{CH}_{3} \mathrm{OH}$.

Figure S76. ${ }^{1} \mathrm{H} \mathrm{NMR}\left(\mathrm{CD}_{3} \mathrm{OD}, 400 \mathrm{MHz}\right)$ spectrum of compound $\mathbf{1 0}$.

Figure S77. DEPTQ NMR $\left(\mathrm{CD}_{3} \mathrm{OD}, 100 \mathrm{MHz}\right)$ spectrum of compound 10.

Figure S78. ${ }^{1} \mathrm{H}-{ }^{1} \mathrm{H}$ COSY NMR spectrum of compound 10.

Figure S79. HSQC NMR spectrum of compound $\mathbf{1 0}$.

Figure S80. HMBC NMR spectrum of compound $\mathbf{1 0 .}$

Figure S81. FT-ICR-MS spectrum of compound $\mathbf{1 0 .}$

Figure S82. UV spectrum of compound 10 in $\mathrm{CH}_{3} \mathrm{OH}$.

Figure S83. FT-IR spectrum of compound 10 in $\mathrm{CH}_{3} \mathrm{OH}$.

Figure S84. ${ }^{1} \mathrm{H}$ NMR $\left(\mathrm{CDCl}_{3}, 400 \mathrm{MHz}\right)$ spectrum of compound 10 after acetylation reaction.

Figure S85. ${ }^{1} \mathrm{H}-{ }^{1} \mathrm{H}$ COSY NMR spectrum of compound $\mathbf{1 0}$ after acetylation reaction.

Figure S86. DEPTQ NMR $\left(\mathrm{CDCl}_{3}, 100 \mathrm{MHz}\right)$ spectrum of compound $\mathbf{1 0}$ after acetylation reaction.

Figure S87. ${ }^{1} \mathrm{H} \mathrm{NMR}\left(\mathrm{CD}_{3} \mathrm{OD}, 400 \mathrm{MHz}\right)$ spectrum of compound $\mathbf{1 1}$.

Figure S88. DEPTQ NMR $\left(\mathrm{CD}_{3} \mathrm{OD}, 100 \mathrm{MHz}\right)$ spectrum of compound 11.

Figure S89. ${ }^{1} \mathrm{H}-{ }^{1} \mathrm{H}$ COSY NMR spectrum of compound 11.

Figure S90. HSQC NMR spectrum of compound 11.

Figure S91. HMBC NMR spectrum of compound 11.

Figure S92. FT-ICR-MS spectrum of compound 11. 
Figure S93. UV spectrum of compound 11 in $\mathrm{CH}_{3} \mathrm{OH}$.

Figure S94. FT-IR spectrum of compound 11 in $\mathrm{CH}_{3} \mathrm{OH}$.

Figure S95. ${ }^{1} \mathrm{H} \mathrm{NMR}\left(\mathrm{CDCl}_{3}, 400 \mathrm{MHz}\right)$ spectrum of compound 11 after acetylation reaction.

Figure S96. ${ }^{1} \mathrm{H}-{ }^{1} \mathrm{H}$ COSY NMR spectrum of compound 11 after acetylation reaction.

Figure S97. DEPTQ NMR ( $\left.\mathrm{CDCl}_{3}, 100 \mathrm{MHz}\right)$ spectrum of compound 11 after acetylation reaction.

Figure S98. ${ }^{1} \mathrm{H} \mathrm{NMR}\left(\mathrm{CD}_{3} \mathrm{OD}, 400 \mathrm{MHz}\right)$ spectrum of compound 12.

Figure S99. DEPTQ NMR (CD 30 OD, $100 \mathrm{MHz})$ spectrum of compound 12.

Figure S100. ${ }^{1} \mathrm{H}-{ }^{1} \mathrm{H}$ COSY NMR spectrum of compound 12.

Figure S101. HSQC NMR spectrum of compound 12.

Figure S102. HMBC NMR spectrum of compound 12.

Figure S103. FT-ICR-MS spectrum of compound 12.

Figure S104. UV spectrum of compound 12 in $\mathrm{CH}_{3} \mathrm{OH}$.

Figure S105. FT-IR spectrum of compound 12 in $\mathrm{CH}_{3} \mathrm{OH}$.

Figure S106. ${ }^{1} \mathrm{H}$ NMR $\left(\mathrm{CDCl}_{3}, 400 \mathrm{MHz}\right)$ spectrum of compound 12 after acetylation reaction.

Figure S107. ${ }^{1} \mathrm{H}-{ }^{1} \mathrm{H}$ COSY NMR spectrum of compound 12 after acetylation reaction.

Figure S108. DEPTQ NMR $\left(\mathrm{CDCl}_{3}, 100 \mathrm{MHz}\right)$ spectrum of compound 12 after acetylation reaction.

Figure S109. ${ }^{1} \mathrm{H}$ NMR $\left(\mathrm{CD}_{3} \mathrm{OD}, 400 \mathrm{MHz}\right)$ spectrum of compound 13.

Figure S110. DEPTQ NMR $\left(\mathrm{CD}_{3} \mathrm{OD}, 100 \mathrm{MHz}\right)$ spectrum of compound 13.

Figure S111. ${ }^{1} \mathrm{H}-{ }^{1} \mathrm{H}$ COSY NMR spectrum of compound 13.

Figure S112. HSQC NMR spectrum of compound 13.

Figure S113. HMBC NMR spectrum of compound 13.

Figure S114. FT-ICR-MS spectrum of compound 13.

Figure S115. UV spectrum of compound 13 in $\mathrm{CH}_{3} \mathrm{OH}$.

Figure S116. FT-IR spectrum of compound 13 in $\mathrm{CH}_{3} \mathrm{OH}$.

Figure S117. ${ }^{1} \mathrm{H}$ NMR $\left(\mathrm{CDCl}_{3}, 400 \mathrm{MHz}\right)$ spectrum of compound 13 after acetylation reaction.

Figure S118. ${ }^{1} \mathrm{H}-{ }^{1} \mathrm{H}$ COSY NMR spectrum of compound 13 after acetylation reaction.

Figure S119. DEPTQ NMR $\left(\mathrm{CDCl}_{3}, 100 \mathrm{MHz}\right)$ spectrum of compound 13 after acetylation reaction.

Figure S120. ${ }^{1} \mathrm{H}-{ }^{1} \mathrm{H}$ NOESY NMR $\left(\mathrm{CD}_{3} \mathrm{OD}, 400 \mathrm{MHz}\right)$ spectrum of compound 13.

Acetylation of compounds 2 and 10-13. 


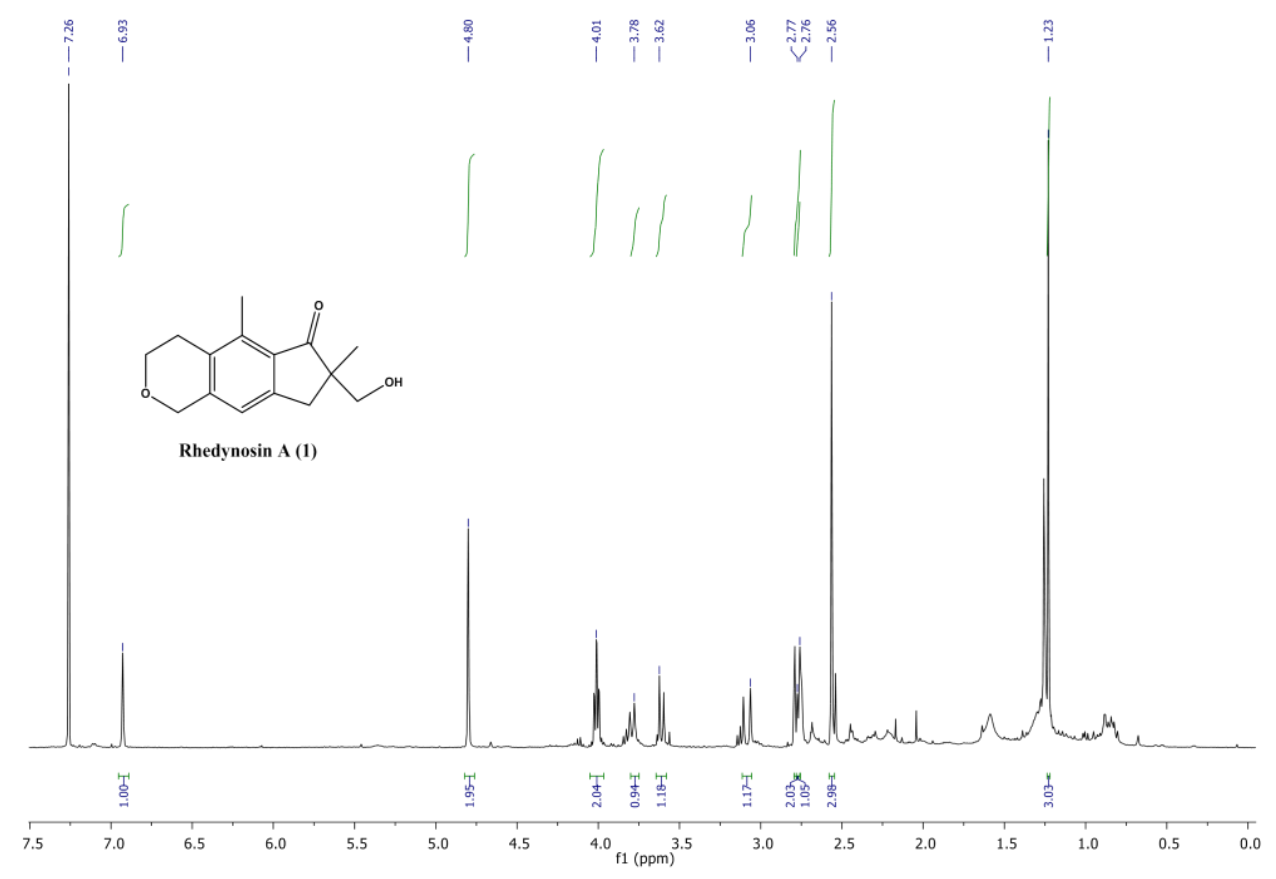

Figure S1. ${ }^{1} \mathrm{H}$ NMR $\left(\mathrm{CDCl}_{3}, 400 \mathrm{MHz}\right)$ spectrum of compound $\mathbf{1}$.

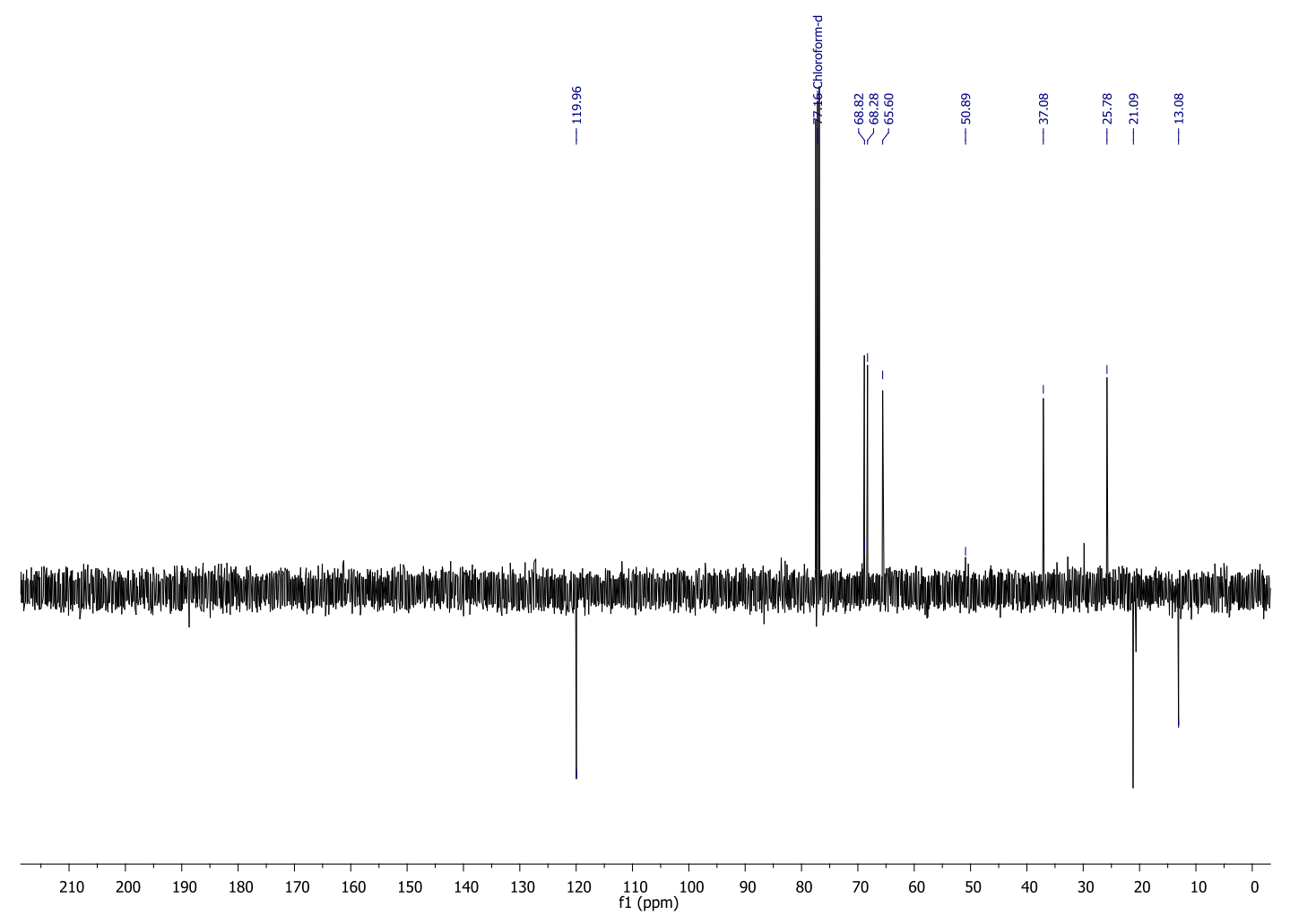

Figure S2. DEPTQ NMR ( $\left.\mathrm{CDCl}_{3}, 100 \mathrm{MHz}\right)$ spectrum of compound 1. 


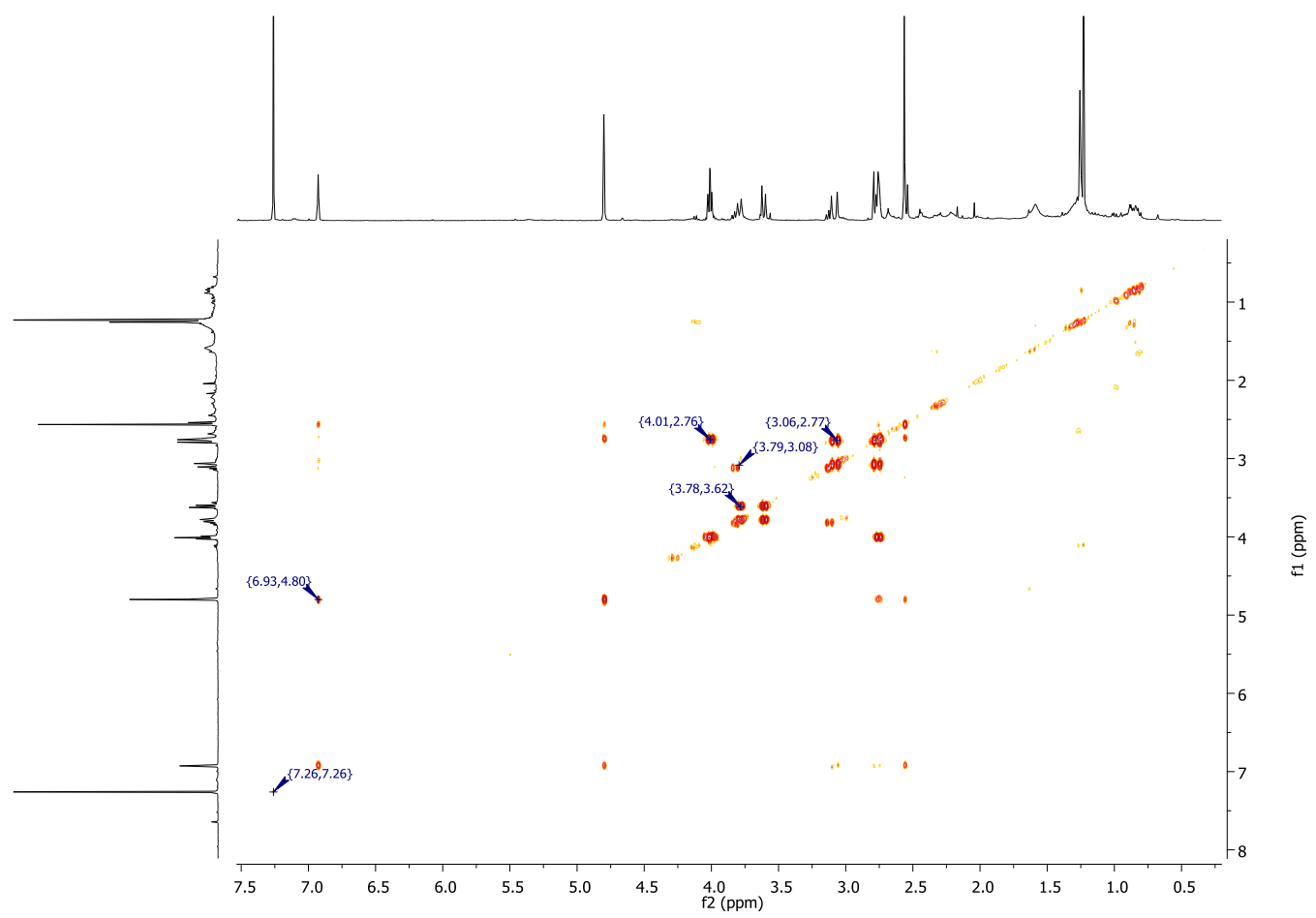

Figure S3. ${ }^{1} \mathrm{H}-{ }^{1} \mathrm{H}$ COSY NMR spectrum of compound 1.

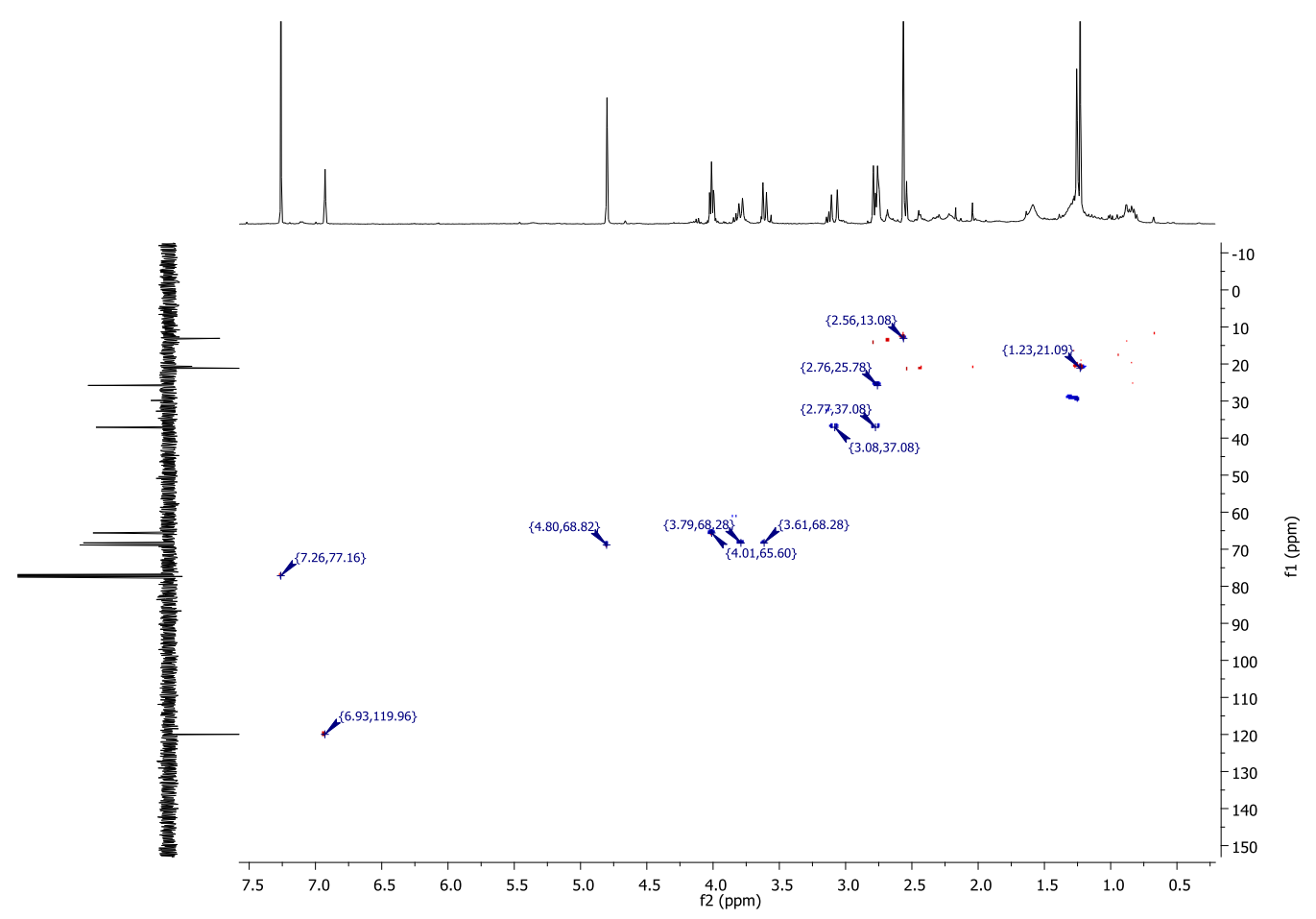

Figure S4. HSQC NMR spectrum of compound 1. 


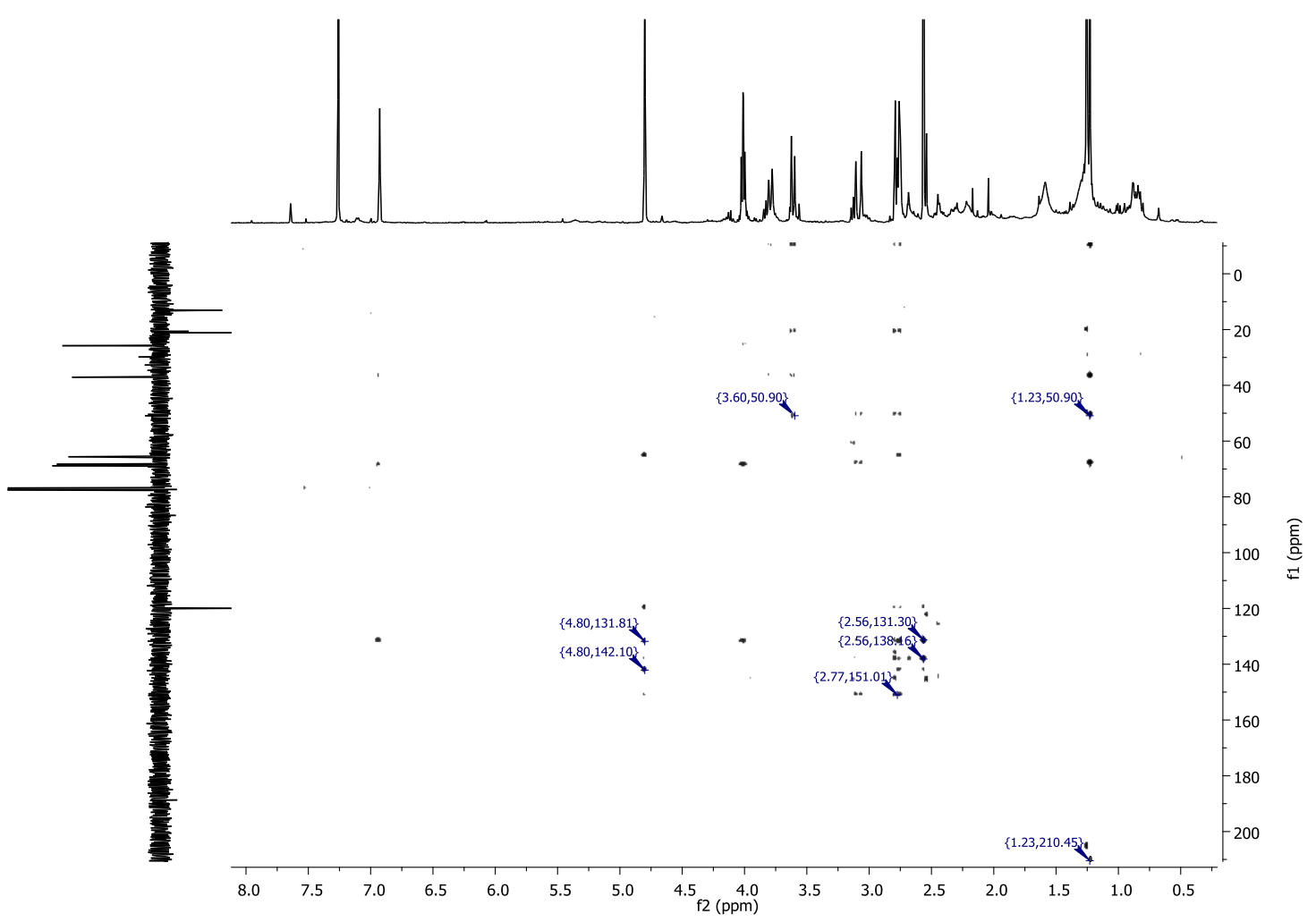

Figure S5. HMBC NMR spectrum of compound 1.

pos \#2 RT: 0.03 AV: 1 NL: $1.17 \mathrm{E} 6$

T: FTMS + p NSI u SIM ms [236.00-256.00]

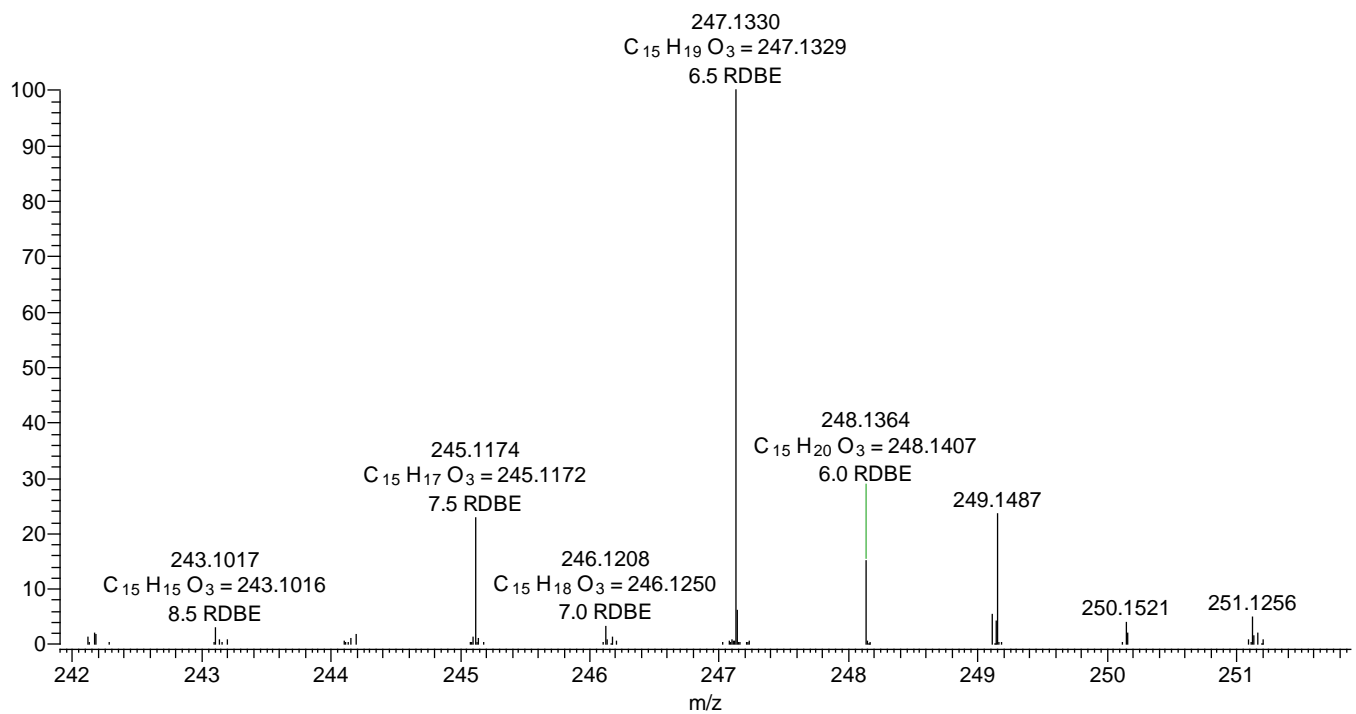

Figure S6. FT-ICR-MS spectrum of compound 1. 


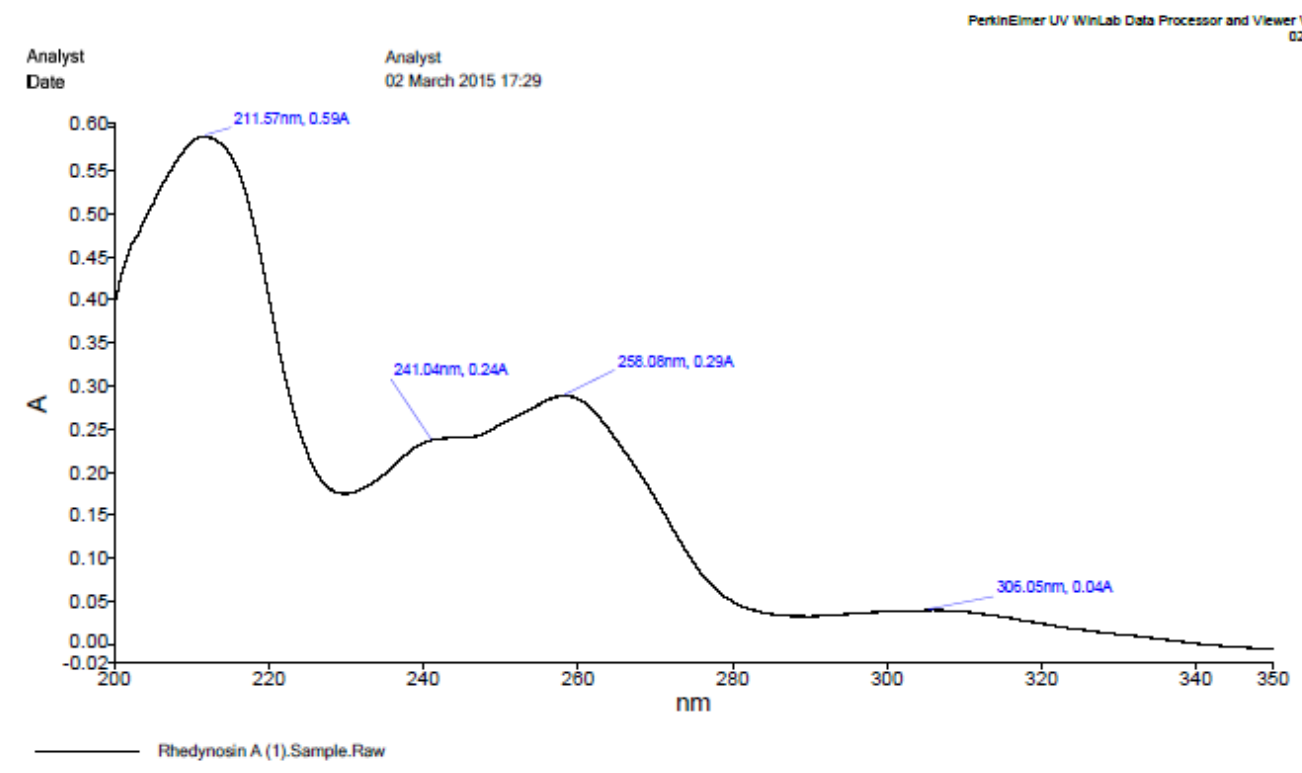

Figure S7. UV spectrum of compound 1 in $\mathrm{CH}_{3} \mathrm{OH}$.

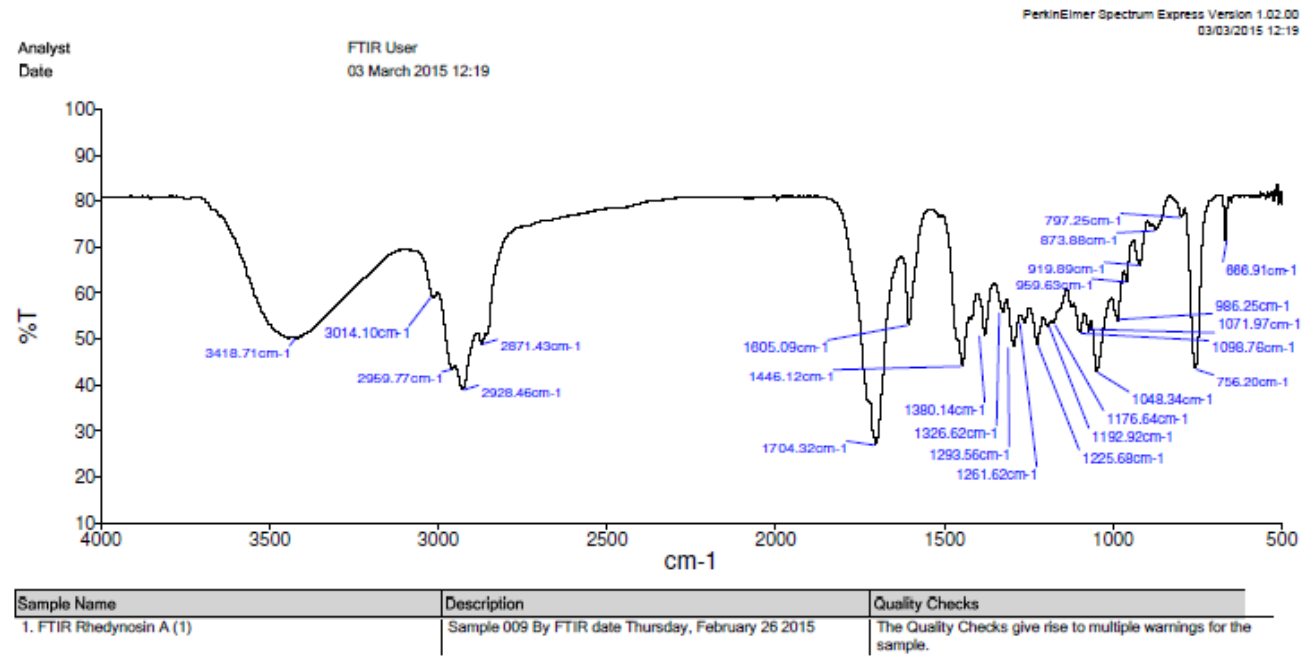

Figure S8. FT-IR spectrum of compound 1 in $\mathrm{CHCl}_{3}$. 


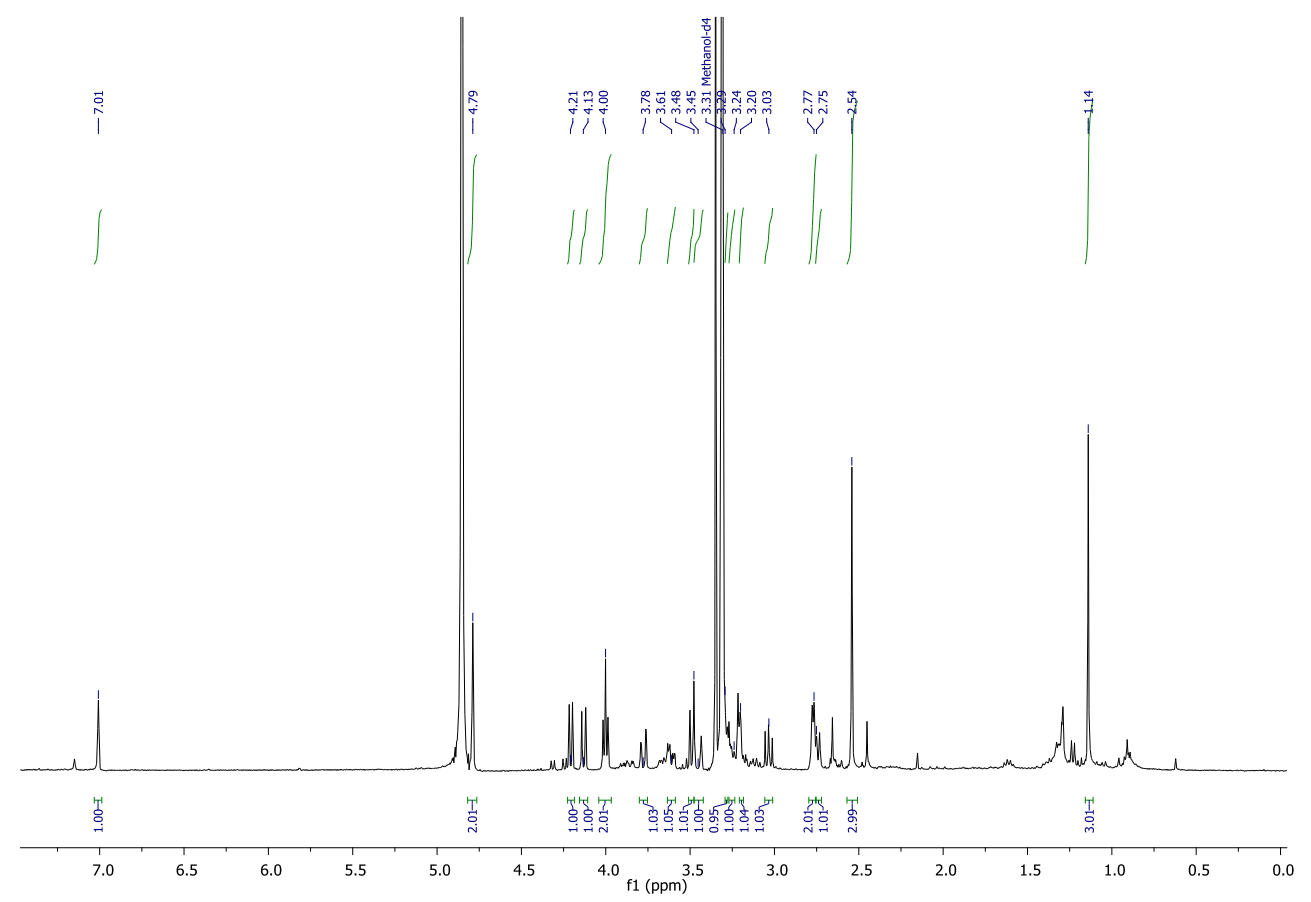

Figure S9. ${ }^{1} \mathrm{H}$ NMR $\left(\mathrm{CD}_{3} \mathrm{OD}, 400 \mathrm{MHz}\right)$ spectrum of compound 2.

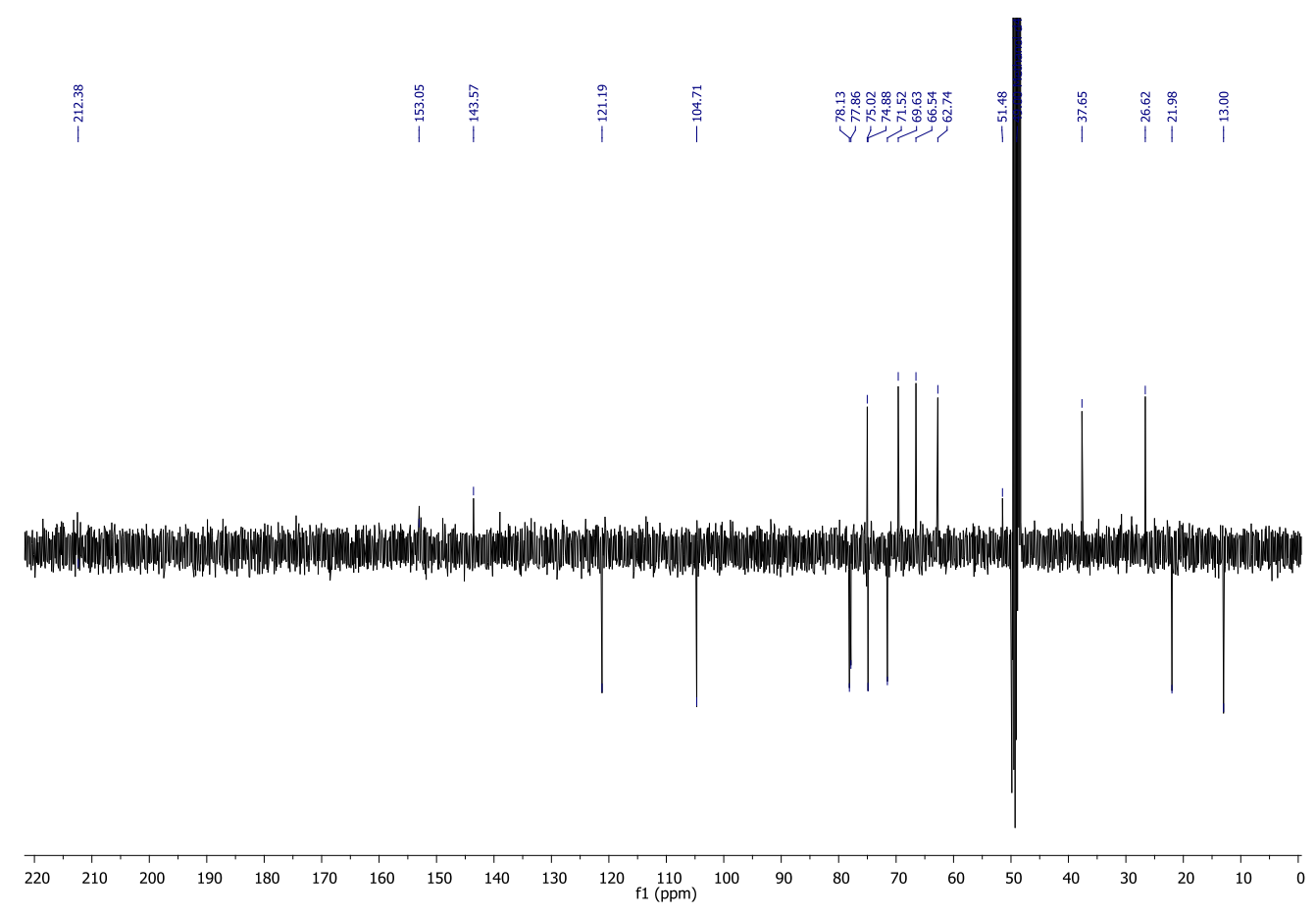

Figure S10. DEPTQ NMR $\left(\mathrm{CD}_{3} \mathrm{OD}, 100 \mathrm{MHz}\right)$ spectrum of compound 2. 


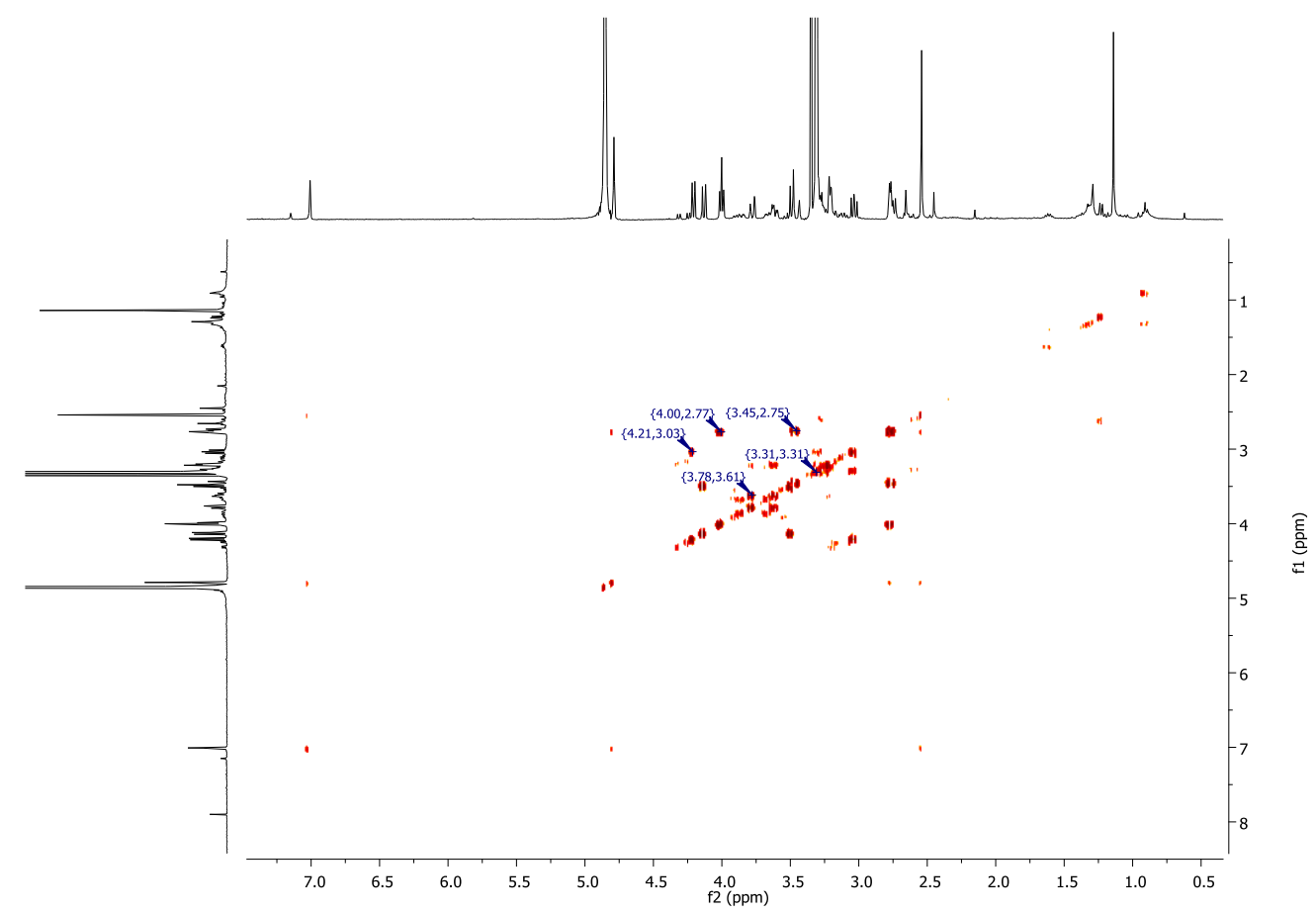

Figure S11. ${ }^{1} \mathrm{H}-{ }^{1} \mathrm{H}$ COSY NMR spectrum of compound 2.

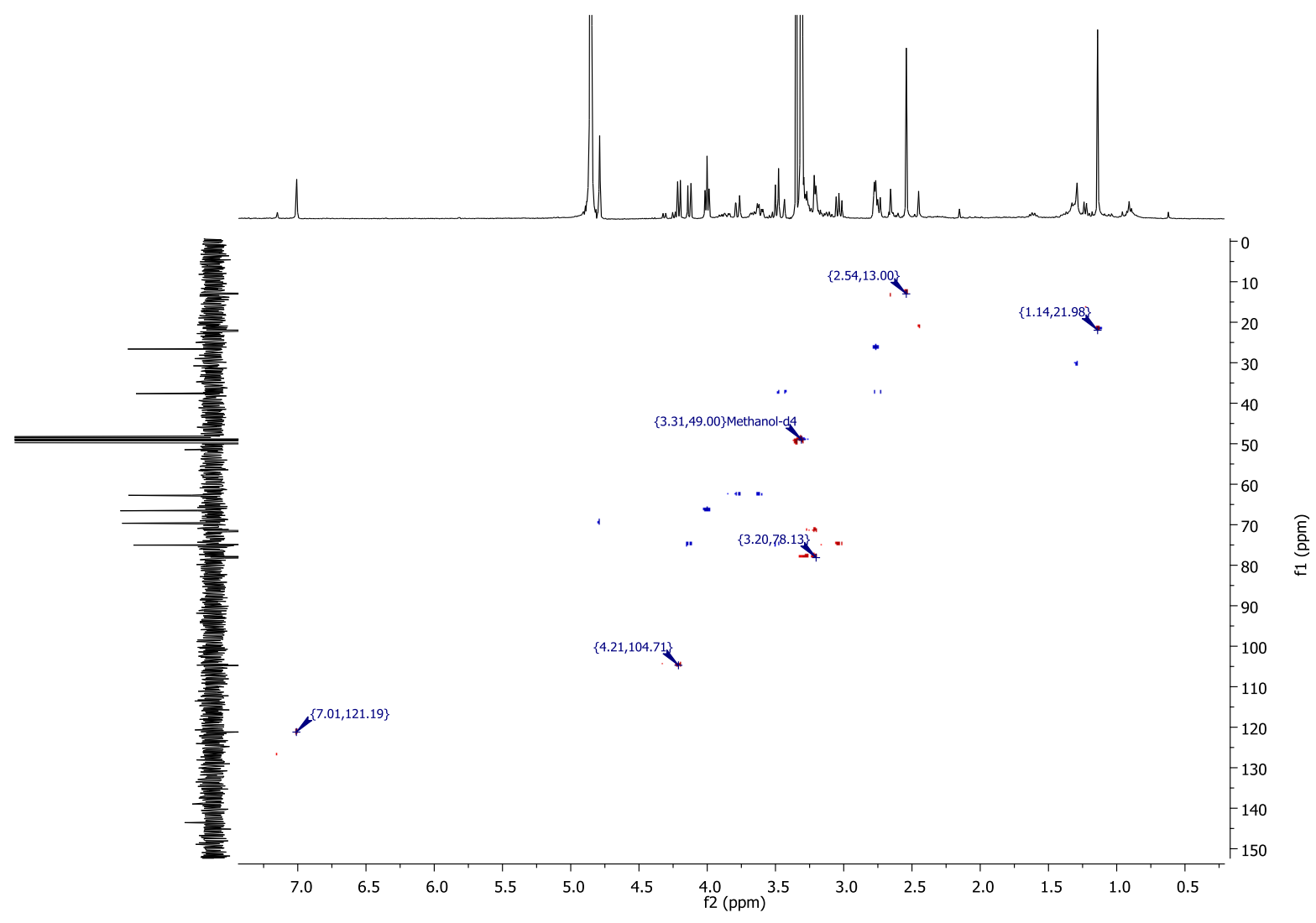

Figure S12. HSQC NMR spectrum of compound 2. 


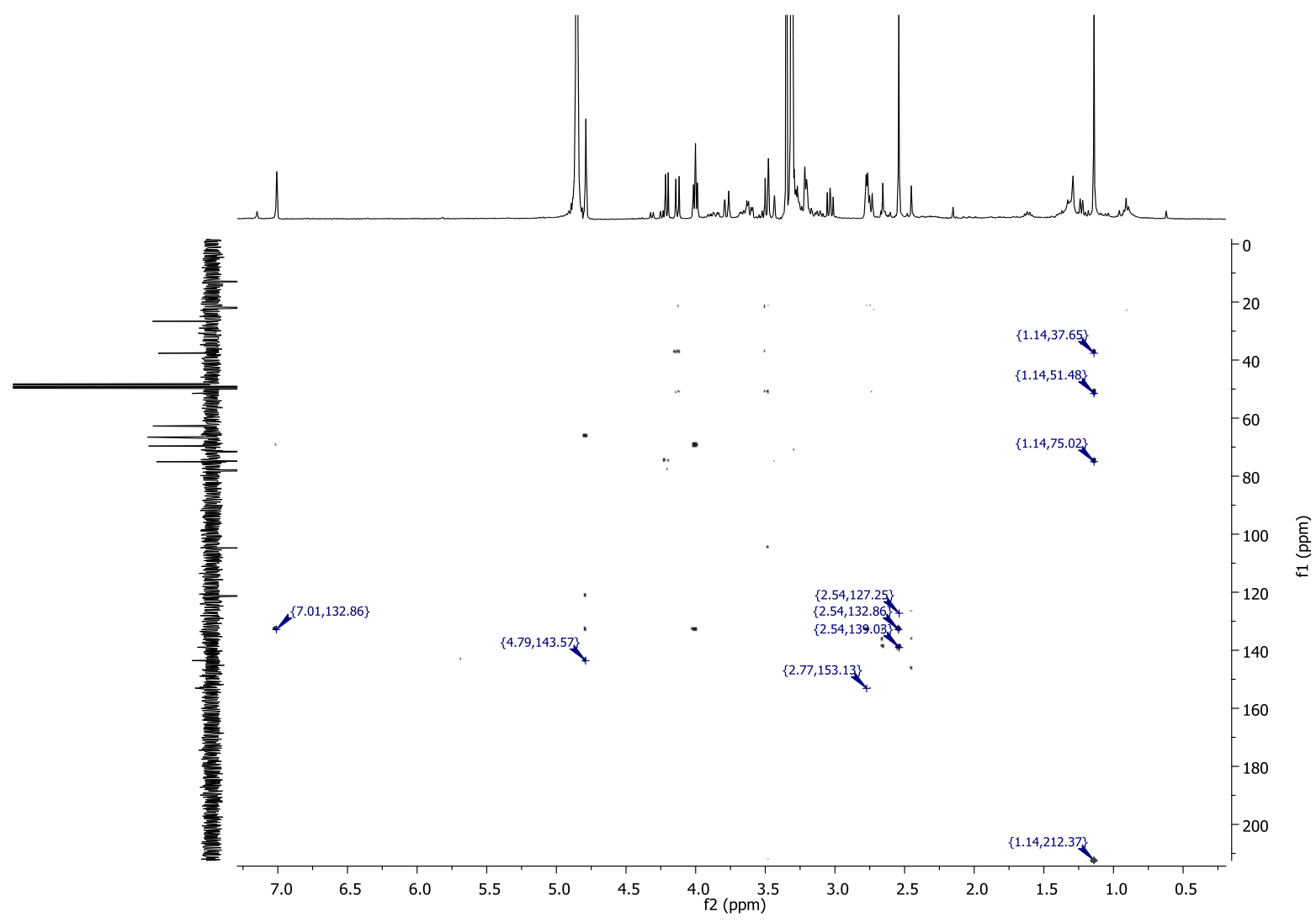

Figure S13. HMBC NMR spectrum of compound 2.

pos \#1 RT: 0.01 AV: 1 NL: 2.06E6

T: FTMS + p NSI u SIM ms [399.00-419.00]

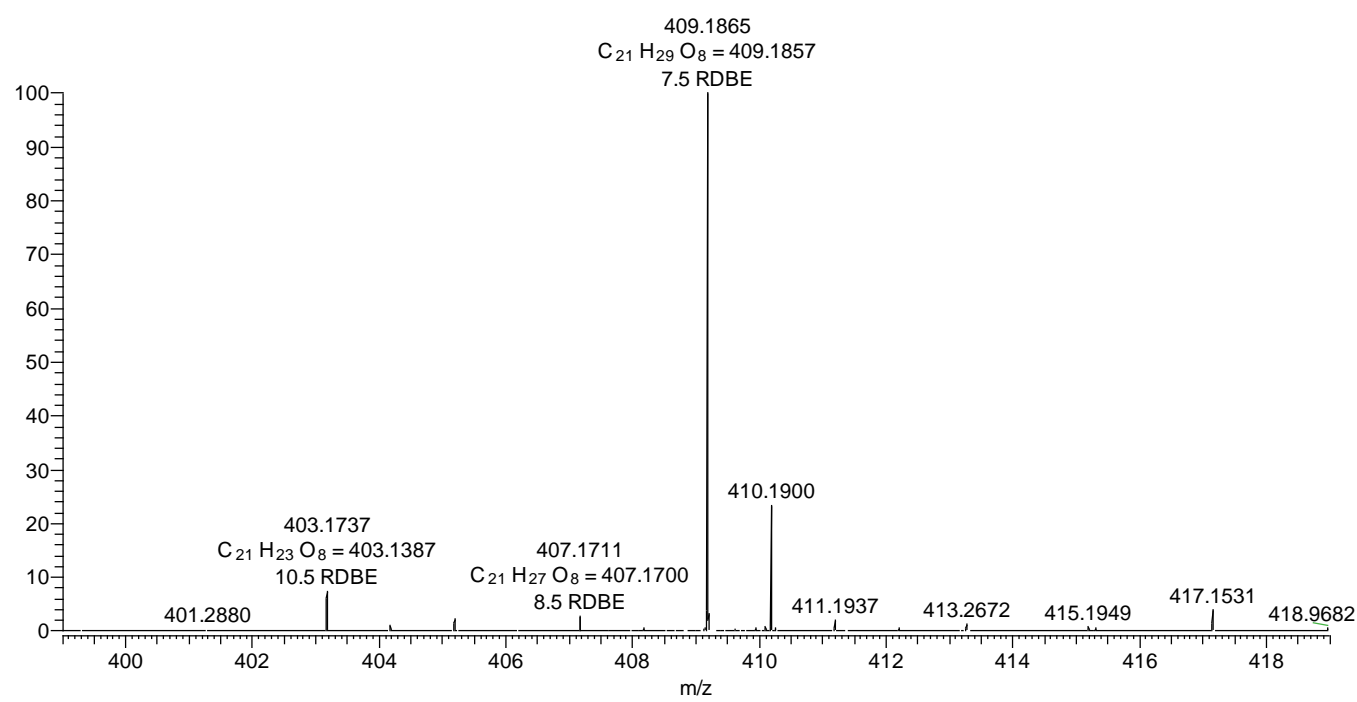

Figure S14. FT-ICR-MS spectrum of compound 2. 


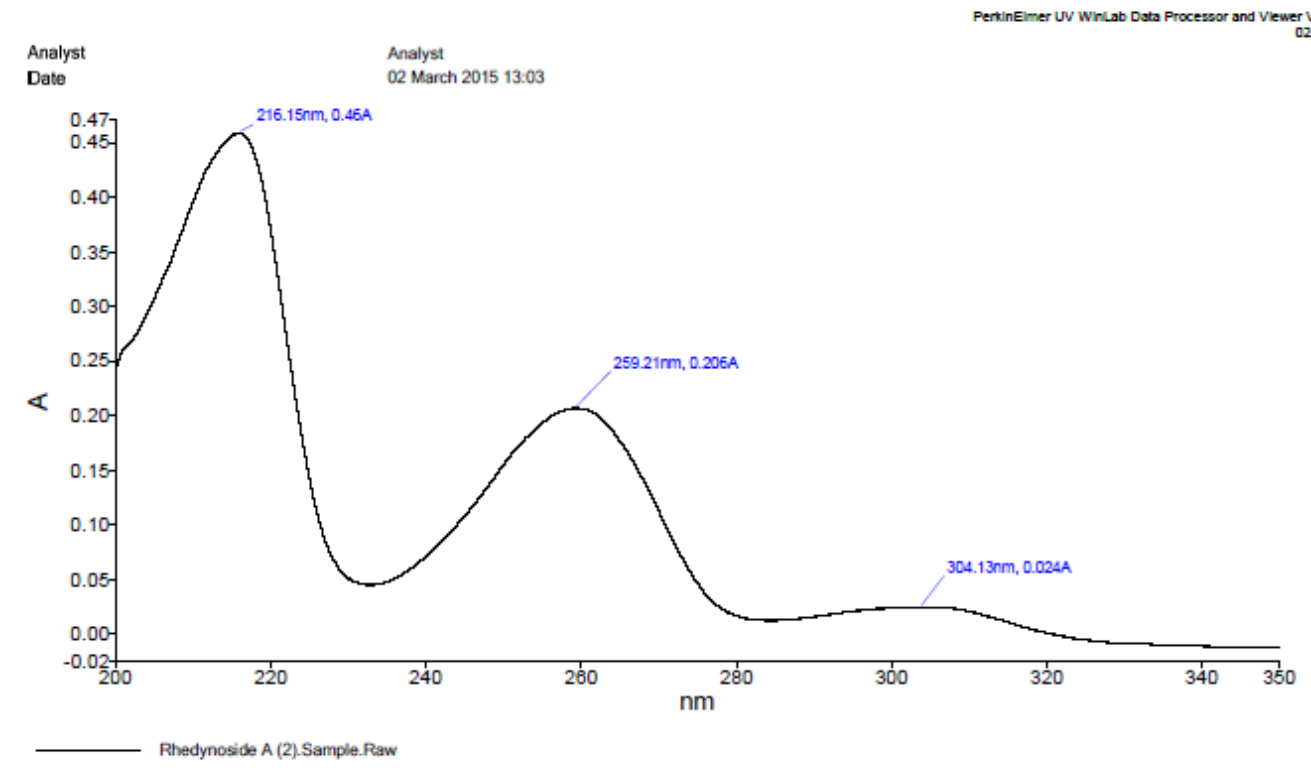

Figure S15. UV spectrum of compound 2 in $\mathrm{CH}_{3} \mathrm{OH}$.

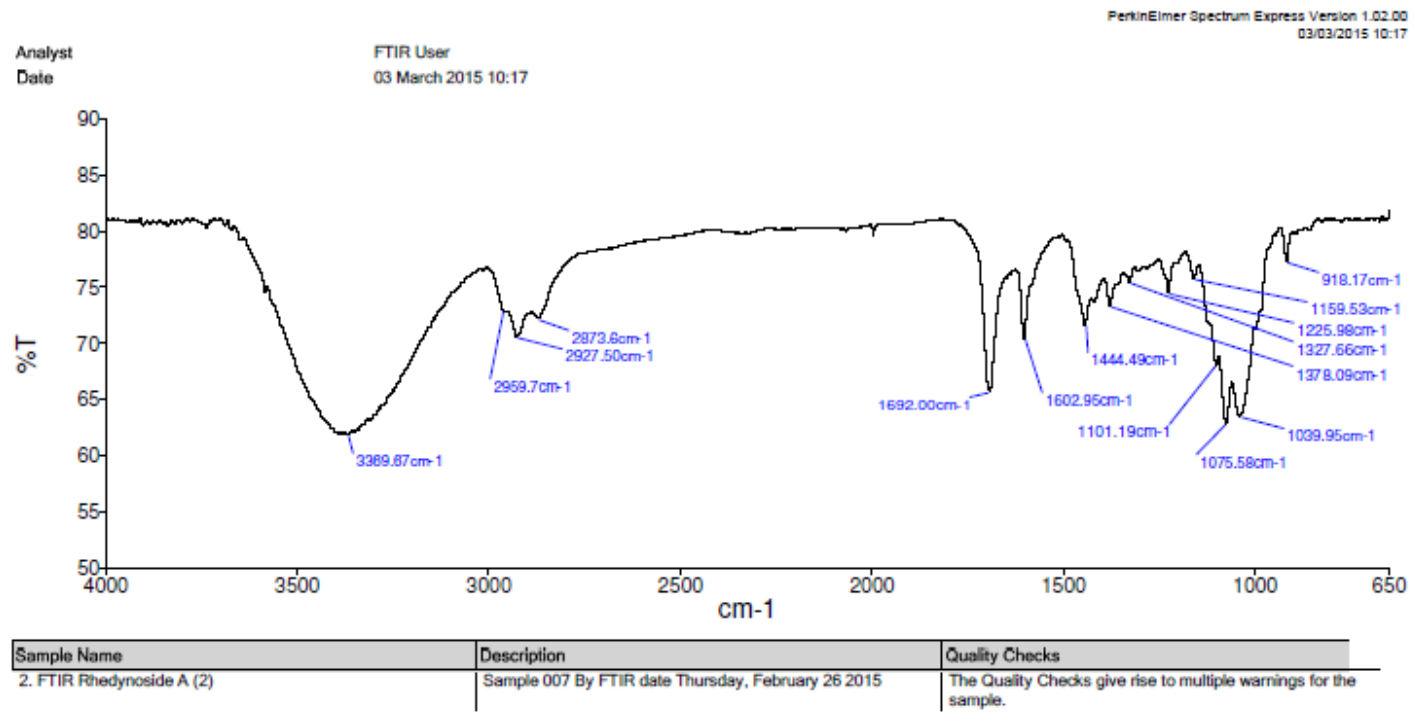

Figure S16. FT-IR spectrum of compound 2 in $\mathrm{CH}_{3} \mathrm{OH}$. 


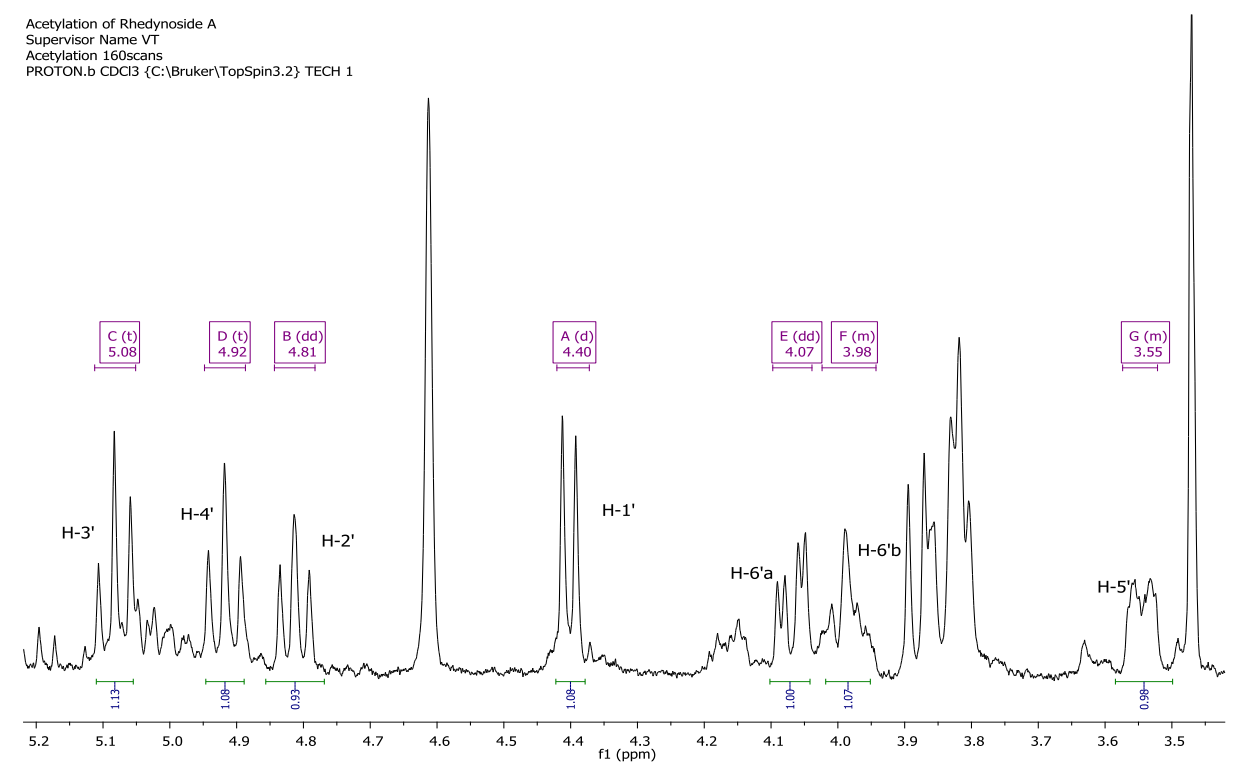

Figure S17. ${ }^{1} \mathrm{H}$ NMR $\left(\mathrm{CDCl}_{3}, 400 \mathrm{MHz}\right)$ spectrum of compound 2 after acetylation reaction

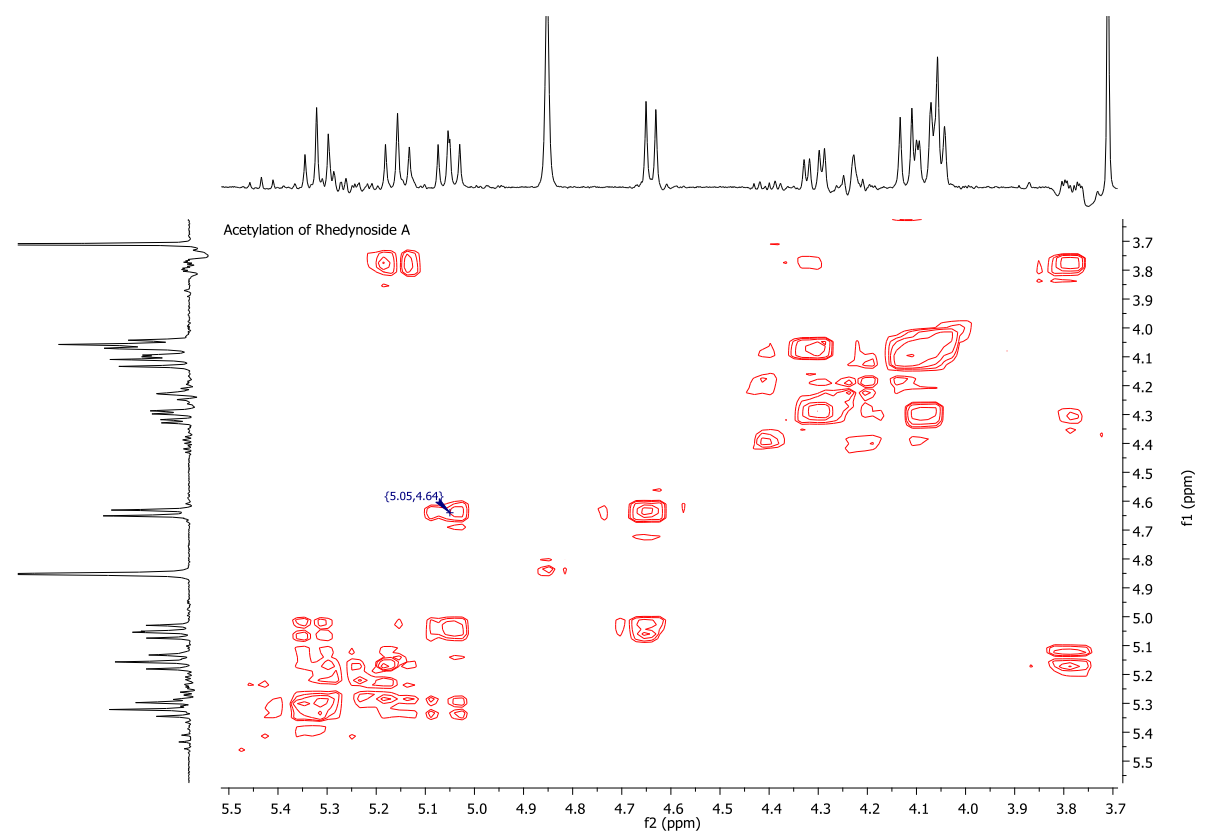

Figure S18. ${ }^{1} \mathrm{H}-{ }^{1} \mathrm{H}$ COSY NMR spectrum of compound 2 after acetylation reaction 


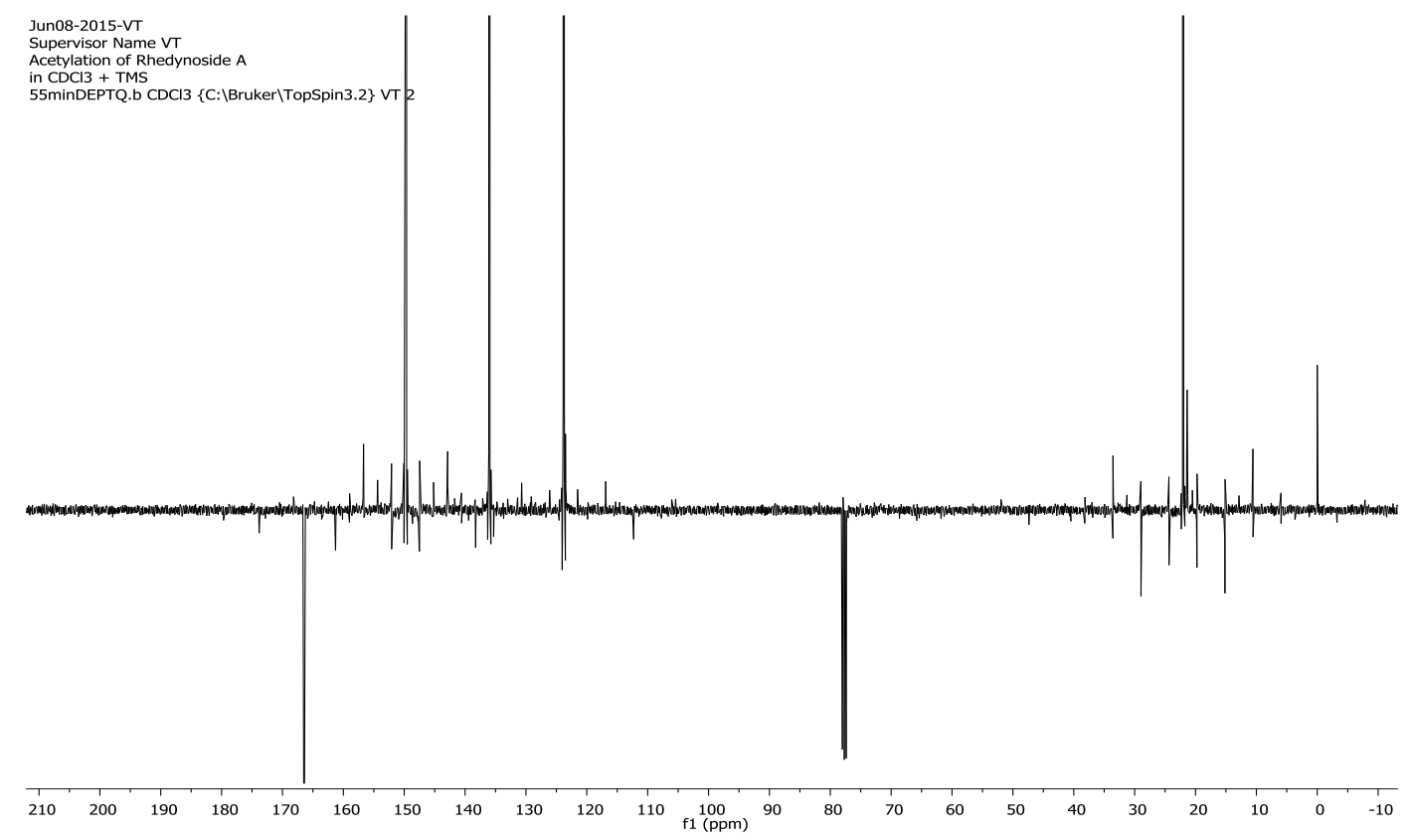

Figure S19. DEPTQ NMR $\left(\mathrm{CDCl}_{3}, 100 \mathrm{MHz}\right)$ spectrum of compound 2 after acetylation reaction

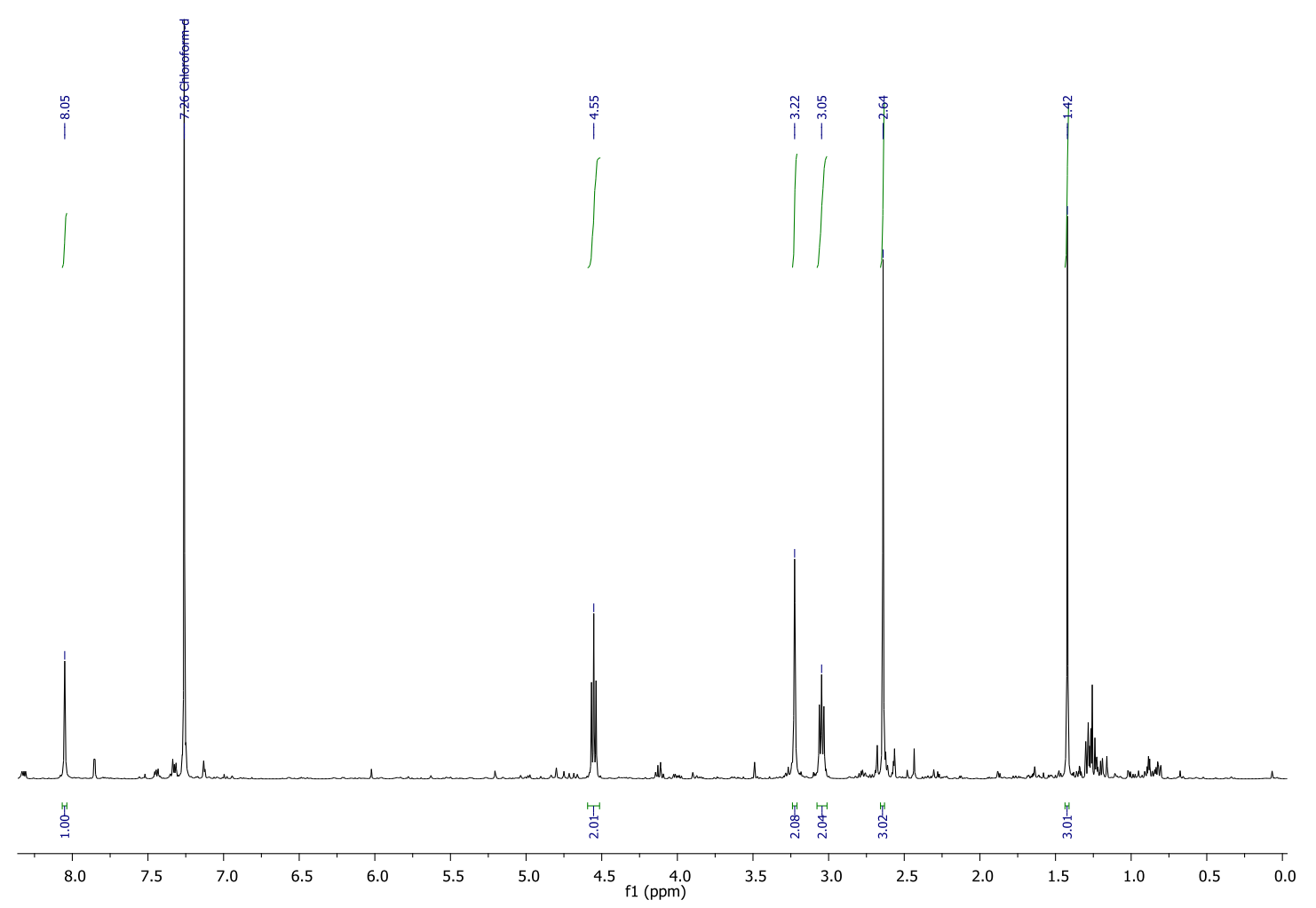

Figure S20. ${ }^{1} \mathrm{H}$ NMR $\left(\mathrm{CDCl}_{3}, 400 \mathrm{MHz}\right)$ spectrum of compound 3. 


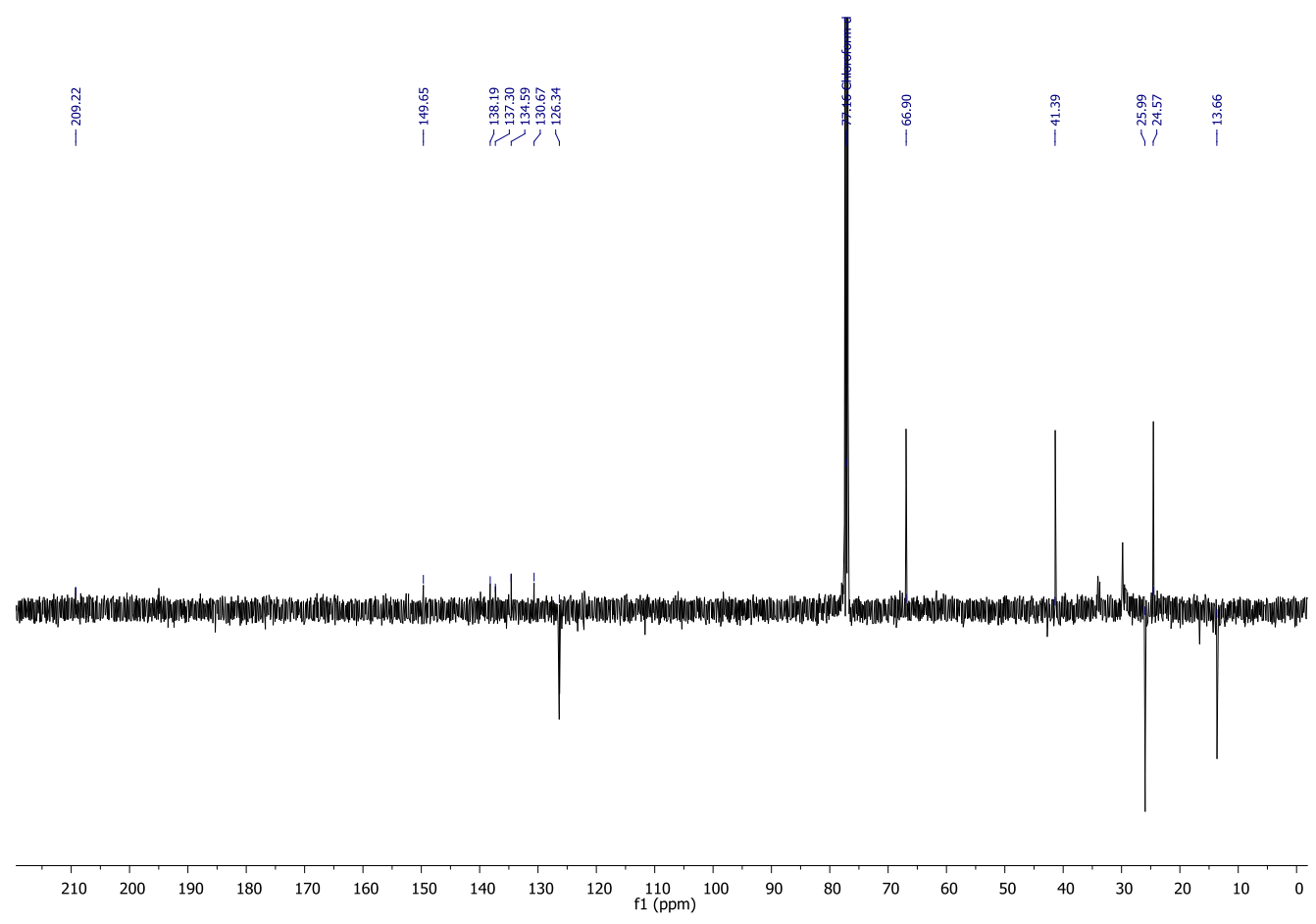

Figure S21. DEPTQ NMR ( $\left.\mathrm{CDCl}_{3}, 100 \mathrm{MHz}\right)$ spectrum of compound 3.

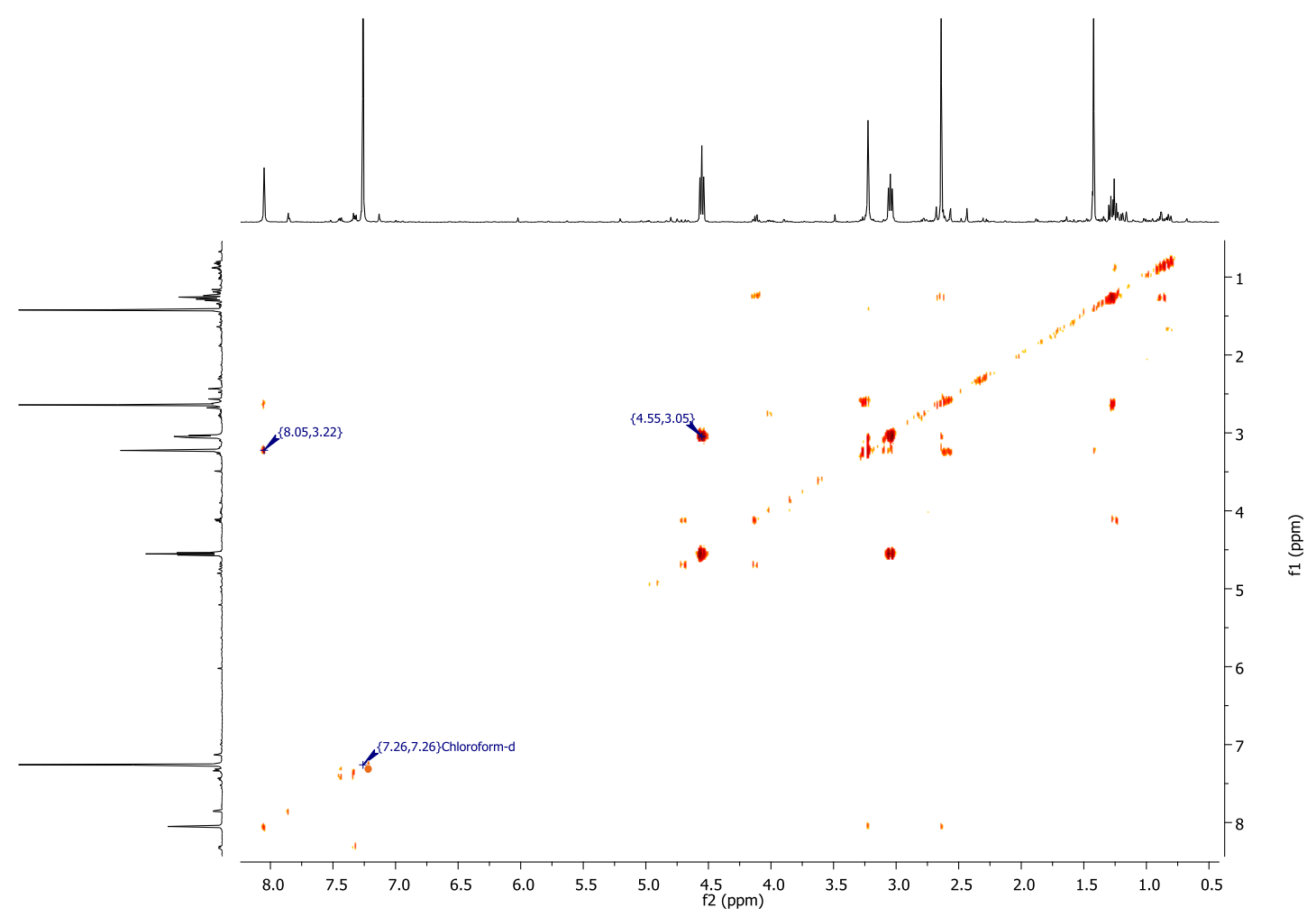

Figure S22. ${ }^{1} \mathrm{H}-{ }^{1} \mathrm{H}$ COSY NMR spectrum of compound 3. 


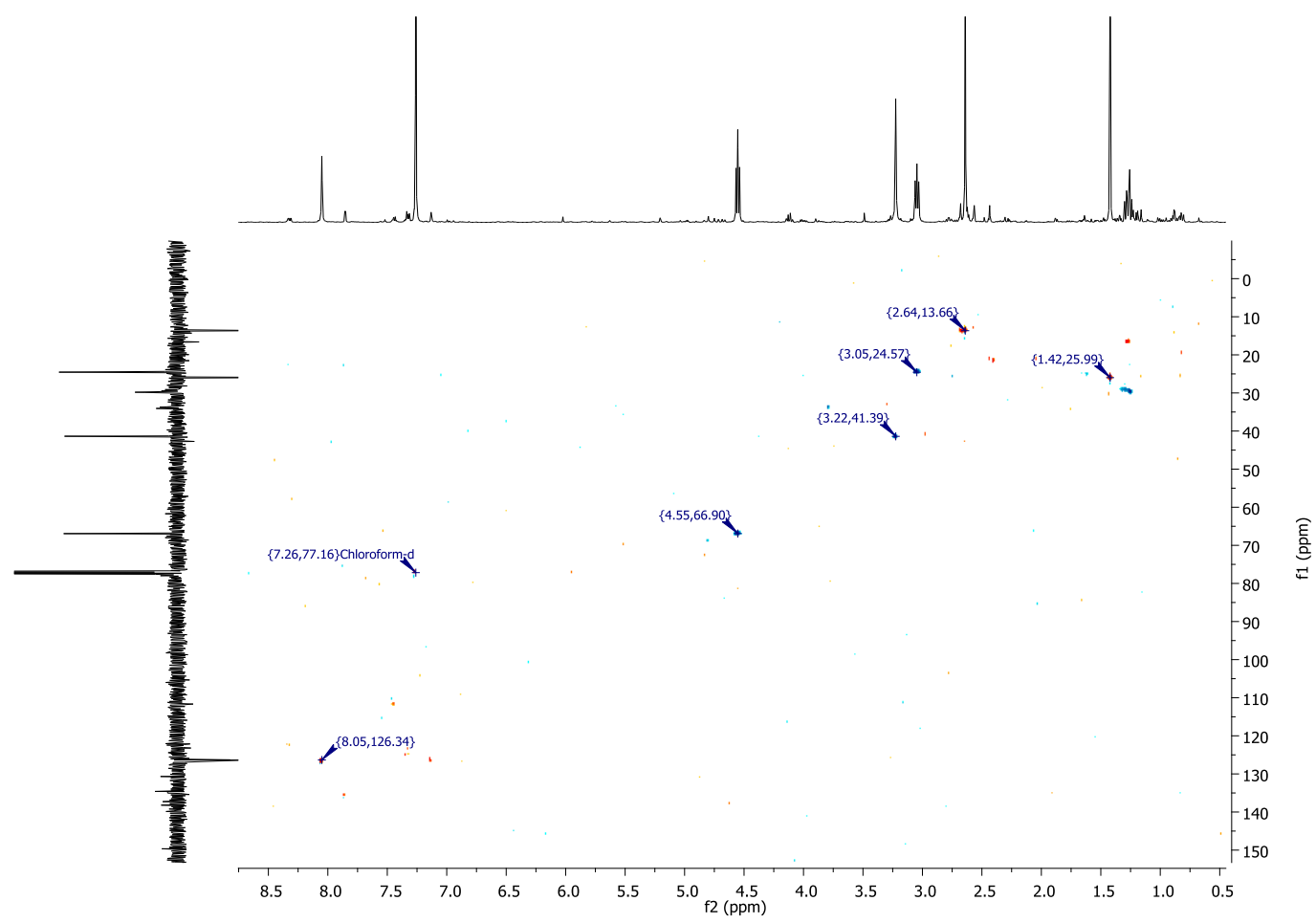

Figure S23. HSQC NMR spectrum of compound 3.

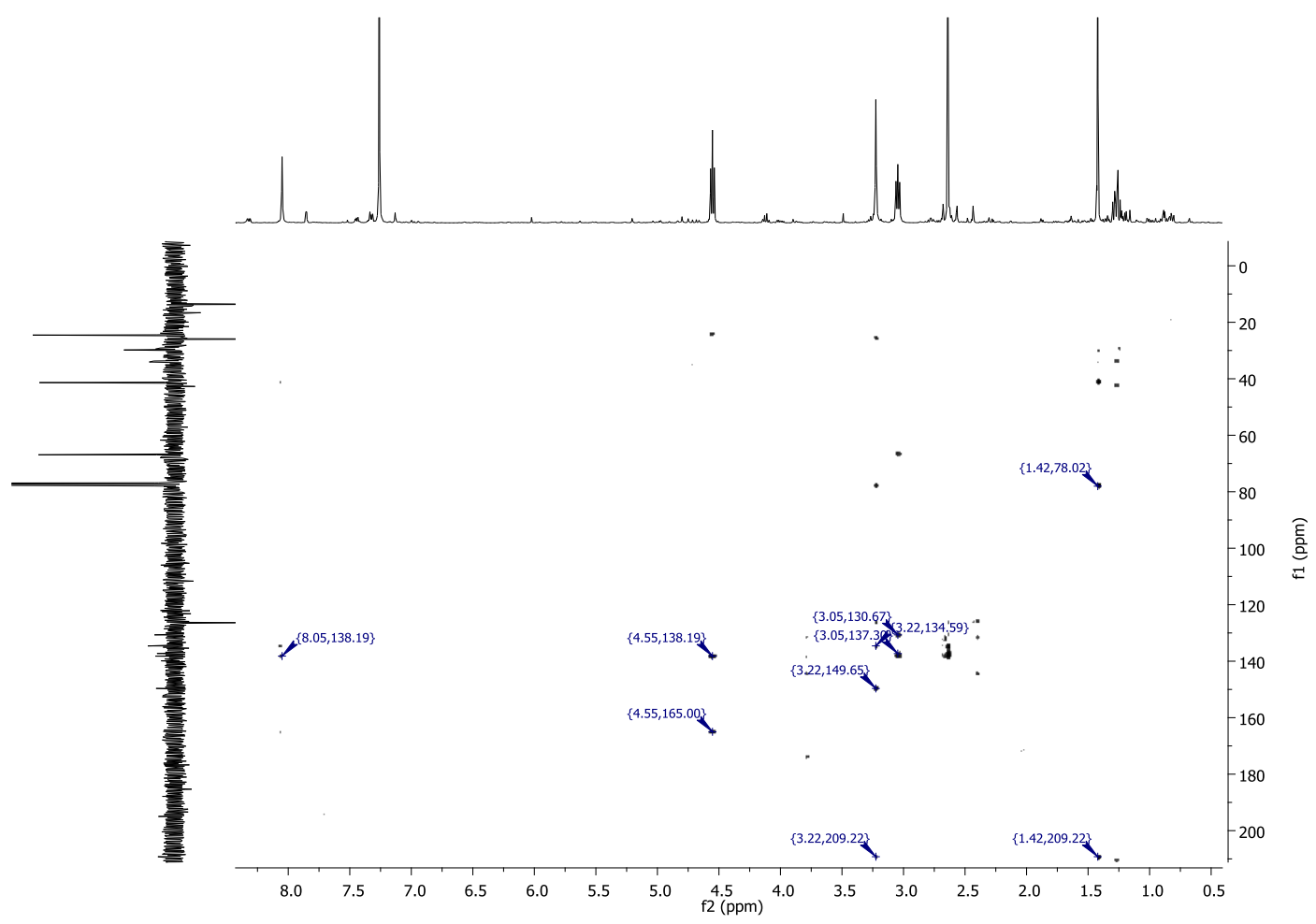

Figure S24. HMBC NMR spectrum of compound 3. 
pos \#3 RT: 0.04 AV: 1 NL: $6.74 \mathrm{E} 5$

T: FTMS + p NSI u SIM ms [235.00-255.00]

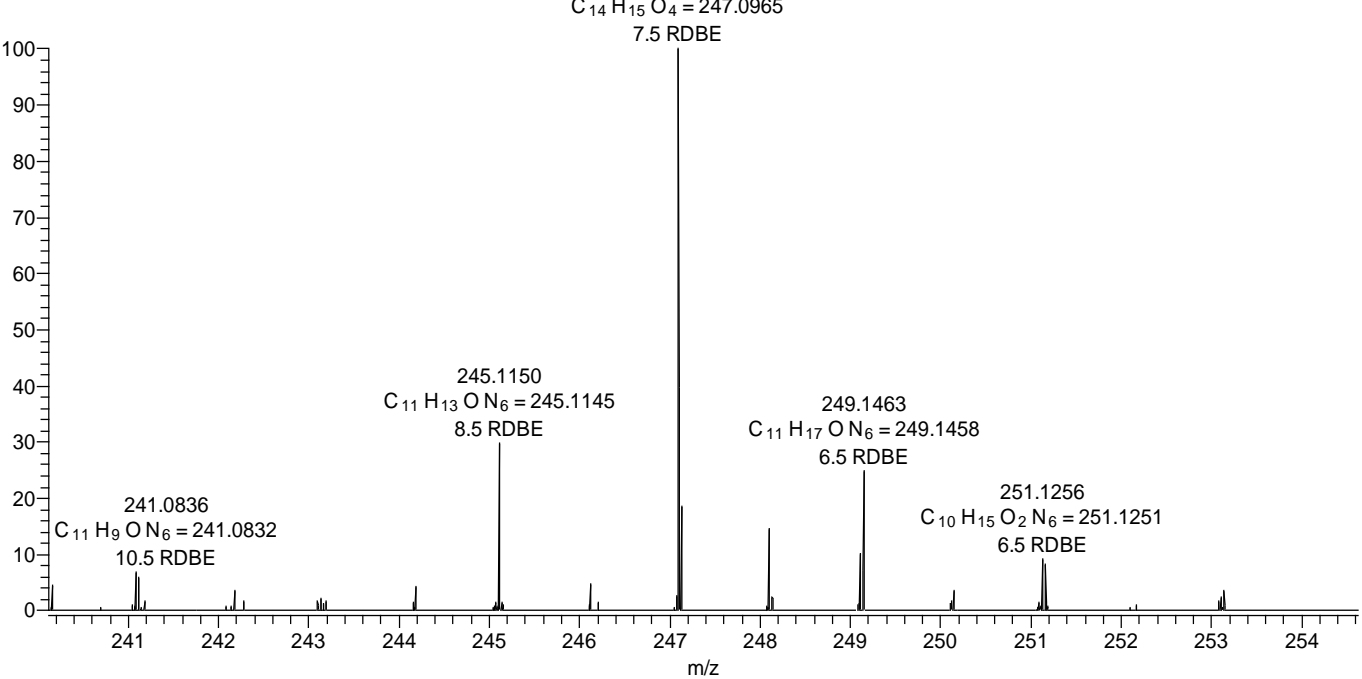

Figure S25. FT-ICR-MS spectrum of compound 3.

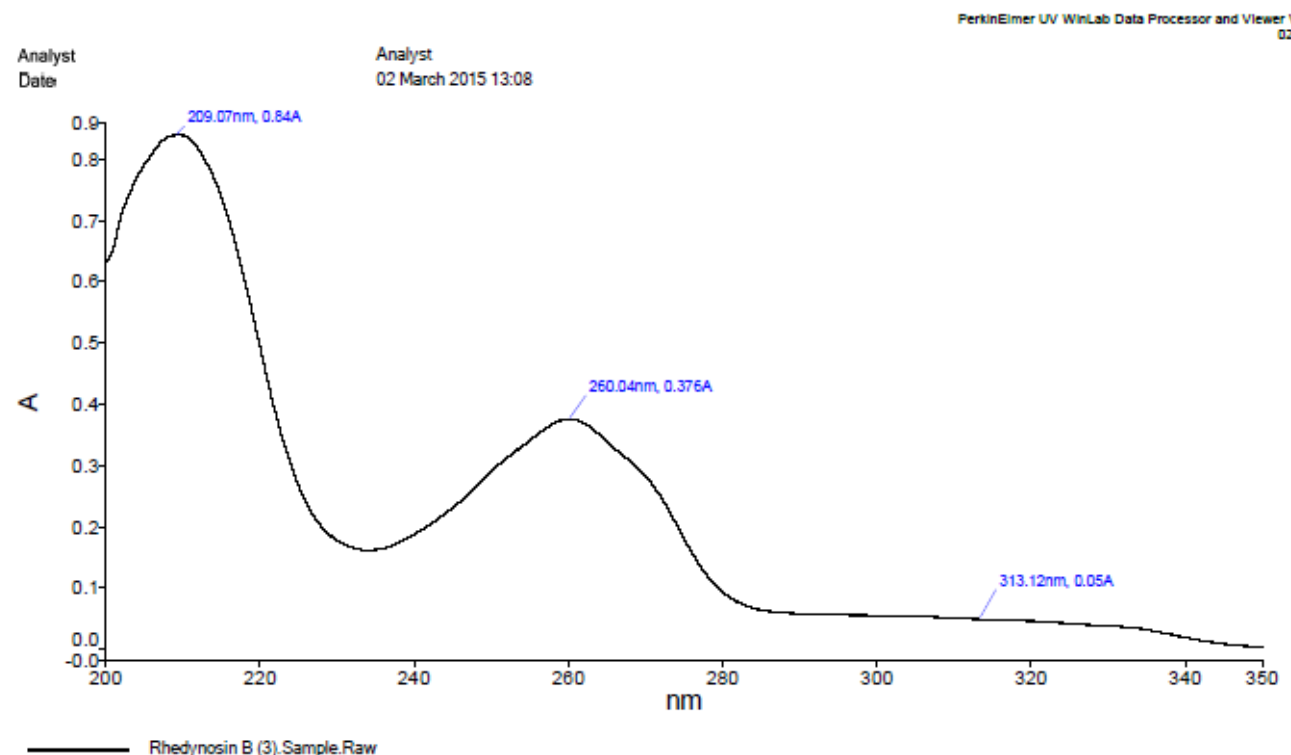

Figure S26. UV spectrum of compound 3 in $\mathrm{CH}_{3} \mathrm{OH}$. 


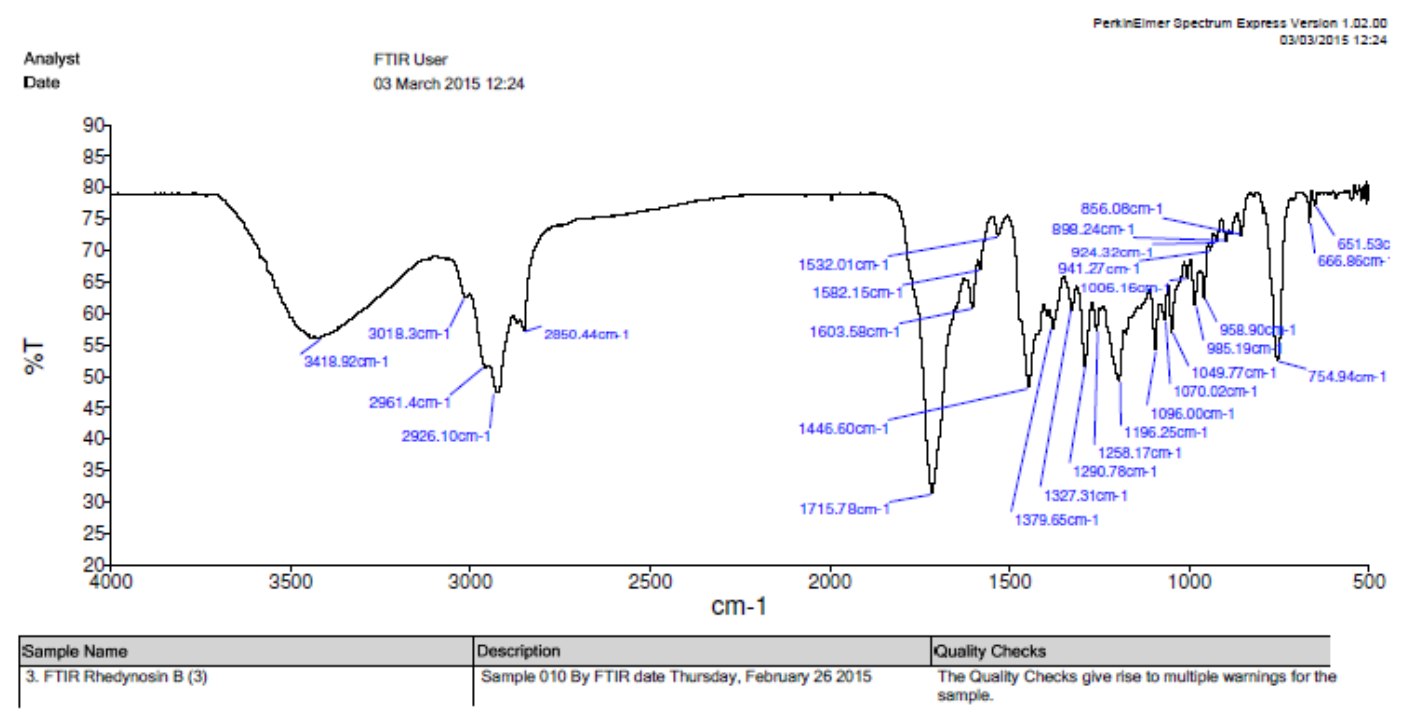

Figure S27. FT-IR spectrum of compound $\mathbf{3}$ in $\mathrm{CHCl}_{3}$.

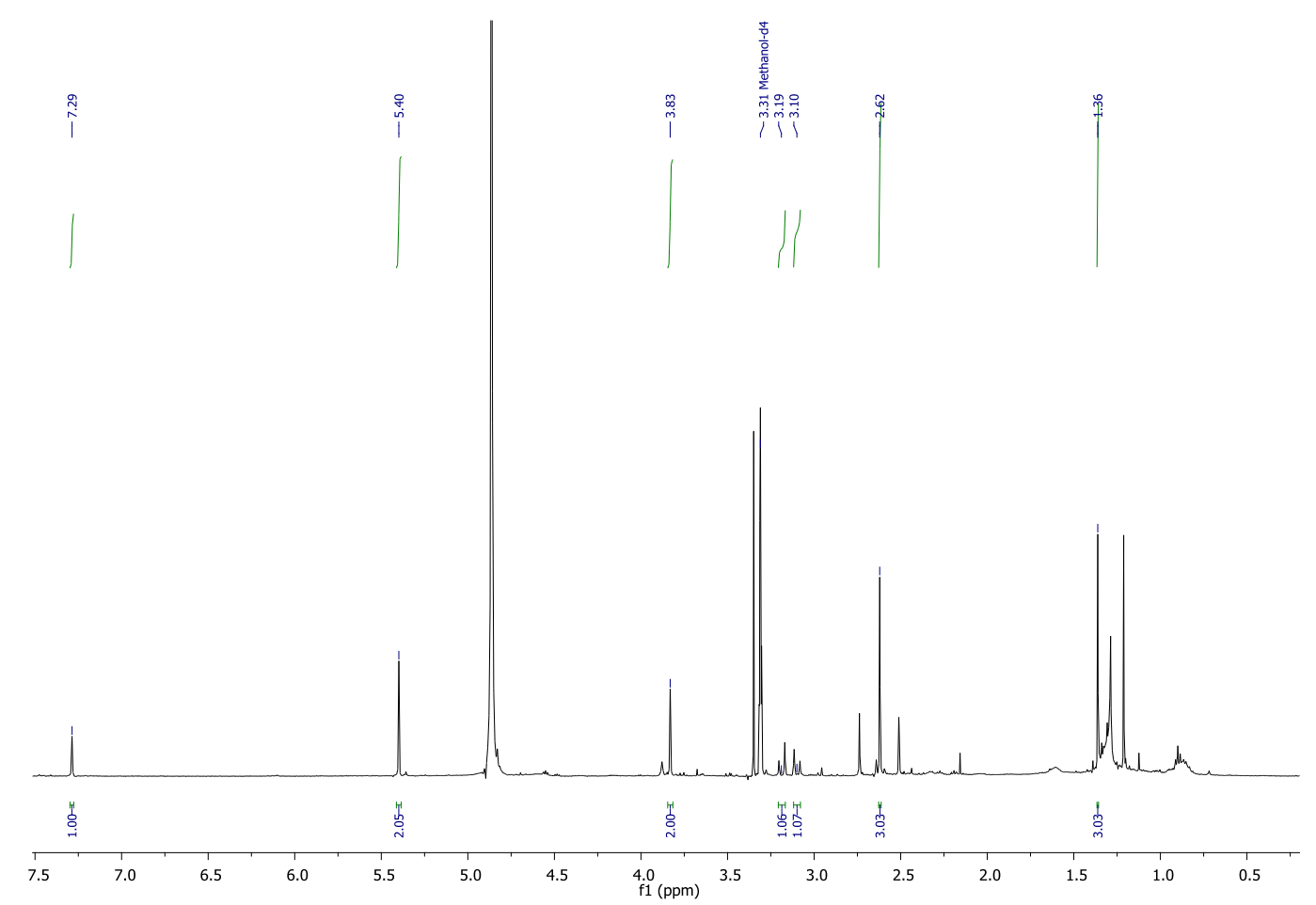

Figure S28. ${ }^{1} \mathrm{H}$ NMR $\left(\mathrm{CD}_{3} \mathrm{OD}, 400 \mathrm{MHz}\right)$ spectrum of compound 4. 


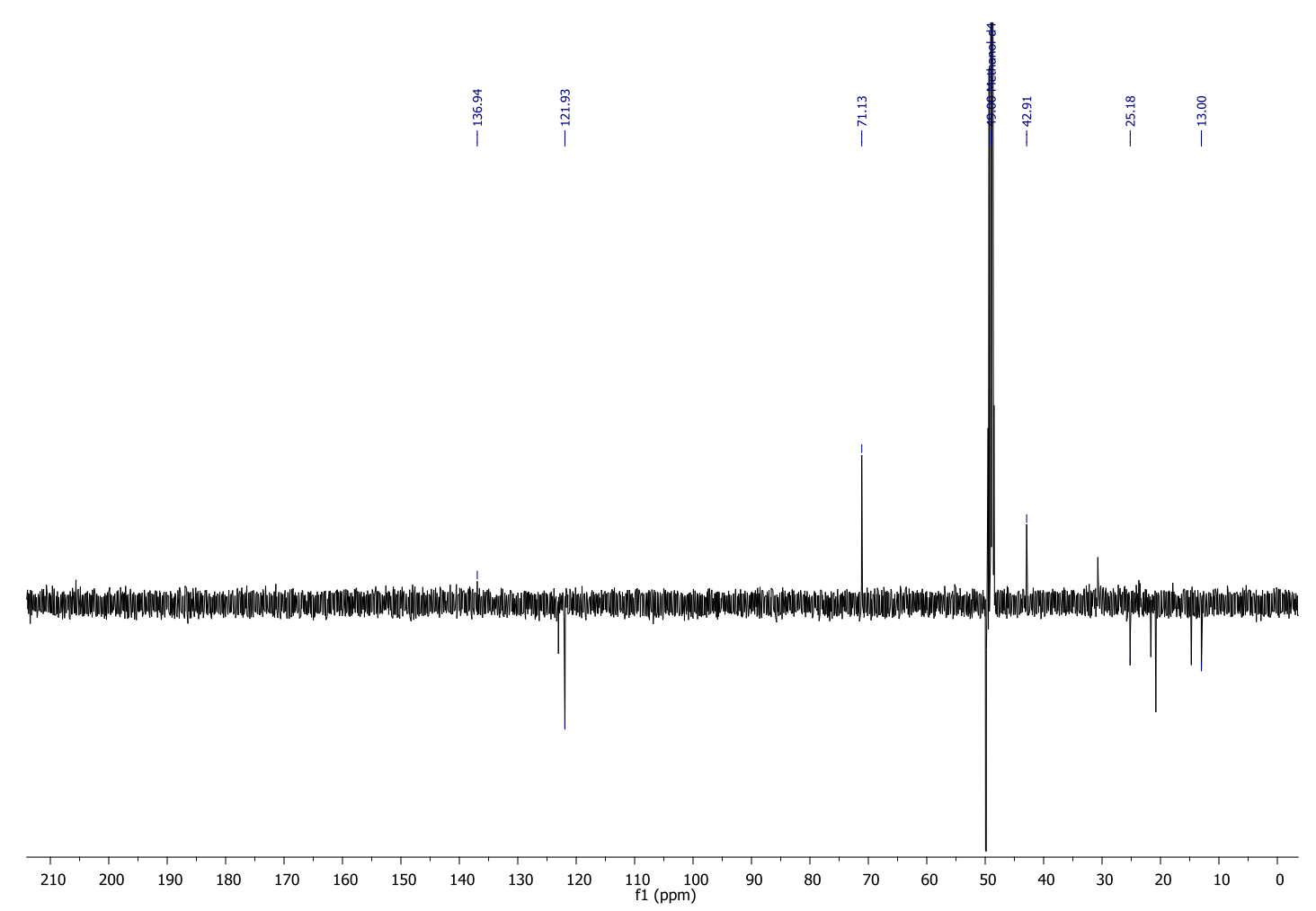

Figure S29. DEPTQ NMR $\left(\mathrm{CD}_{3} \mathrm{OD}, 100 \mathrm{MHz}\right)$ spectrum of compound 4.

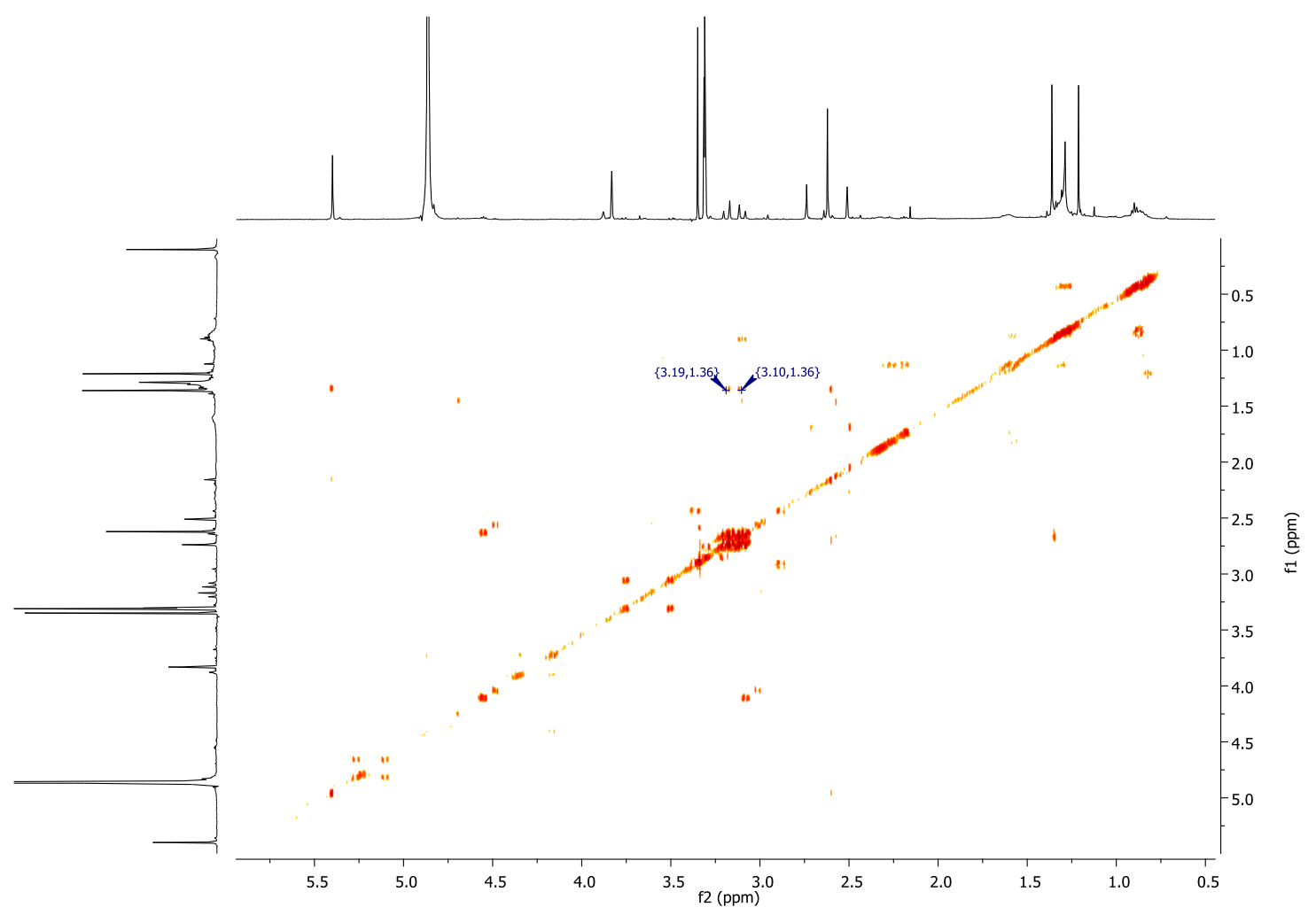

Figure S30. ${ }^{1} \mathrm{H}-{ }^{1} \mathrm{H}$ COSY NMR spectrum of compound 4. 


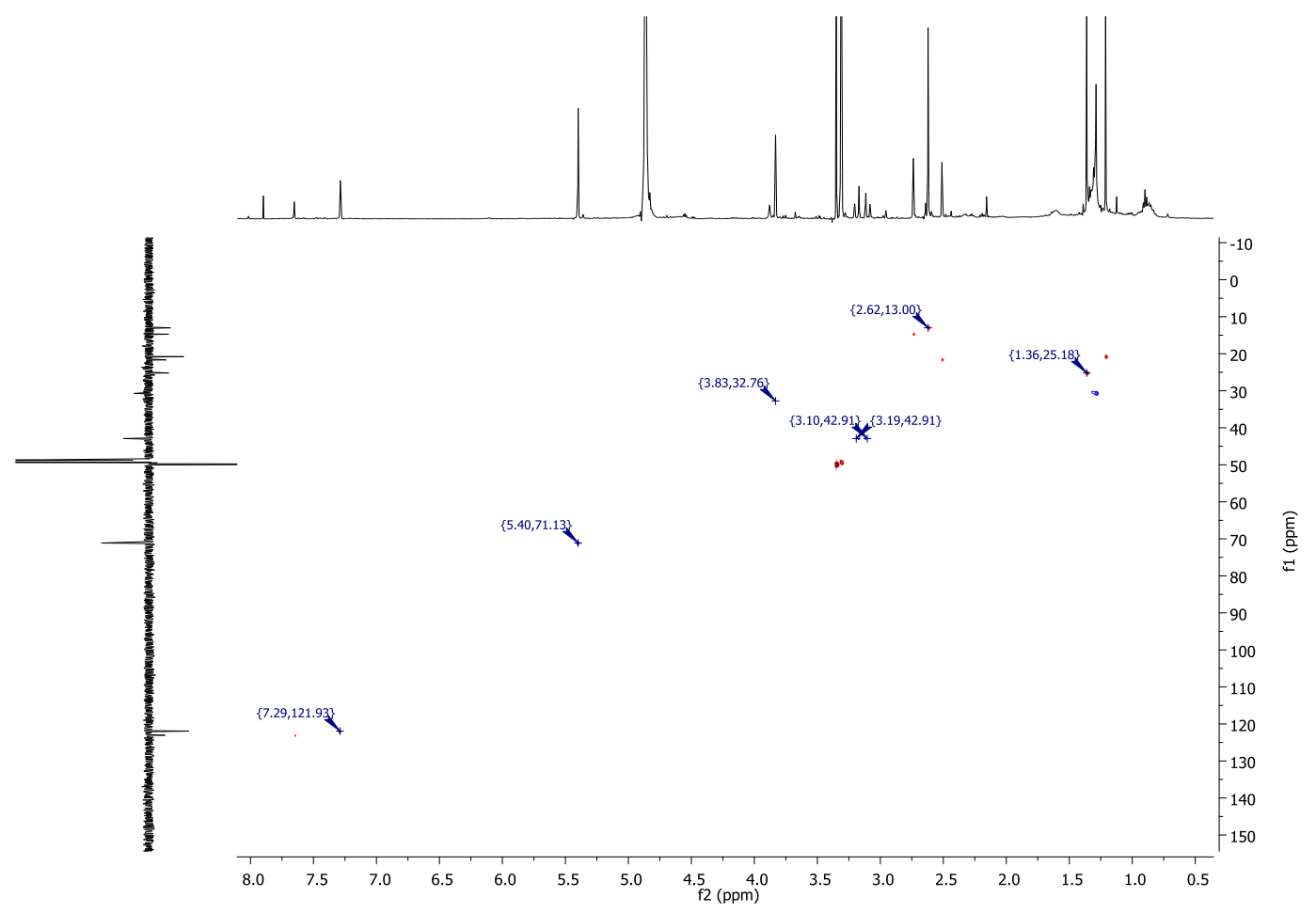

Figure S31. HSQC NMR spectrum of compound 4.

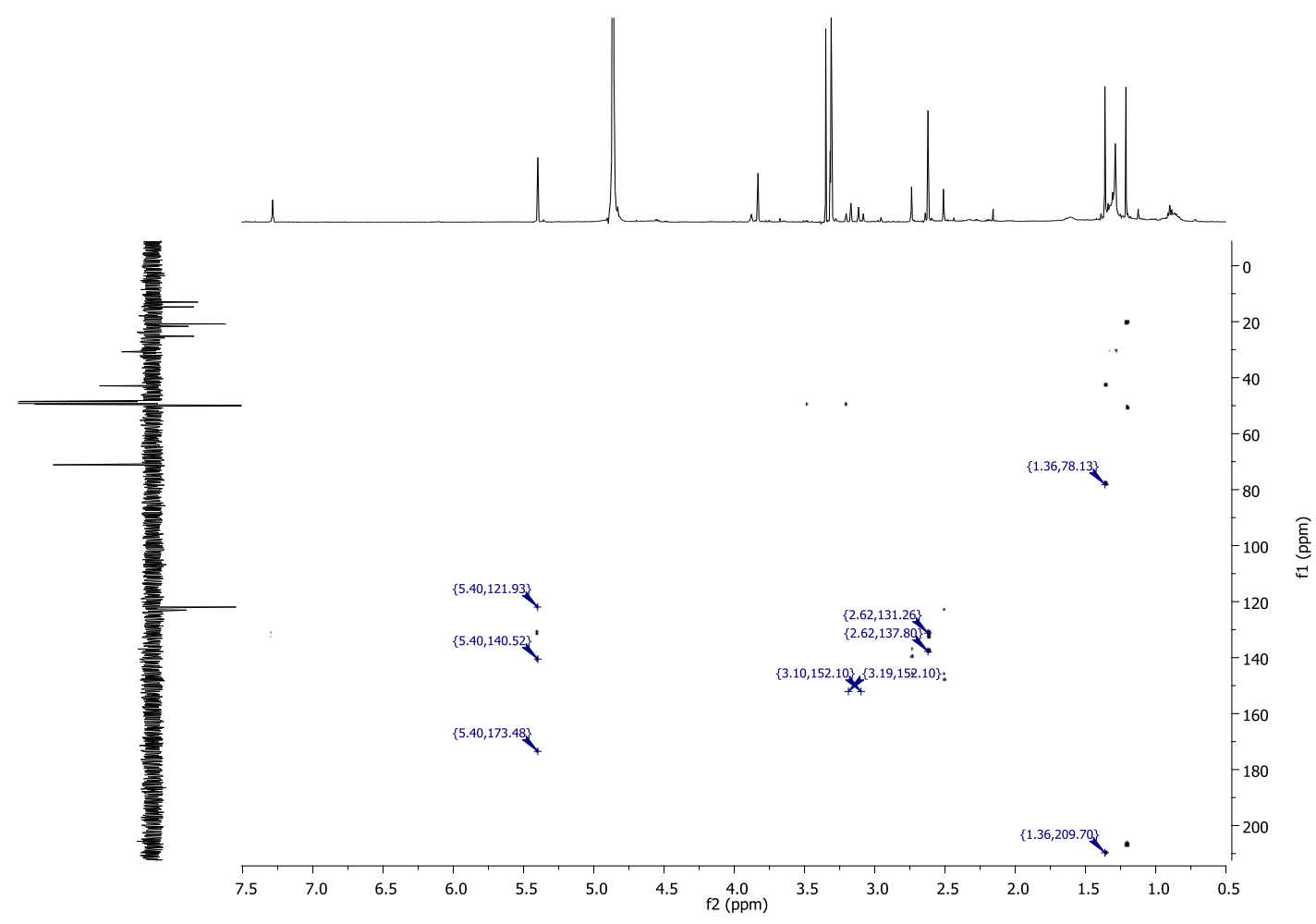

Figure S32. HMBC NMR spectrum of compound 4. 
neg \#2 RT: 0.03 AV: 1 NL: $7.30 E 5$

T: FTMS - p NSI U SIM ms [235.00-255.00]

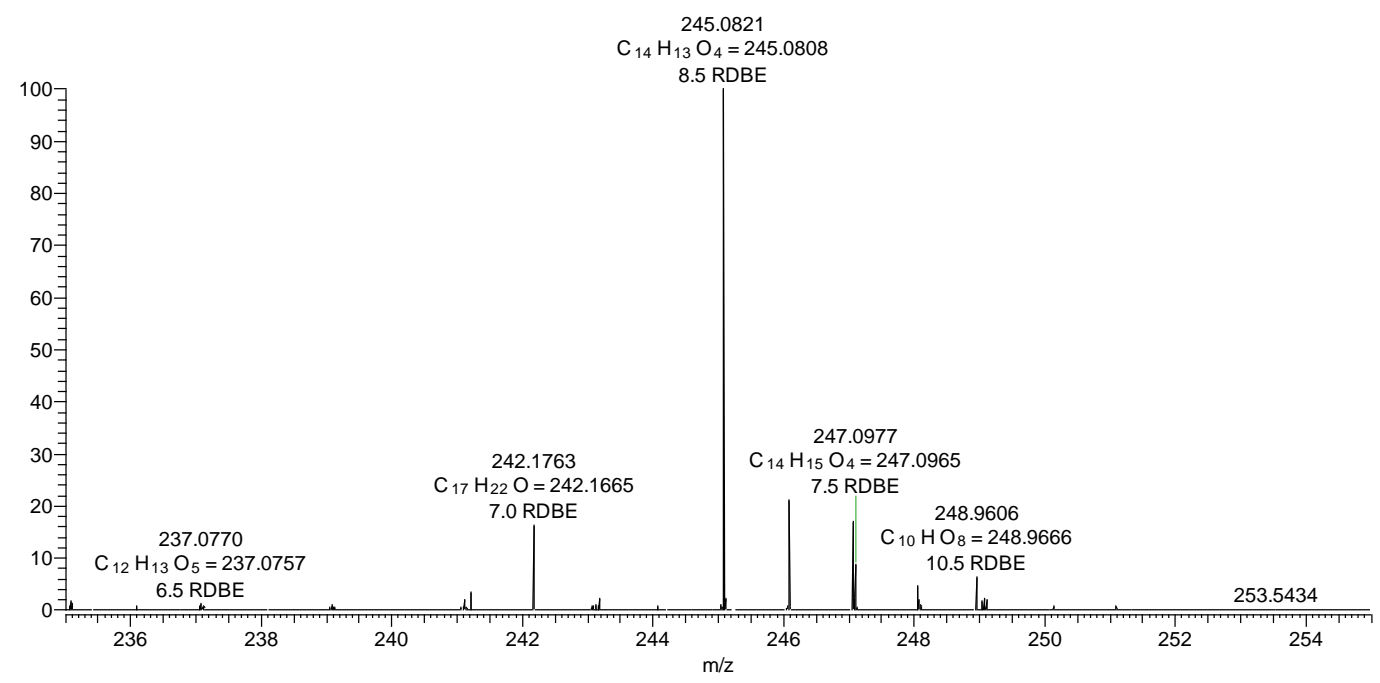

Figure S33. FT-ICR-MS spectrum of compound 4.

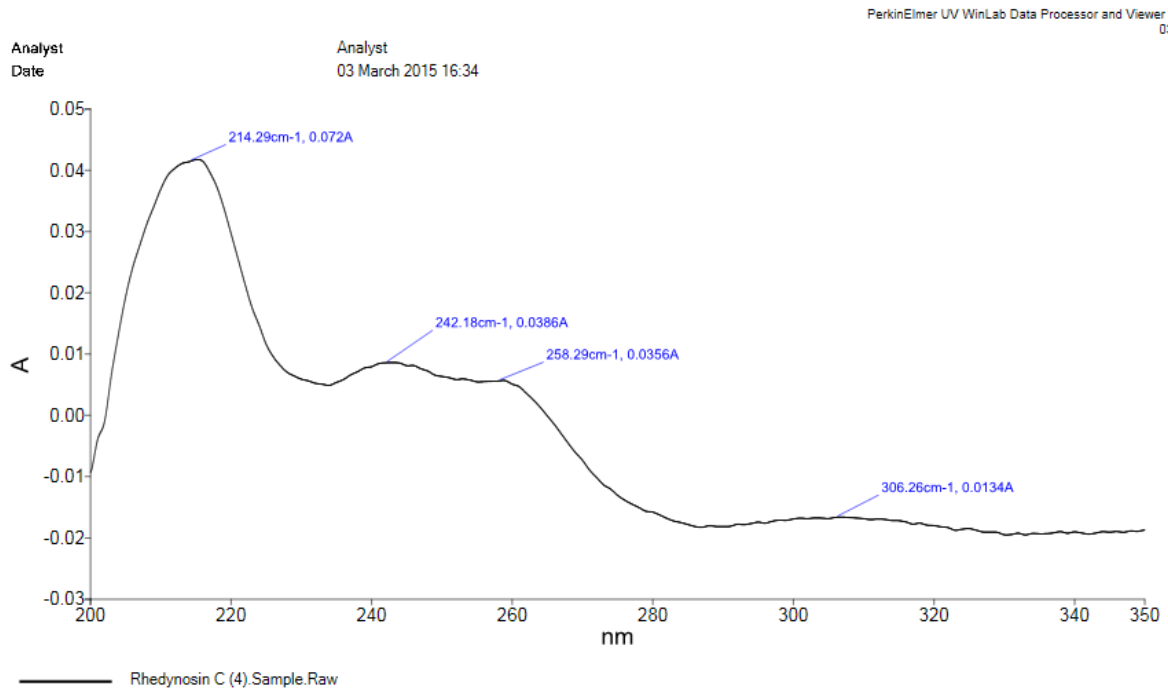

Figure S34. UV spectrum of compound 4 in $\mathrm{CH}_{3} \mathrm{OH}$. 


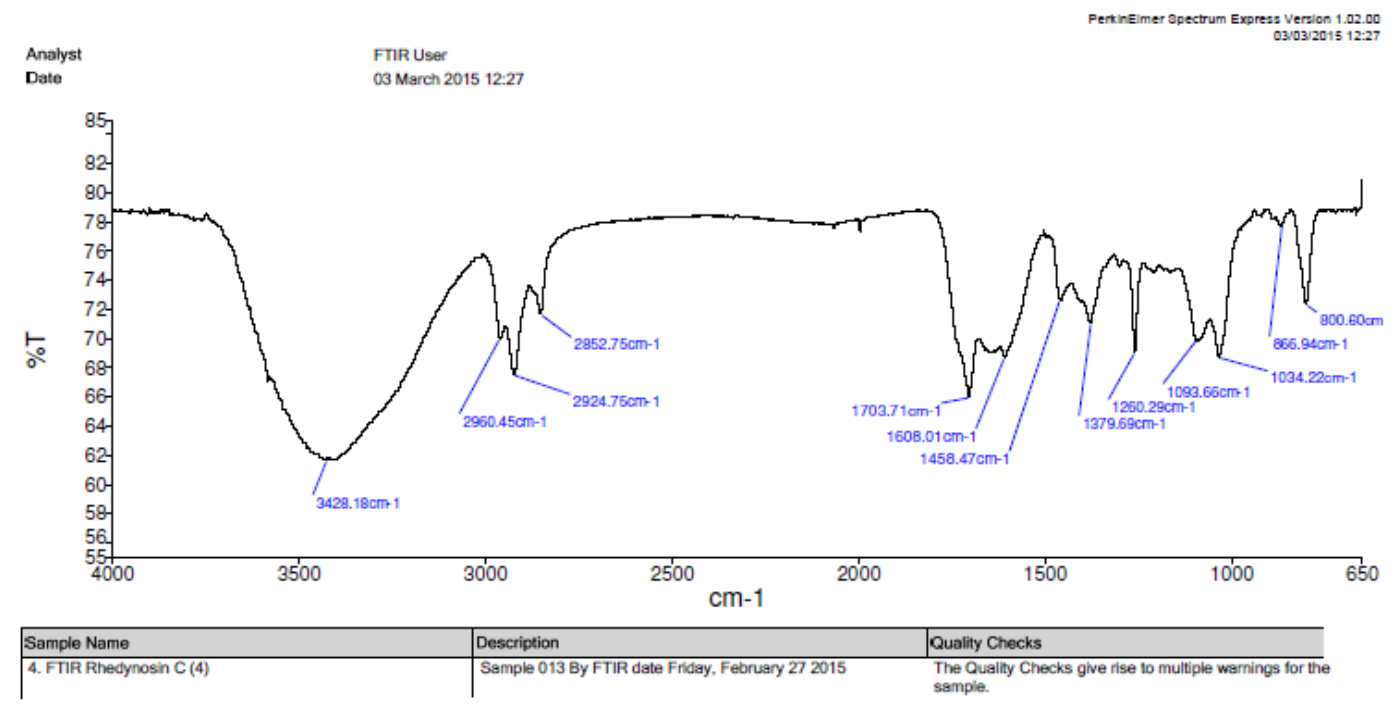

Figure S35. FT-IR spectrum of compound 4 in $\mathrm{CH}_{3} \mathrm{OH}$.

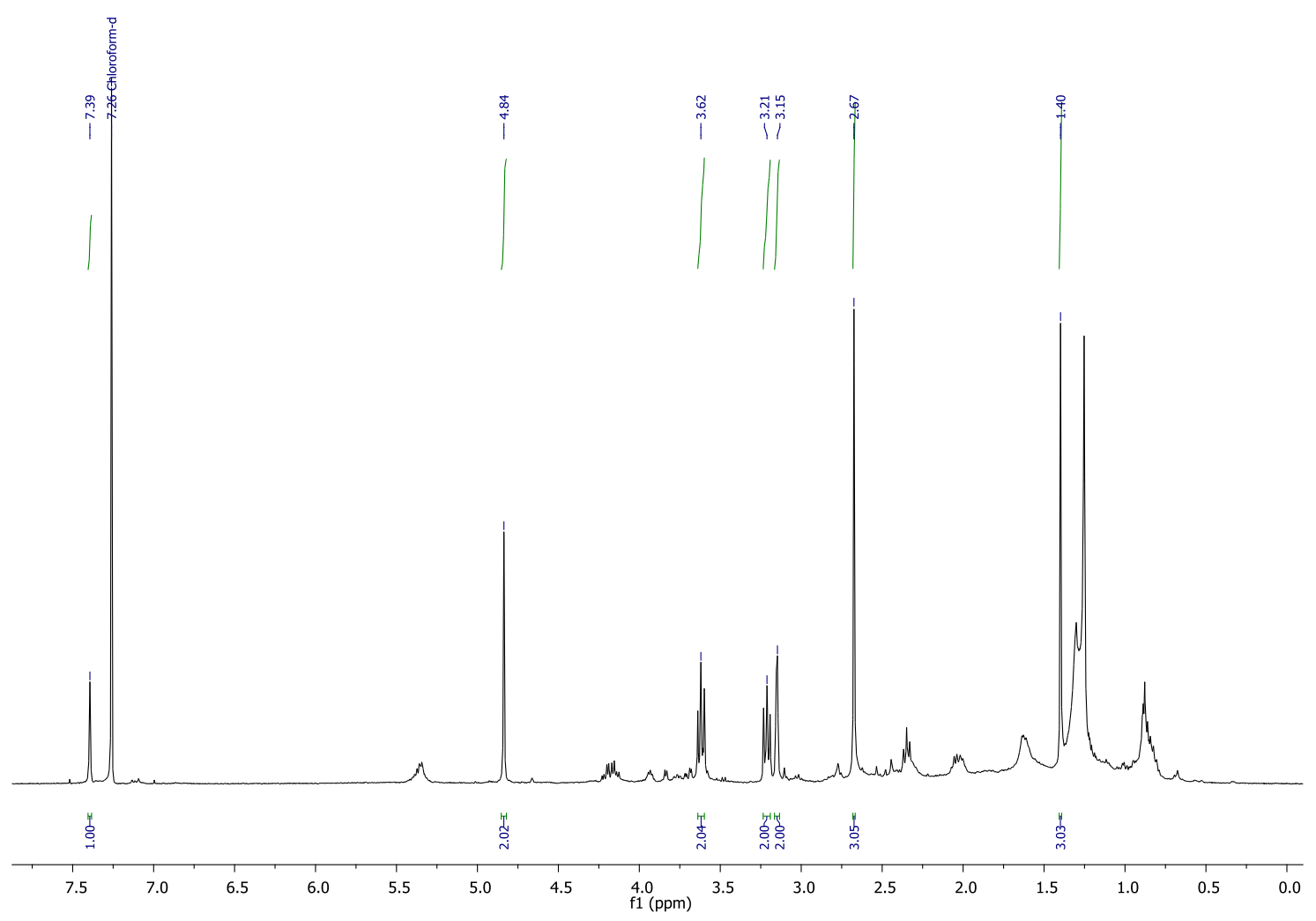

Figure S36. ${ }^{1} \mathrm{H} \mathrm{NMR}\left(\mathrm{CDCl}_{3}, 400 \mathrm{MHz}\right)$ spectrum of compound 5. 


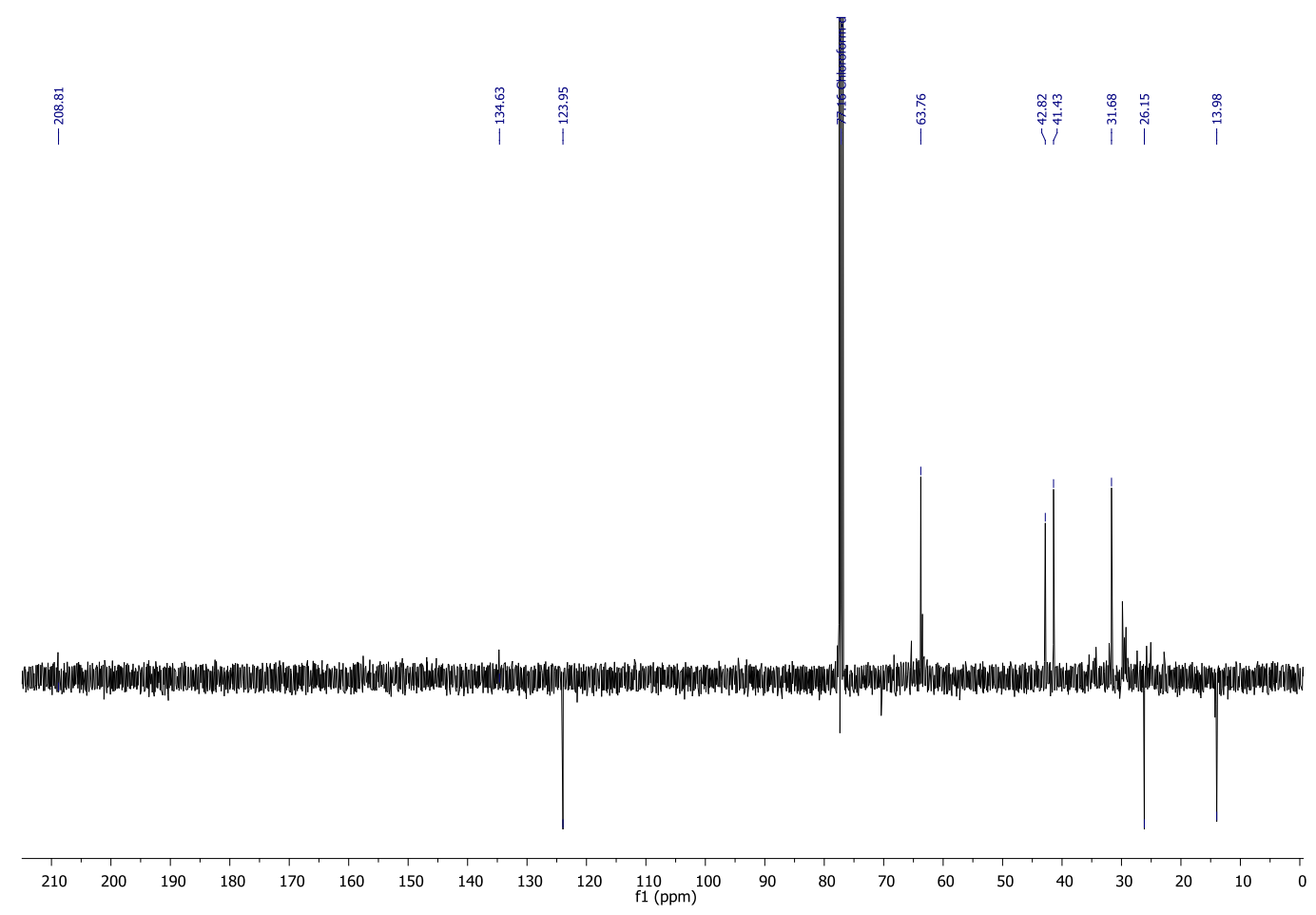

Figure S37. DEPTQ NMR $\left(\mathrm{CDCl}_{3}, 100 \mathrm{MHz}\right)$ spectrum of compound 5.

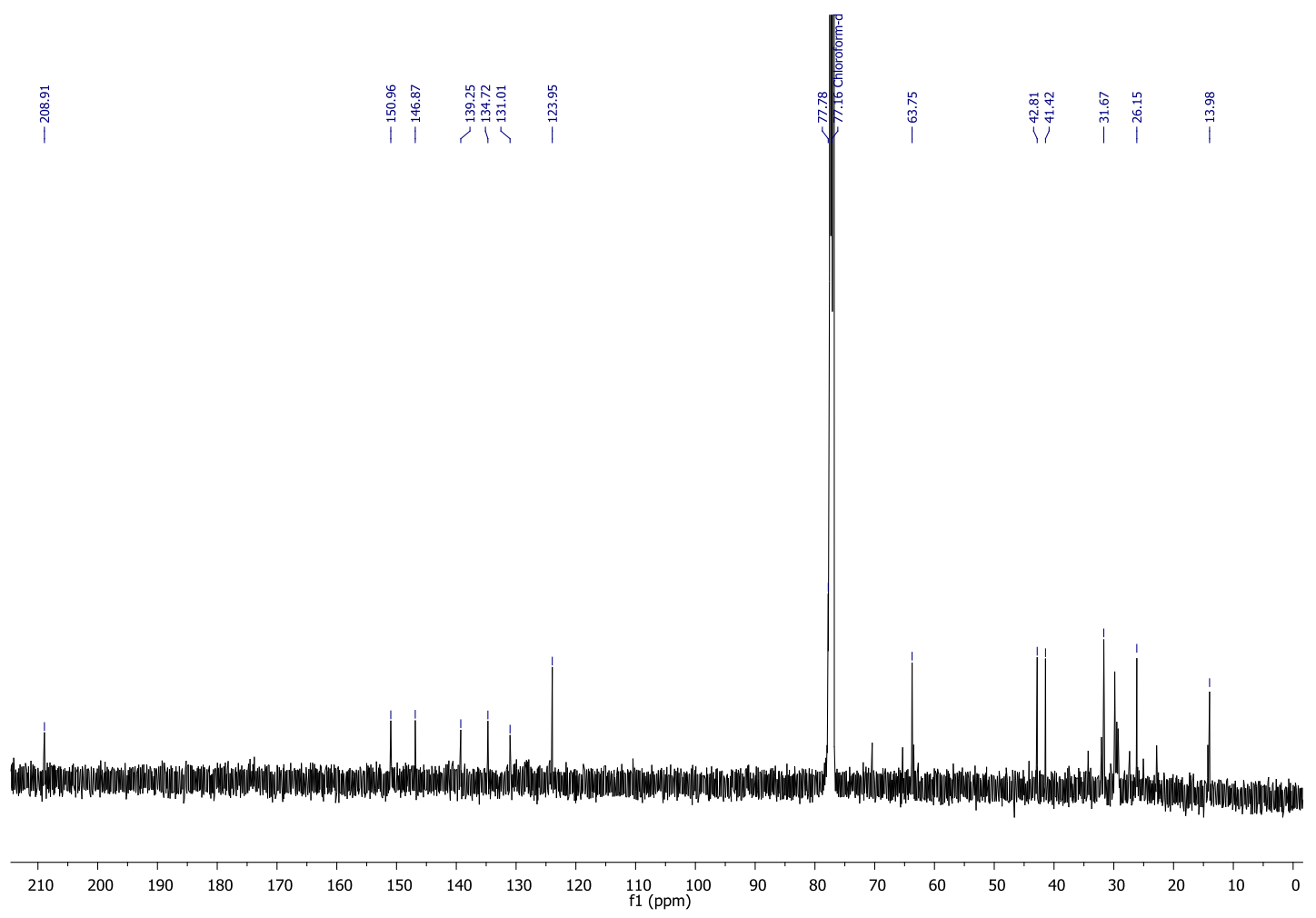

Figure S38. ${ }^{13} \mathrm{C} \mathrm{NMR}\left(\mathrm{CDCl}_{3}, 100 \mathrm{MHz}\right)$ spectrum of compound 5. 


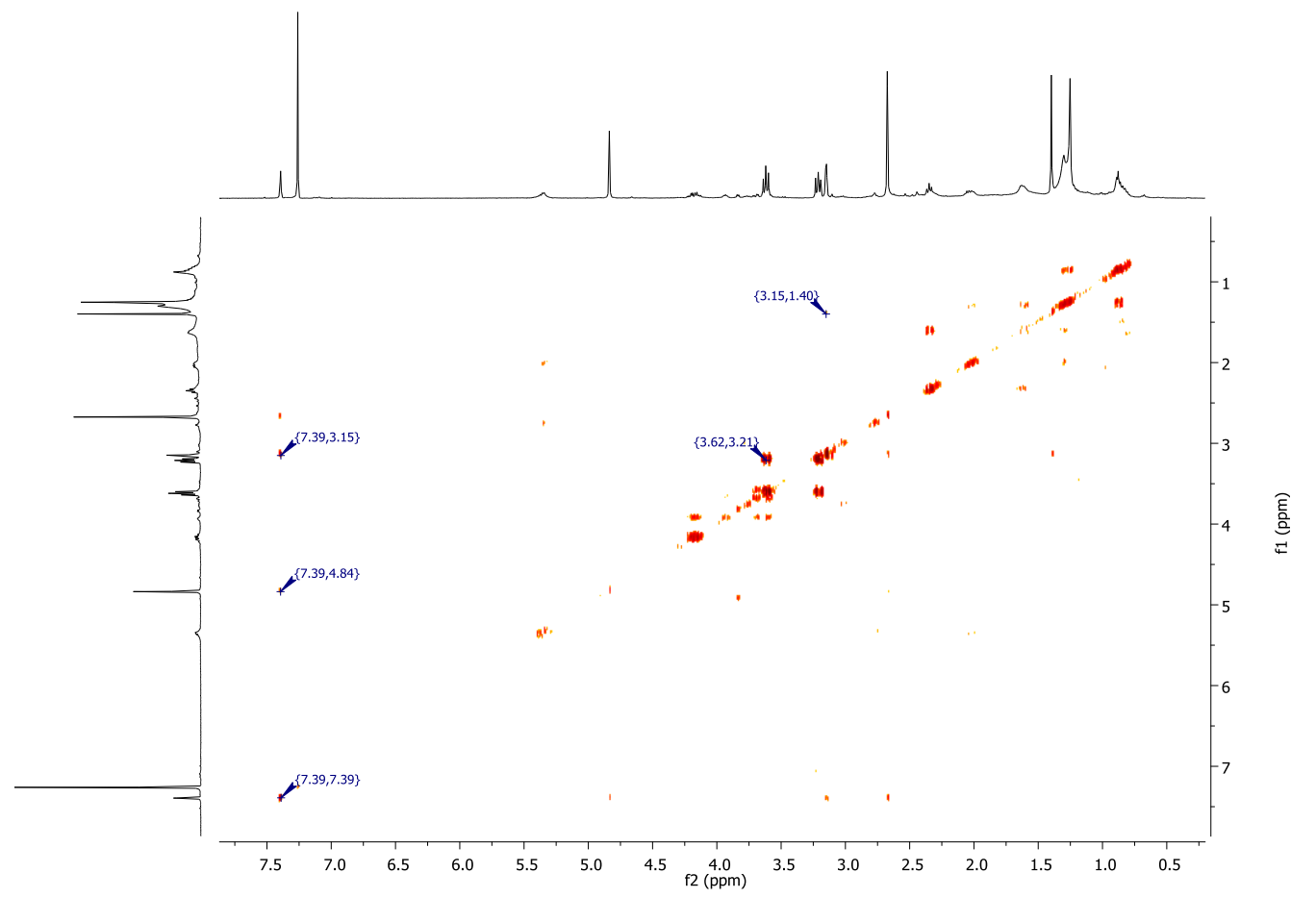

Figure S39. ${ }^{1} \mathrm{H}-{ }^{1} \mathrm{H}$ COSY NMR spectrum of compound 5 .

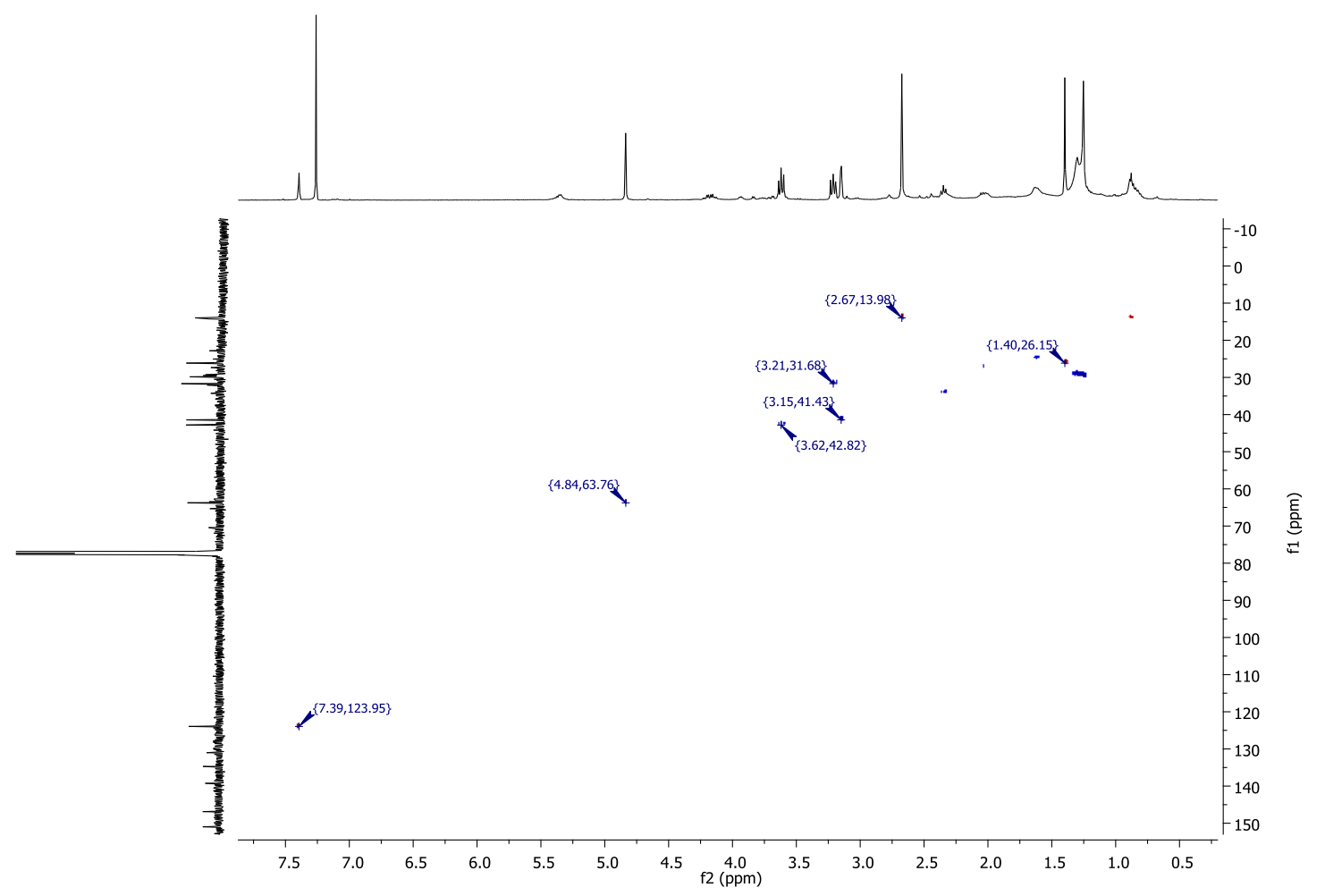

Figure S40. HSQC NMR spectrum of compound 5. 


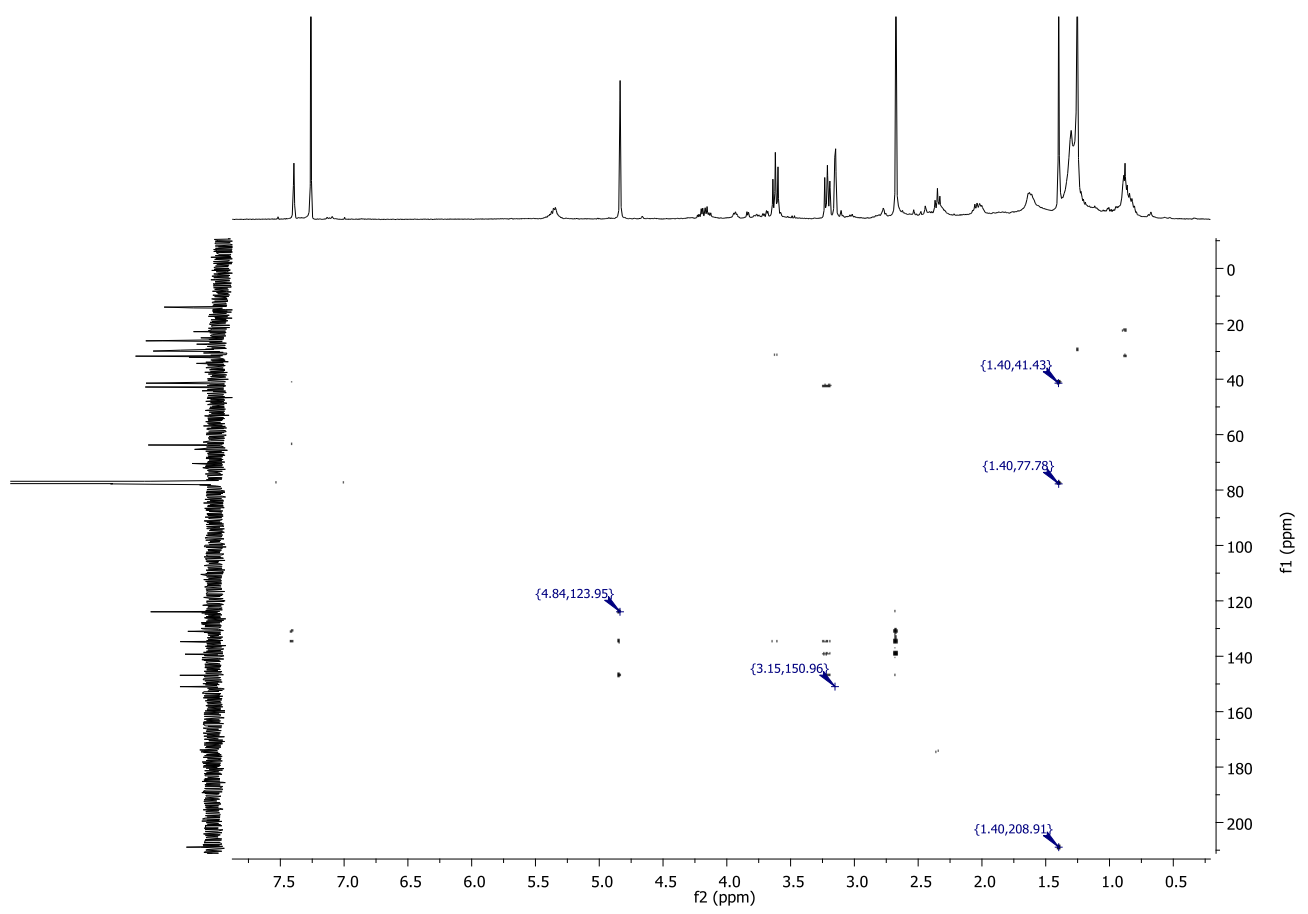

Figure S41. HMBC NMR spectrum of compound 5.

pos \#8 RT: 0.12 AV: 1 NL: $1.73 E 5$

T: FTMS + p NSI u SIM ms [259.00-279.00]

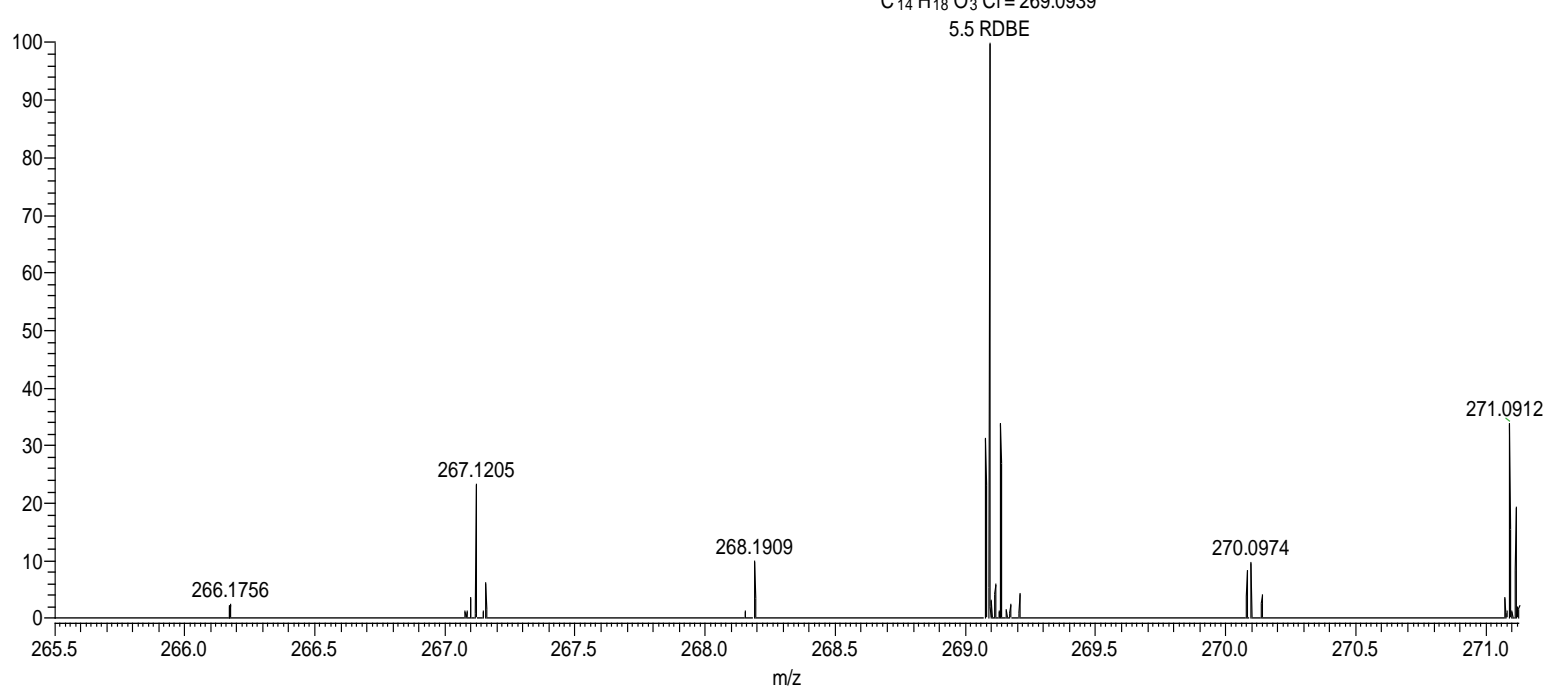

Figure S42. FT-ICR-MS spectrum of compound 5. 


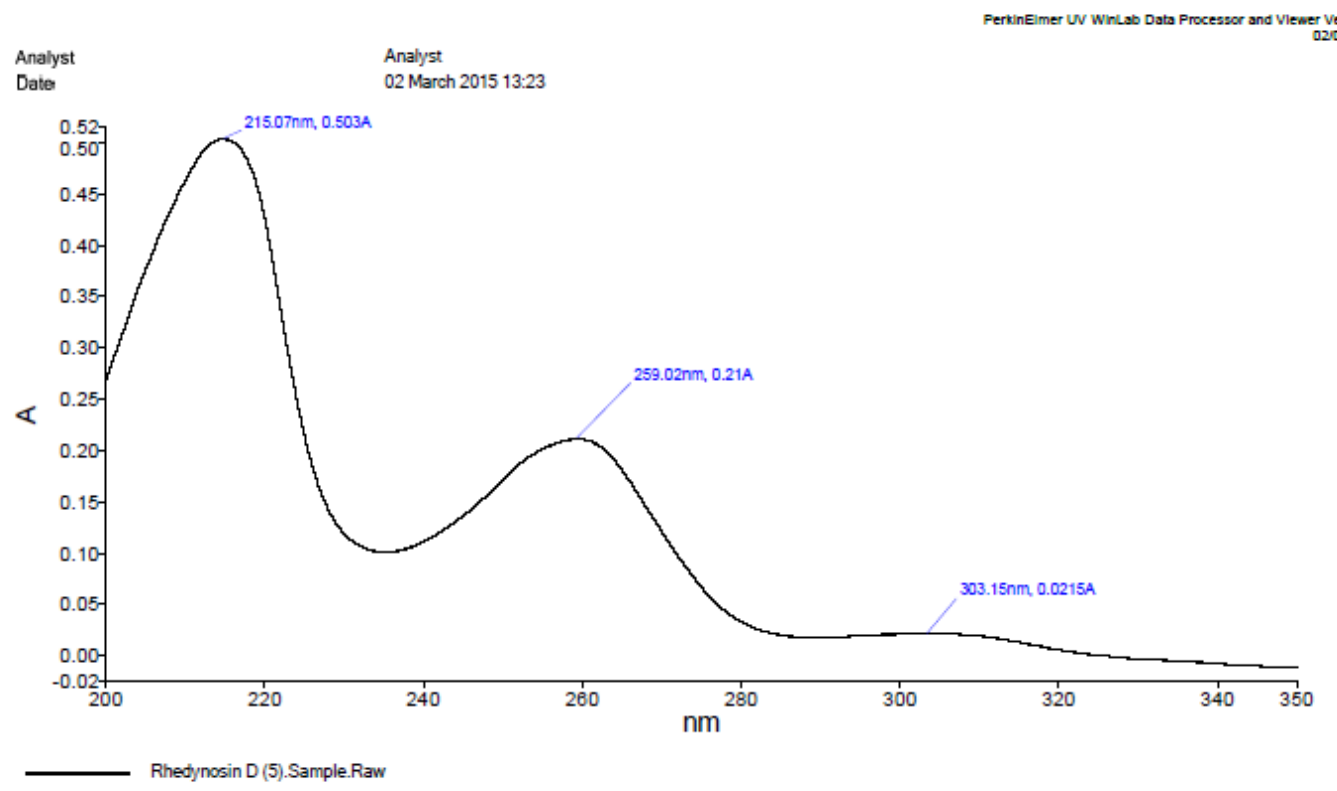

Figure S43. UV spectrum of compound 5 in $\mathrm{CH}_{3} \mathrm{OH}$.

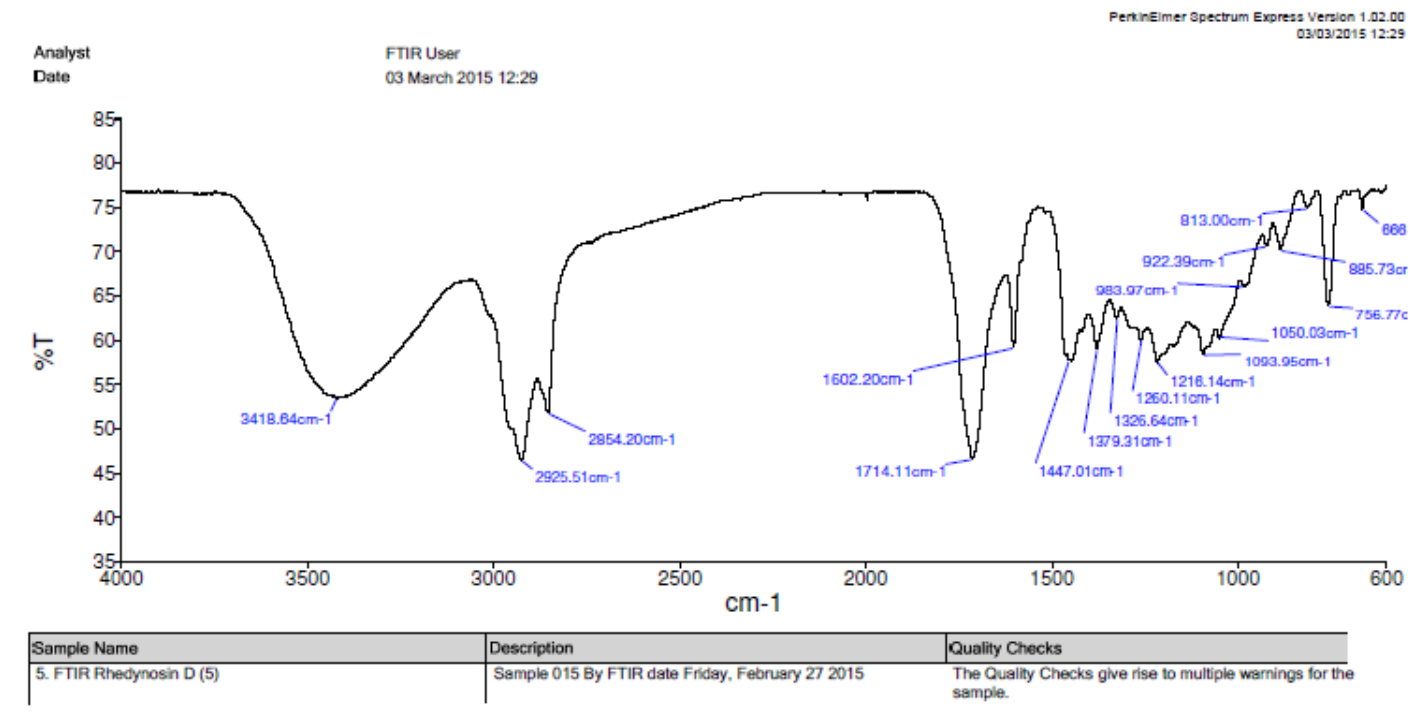

Figure S44. FT-IR spectrum of compound 5 in $\mathrm{CHCl}_{3}$. 


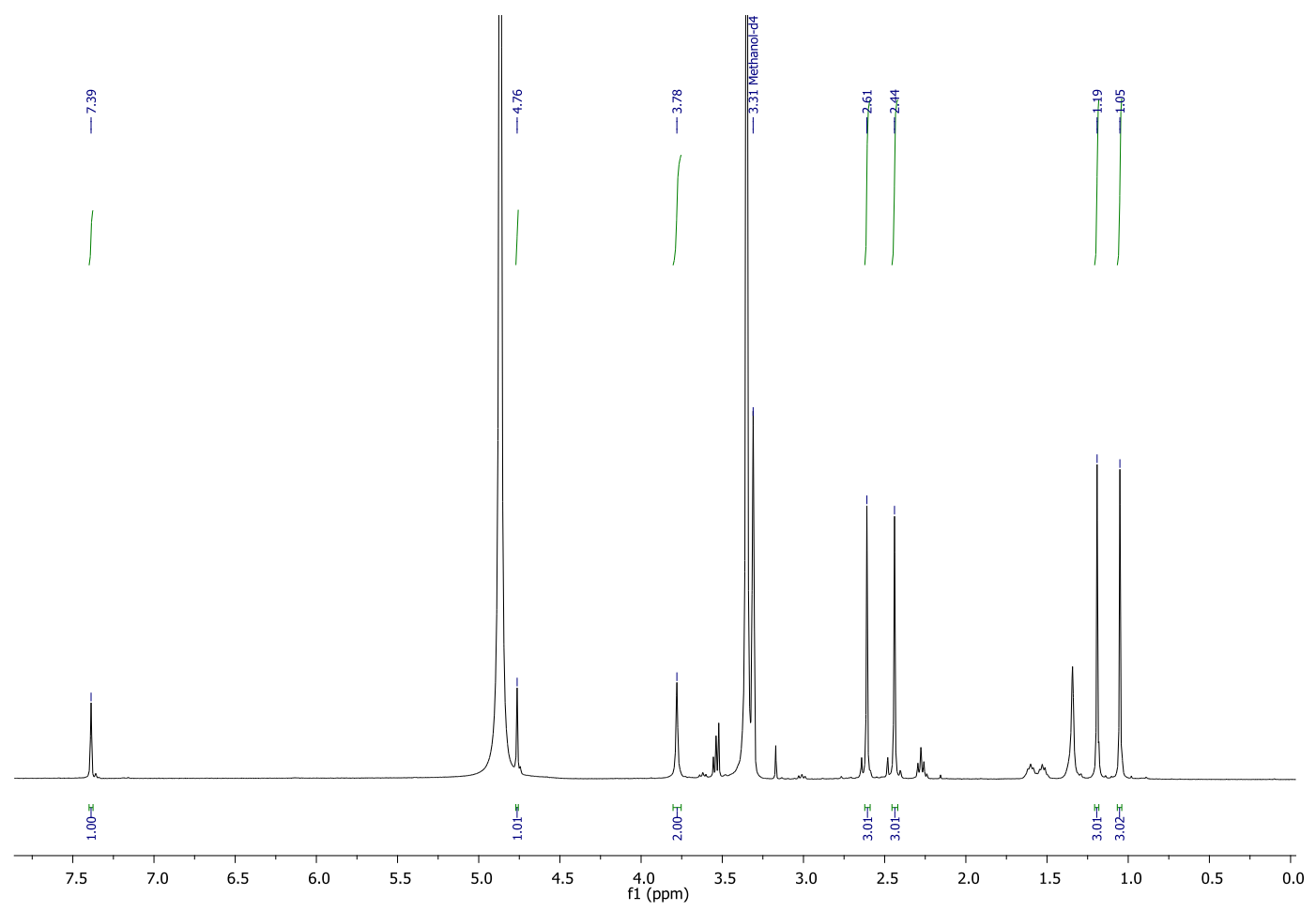

Figure S45. ${ }^{1} \mathrm{H}$ NMR $\left(\mathrm{CD}_{3} \mathrm{OD}, 400 \mathrm{MHz}\right)$ spectrum of compound 6.

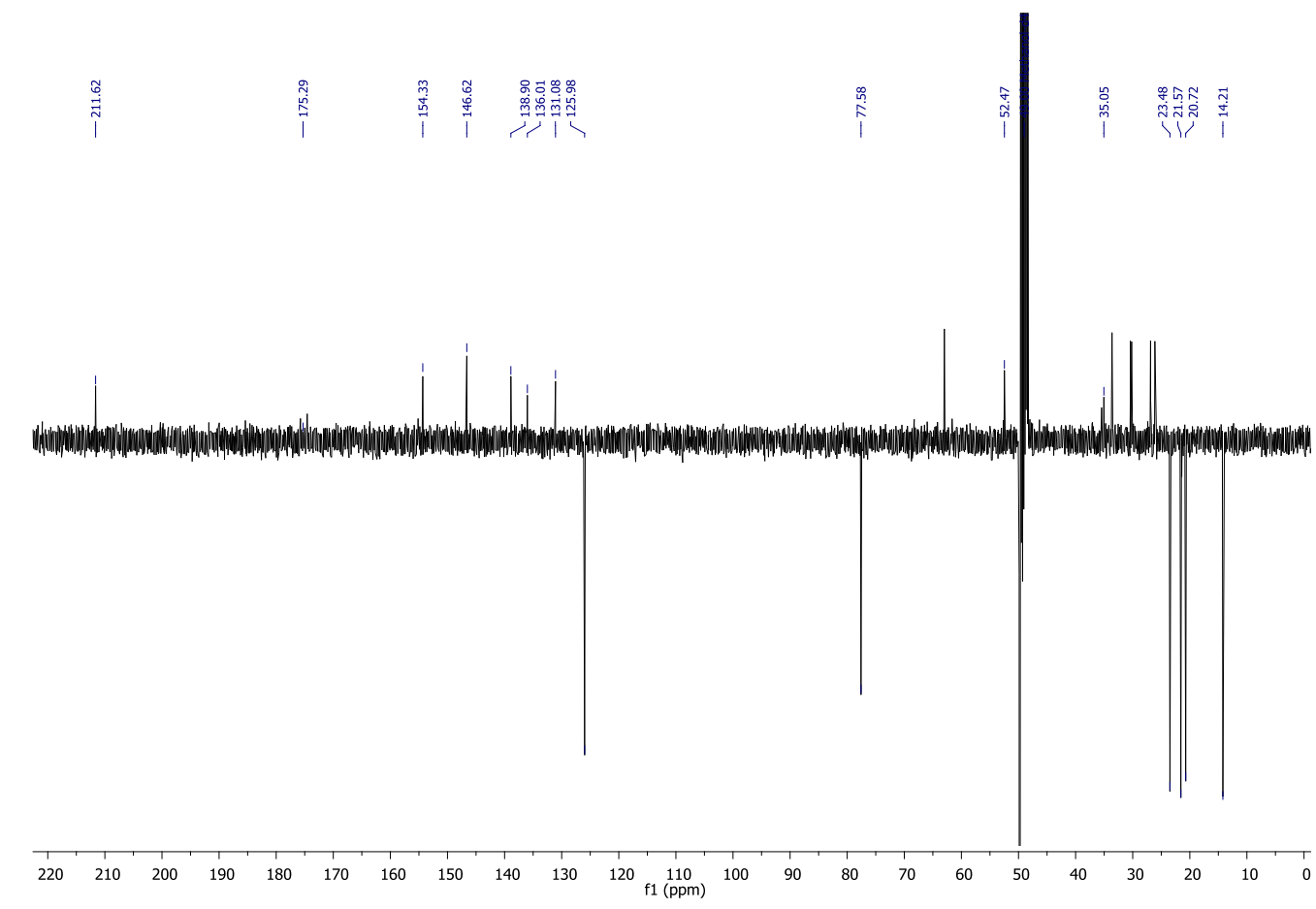

Figure S46. DEPTQ NMR (CD $\left.\mathrm{CD}_{3} \mathrm{OD} 100 \mathrm{MHz}\right)$ spectrum of compound 6. 


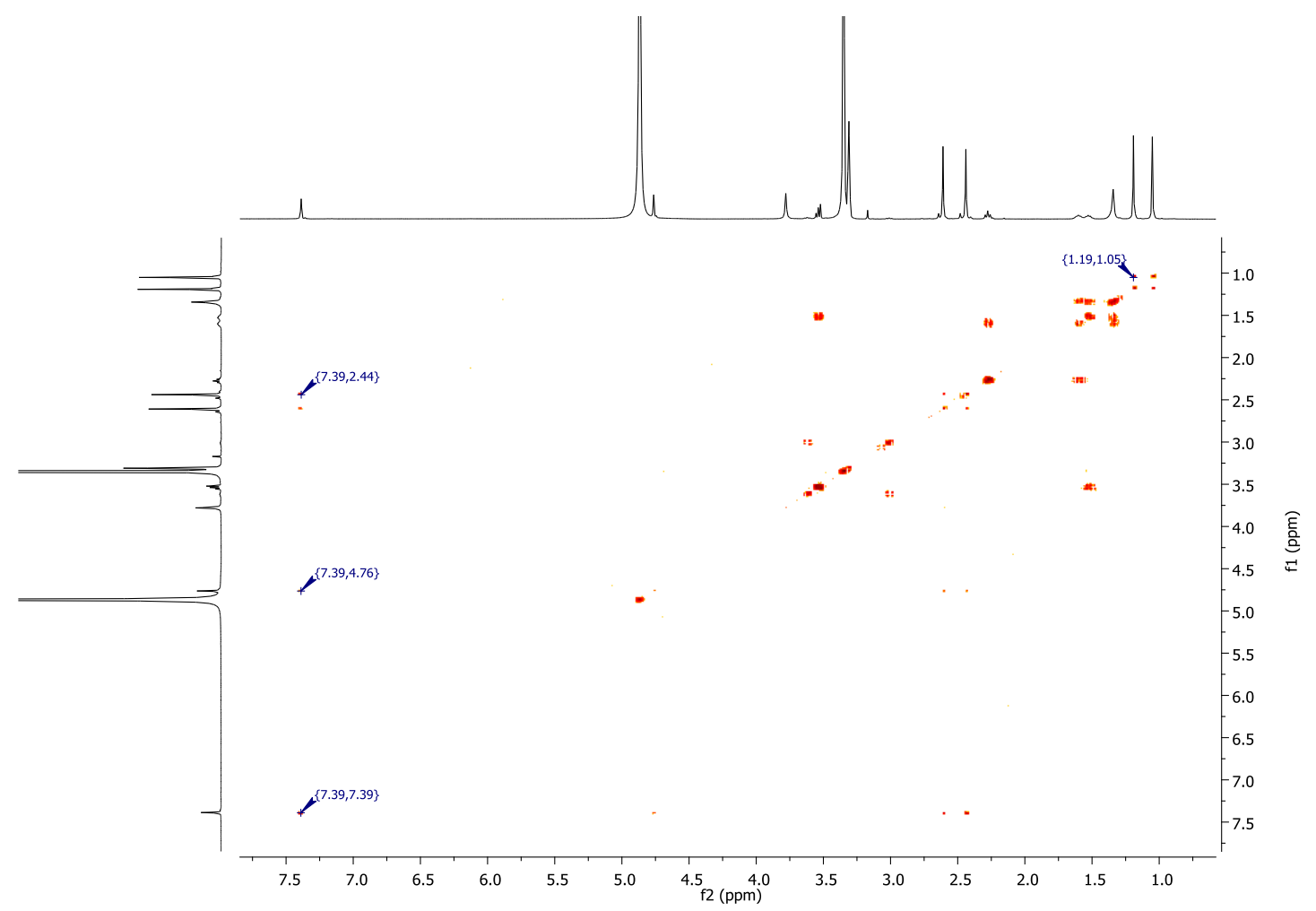

Figure S47. ${ }^{1} \mathrm{H}-{ }^{1} \mathrm{H}$ COSY NMR spectrum of compound 6.

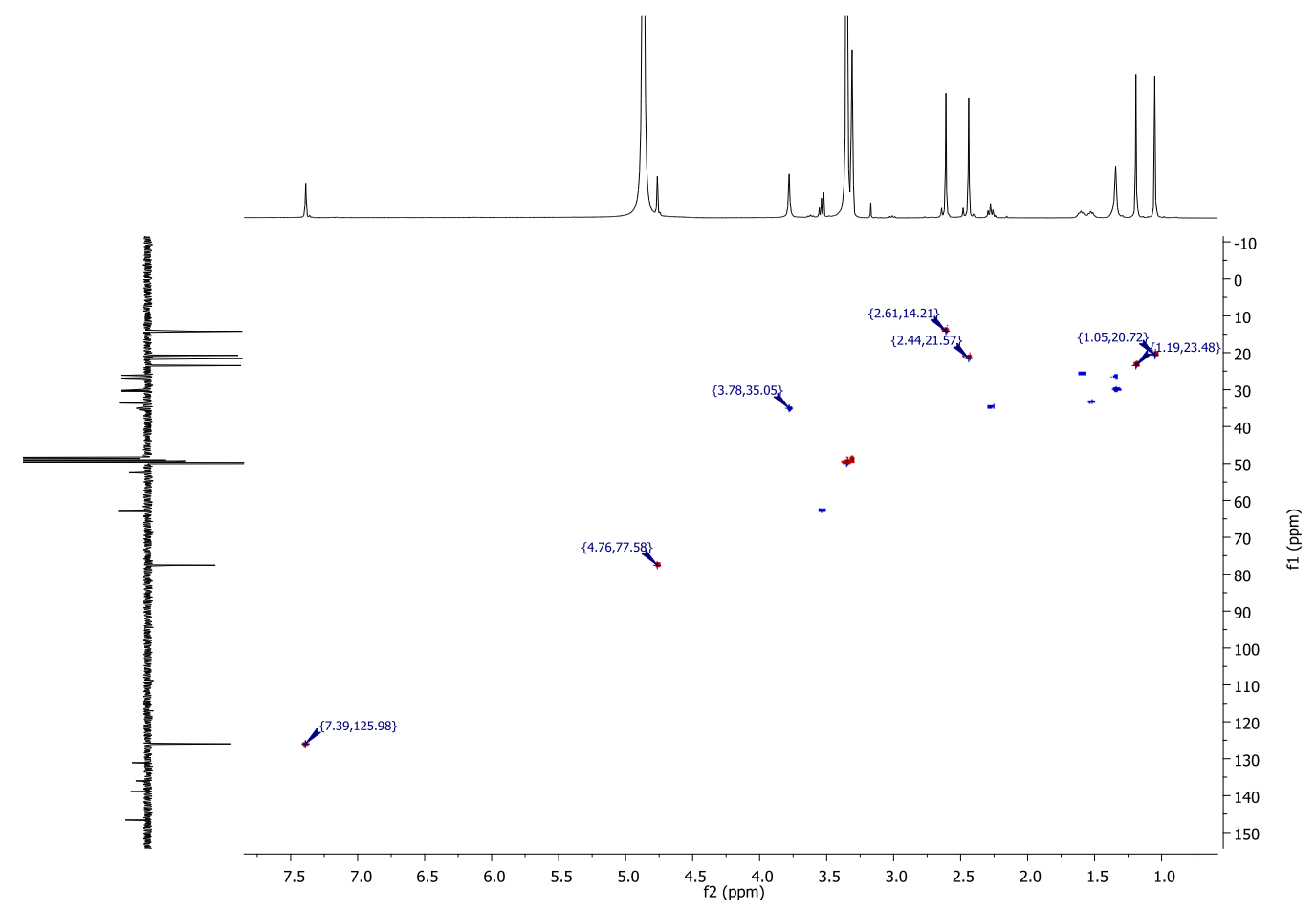

Figure S48. HSQC NMR spectrum of compound 6. 


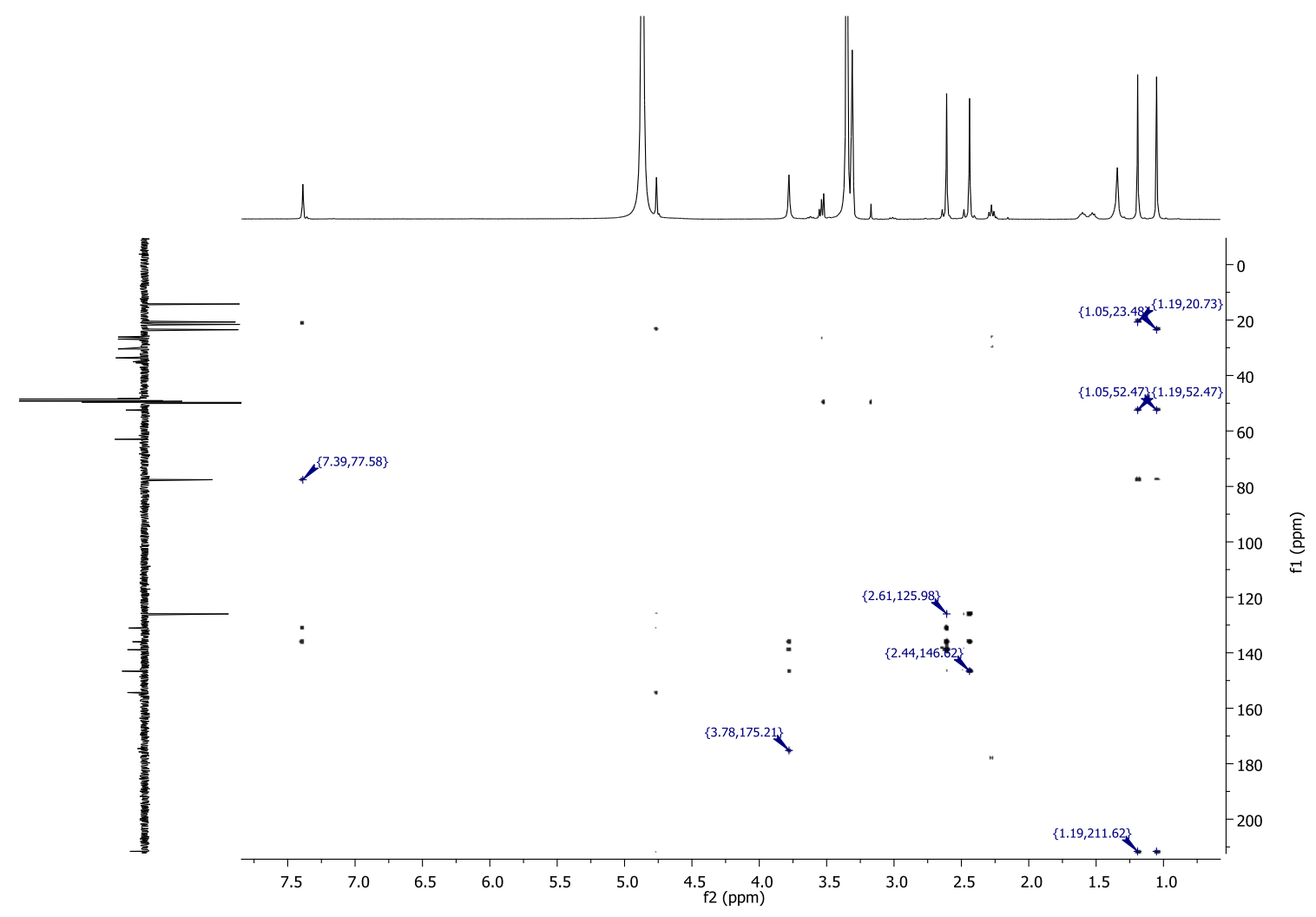

Figure S49. HMBC NMR spectrum of compound 6.

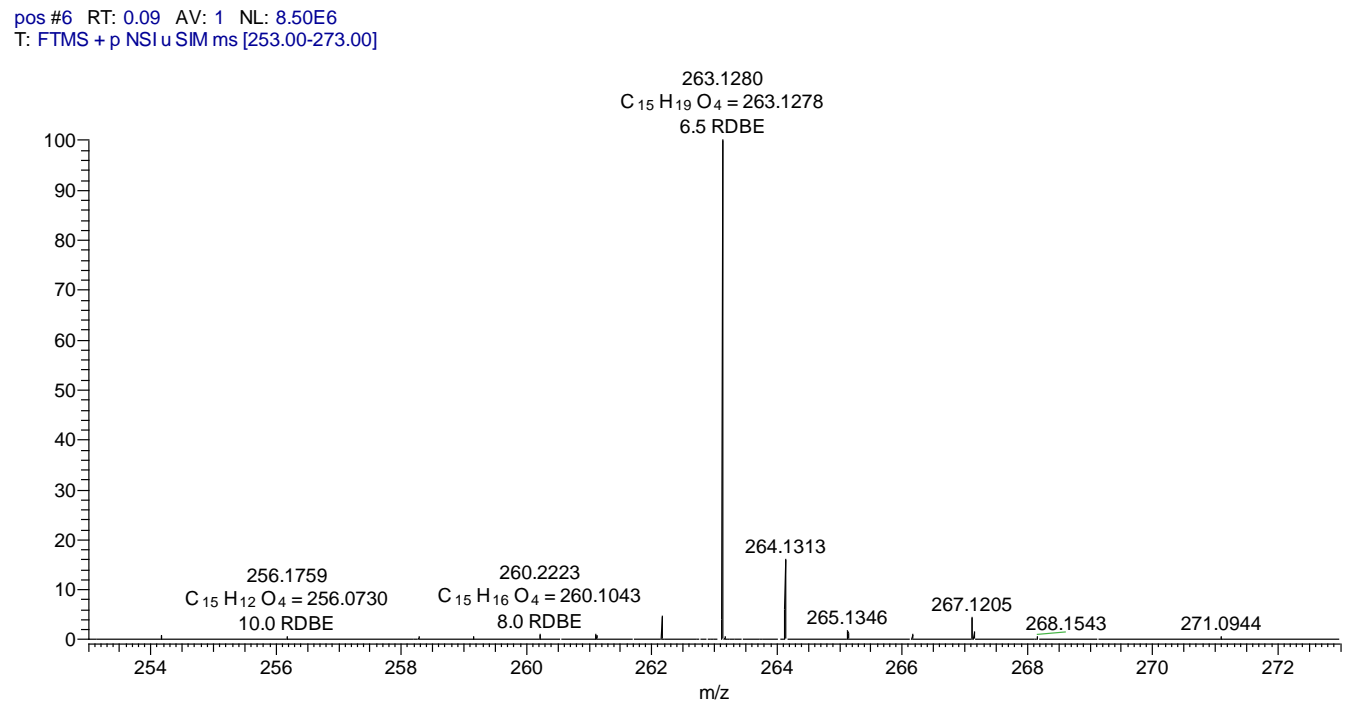

Figure S50. FT-ICR-MS spectrum of compound 6. 


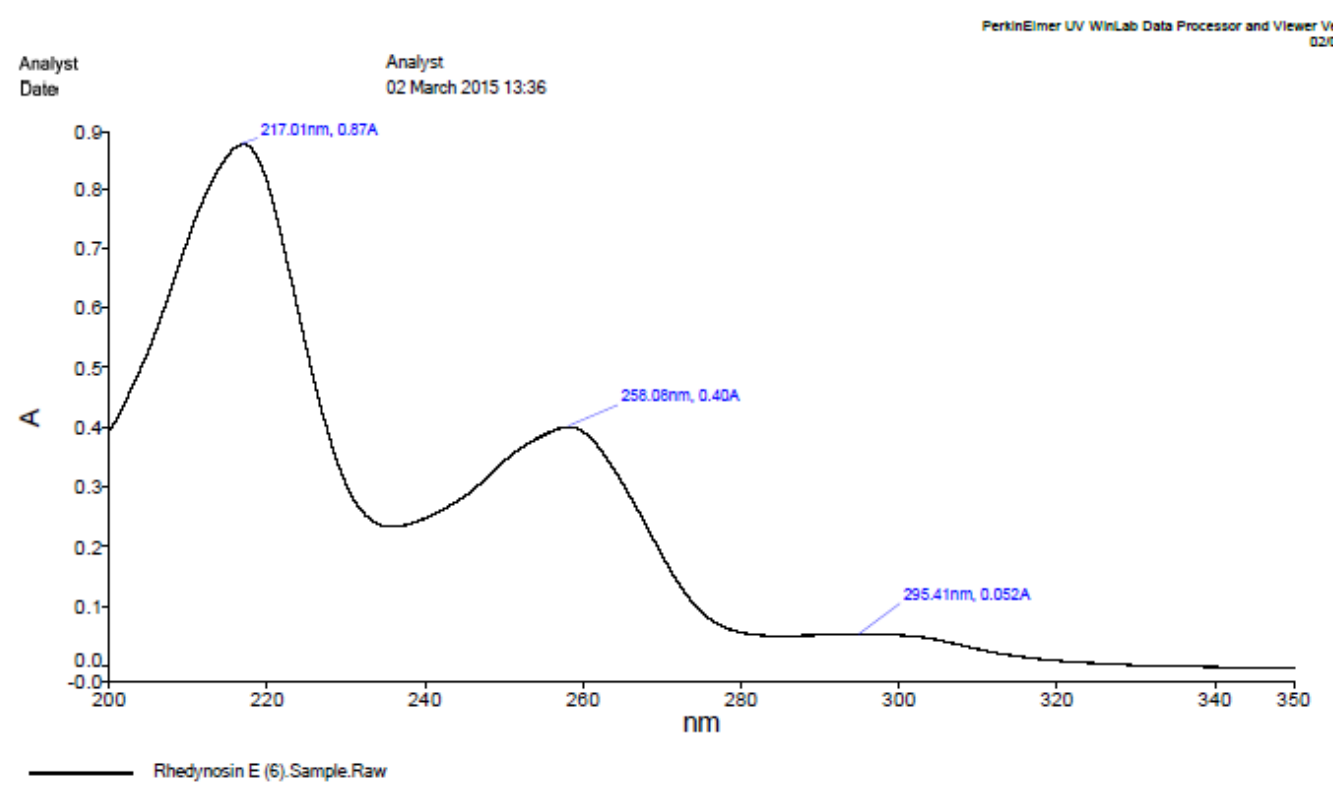

Figure S51. UV spectrum of compound 6 in $\mathrm{CH}_{3} \mathrm{OH}$.

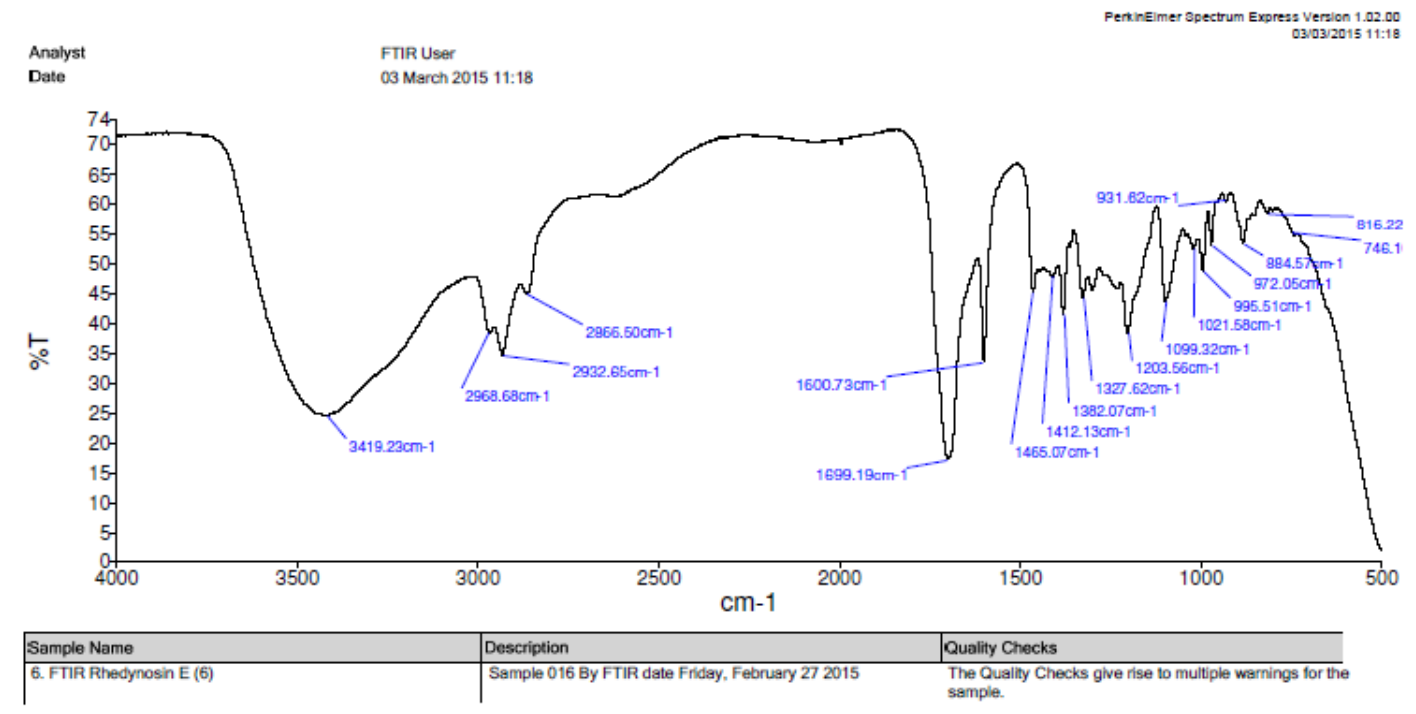

Figure S52. FT-IR spectrum of compound 6 in $\mathrm{CH}_{3} \mathrm{OH}$. 


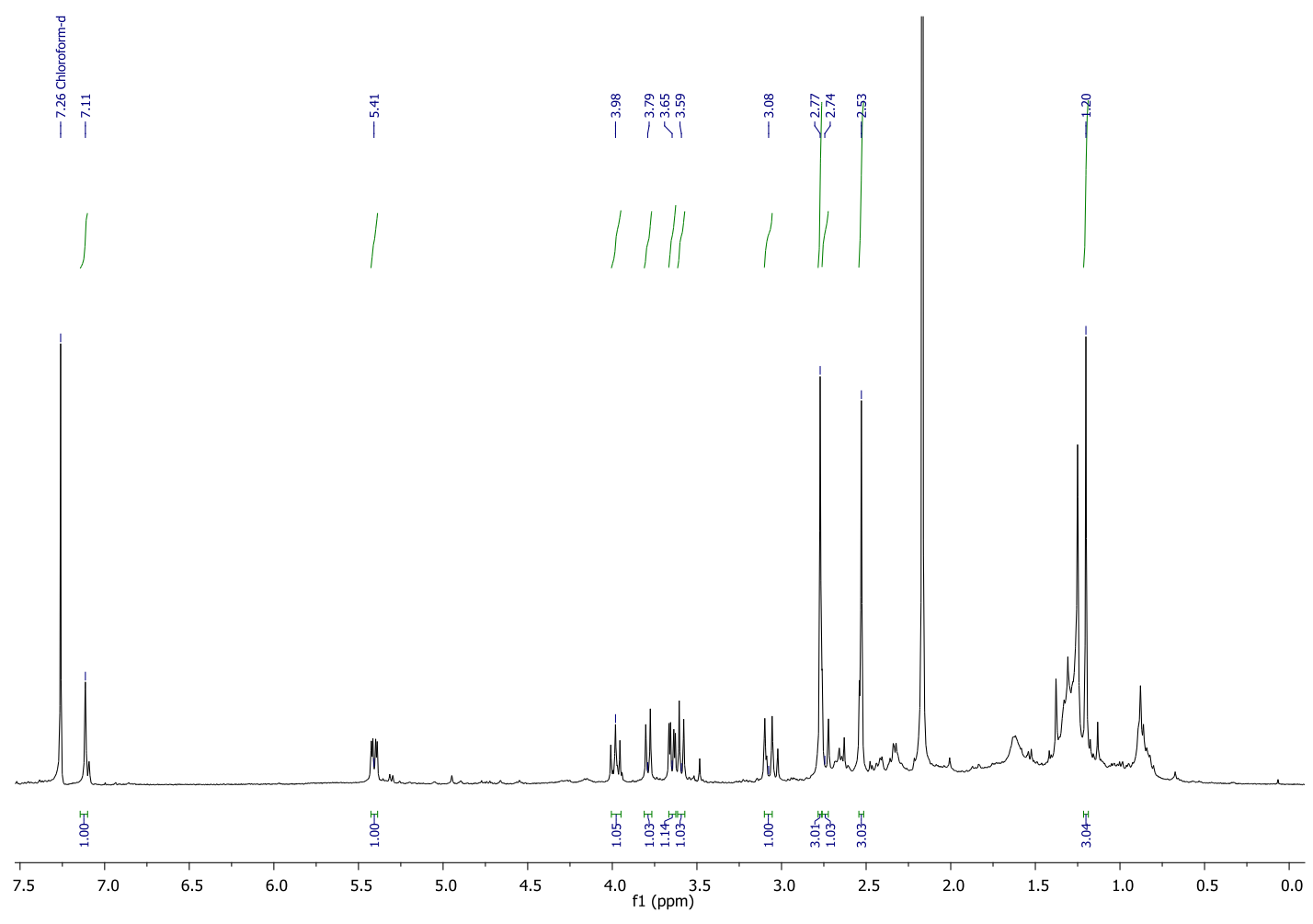

Figure S53. ${ }^{1} \mathrm{H} \mathrm{NMR}\left(\mathrm{CDCl}_{3}, 400 \mathrm{MHz}\right)$ spectrum of compound 7.

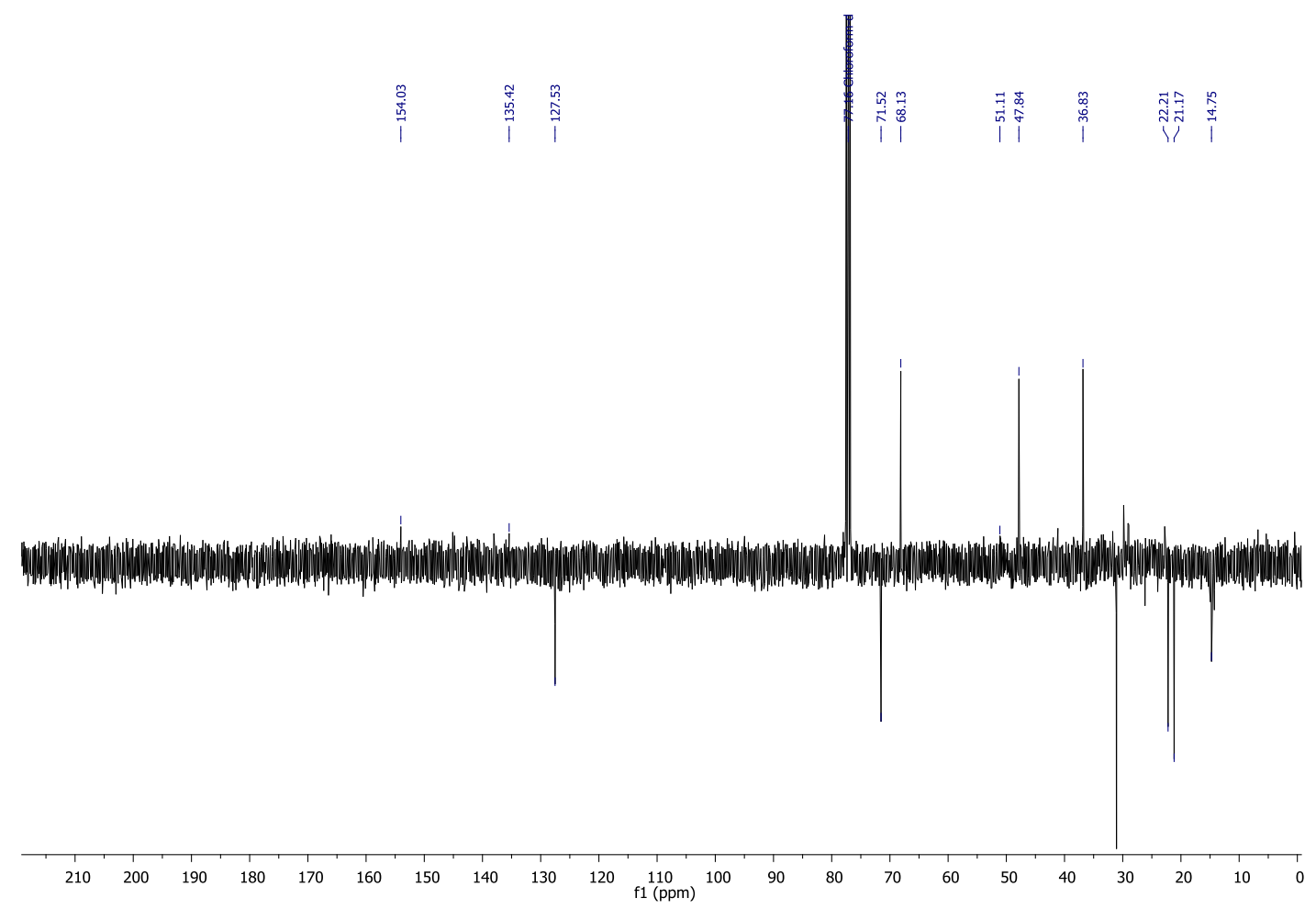

Figure S54. DEPTQ NMR $\left(\mathrm{CDCl}_{3}, 100 \mathrm{MHz}\right)$ spectrum of compound 7. 


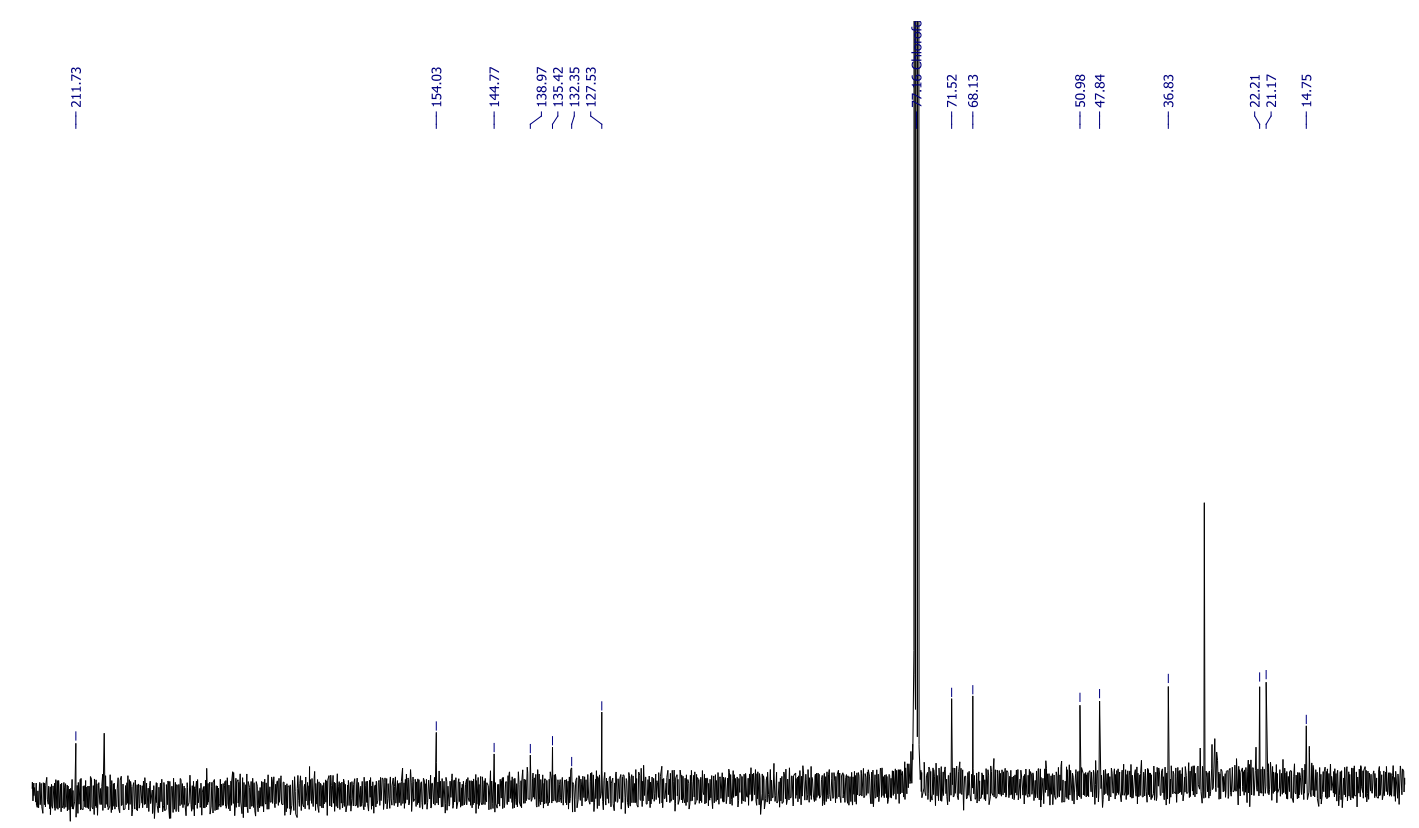

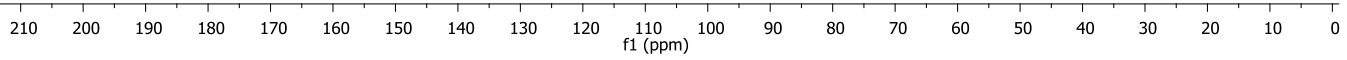

Figure S55. ${ }^{13} \mathrm{C} \mathrm{NMR}\left(\mathrm{CDCl}_{3}, 100 \mathrm{MHz}\right)$ spectrum of compound 7.

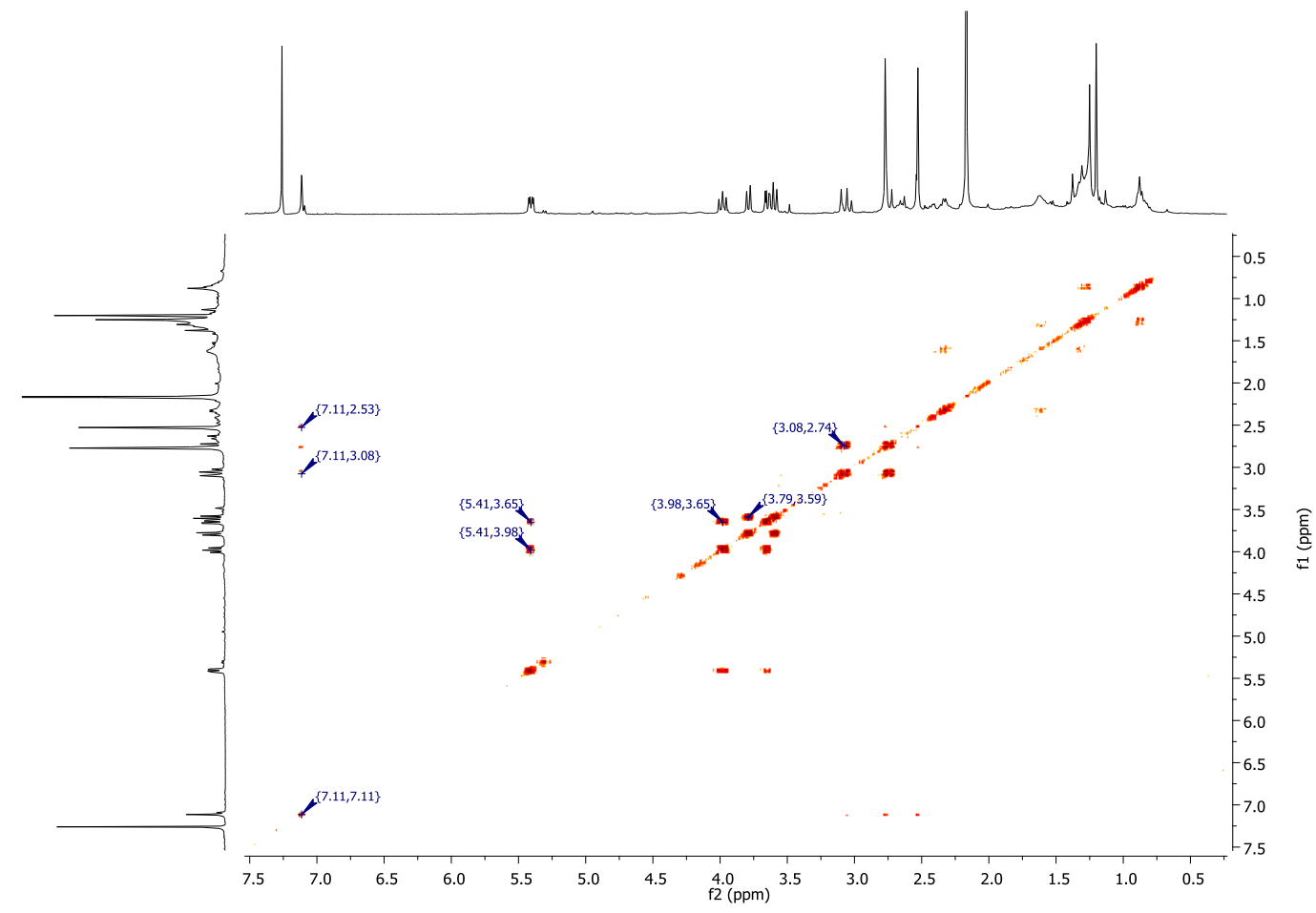

Figure S56. ${ }^{1} \mathrm{H}-{ }^{1} \mathrm{H}$ COSY NMR spectrum of compound 7. 


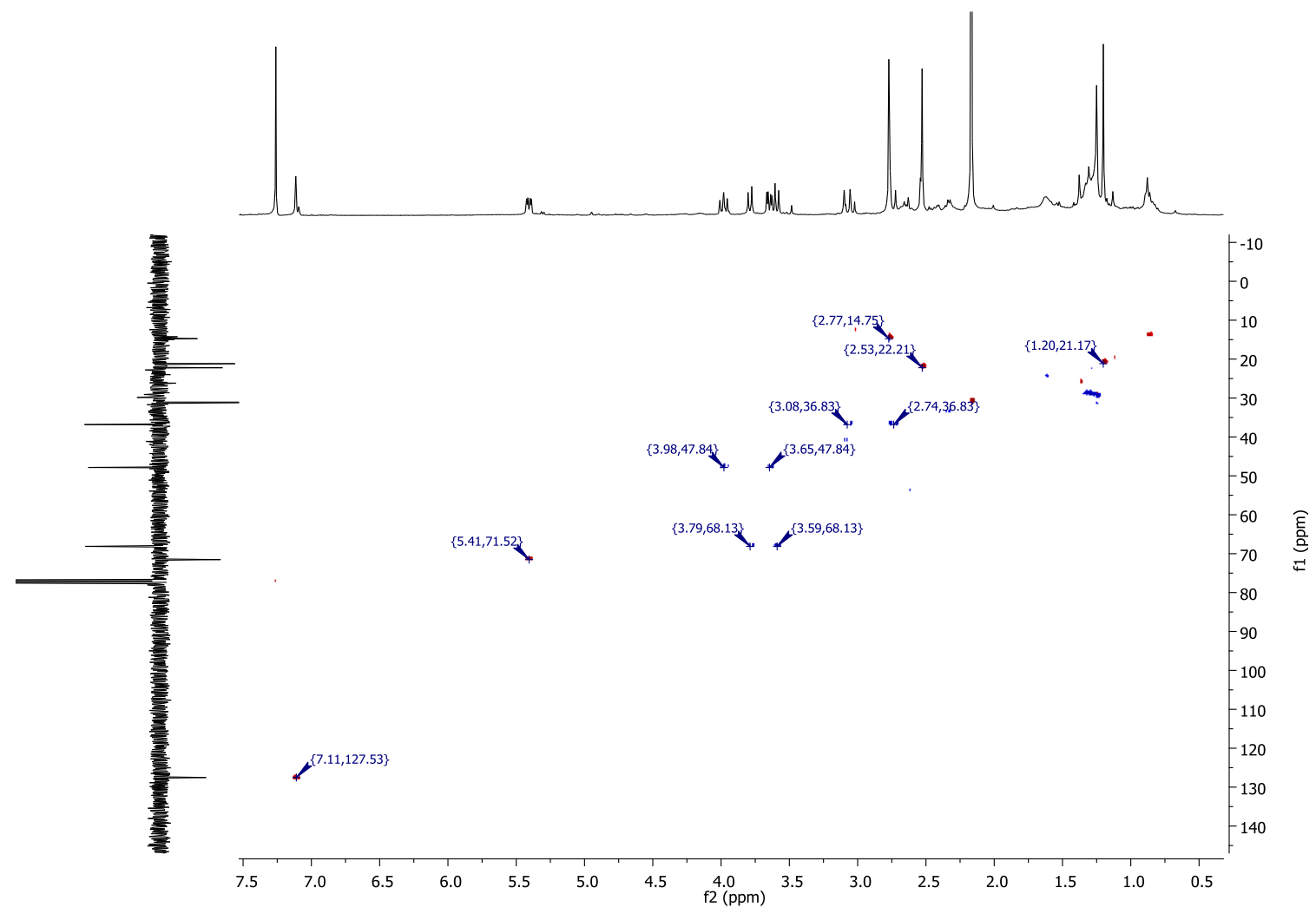

Figure S57. HSQC NMR spectrum of compound 7.

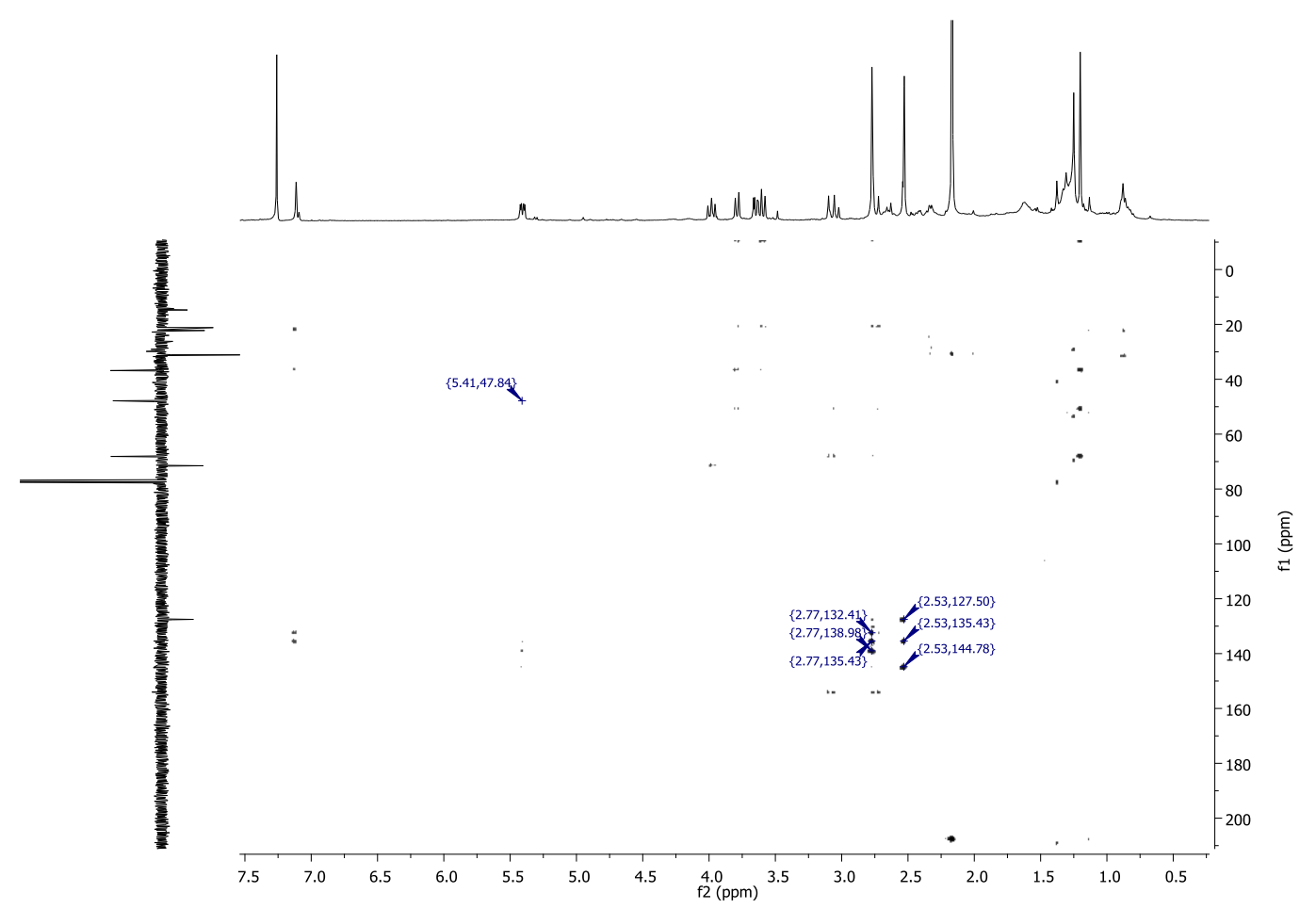

Figure S58. HMBC NMR spectrum of compound 7. 


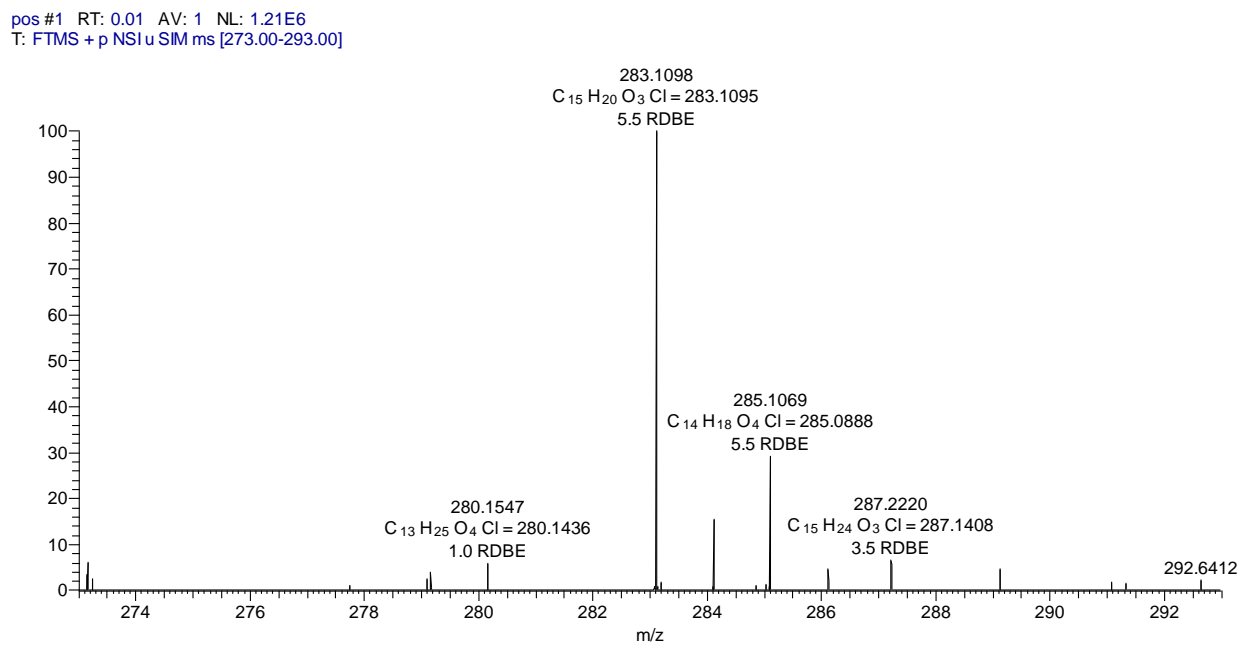

Figure S59. FT-ICR-MS spectrum of compound 7.

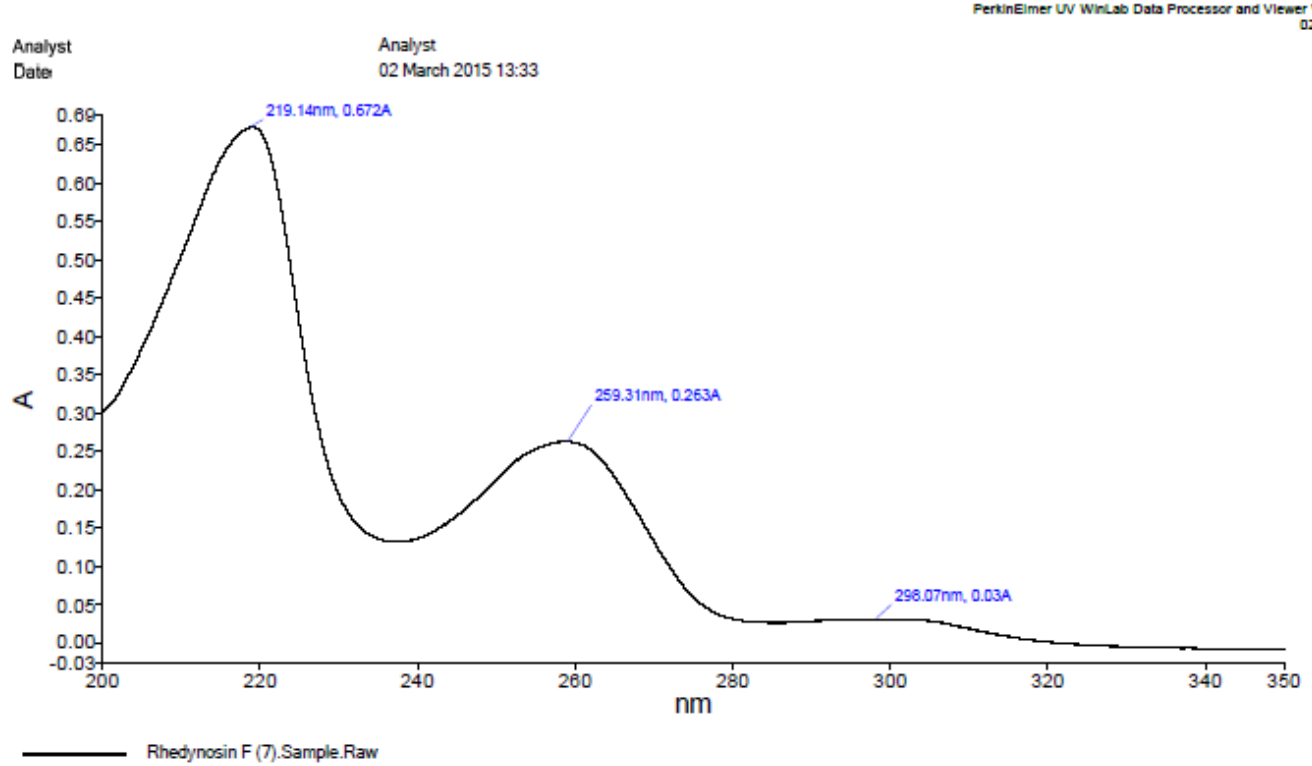

Figure S60. UV spectrum of compound 7 in $\mathrm{CH}_{3} \mathrm{OH}$. 


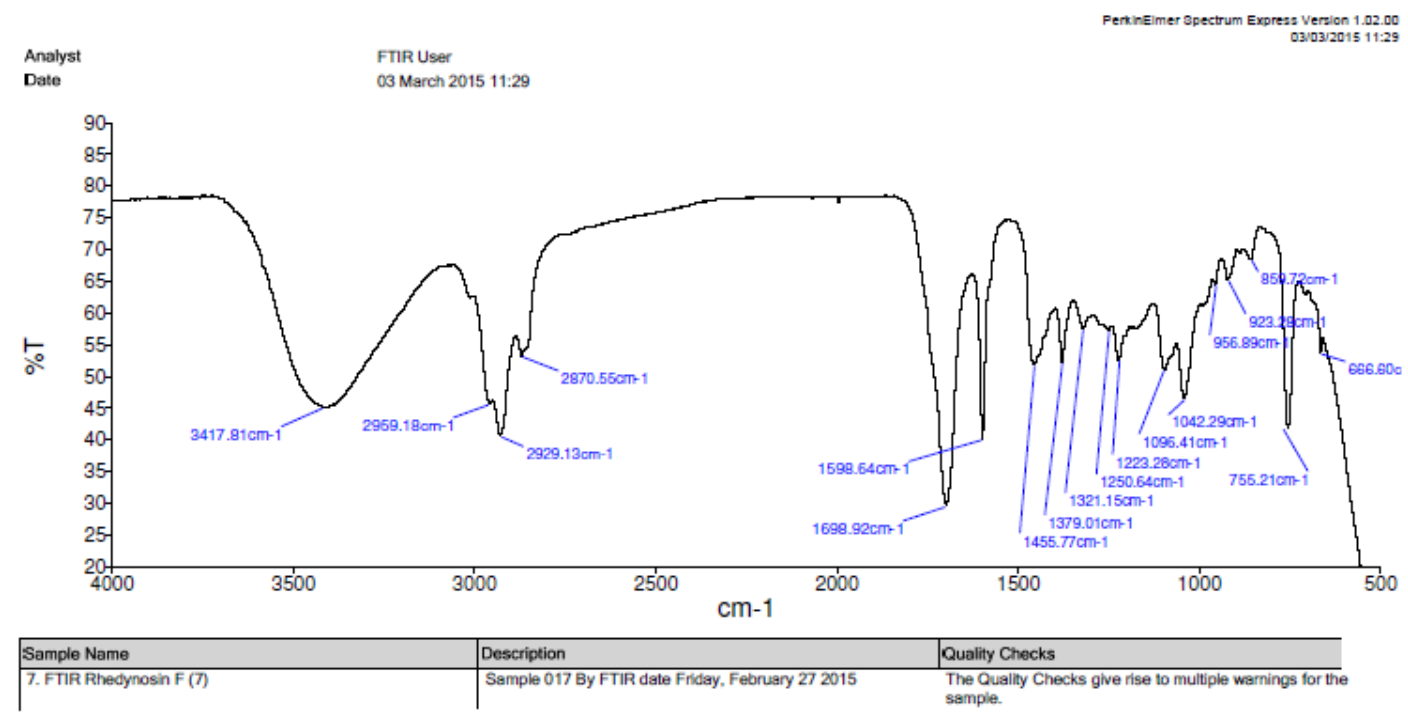

Figure S61. FT-IR spectrum of compound 7 in $\mathrm{CHCl}_{3}$.

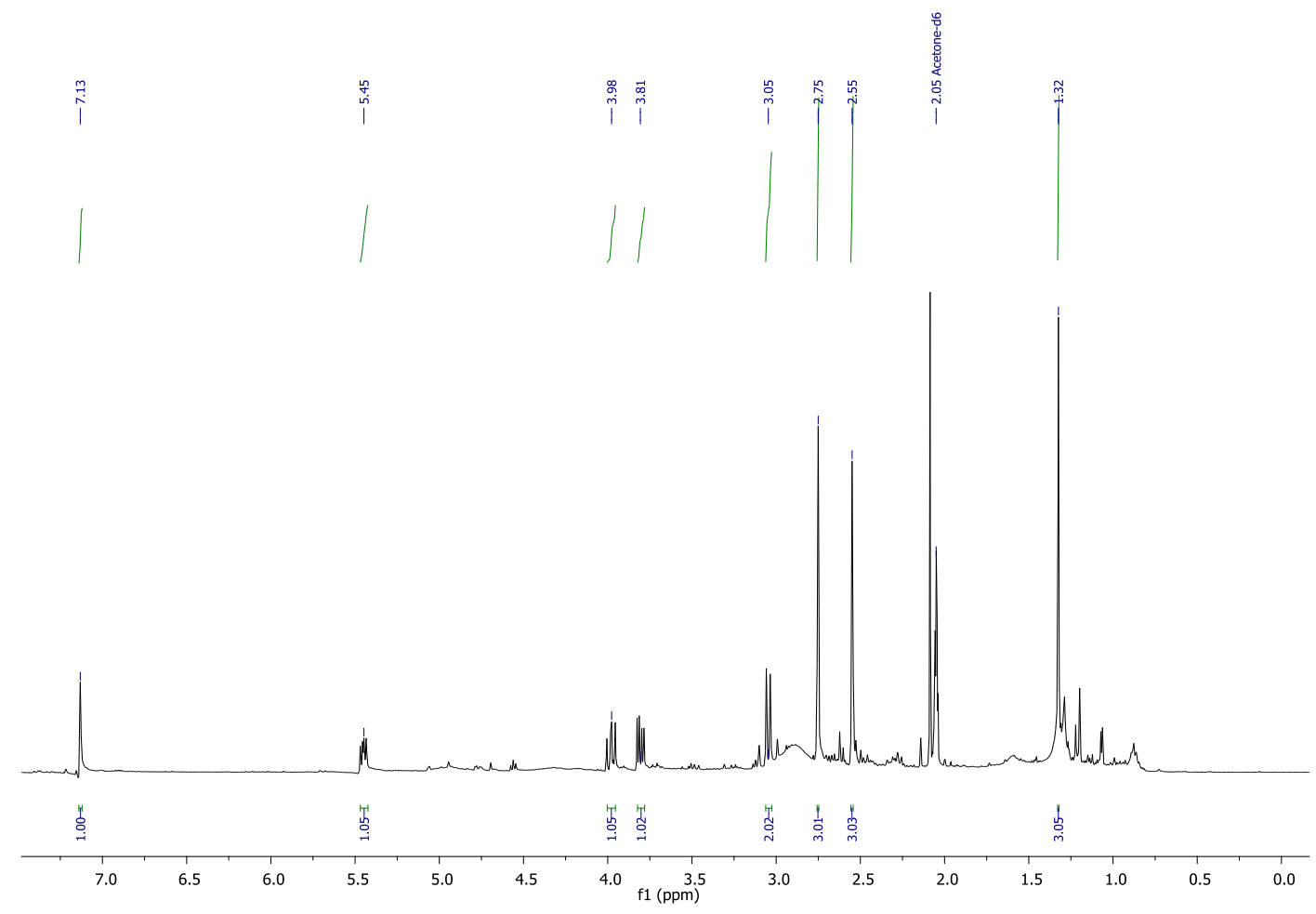

Figure S62. ${ }^{1} \mathrm{H}$ NMR $\left(\left(\mathrm{CD}_{3}\right)_{2} \mathrm{CO}, 400 \mathrm{MHz}\right)$ spectrum of compound 8 . 


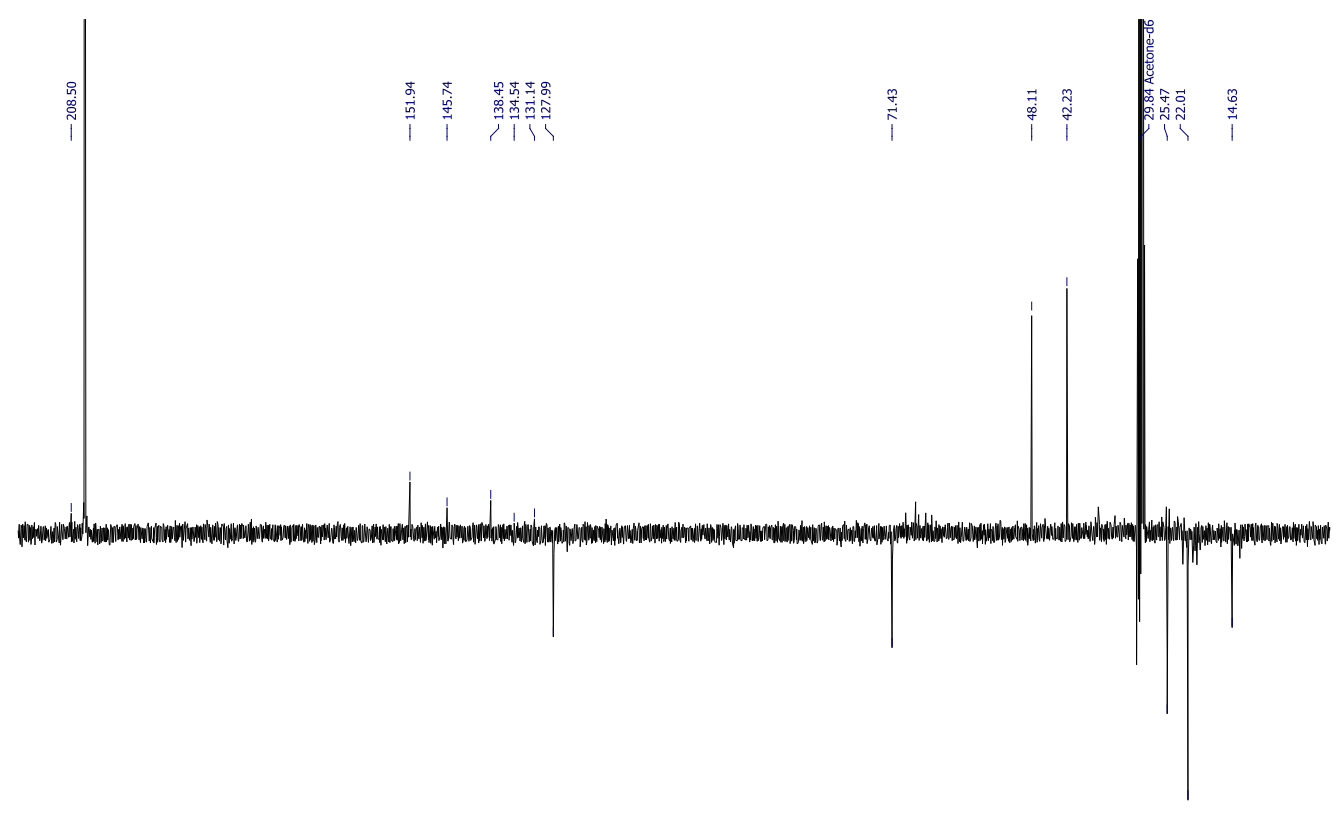

$\begin{array}{lllllllllllllllllllllllll}1 & 10 & 200 & 190 & 180 & 170 & 160 & 150 & 140 & 130 & 120 & \begin{array}{l}110 \\ f 1(\mathrm{ppm})\end{array} & 100 & 90 & 80 & 70 & 60 & 50 & 40 & 30 & 20 & 10 & 0\end{array}$

Figure S63. DEPTQ NMR $\left(\left(\mathrm{CD}_{3}\right)_{2} \mathrm{CO}, 100 \mathrm{MHz}\right)$ spectrum of compound 8 .

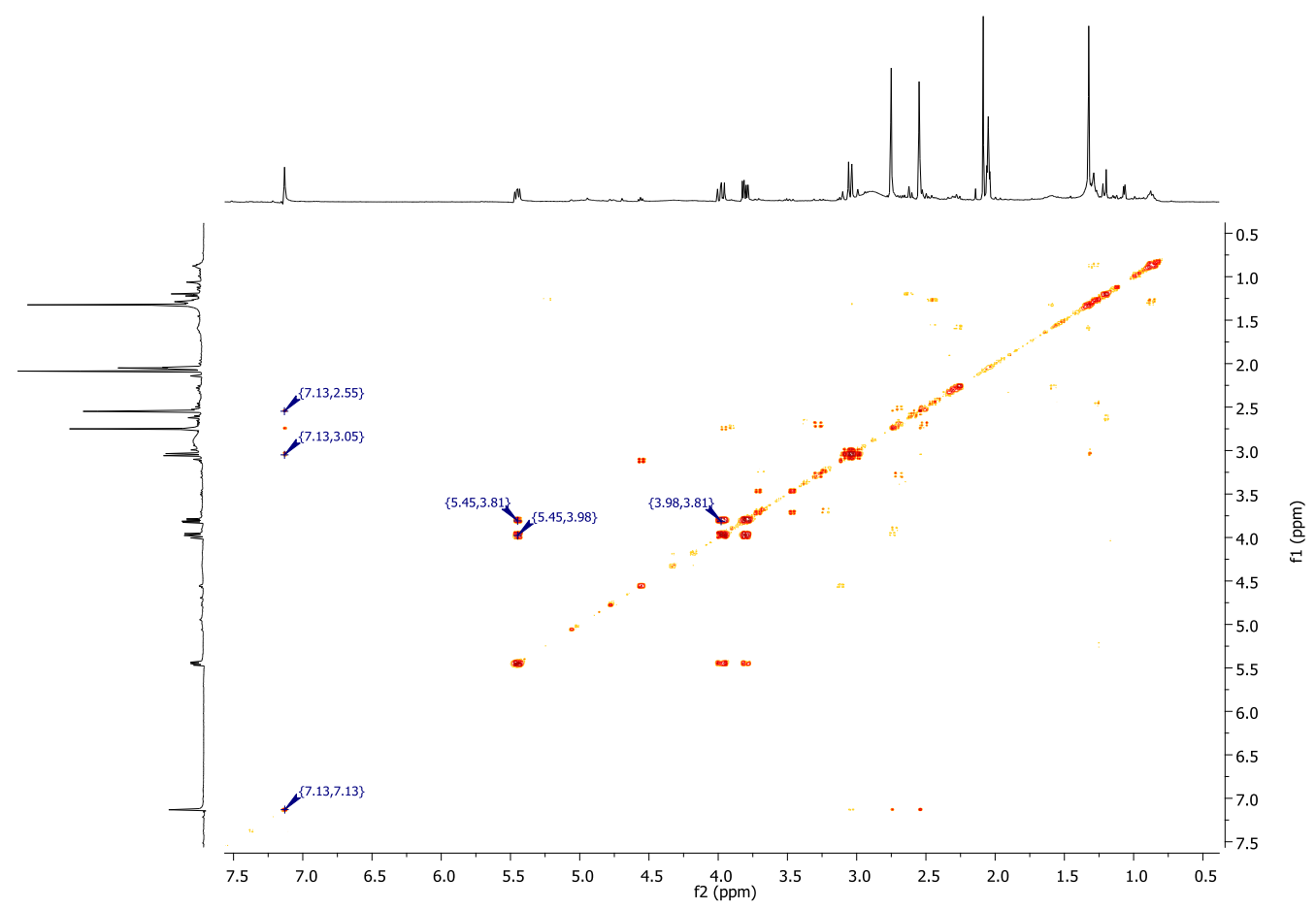

Figure S64. ${ }^{1} \mathrm{H}-{ }^{1} \mathrm{H}$ COSY NMR spectrum of compound 8. 


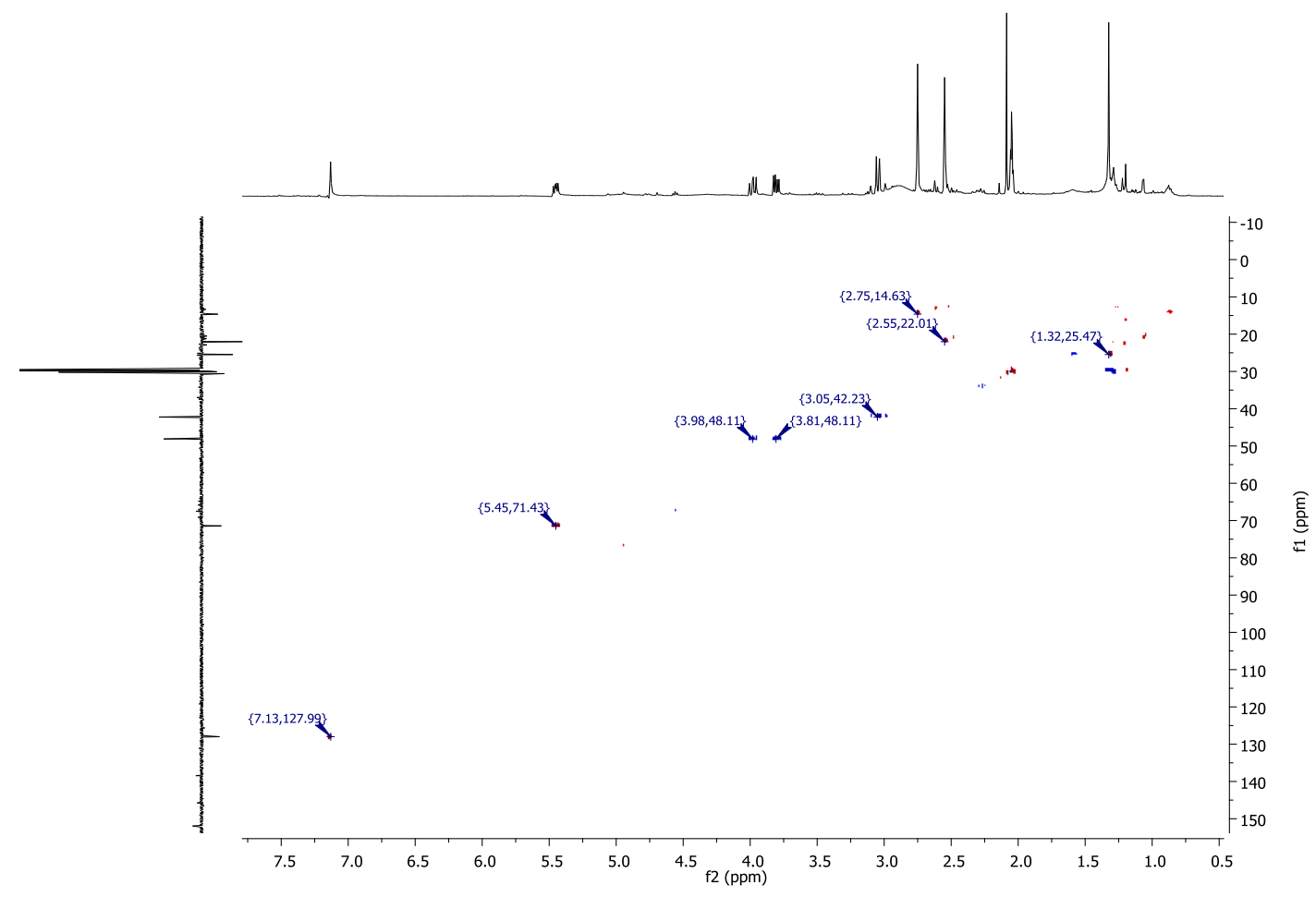

Figure S65. HSQC NMR spectrum of compound 8.

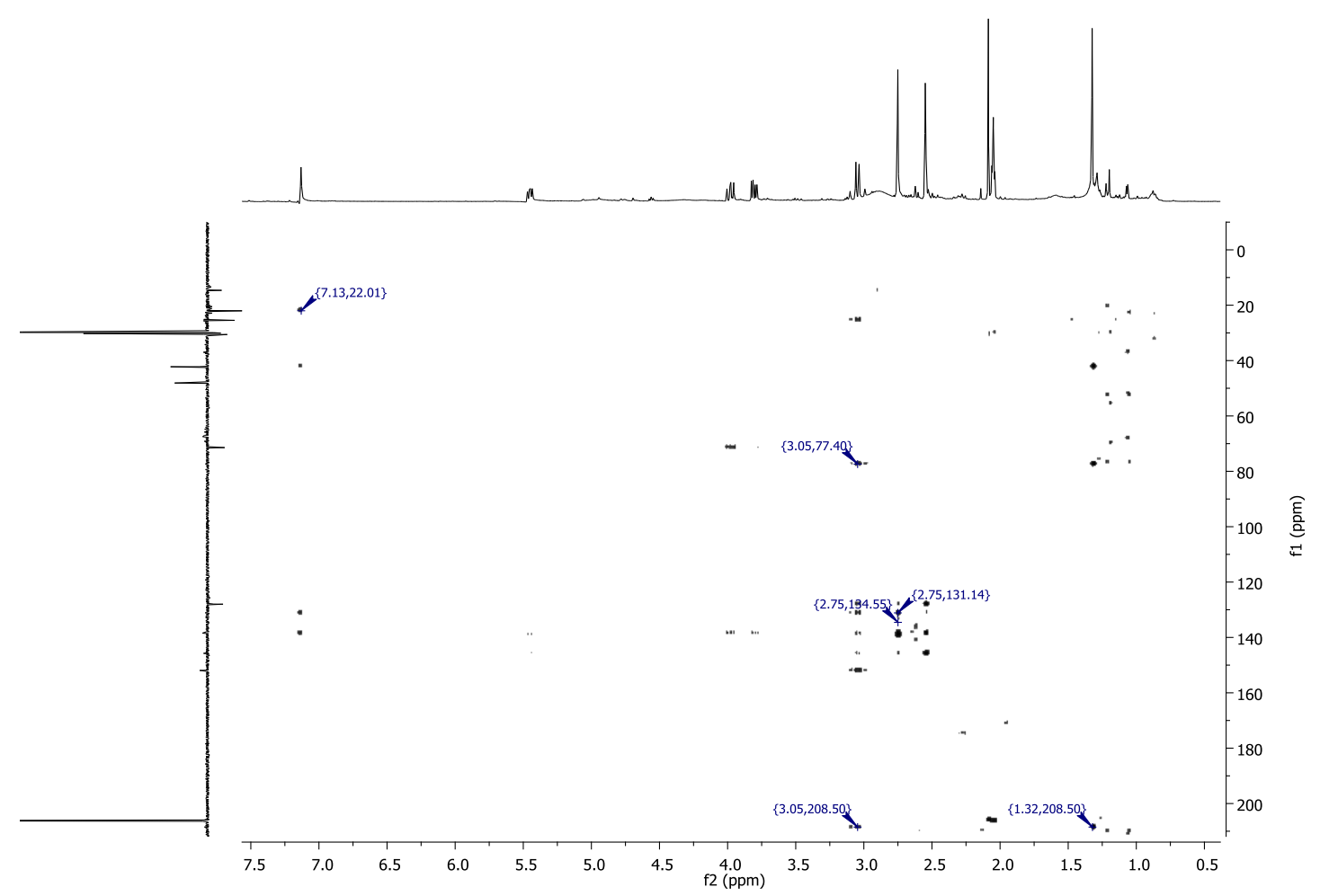

Figure S66. HMBC NMR spectrum of compound 8 . 
pos \#1 RT: $0.01 \quad$ AV: $1 \quad$ NL: $8.96 \mathrm{E} 6$

T: FTMS + p NSI u SIM ms [257.00-277.00]

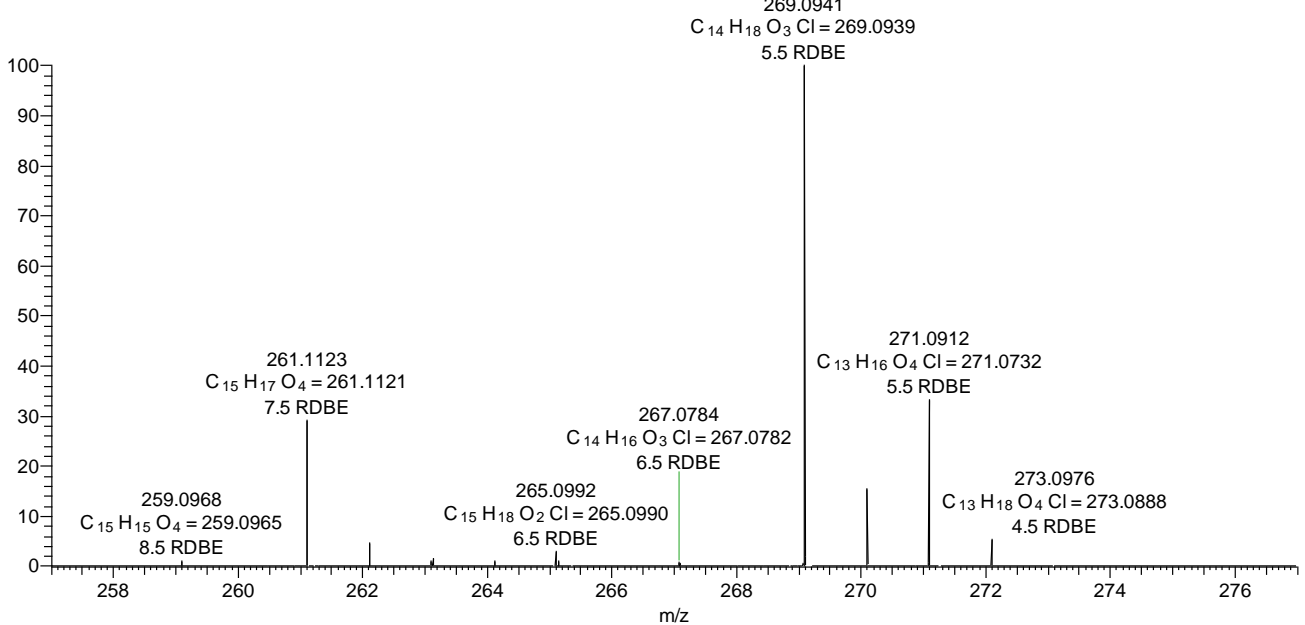

Figure S67. FT-ICR-MS spectrum of compound 8.

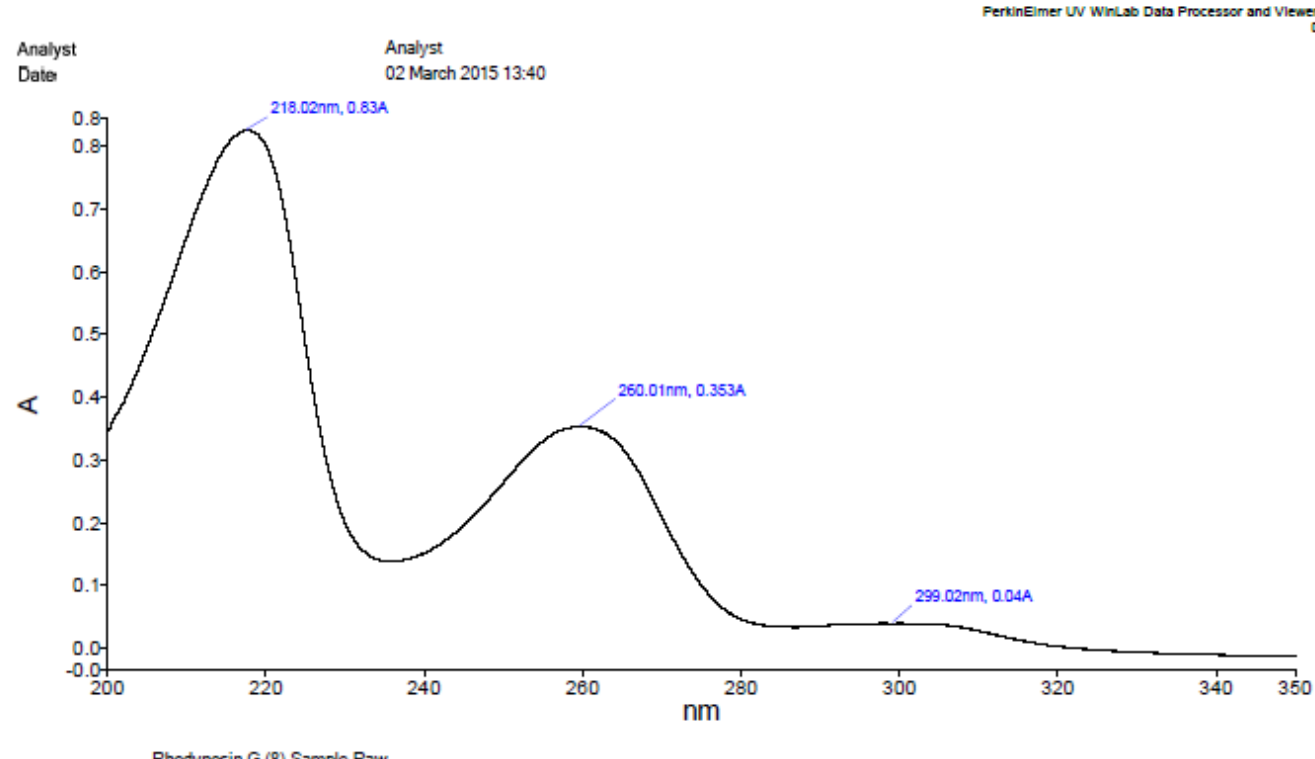

Rhedynosin G (8).Sample. Raw

Figure S68. UV spectrum of compound 8 in $\mathrm{CH}_{3} \mathrm{OH}$. 


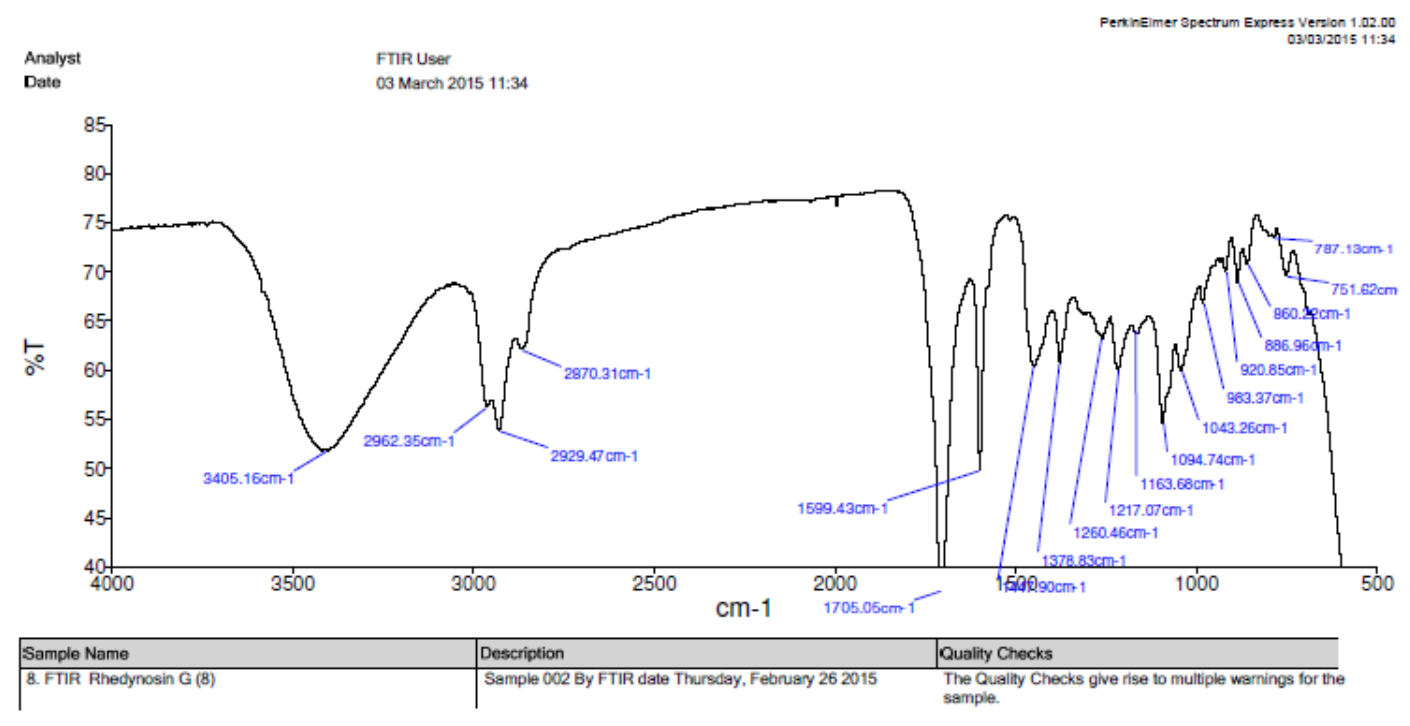

Figure S69. FT-IR spectrum of compound 8 in $\mathrm{CH}_{3} \mathrm{OH}$.

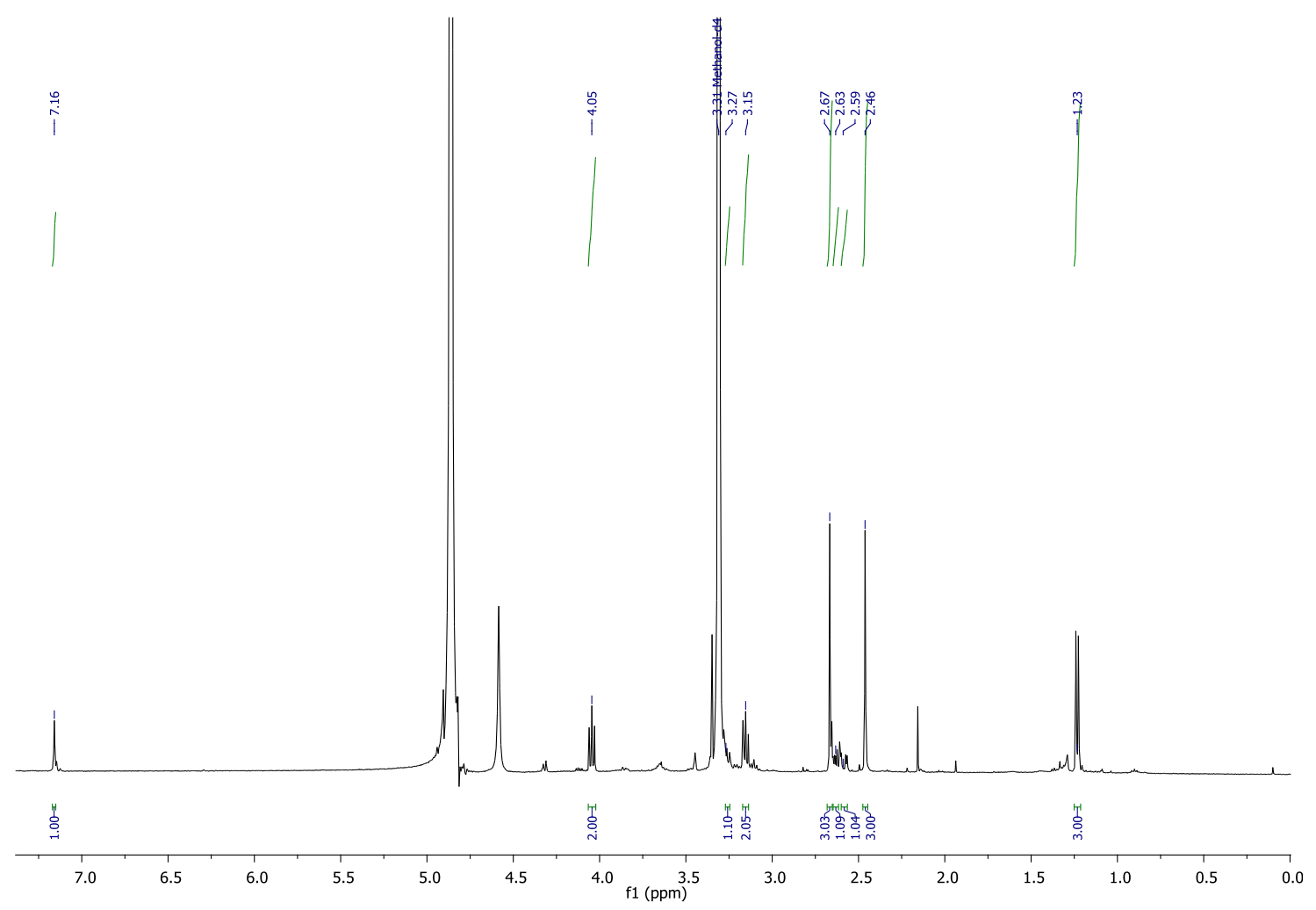

Figure S70. ${ }^{1} \mathrm{H}$ NMR $\left(\mathrm{CD}_{3} \mathrm{OD}, 500 \mathrm{MHz}\right)$ spectrum of compound 9. 


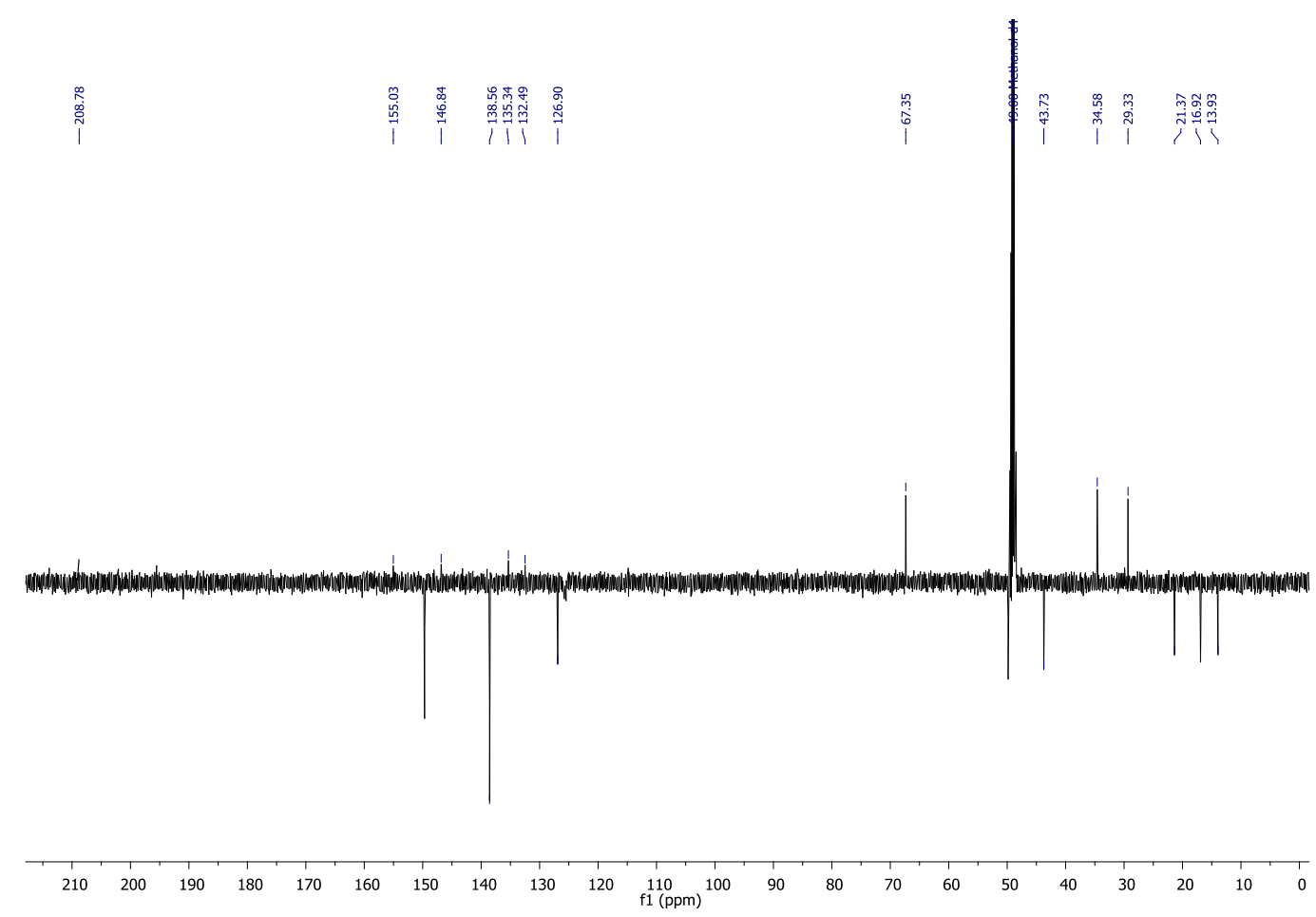

Figure S71. DEPTQ NMR ( $\left.\mathrm{CD}_{3} \mathrm{OD}, 125 \mathrm{MHz}\right)$ spectrum of compound 9.

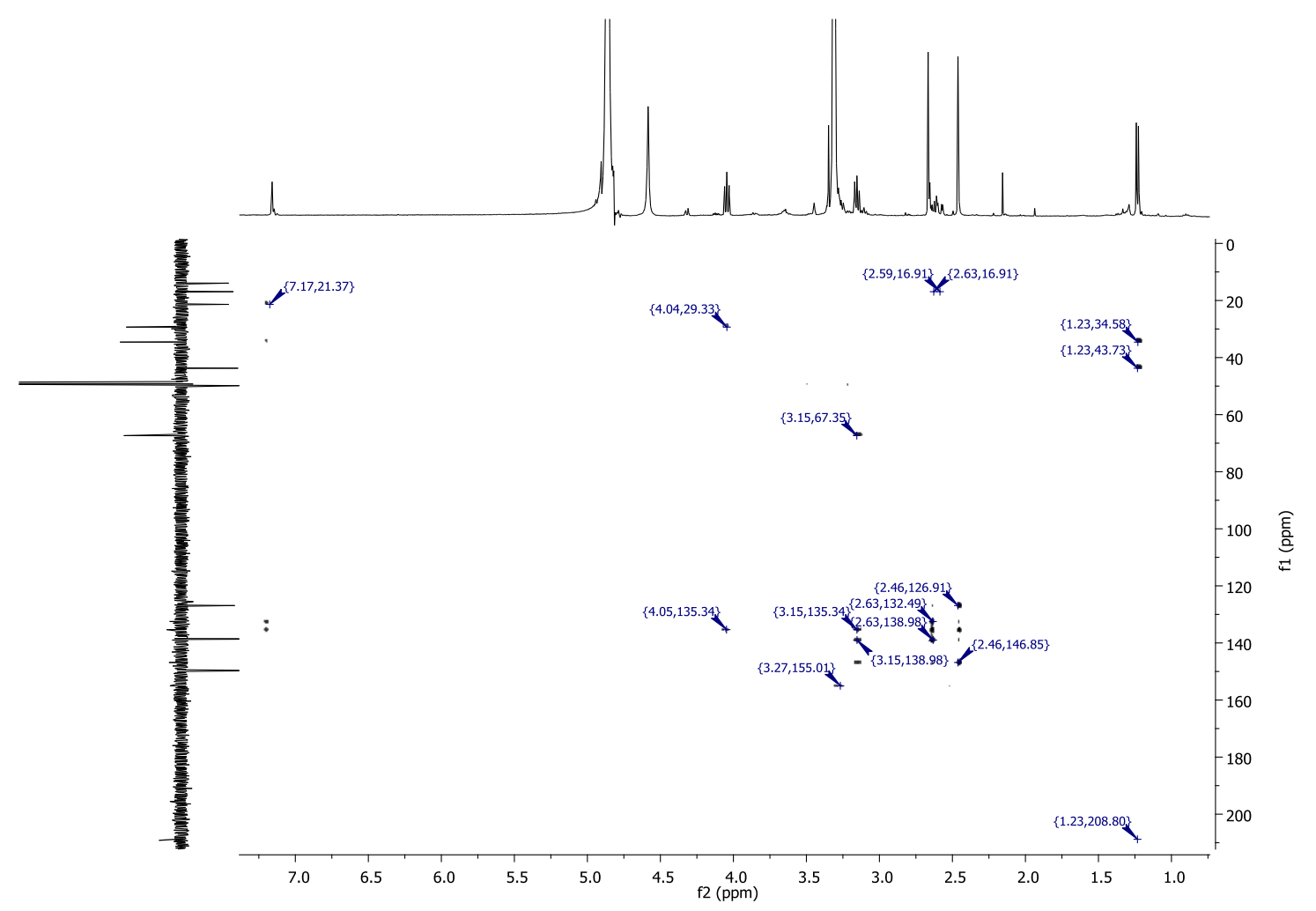

Figure S72. HMBC NMR spectrum of compound 9. 
35_neg \#1 RT: 0.00 AV: 1 NL: 7.79E6

T: FTMS - c NSIFUll ms [200.00-800,00]

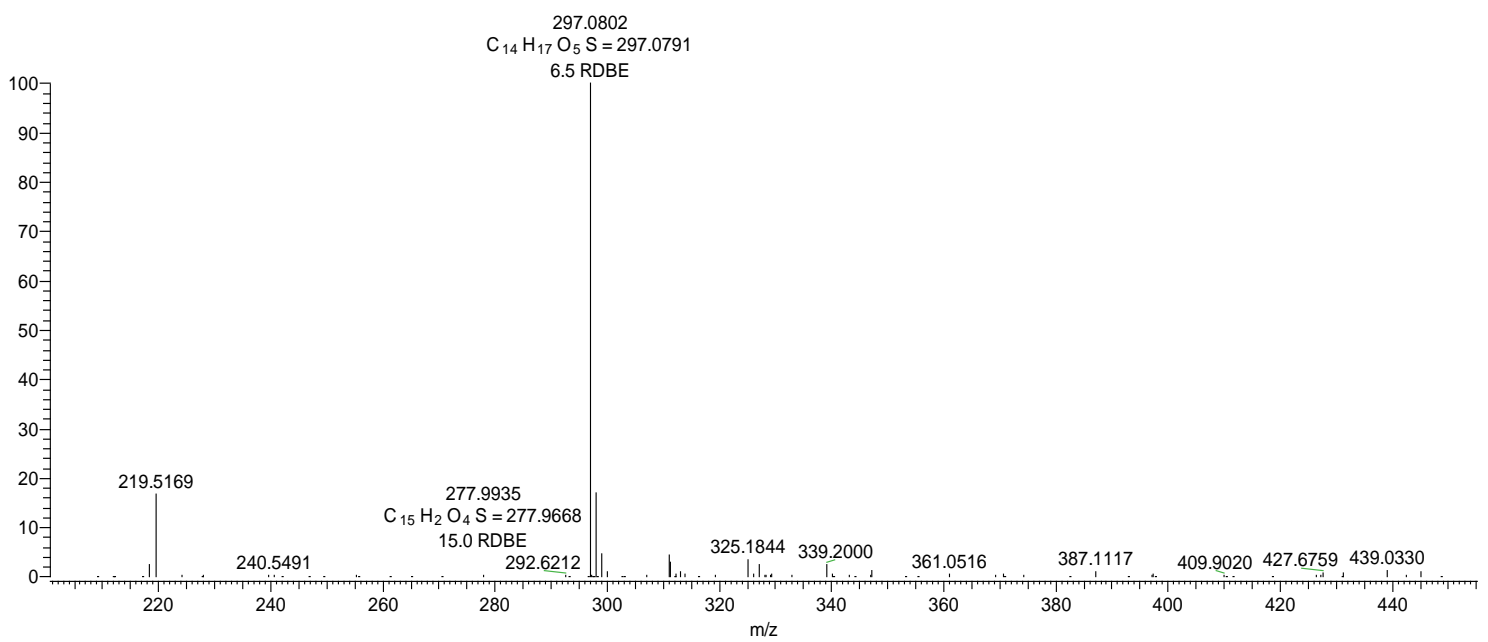

Figure S73. FT-ICR-MS spectrum of compound 9.

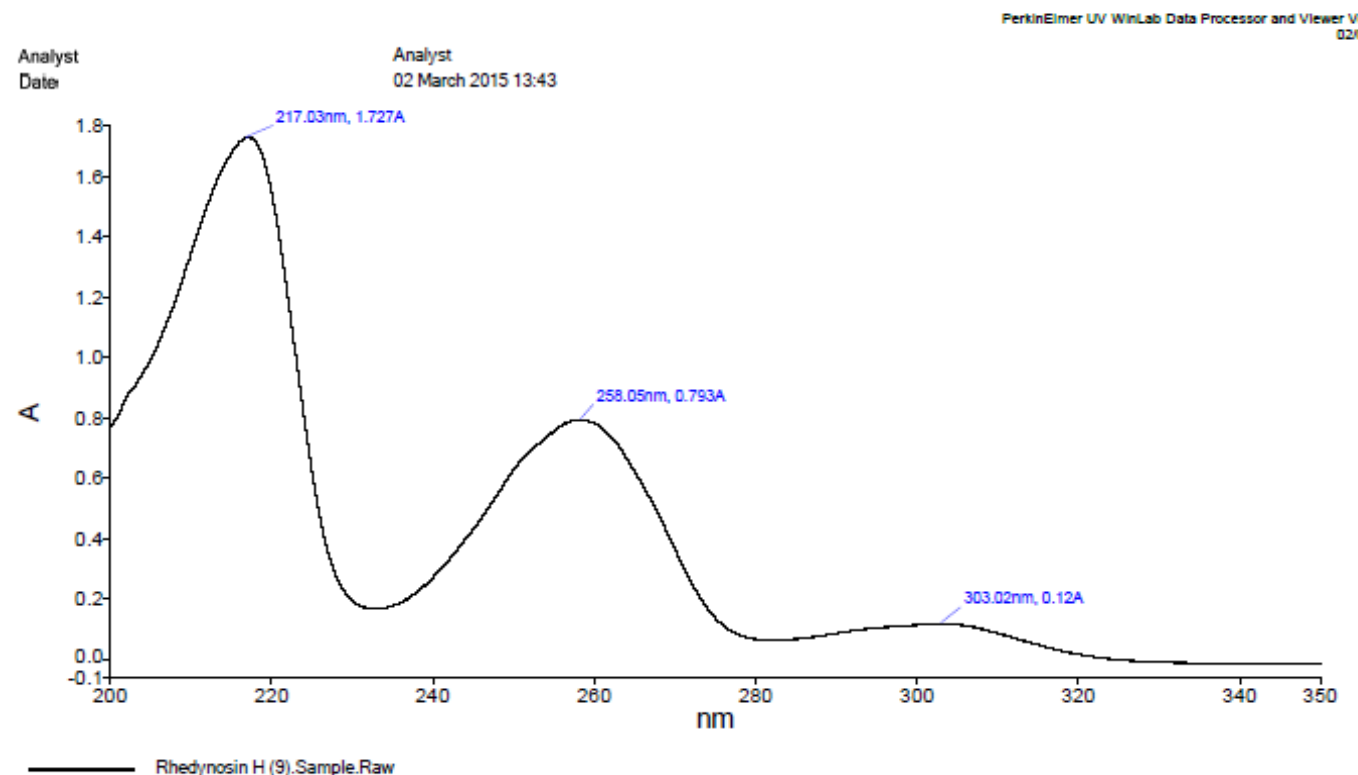

Figure S74. UV spectrum of compound 9 in $\mathrm{CH}_{3} \mathrm{OH}$. 


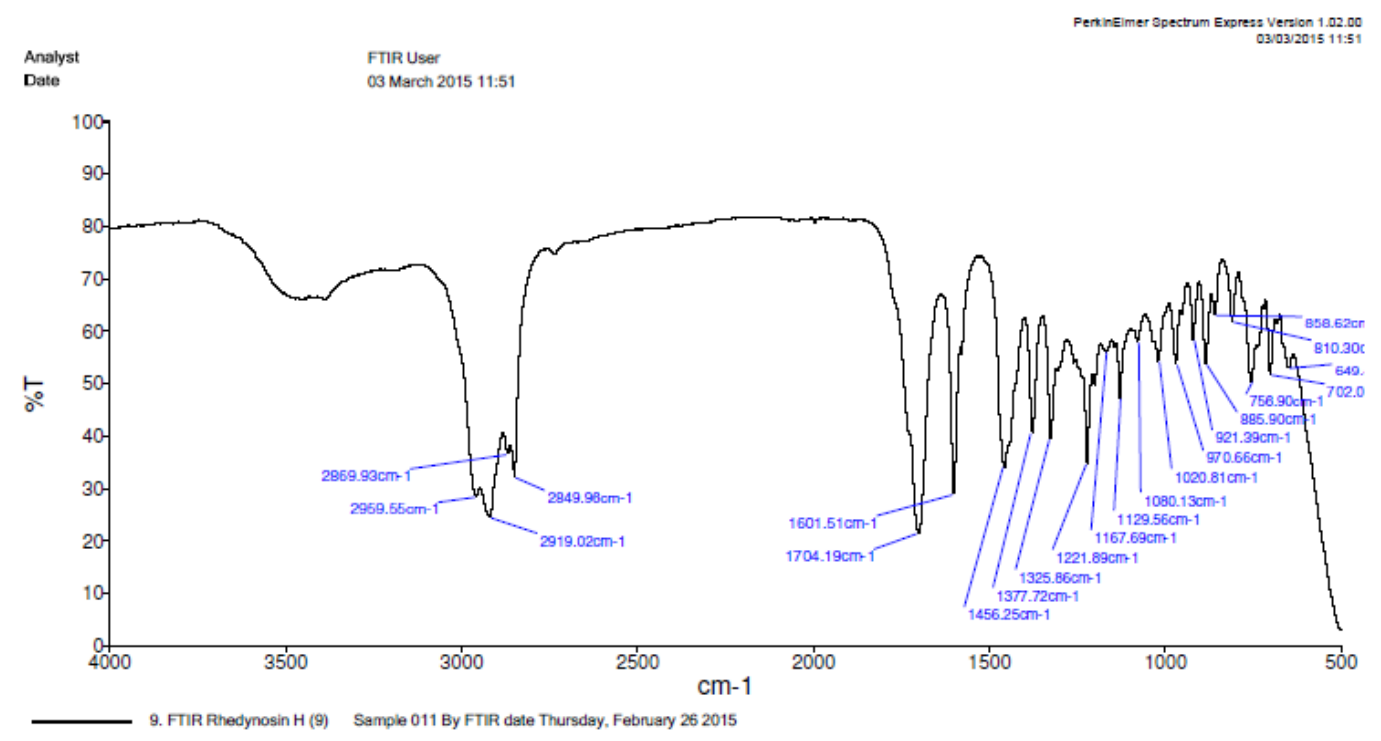

Figure S75. FT-IR spectrum of compound 9 in $\mathrm{CH}_{3} \mathrm{OH}$.

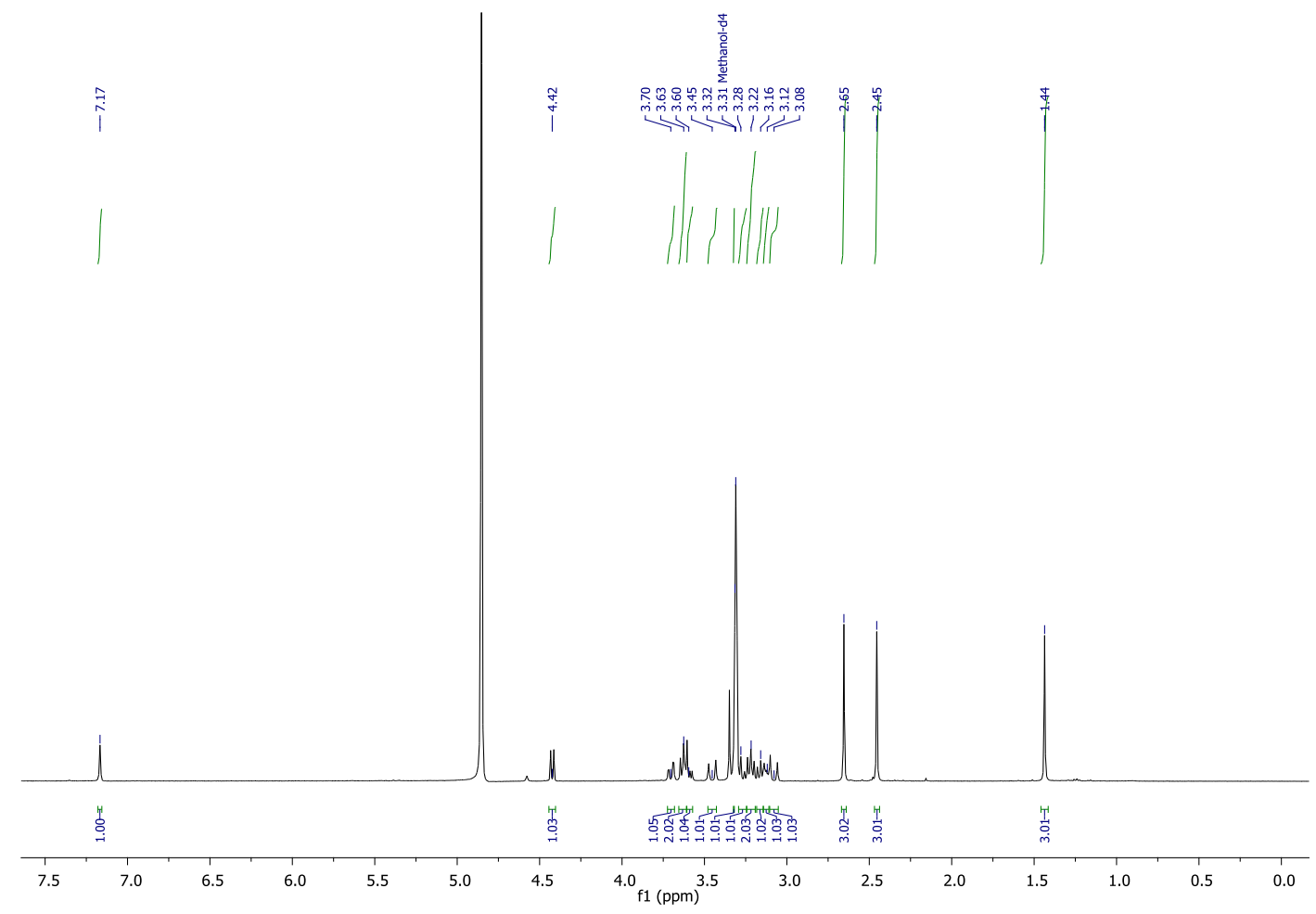

Figure S76. ${ }^{1} \mathrm{H}$ NMR $\left(\mathrm{CD}_{3} \mathrm{OD}, 400 \mathrm{MHz}\right)$ spectrum of compound $\mathbf{1 0}$. 


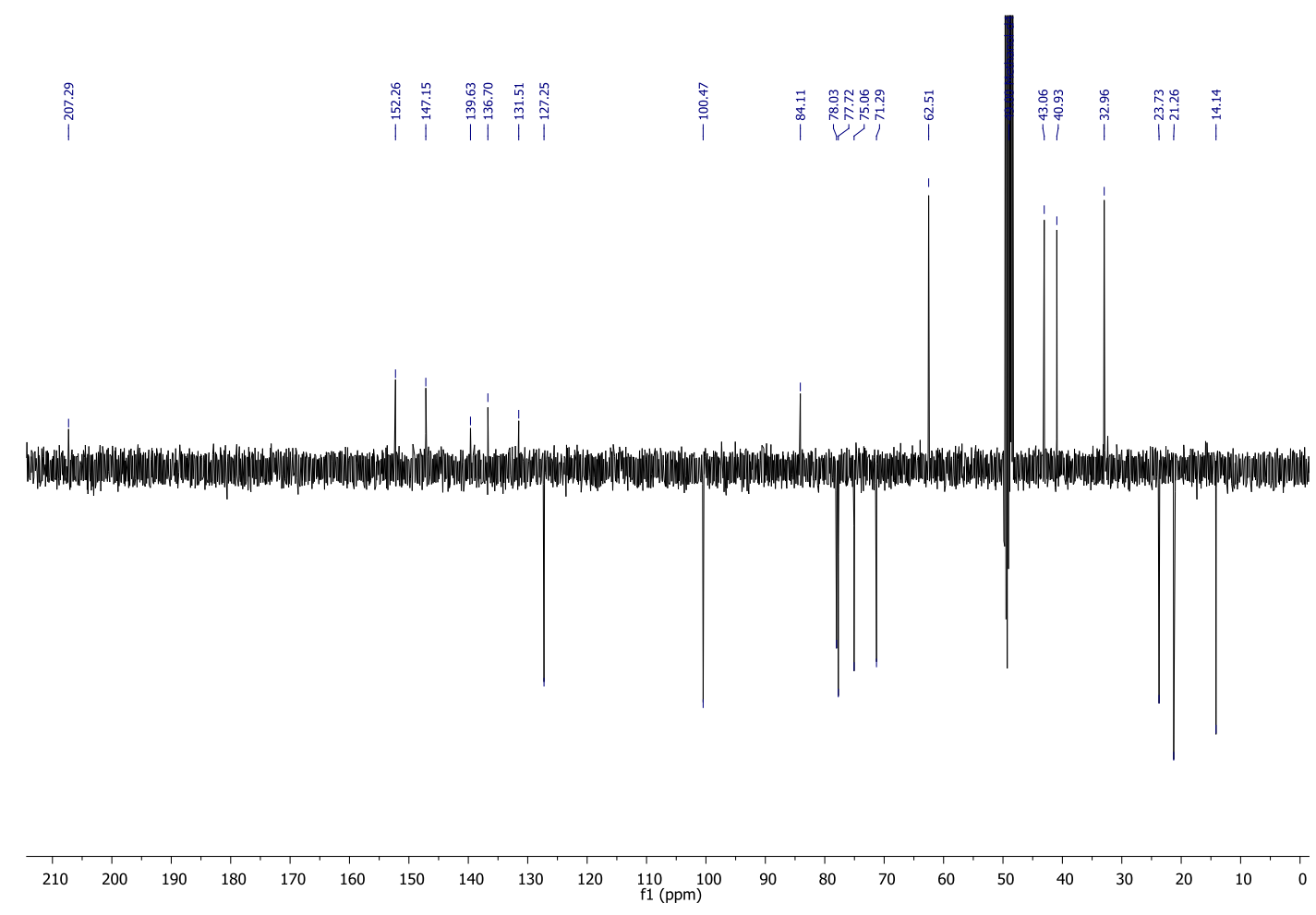

Figure S77. DEPTQ NMR (CD 30 D, $100 \mathrm{MHz})$ spectrum of compound $\mathbf{1 0}$.

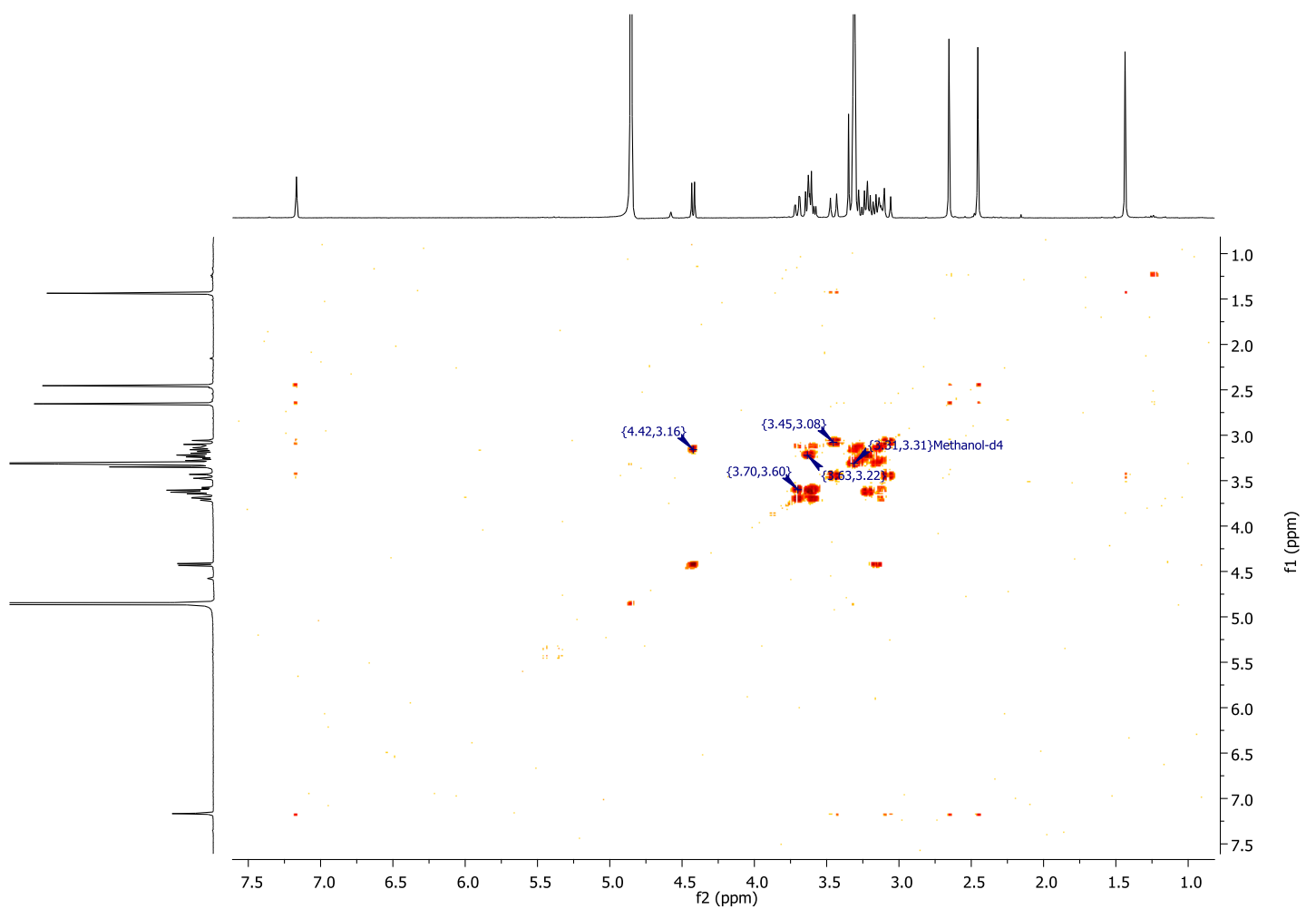

Figure S78. ${ }^{1} \mathrm{H}-{ }^{1} \mathrm{H}$ COSY NMR spectrum of compound 10. 


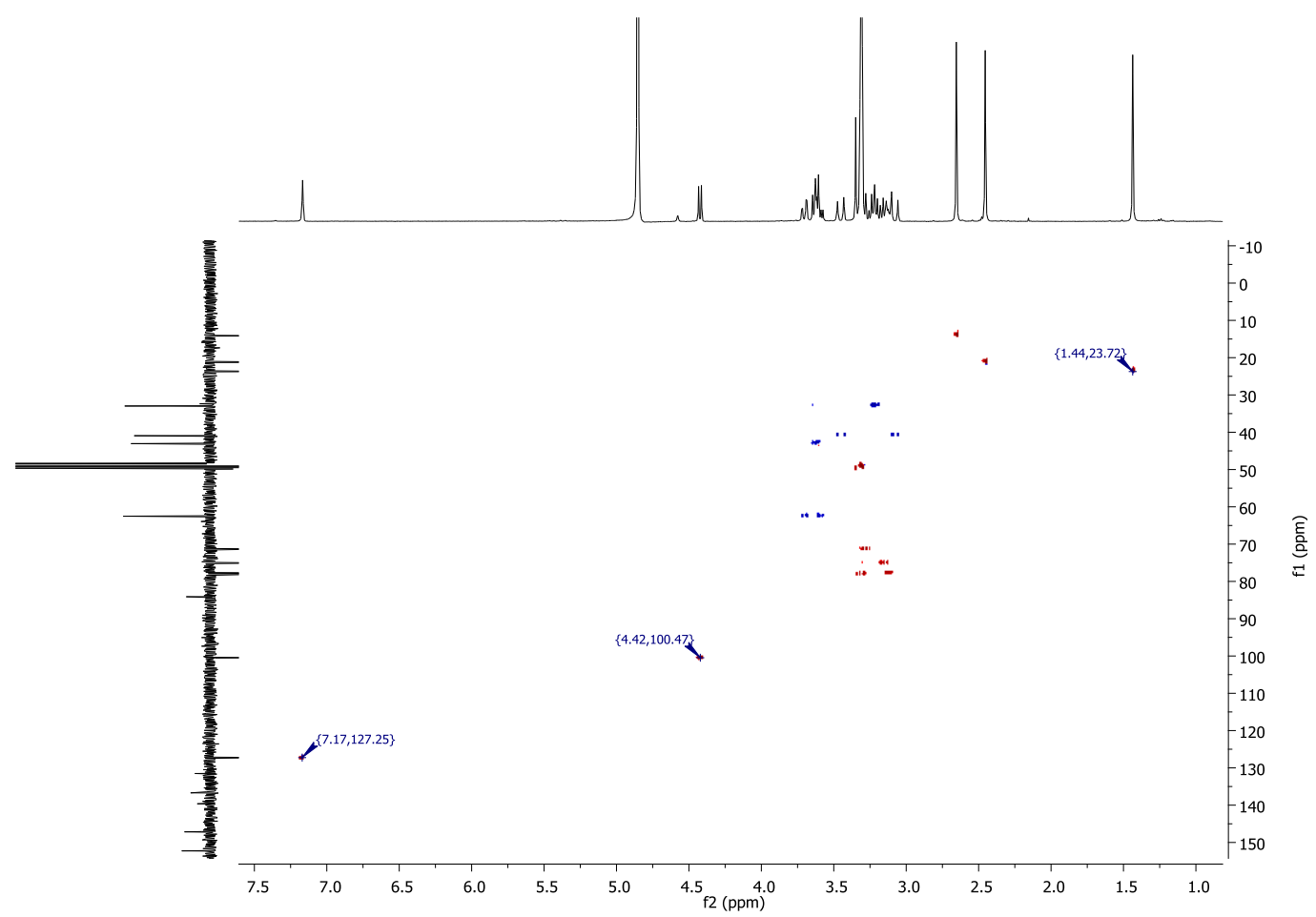

Figure S79. HSQC NMR spectrum of compound $\mathbf{1 0 .}$

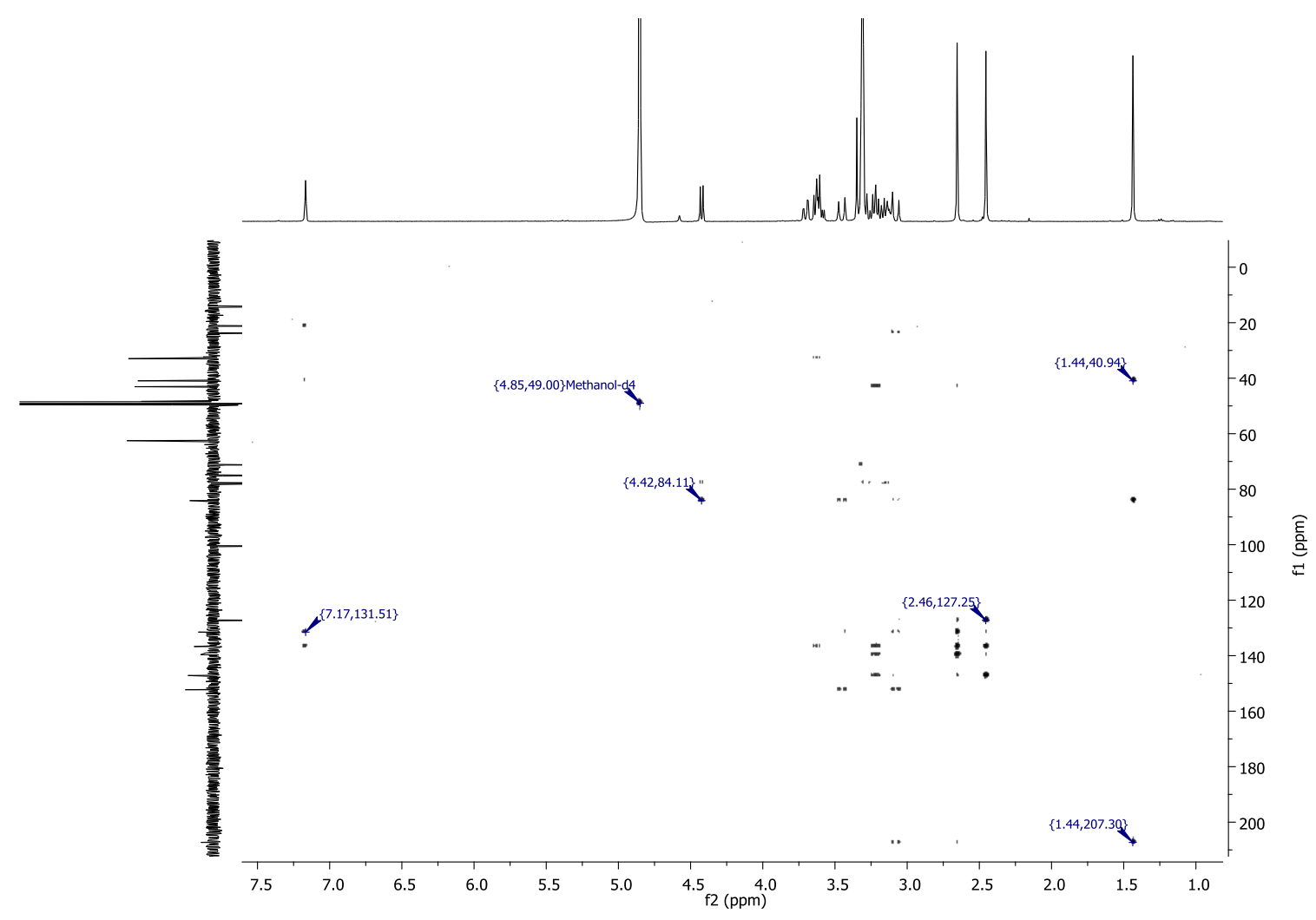

Figure S80. HMBC NMR spectrum of compound $\mathbf{1 0 .}$ 
pos\#1 RT: 0.00 AV: 1 NL: 6.3554

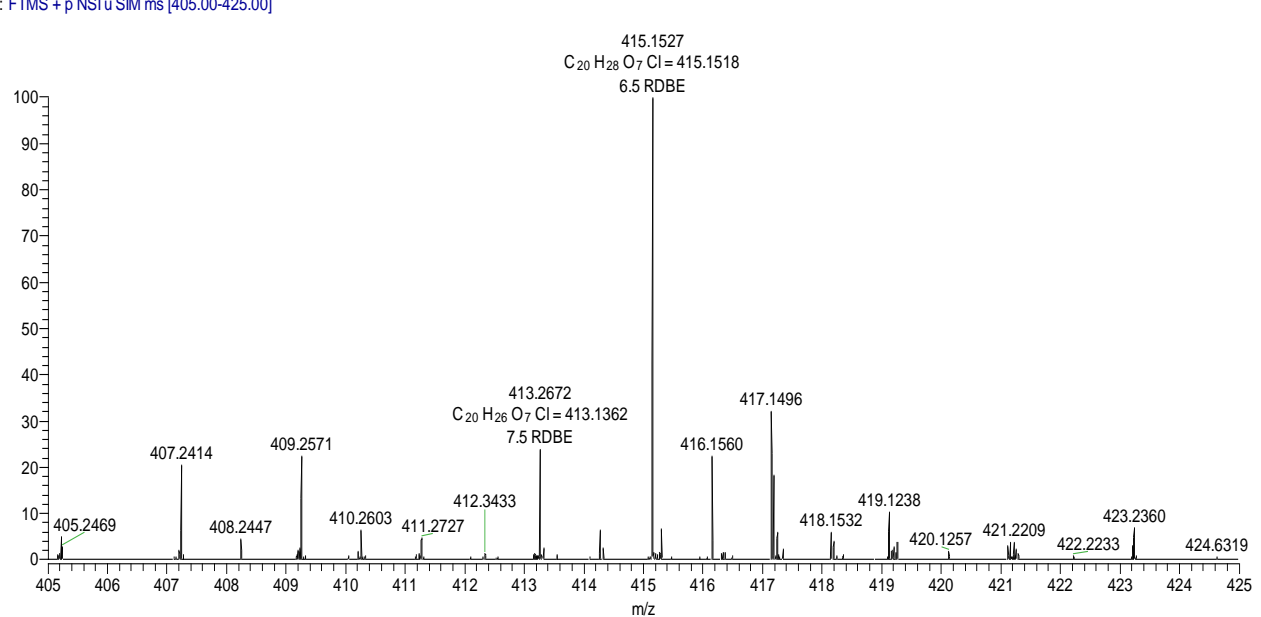

Figure S81. FT-ICR-MS spectrum of compound $\mathbf{1 0 .}$

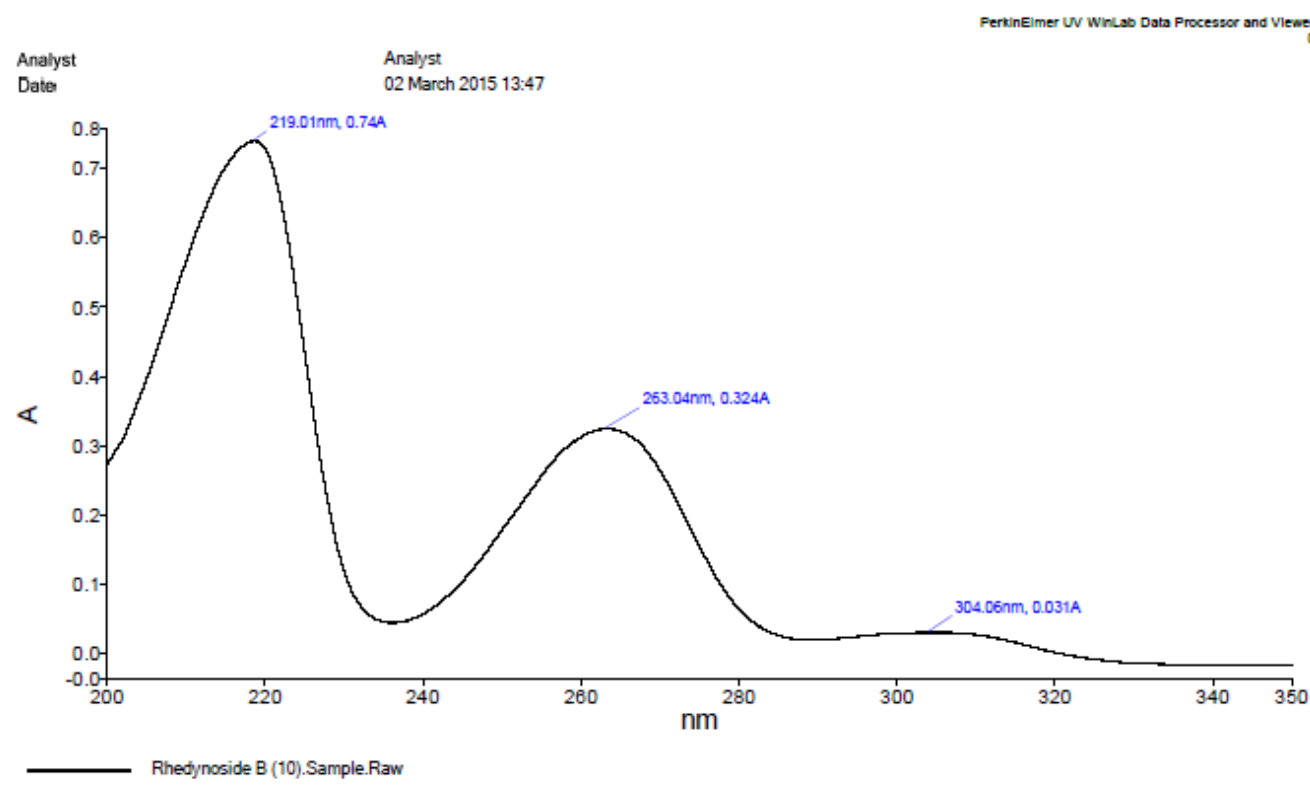

Figure S82. UV spectrum of compound 10 in $\mathrm{CH}_{3} \mathrm{OH}$. 


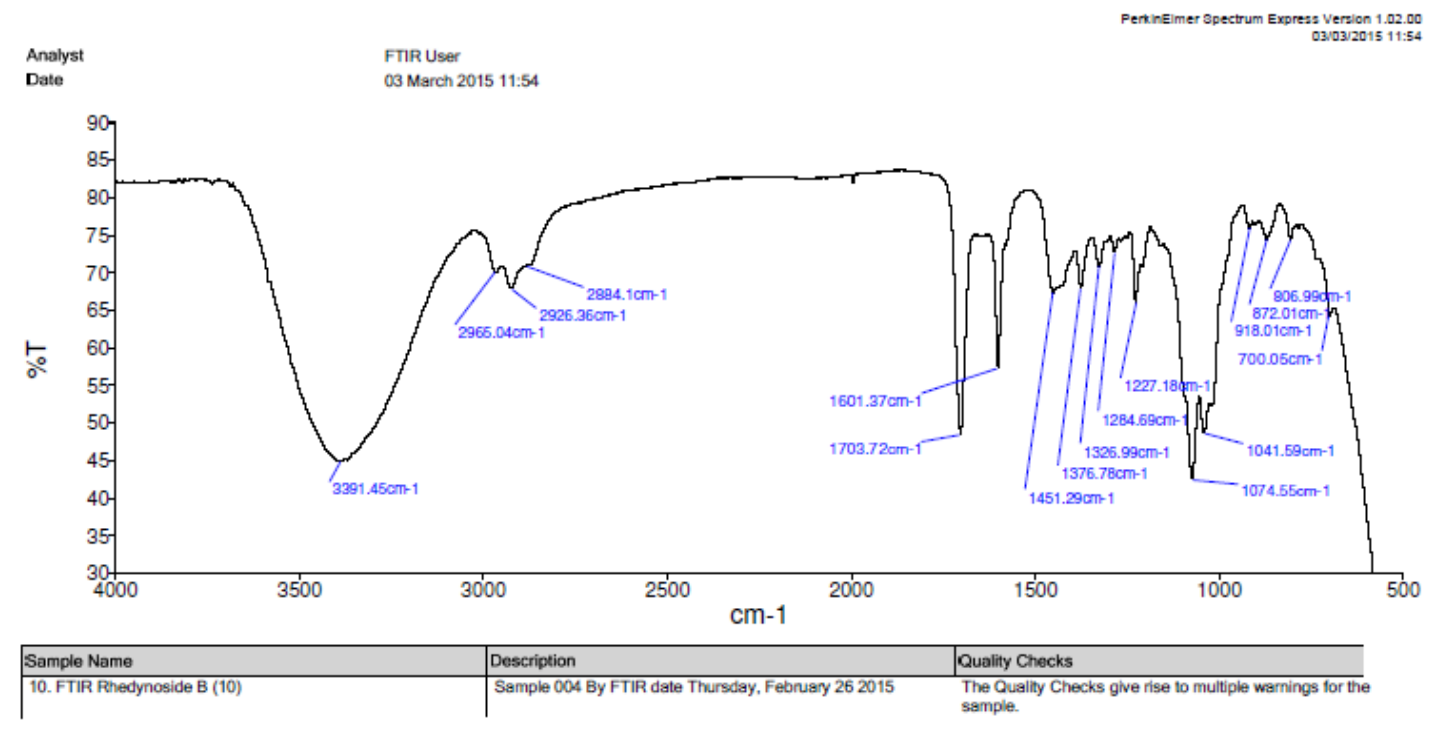

Figure S83. FT-IR spectrum of compound $\mathbf{1 0}$ in $\mathrm{CH}_{3} \mathrm{OH}$.

Jun15-2015-VT
Supervisor Name

Acetylation of Rhedynoside B

PROTON.b CDC13 \{C: IBruker|TopSpin3.2\} TECH 17

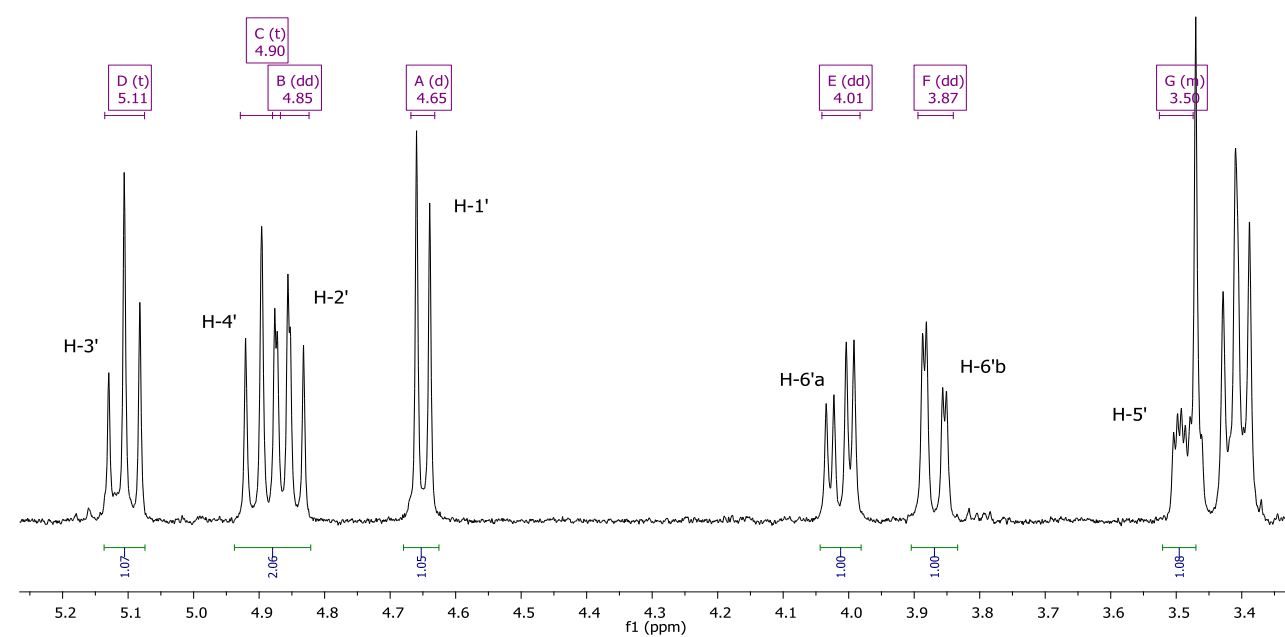

Figure S84. ${ }^{1} \mathrm{H} \mathrm{NMR}\left(\mathrm{CDCl}_{3}, 400 \mathrm{MHz}\right)$ spectrum of compound 10 after acetylation reaction 


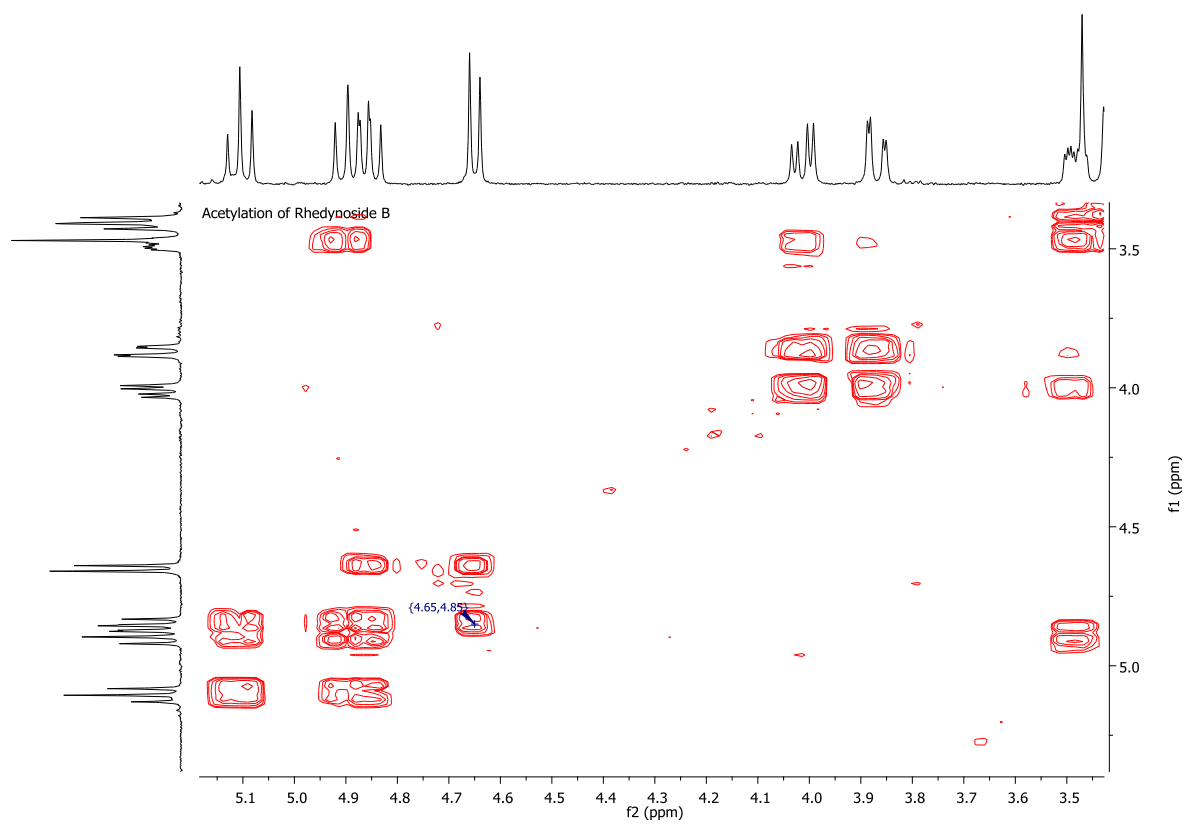

Figure S85. ${ }^{1} \mathrm{H}-{ }^{1} \mathrm{H}$ COSY NMR spectrum of compound $\mathbf{1 0}$ after acetylation reaction

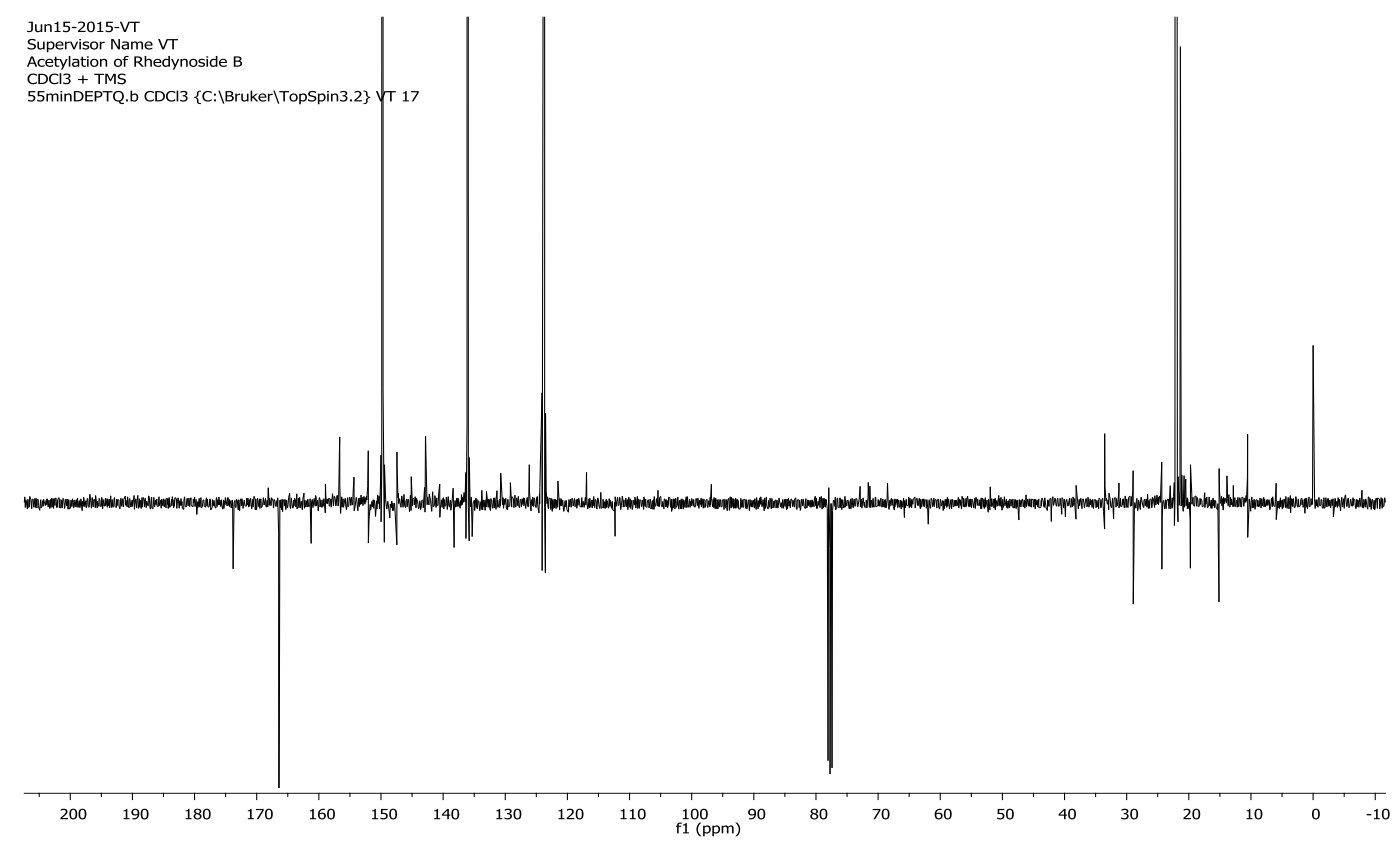

Figure S86. DEPTQ NMR $\left(\mathrm{CDCl}_{3}, 100 \mathrm{MHz}\right)$ spectrum of compound 10 after acetylation reaction 


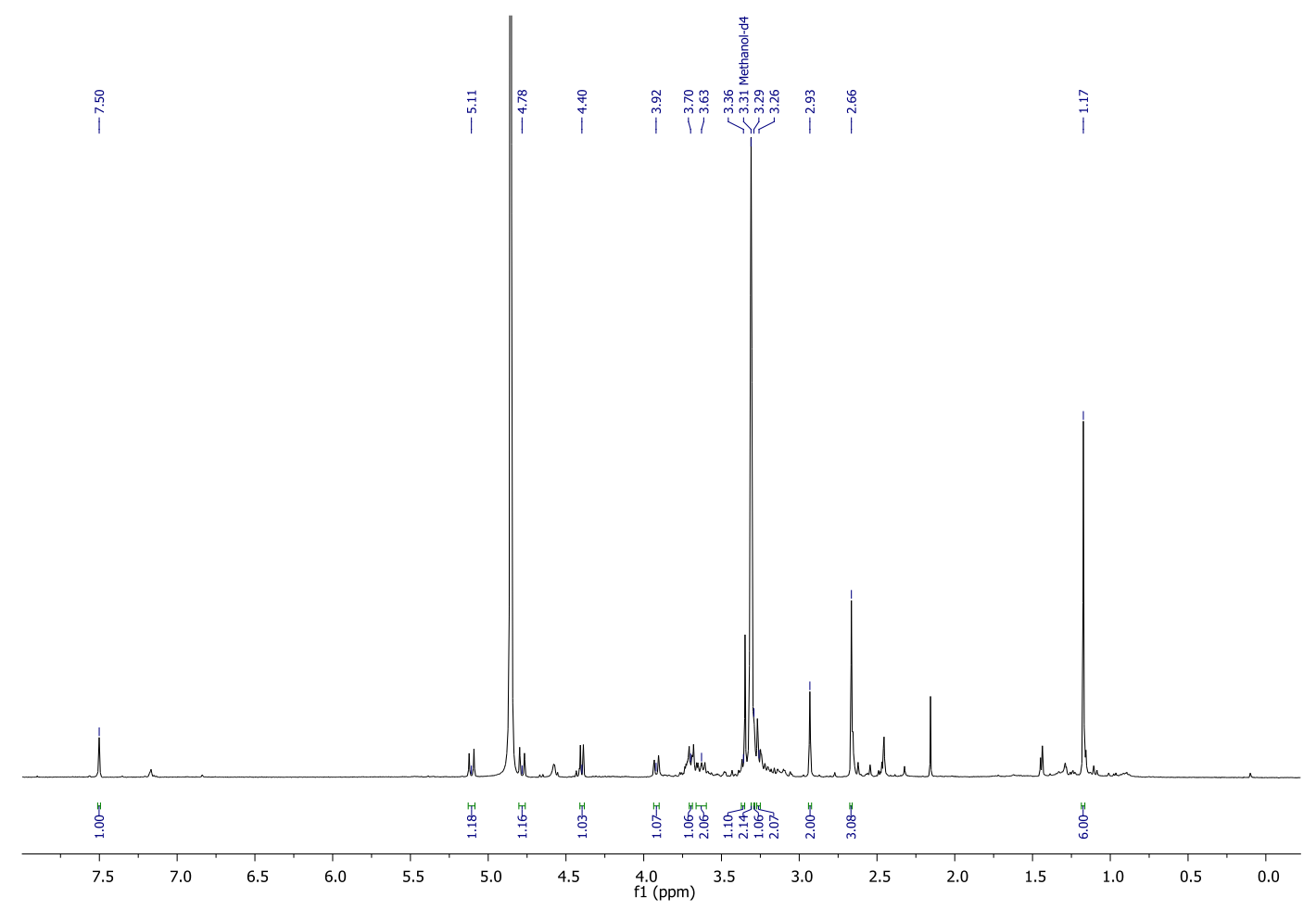

Figure S87. ${ }^{1} \mathrm{H}$ NMR $\left(\mathrm{CD}_{3} \mathrm{OD}, 400 \mathrm{MHz}\right)$ spectrum of compound 11.

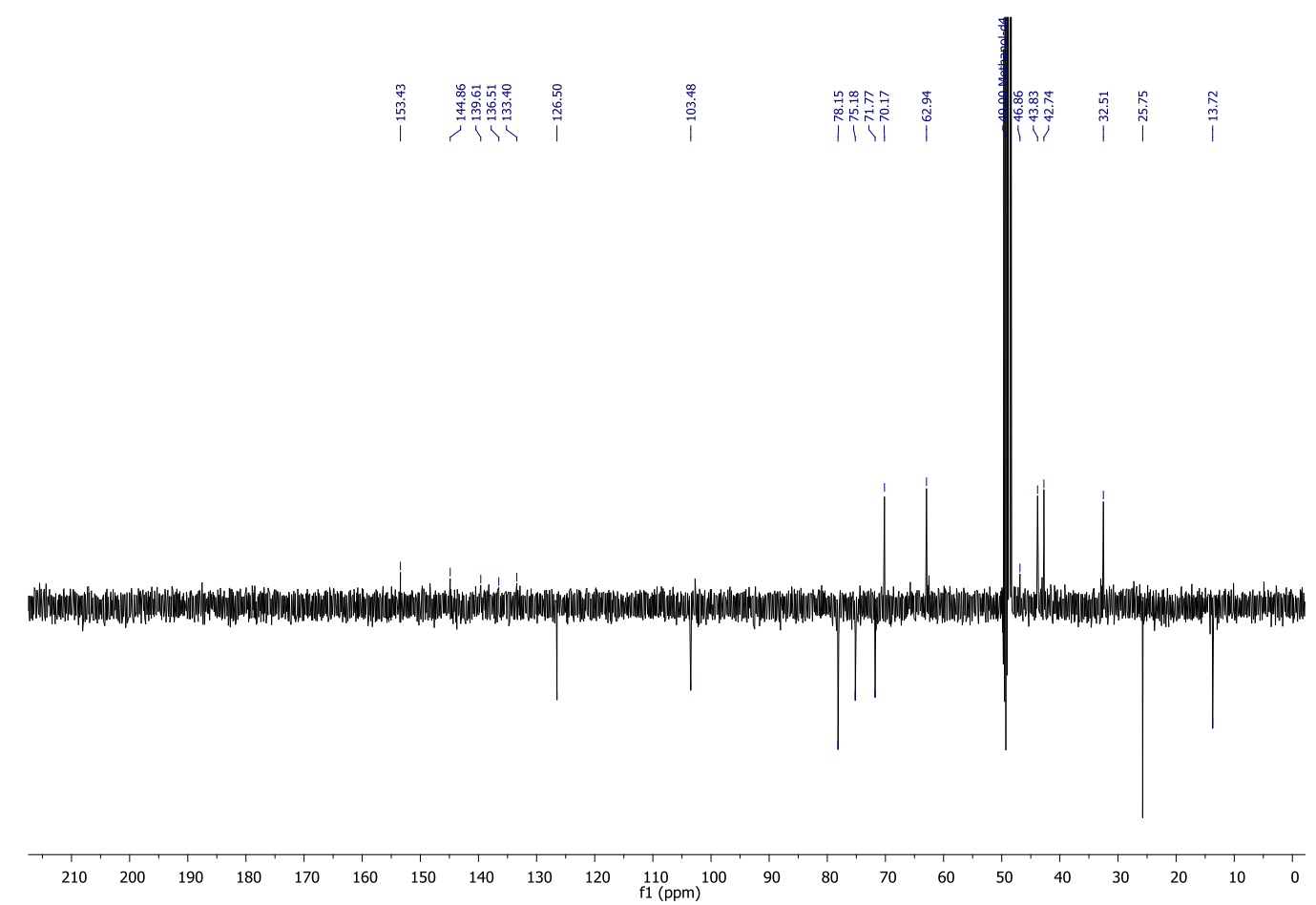

Figure S88. DEPTQ NMR (CD 3 OD, $100 \mathrm{MHz})$ spectrum of compound 11. 


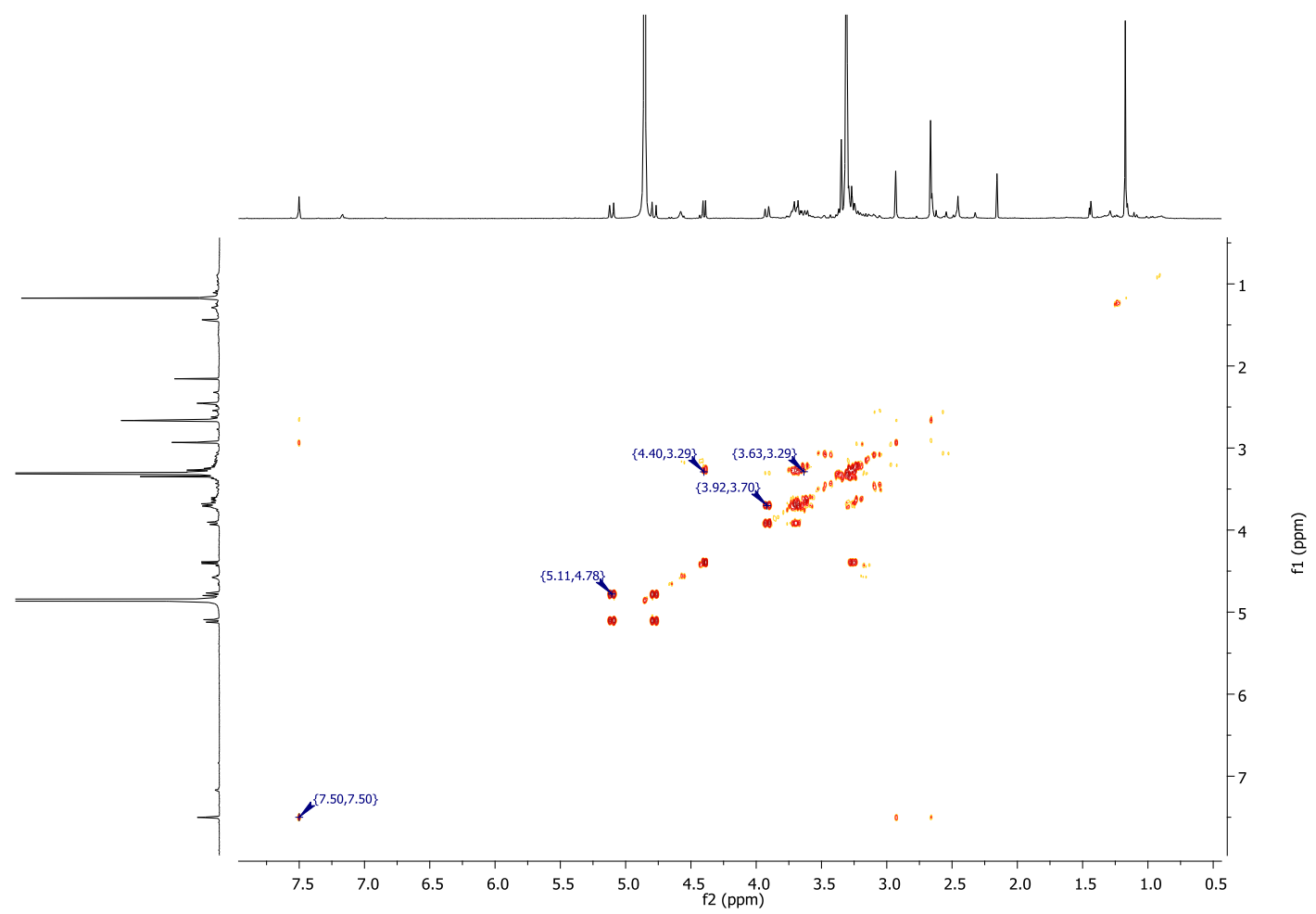

Figure S89. ${ }^{1} \mathrm{H}-{ }^{1} \mathrm{H}$ COSY NMR spectrum of compound 11.

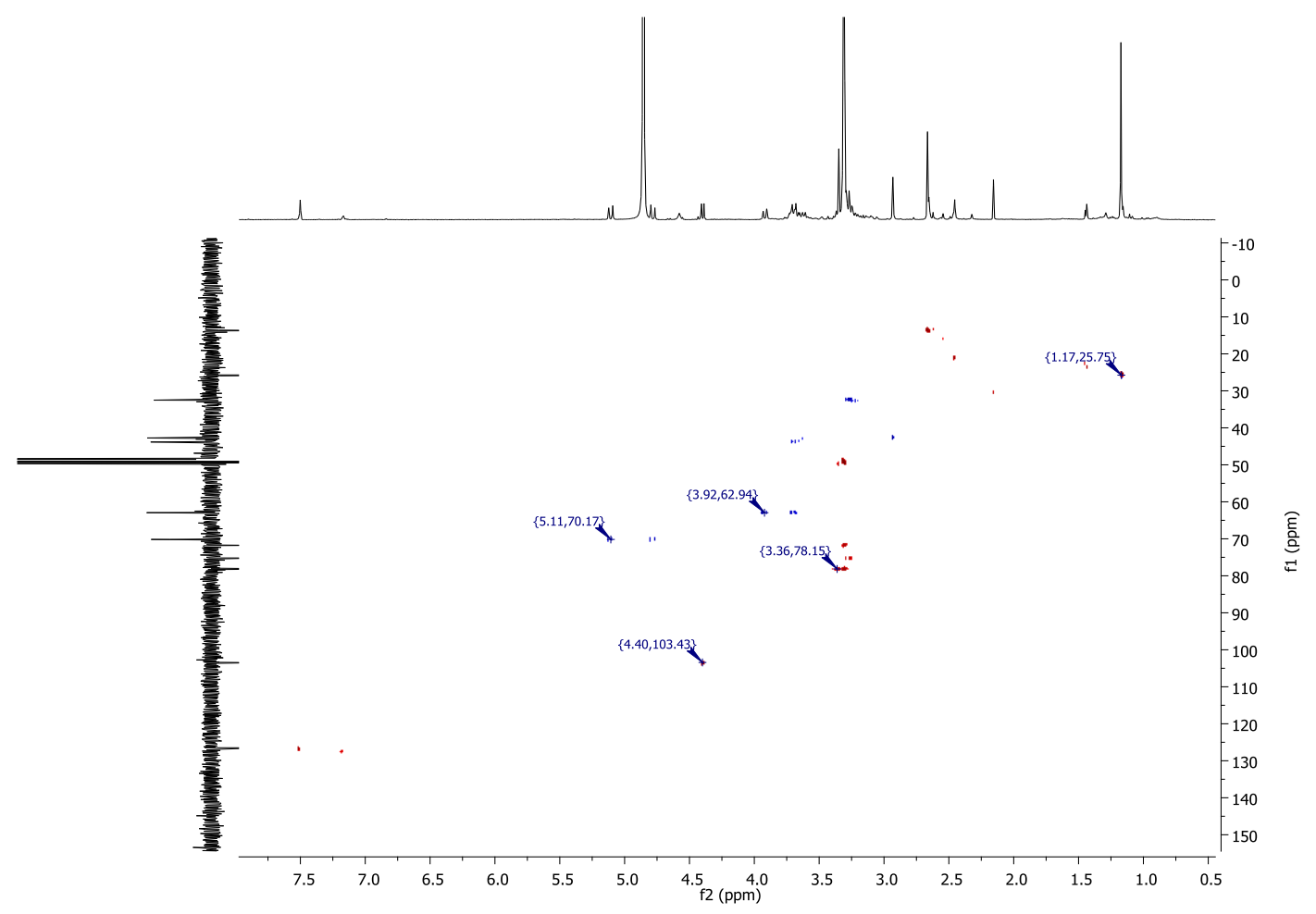

Figure S90. HSQC NMR spectrum of compound 11. 


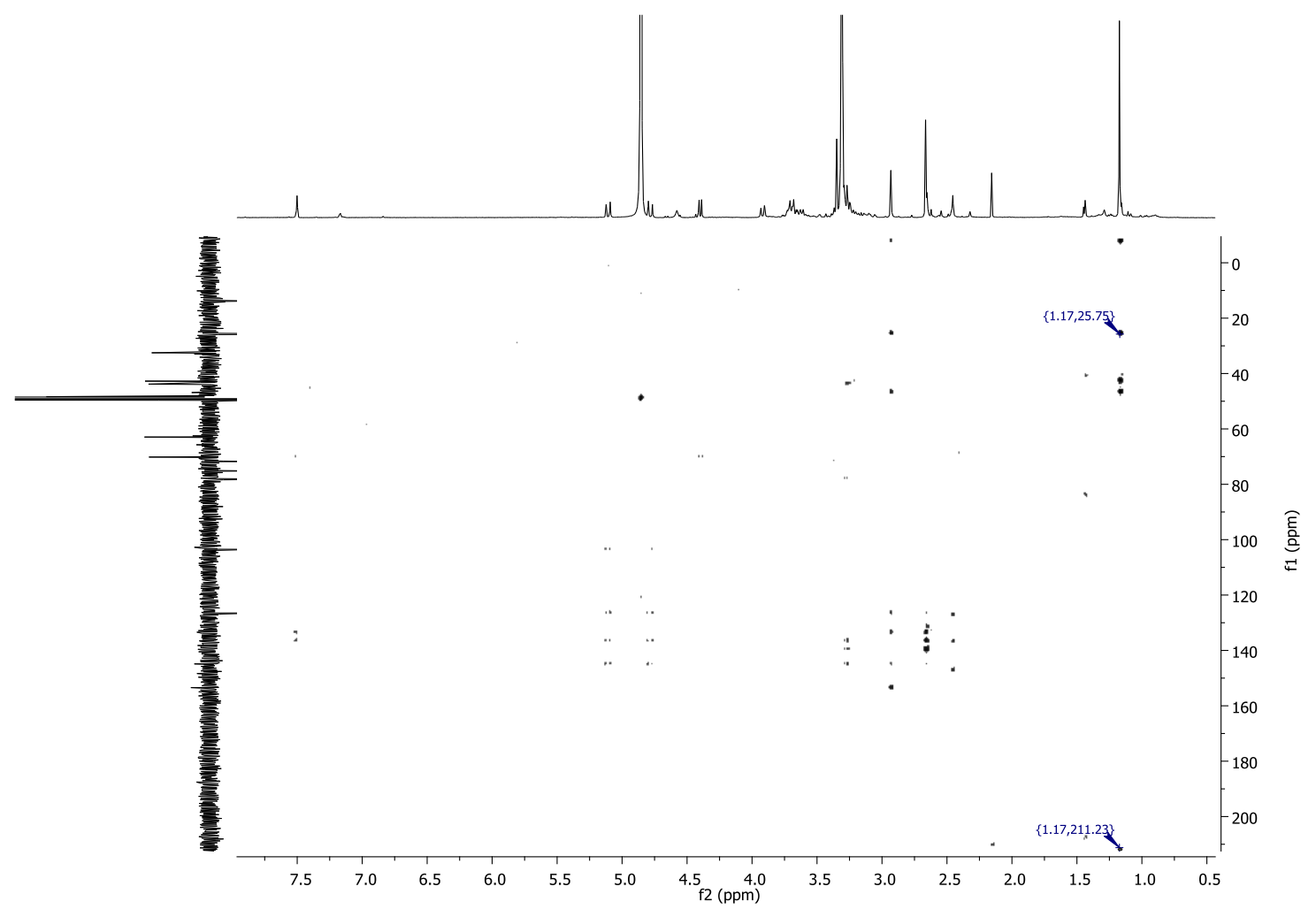

Figure S91. HMBC NMR spectrum of compound 11.

neg \#1 RT: $0.00 \quad$ AV: $1 \quad$ NL: $1.84 E 4$

T: FTMS - p NSI U SIM ms [417.00-437.00]

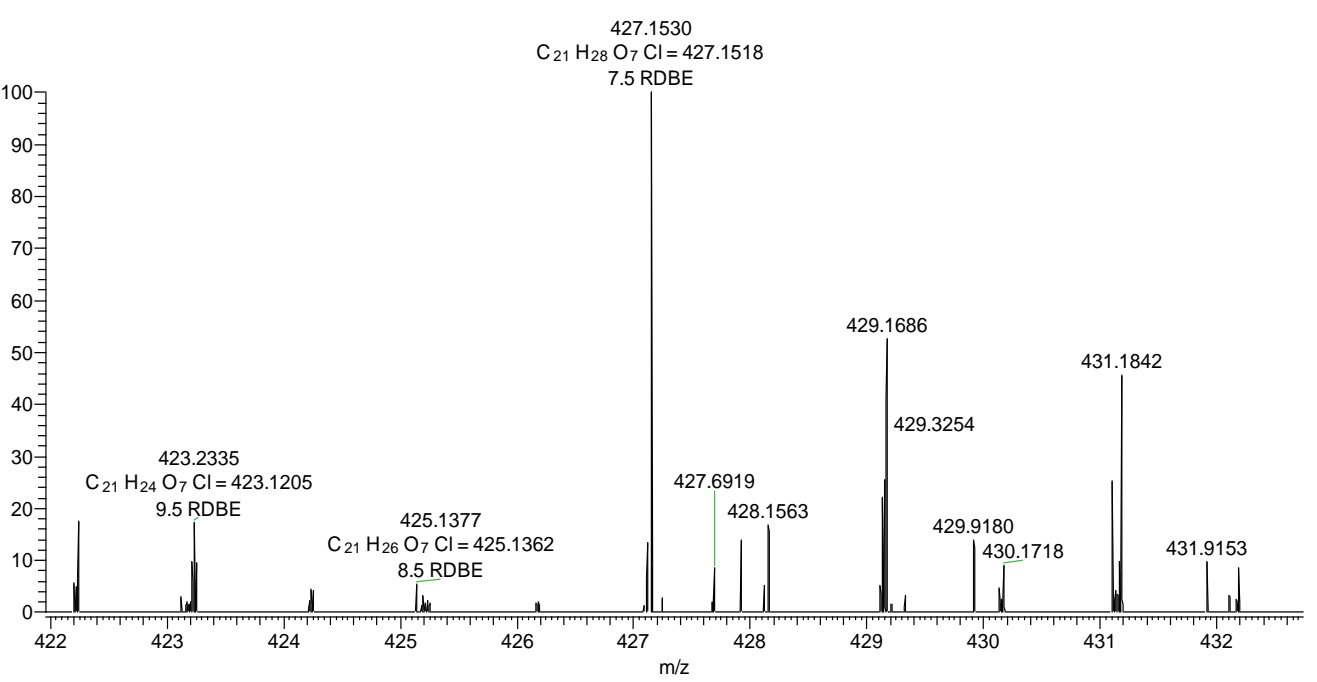

Figure S92. FT-ICR-MS spectrum of compound 11. 


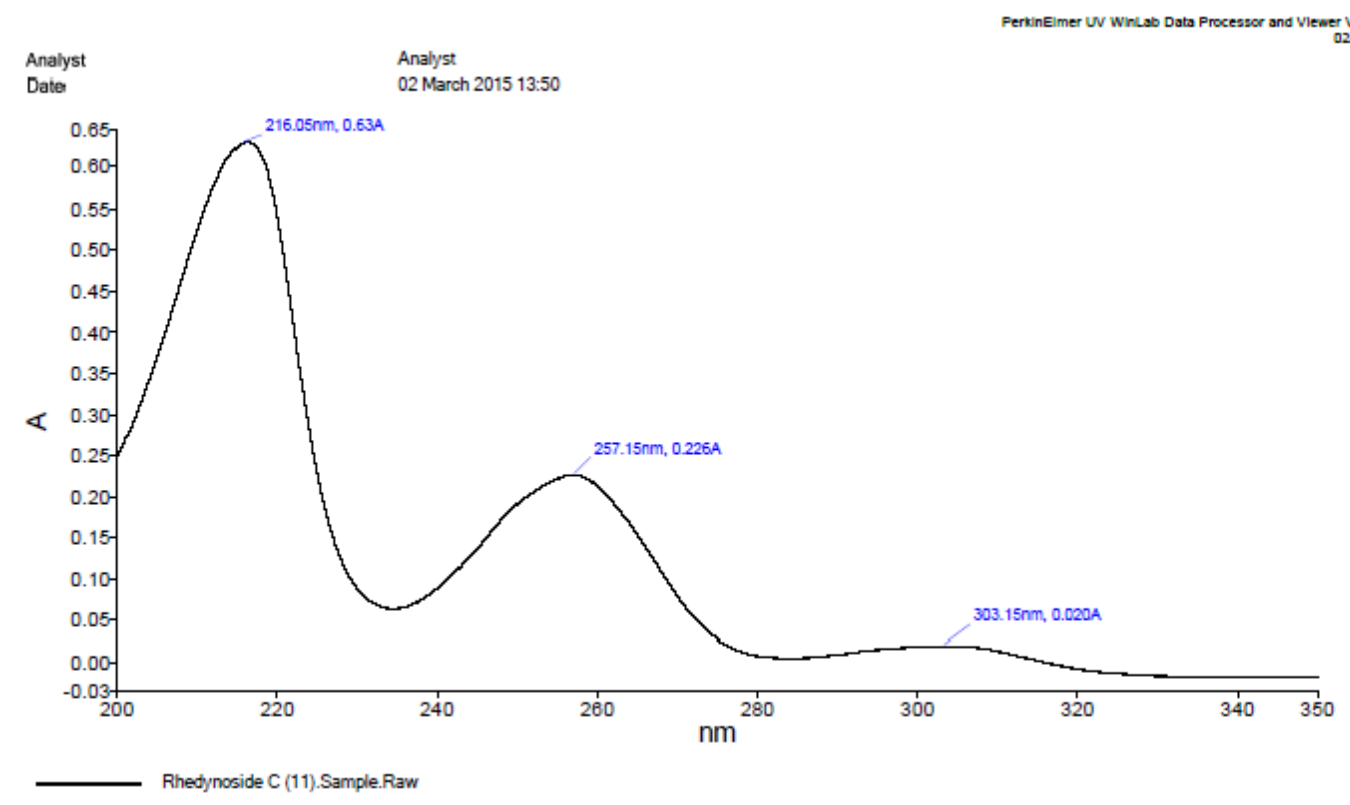

Figure S93. UV spectrum of compound 11 in $\mathrm{CH}_{3} \mathrm{OH}$.

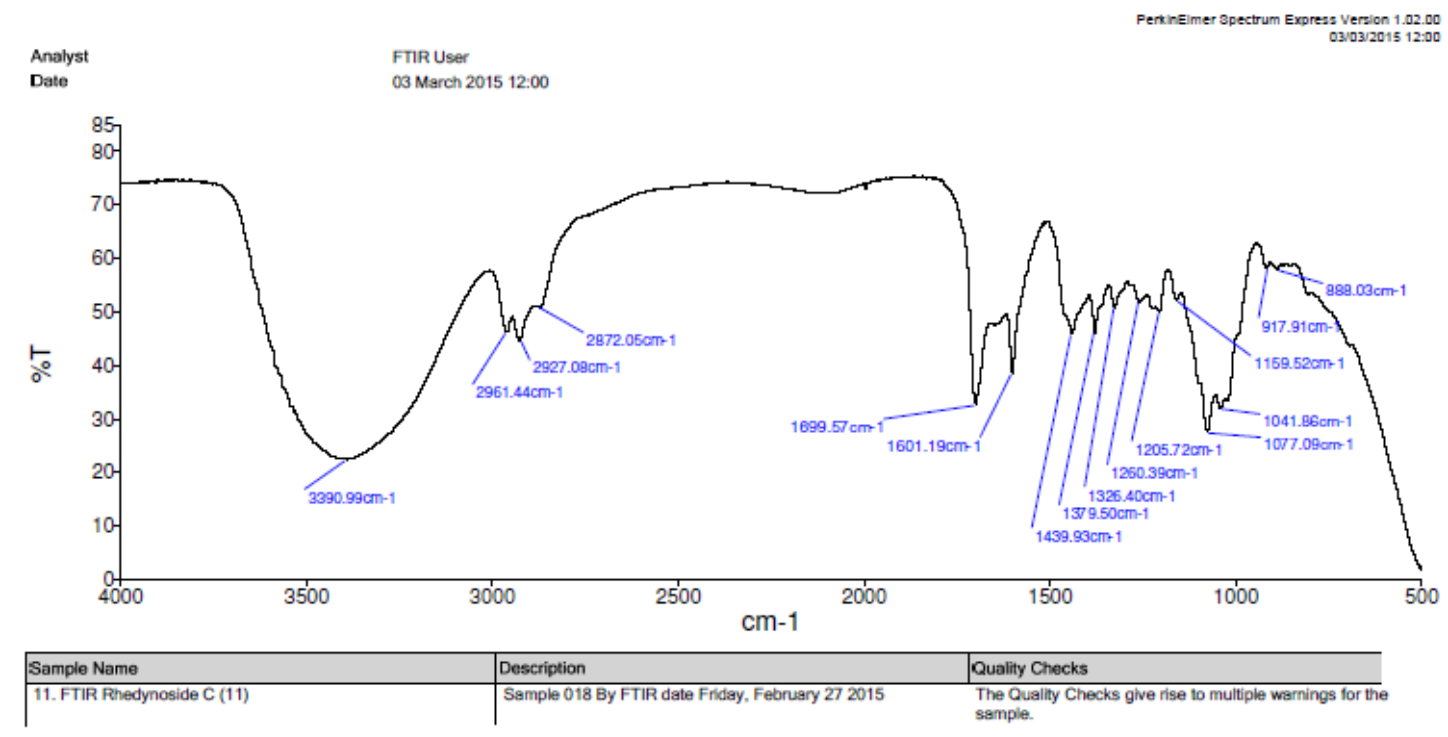

Figure S94. FT-IR spectrum of compound 11 in $\mathrm{CH}_{3} \mathrm{OH}$. 
PROTON.b CDCI3 \{C:|Bruker|TopSpin3.2\} TECH 21
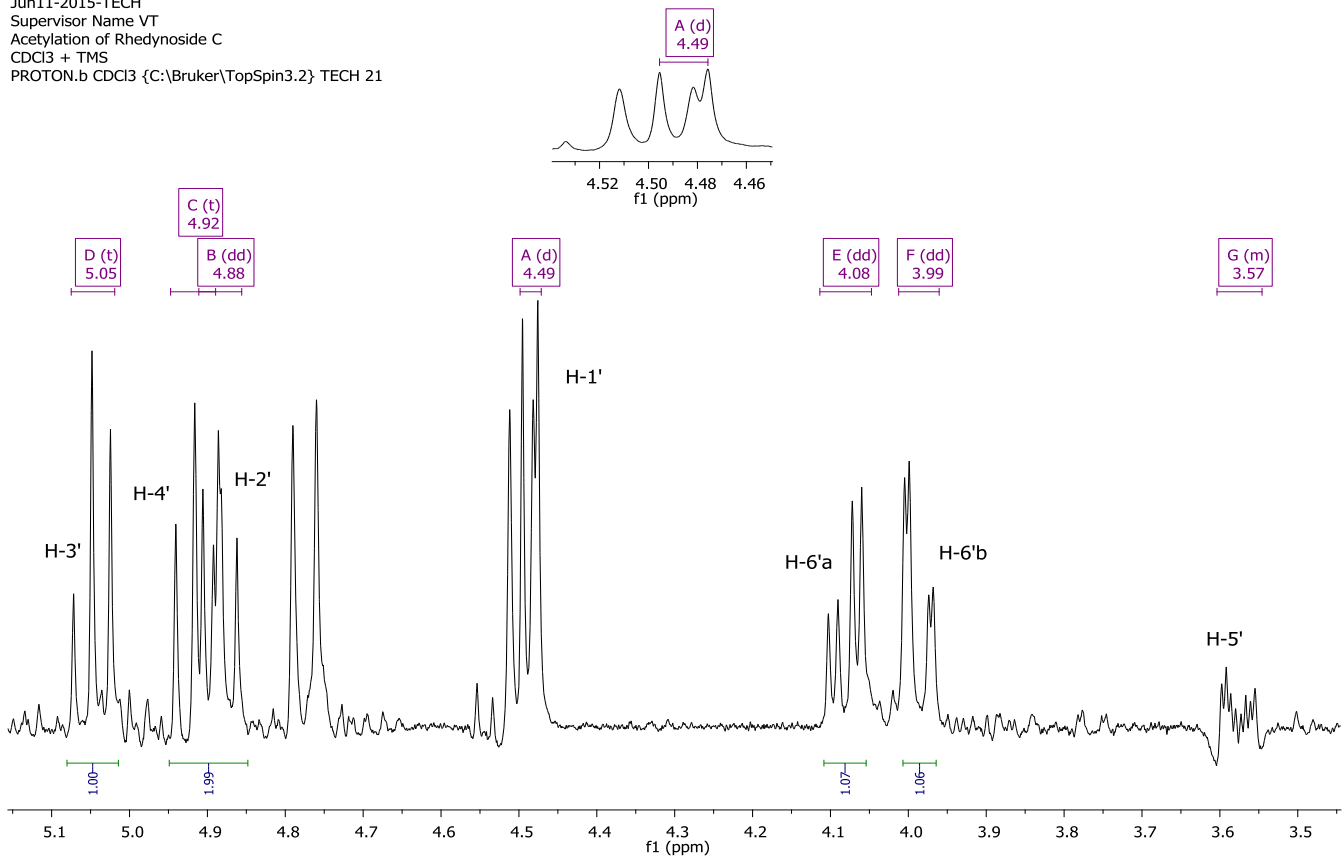

Figure S95. ${ }^{1} \mathrm{H} \mathrm{NMR}\left(\mathrm{CDCl}_{3}, 400 \mathrm{MHz}\right)$ spectrum of compound 11 after acetylation reaction

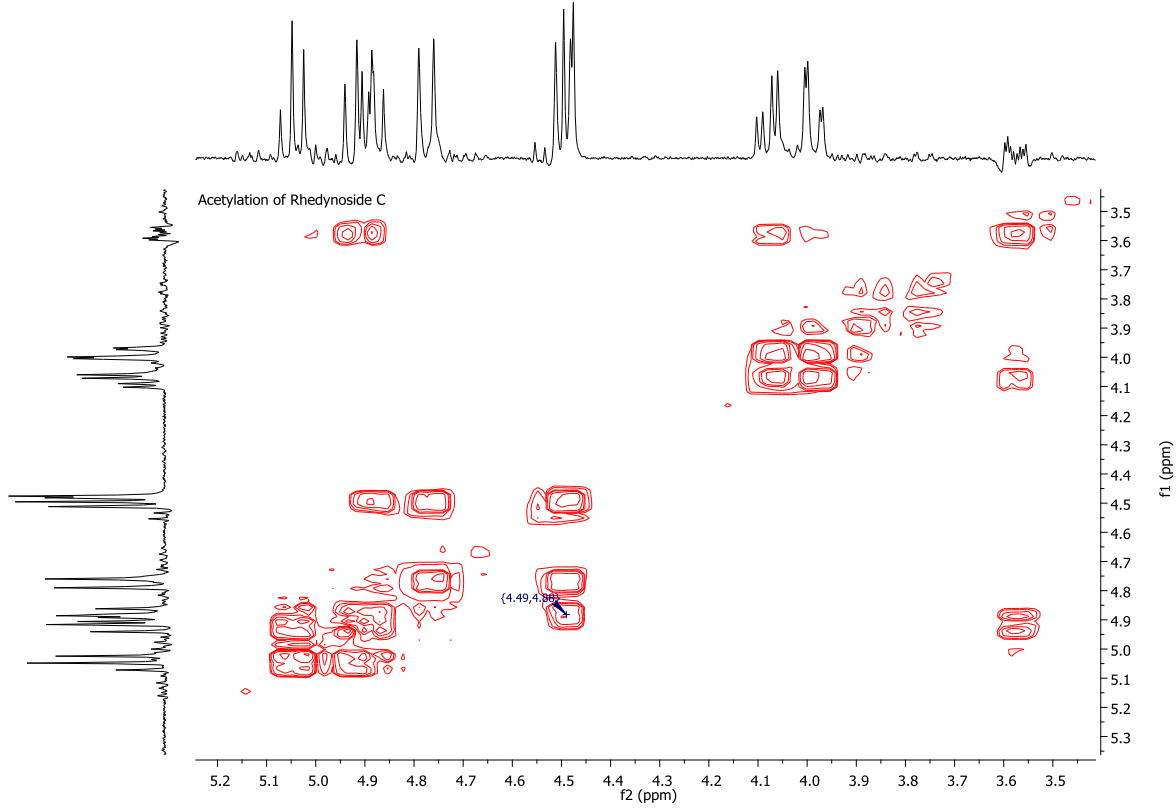

Figure S96. ${ }^{1} \mathrm{H}-{ }^{1} \mathrm{H}$ COSY NMR spectrum of compound 11 after acetylation reaction 


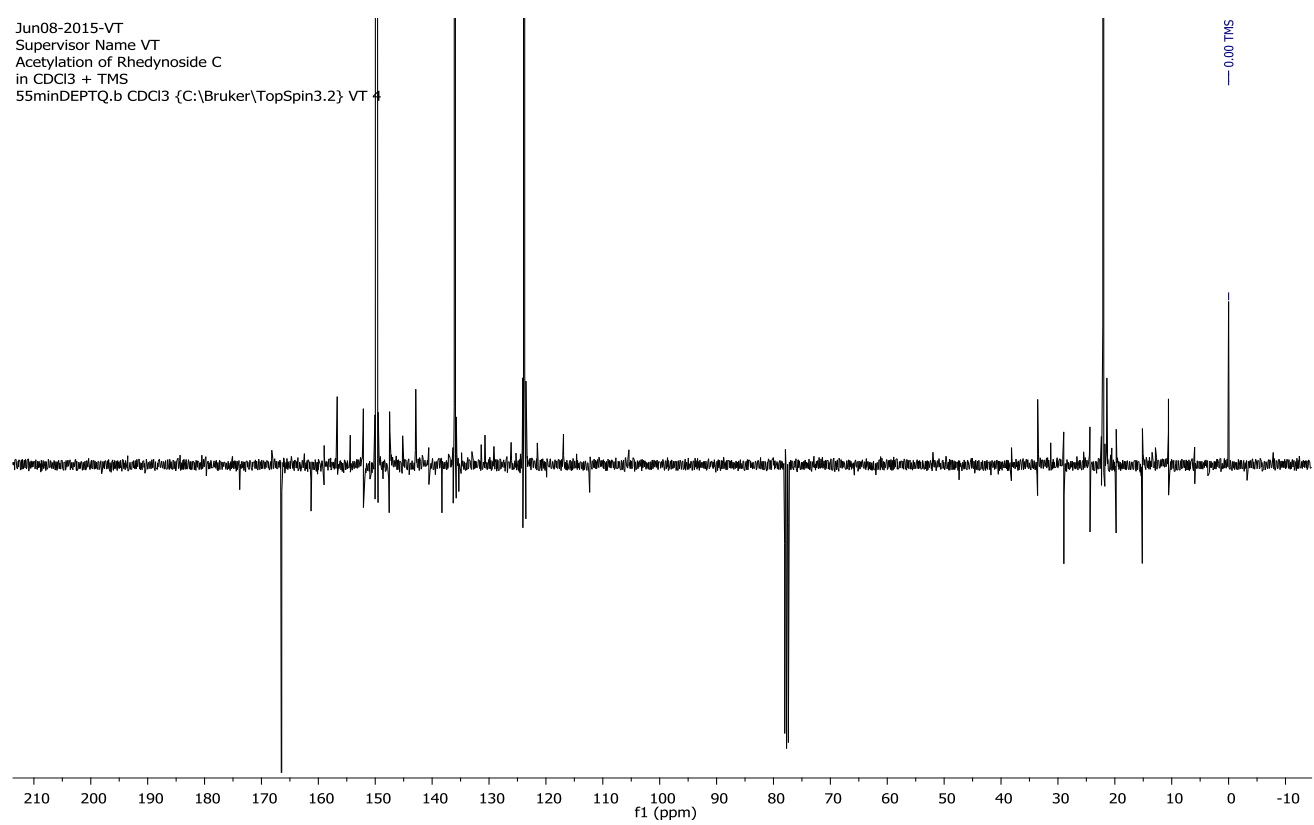

Figure S97. DEPTQ NMR $\left(\mathrm{CDCl}_{3}, 100 \mathrm{MHz}\right)$ spectrum of compound 11 after acetylation reaction

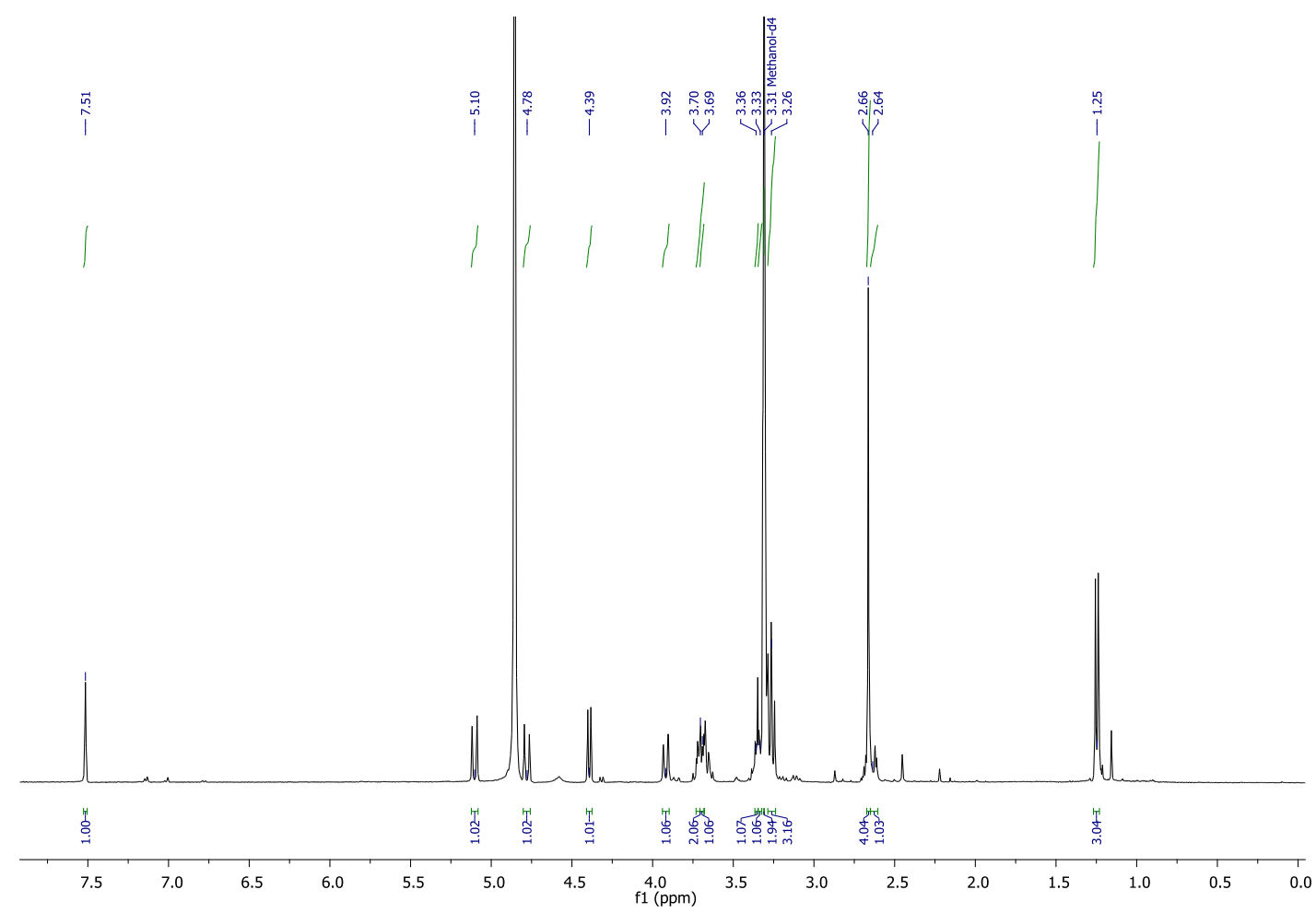

Figure S98. ${ }^{1} \mathrm{H}$ NMR $\left(\mathrm{CD}_{3} \mathrm{OD}, 400 \mathrm{MHz}\right)$ spectrum of compound 12. 


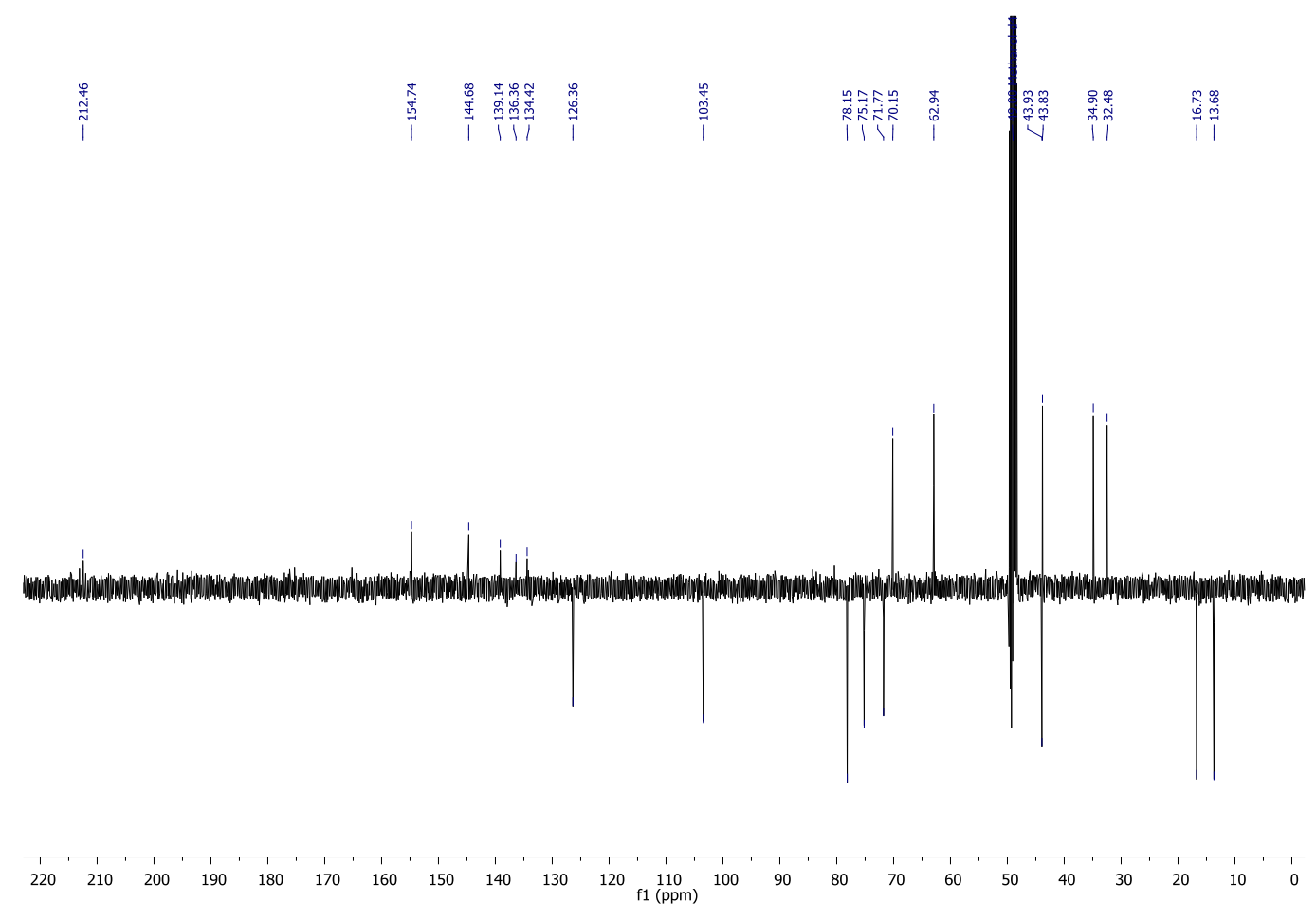

Figure S99. DEPTQ NMR $\left(\mathrm{CD}_{3} \mathrm{OD}, 100 \mathrm{MHz}\right)$ spectrum of compound 12.

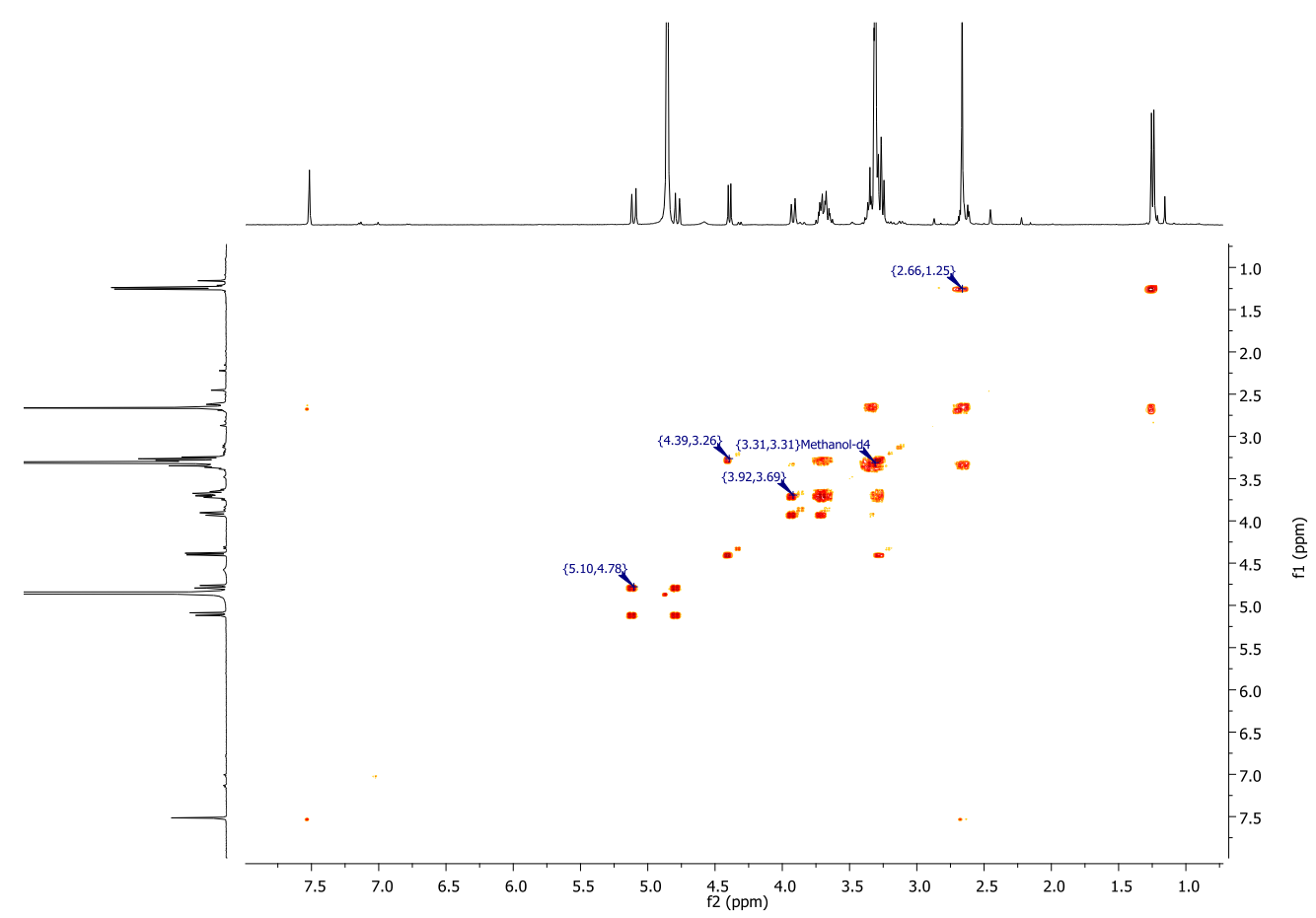

Figure S100. ${ }^{1} \mathrm{H}-{ }^{1} \mathrm{H}$ COSY NMR spectrum of compound 12. 


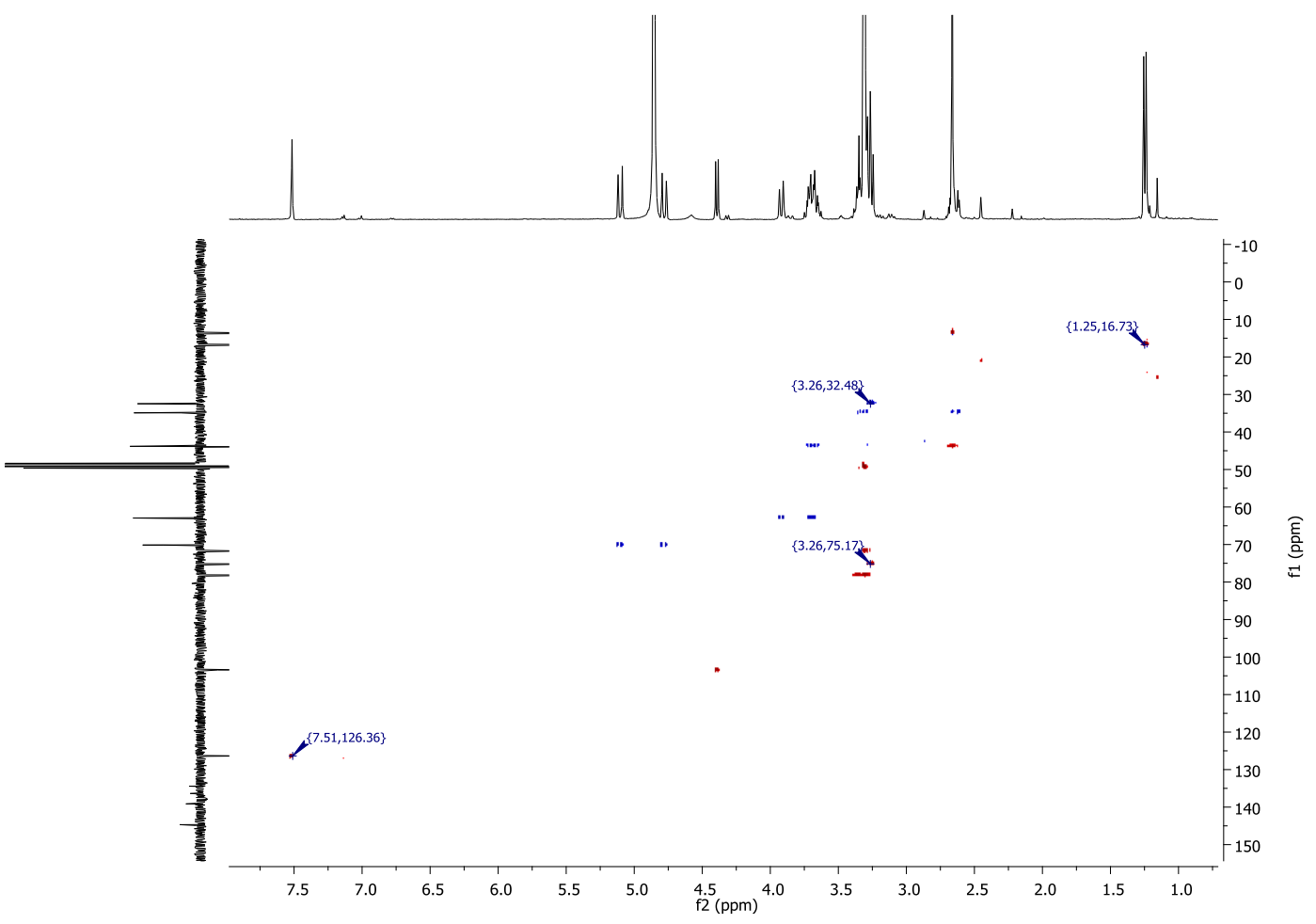

Figure S101. HSQC NMR spectrum of compound 12.

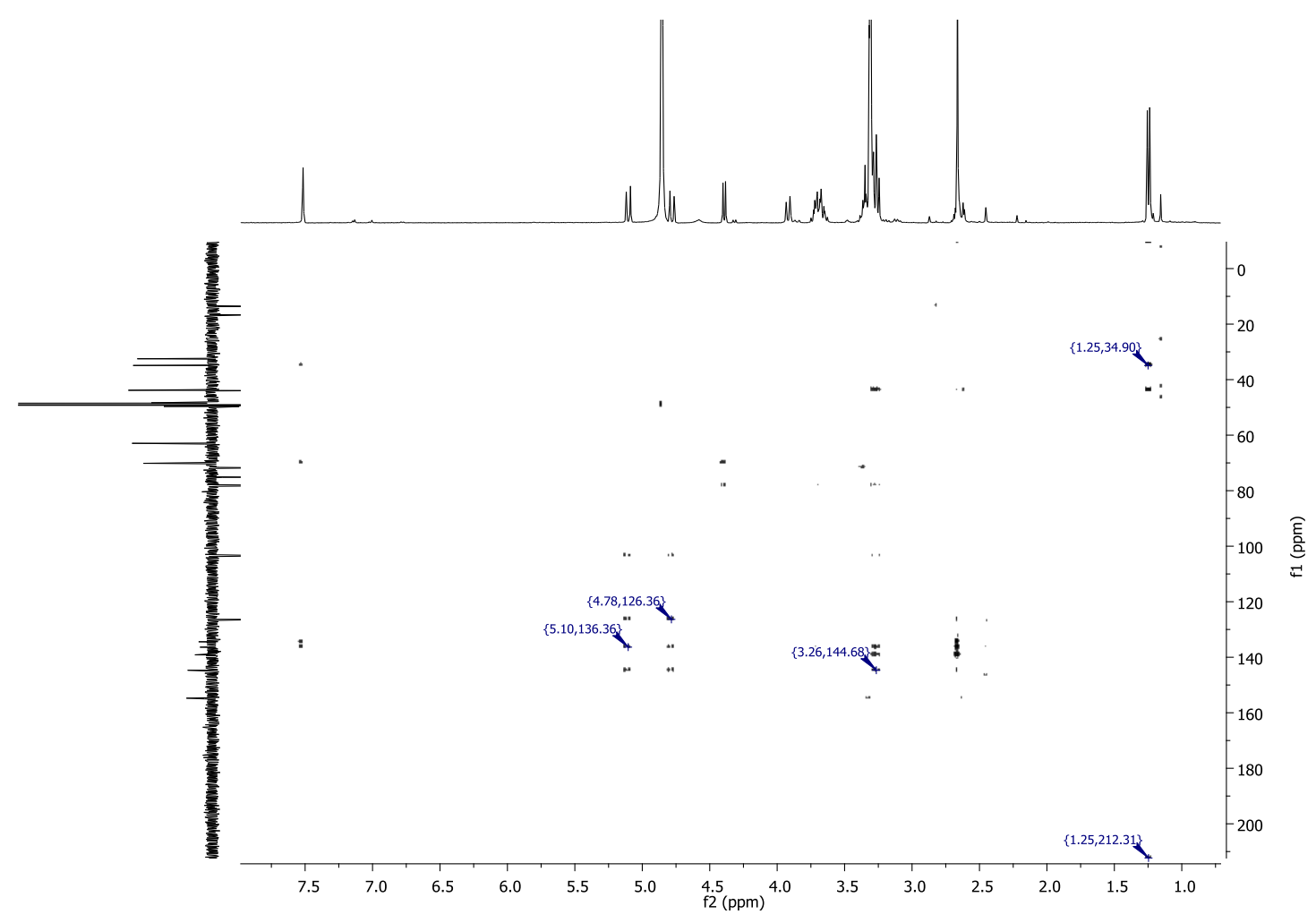

Figure S102. HMBC NMR spectrum of compound 12. 
neg \#3 RT: 0.04 AV: 1 NL: 8.54E4

T: FTMS - p NSI u SIM ms [403.00-423.00]

413.1374

$\mathrm{C}_{20} \mathrm{H}_{26} \mathrm{O}_{7} \mathrm{Cl}=413.1362$

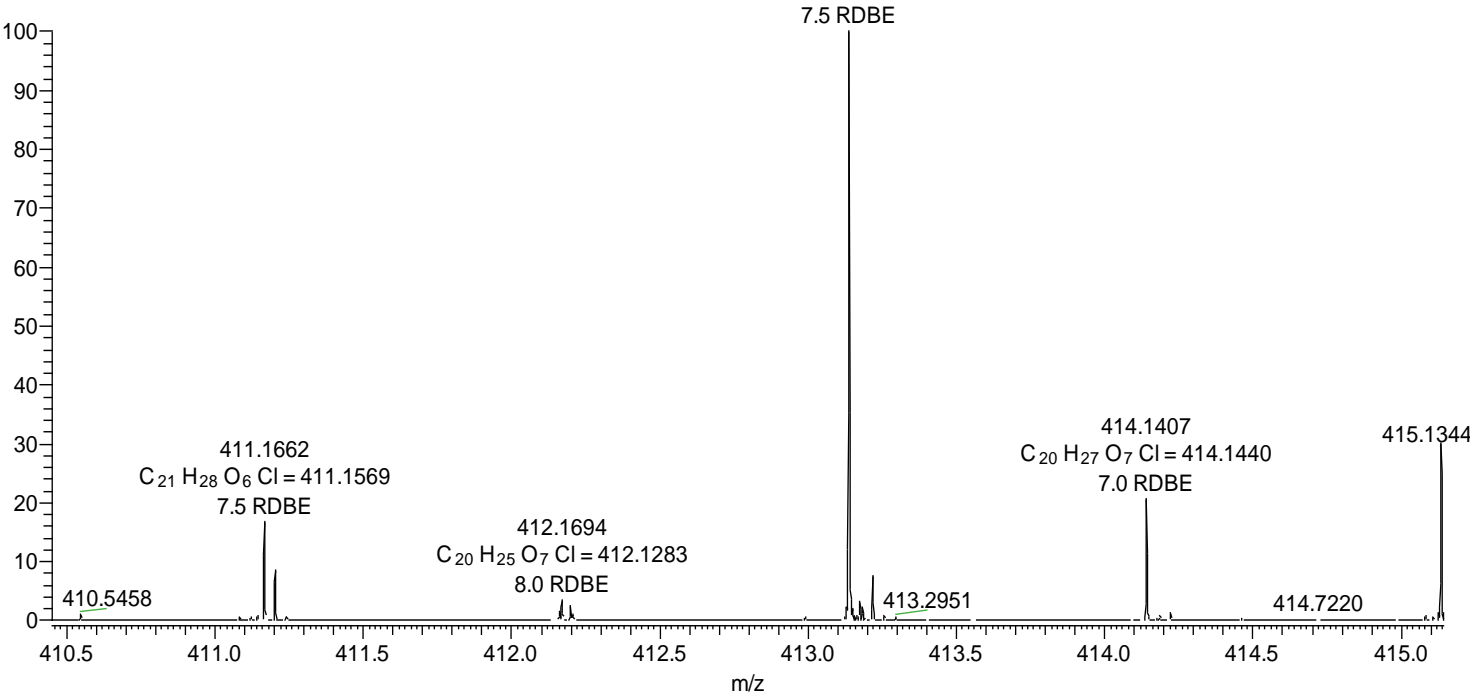

Figure 103. FT-ICR-MS spectrum of compound 12.

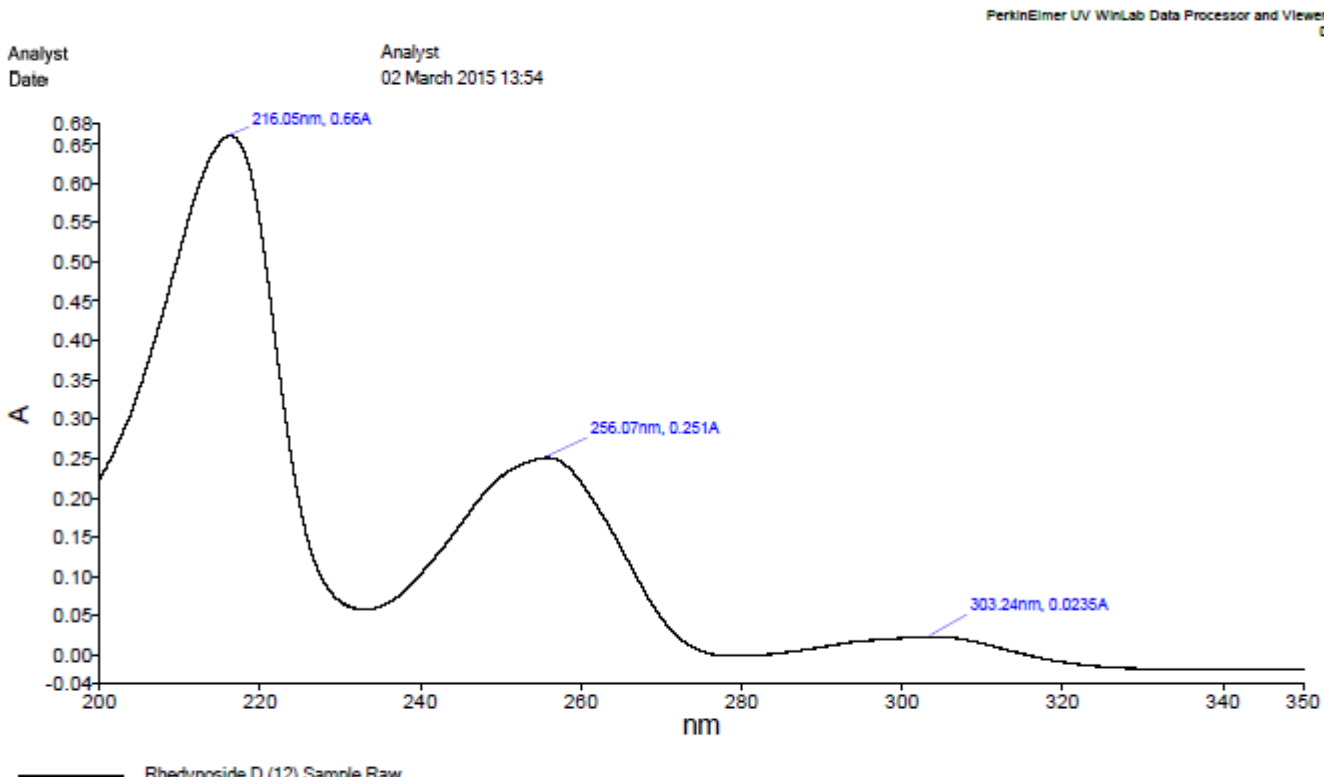

Figure S104. UV spectrum of compound 12 in $\mathrm{CH}_{3} \mathrm{OH}$. 


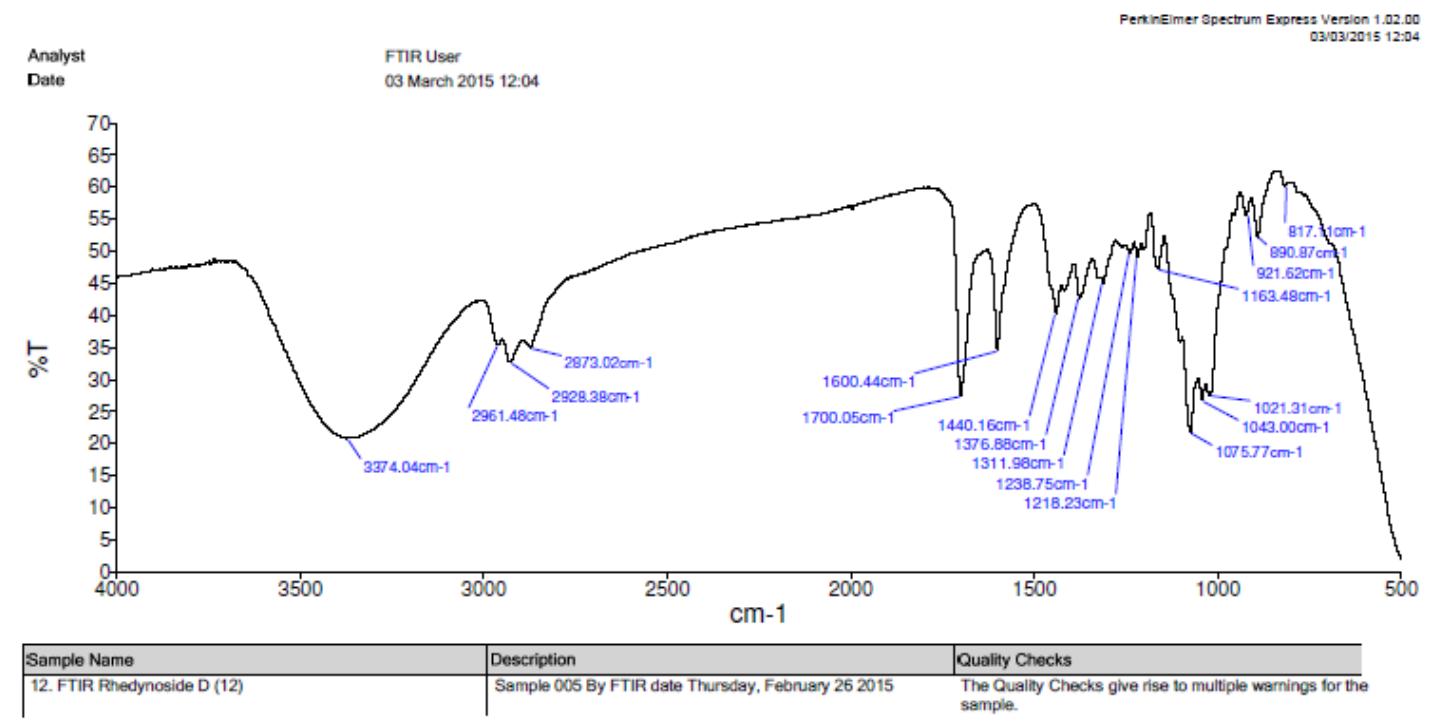

Figure S105. FT-IR spectrum of compound 12 in $\mathrm{CH}_{3} \mathrm{OH}$.

Jun11-2015-TECH
Supervisor Name $V$ T

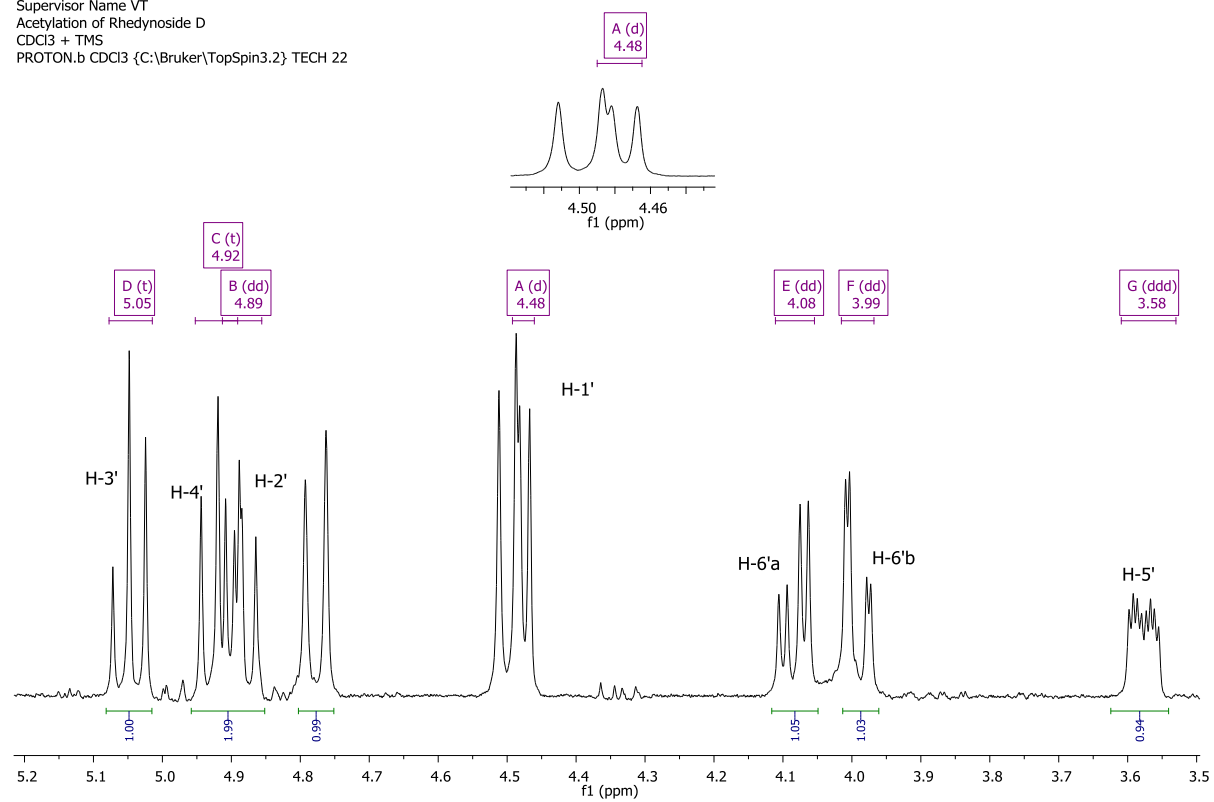

Figure S106. ${ }^{1} \mathrm{H} \mathrm{NMR}\left(\mathrm{CDCl}_{3}, 400 \mathrm{MHz}\right)$ spectrum of compound 12 after acetylation reaction 


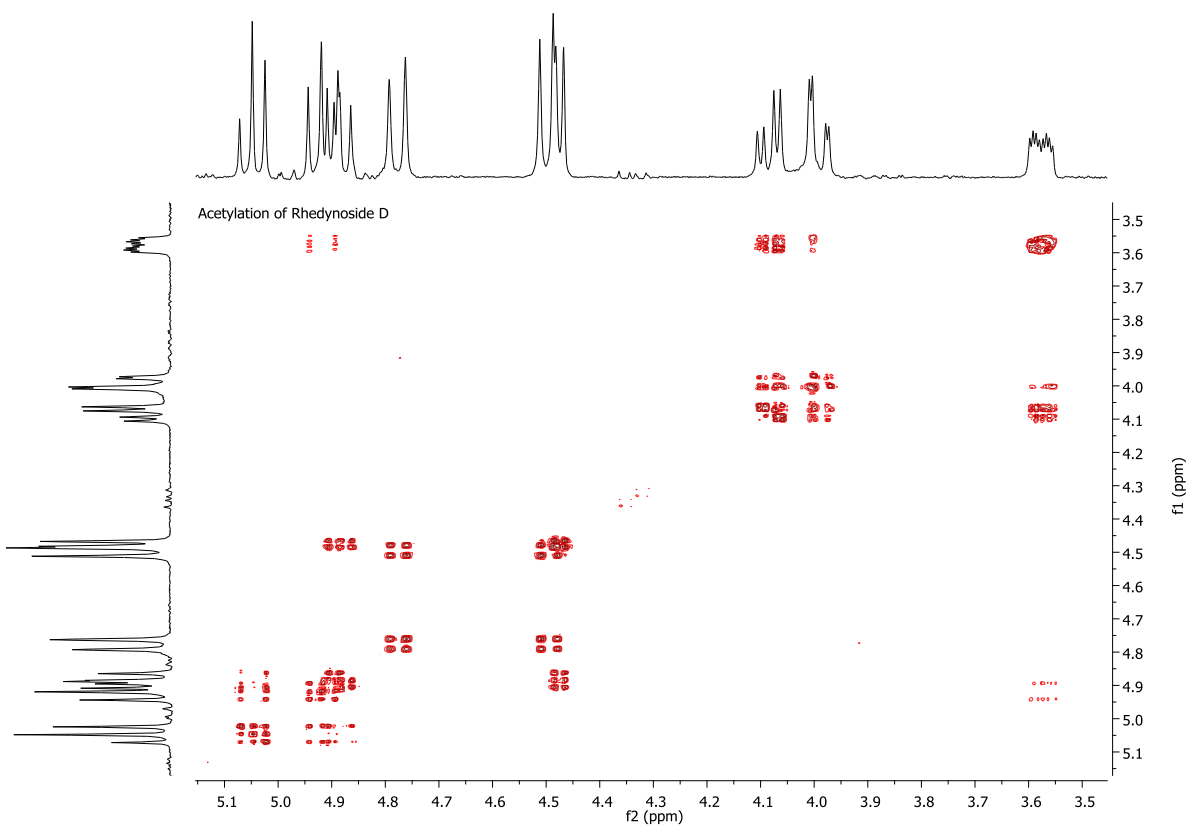

Figure S107. ${ }^{1} \mathrm{H}-{ }^{1} \mathrm{H}$ COSY NMR spectrum of compound 12 after acetylation reaction

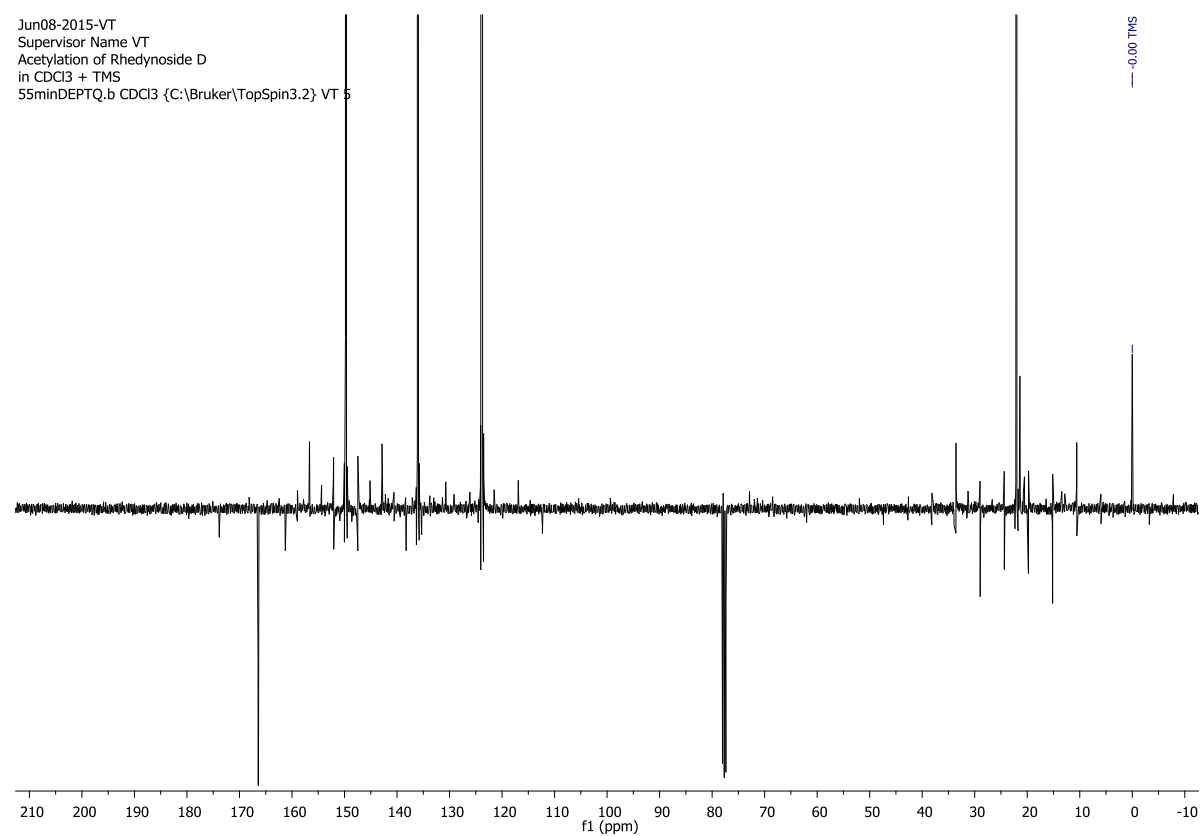

Figure S108. DEPTQ NMR $\left(\mathrm{CDCl}_{3}, 100 \mathrm{MHz}\right)$ spectrum of compound 12 after acetylation reaction 


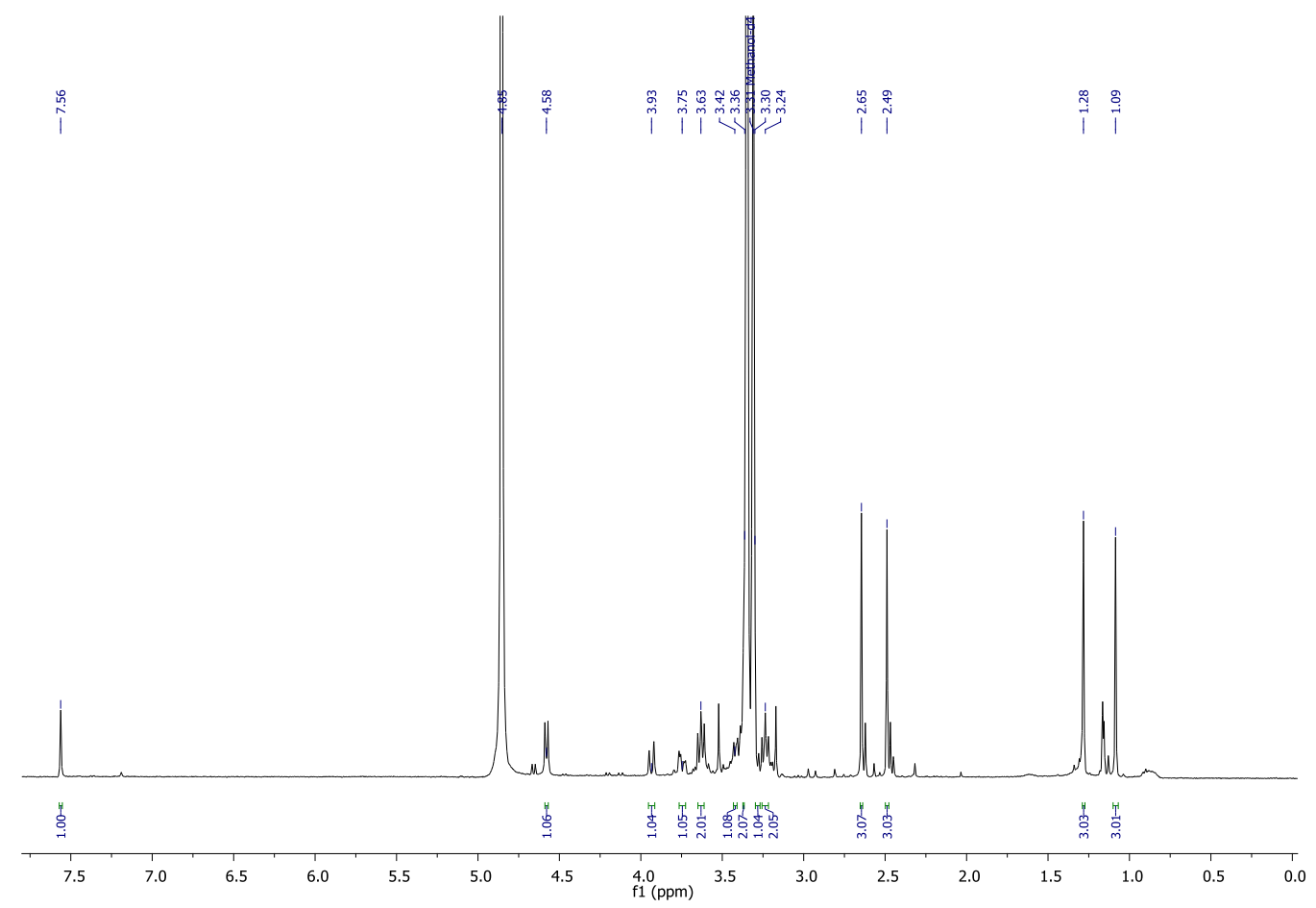

Figure S109. ${ }^{1} \mathrm{H}$ NMR $\left(\mathrm{CD}_{3} \mathrm{OD}, 400 \mathrm{MHz}\right)$ spectrum of compound 13.

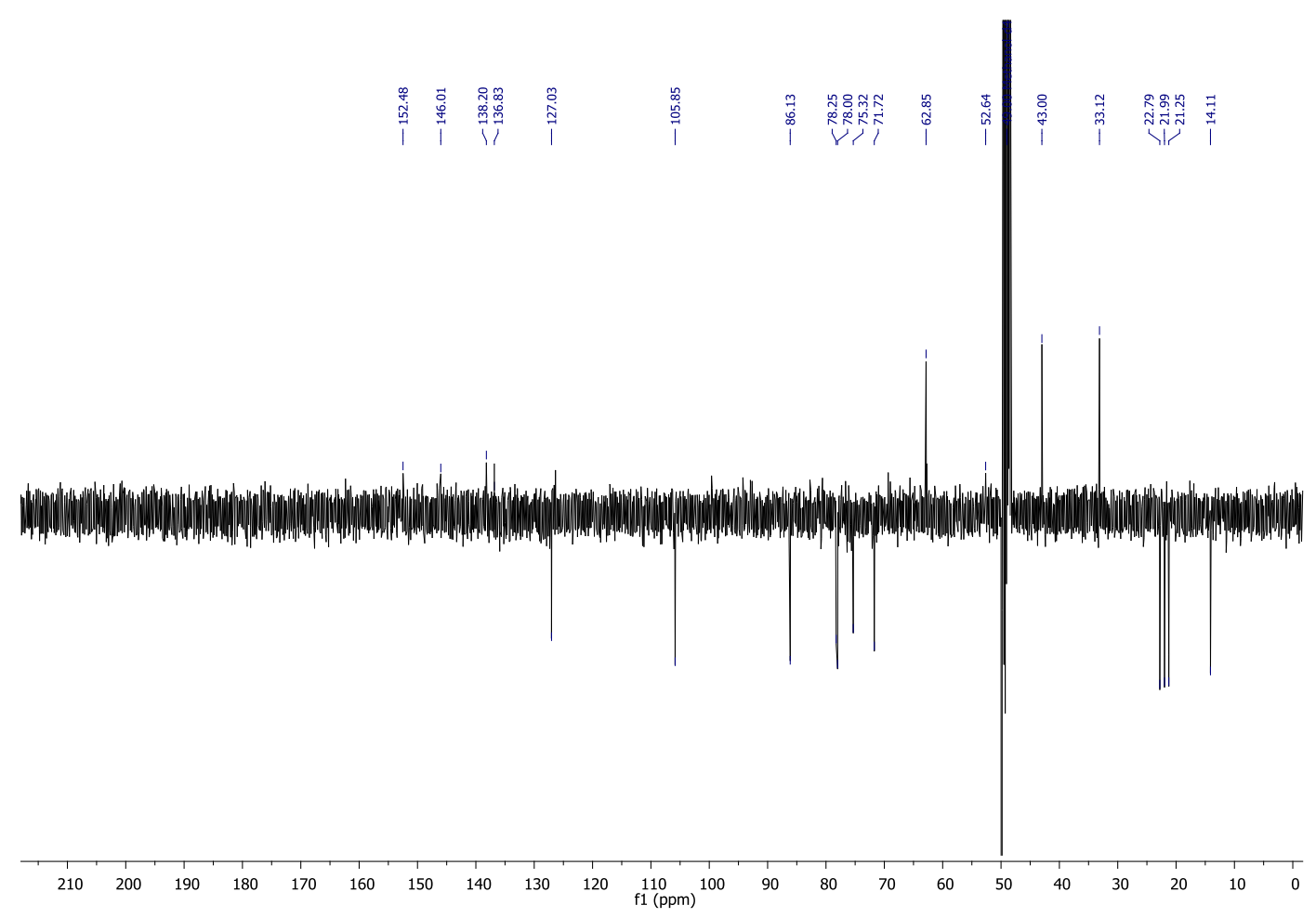

Figure S110. DEPTQ NMR ( $\left.\mathrm{CD}_{3} \mathrm{OD}, 100 \mathrm{MHz}\right)$ spectrum of compound 13. 


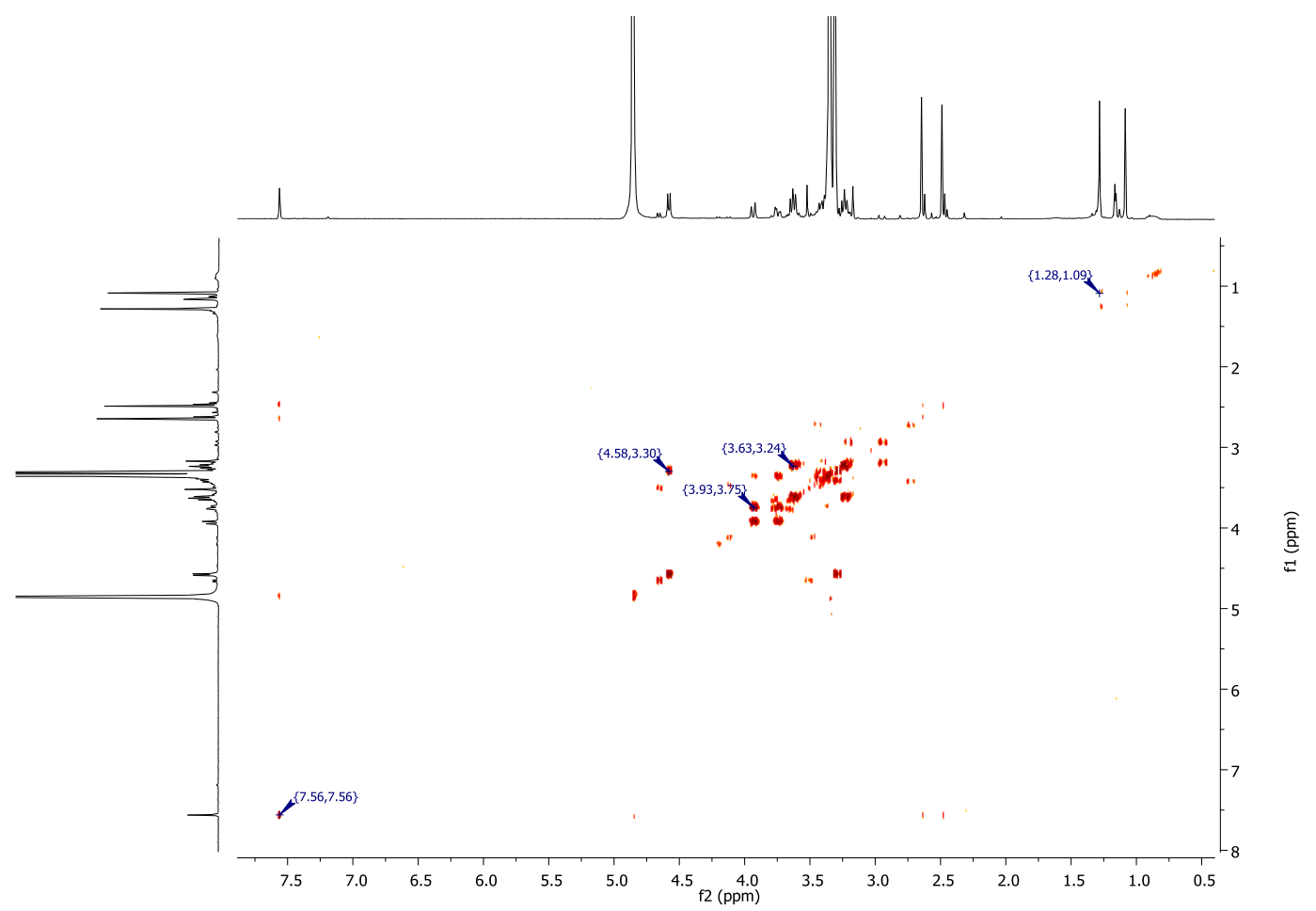

Figure S111. ${ }^{1} \mathrm{H}-{ }^{1} \mathrm{H}$ COSY NMR spectrum of compound 13.

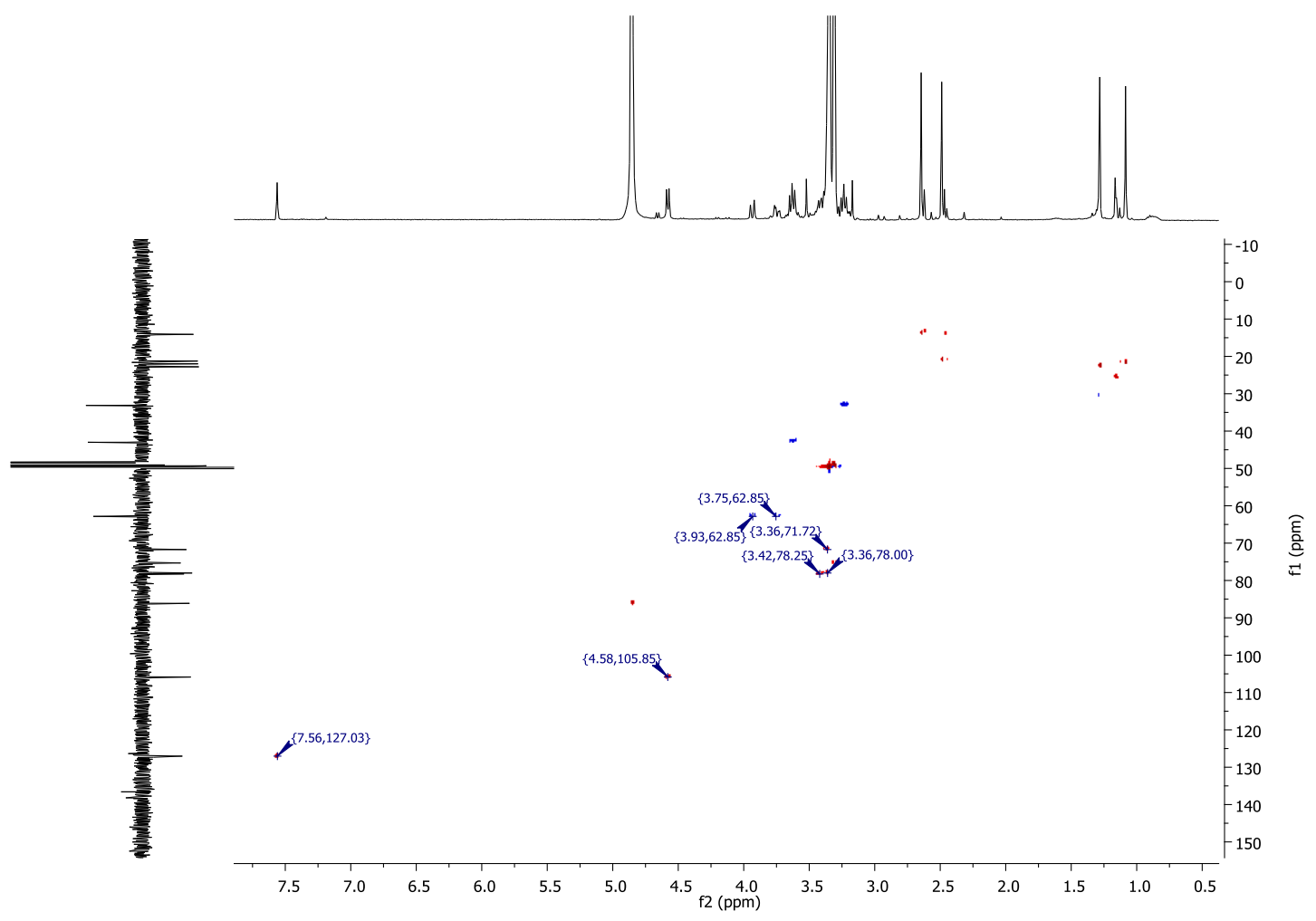

Figure S112. HSQC NMR spectrum of compound 13. 


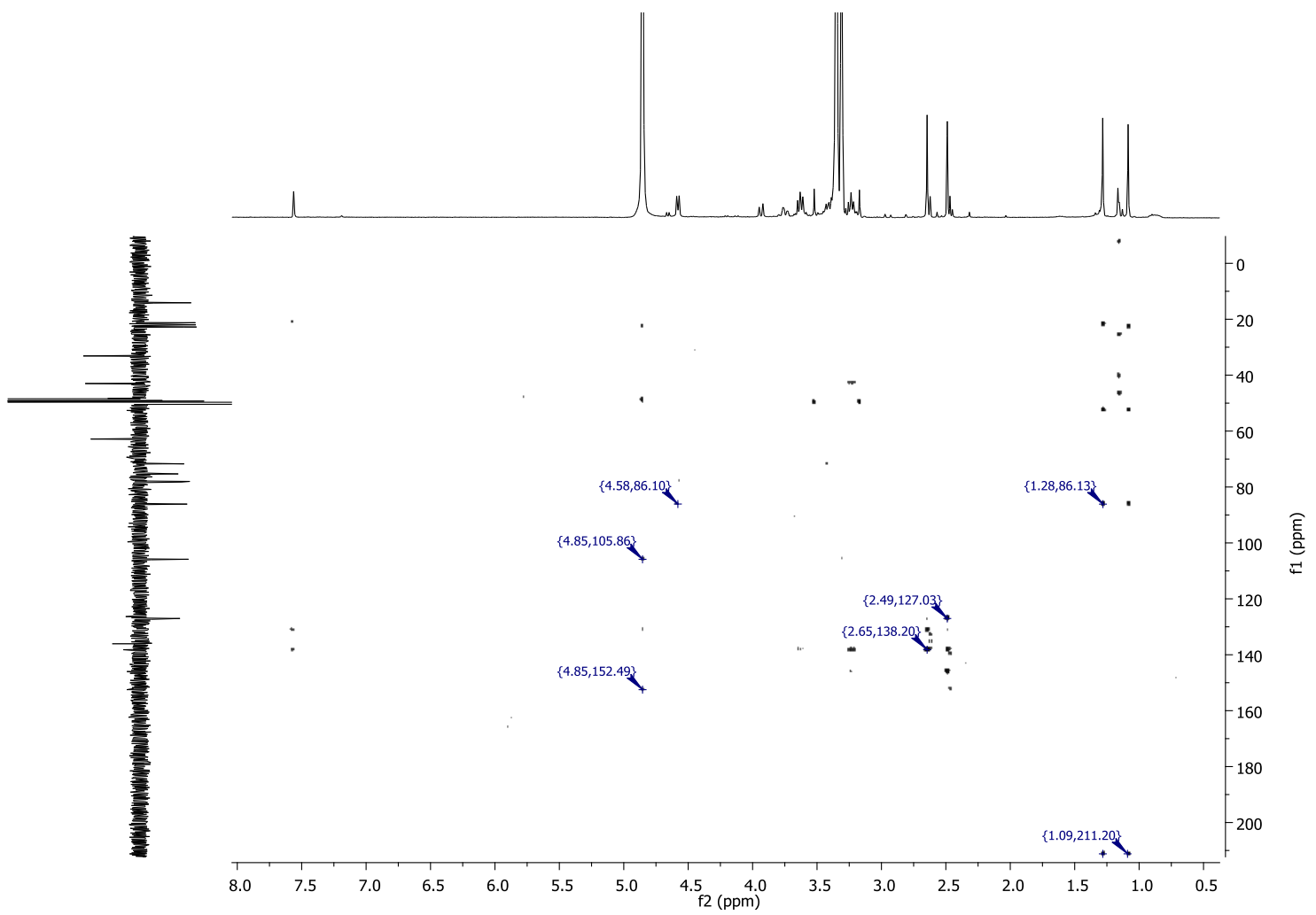

Figure S113. HMBC NMR spectrum of compound 13.

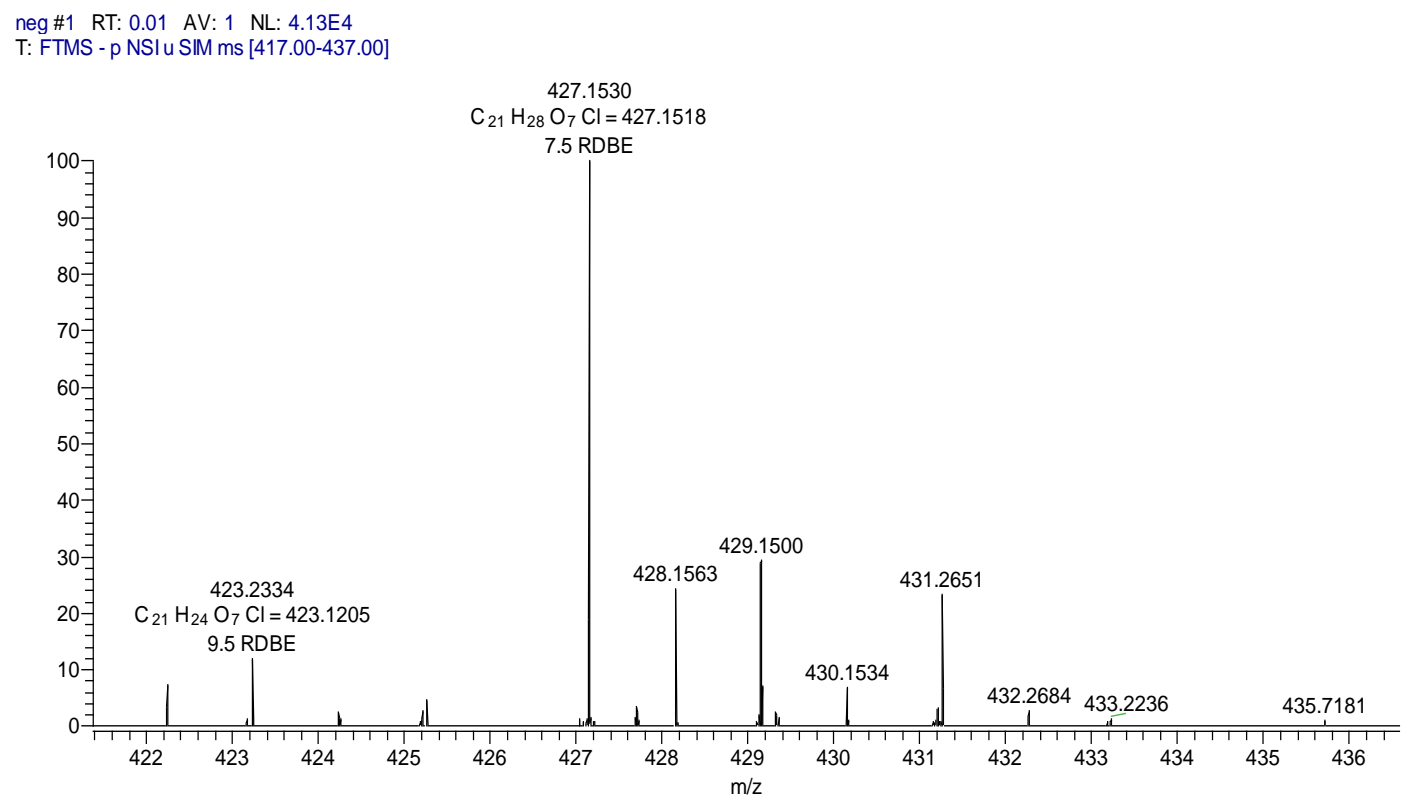

Figure S114. FT-ICR-MS spectrum of compound 13. 


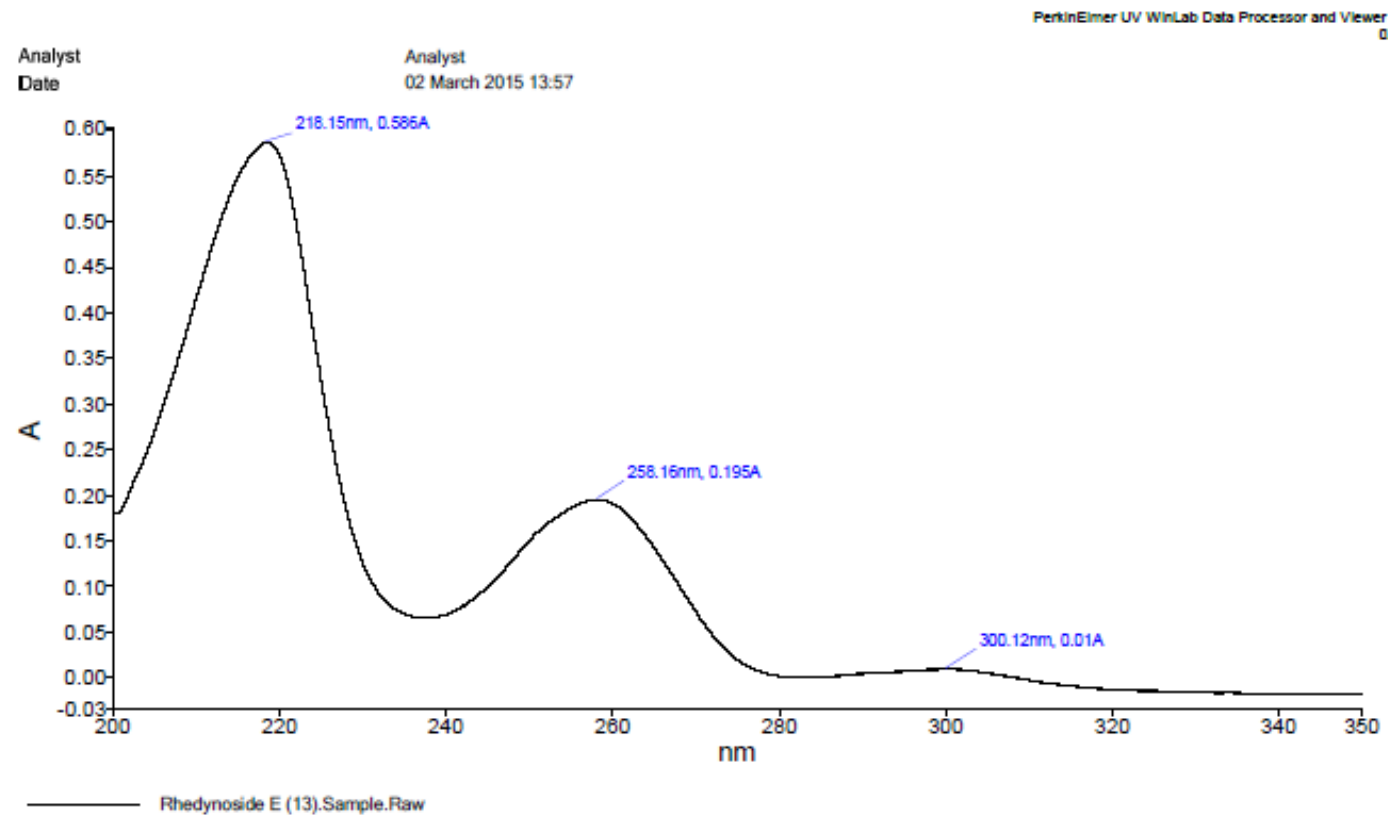

Figure S115. UV spectrum of compound 13 in $\mathrm{CH}_{3} \mathrm{OH}$.

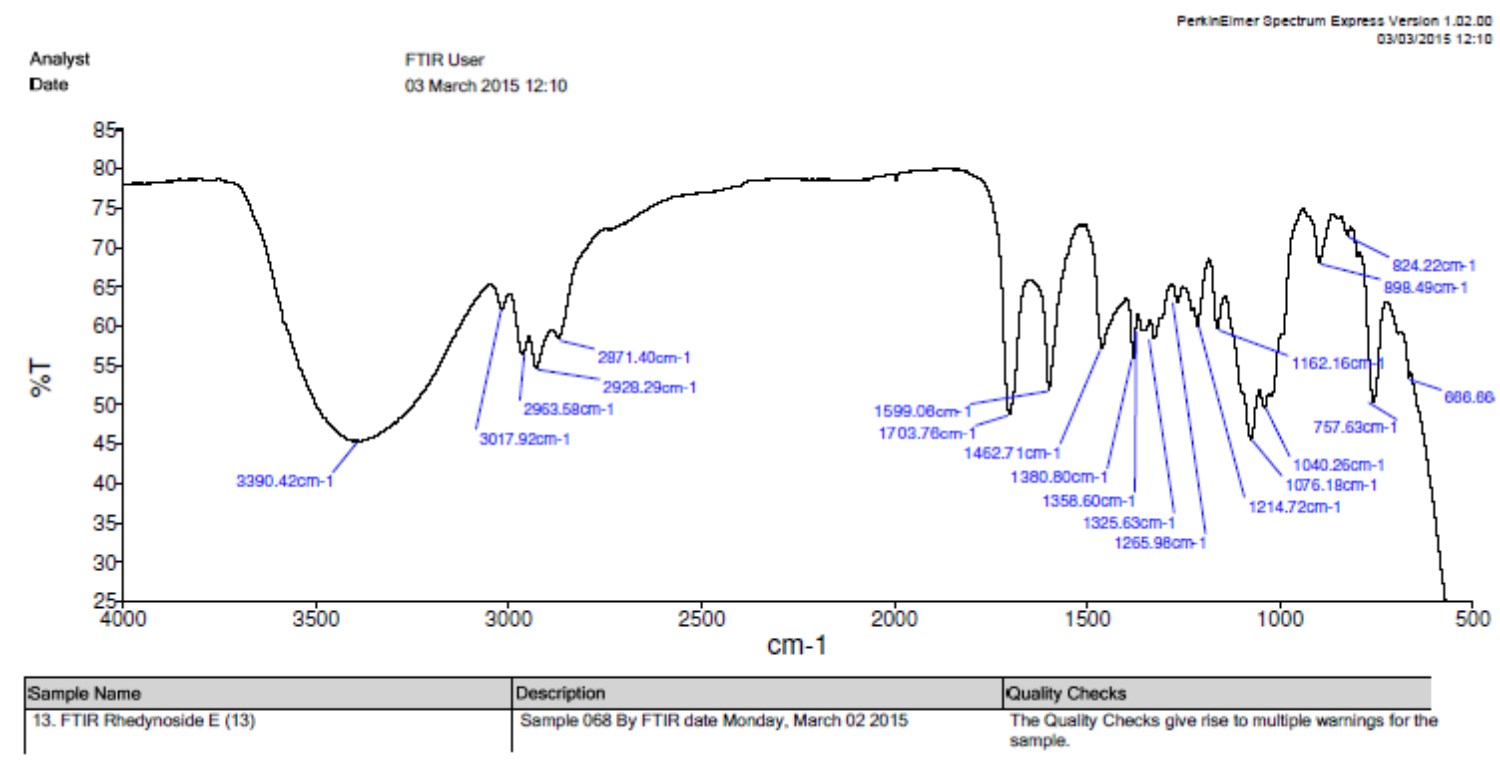

Figure S116. FT-IR spectrum of compound 13 in $\mathrm{CH}_{3} \mathrm{OH}$. 


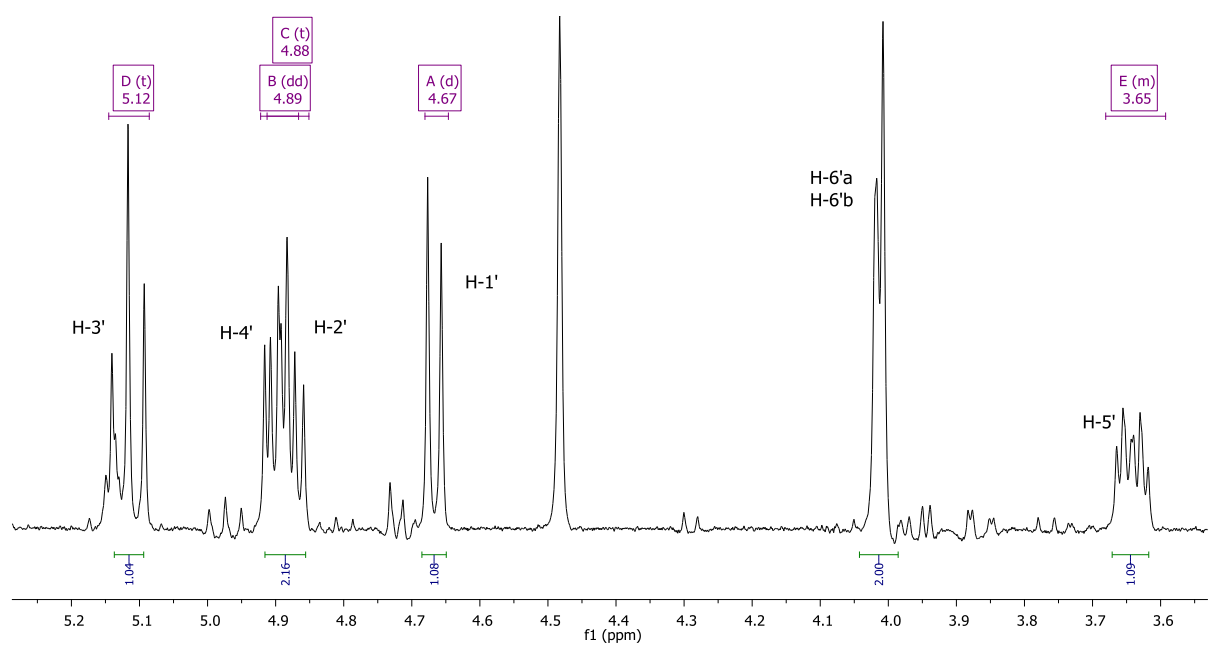

Figure S117. ${ }^{1} \mathrm{H}$ NMR $\left(\mathrm{CDCl}_{3}, 400 \mathrm{MHz}\right)$ spectrum of compound 13 after acetylation reaction

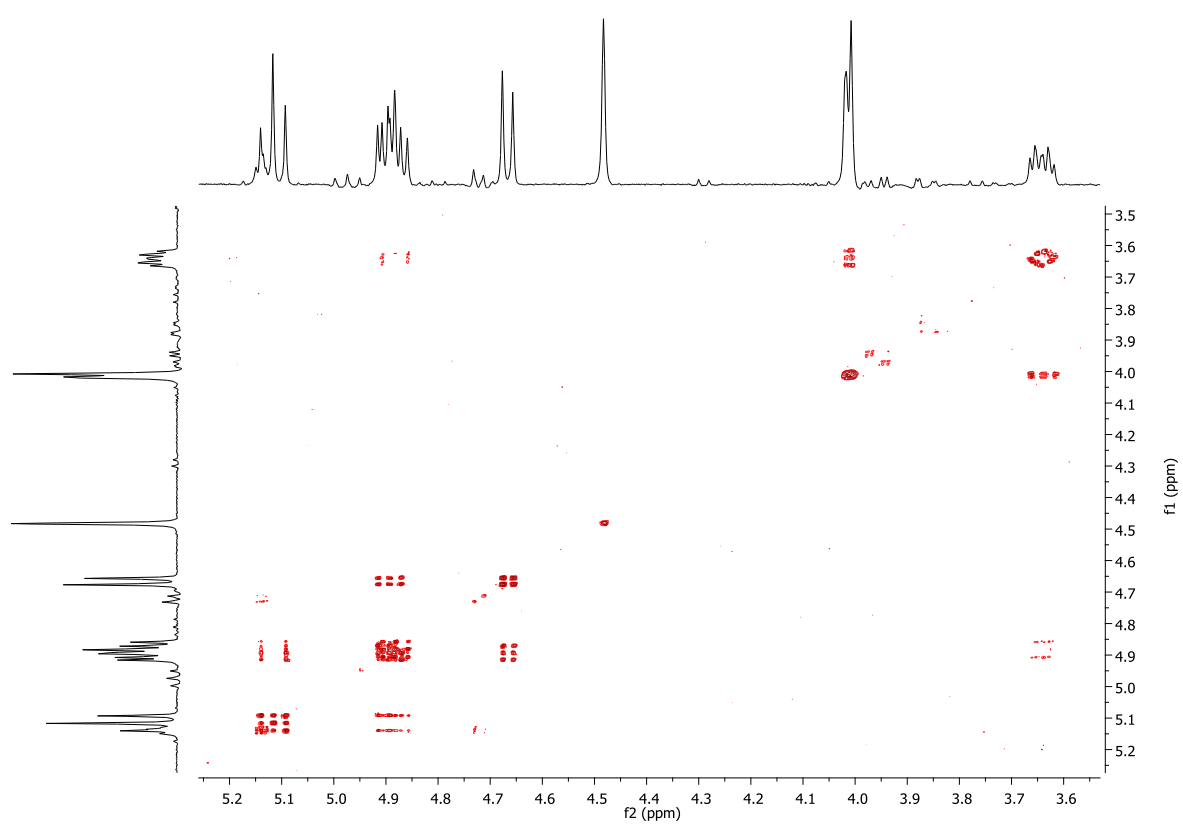

Figure S118. ${ }^{1} \mathrm{H}-{ }^{1} \mathrm{H}$ COSY NMR spectrum of compound 13 after acetylation reaction 


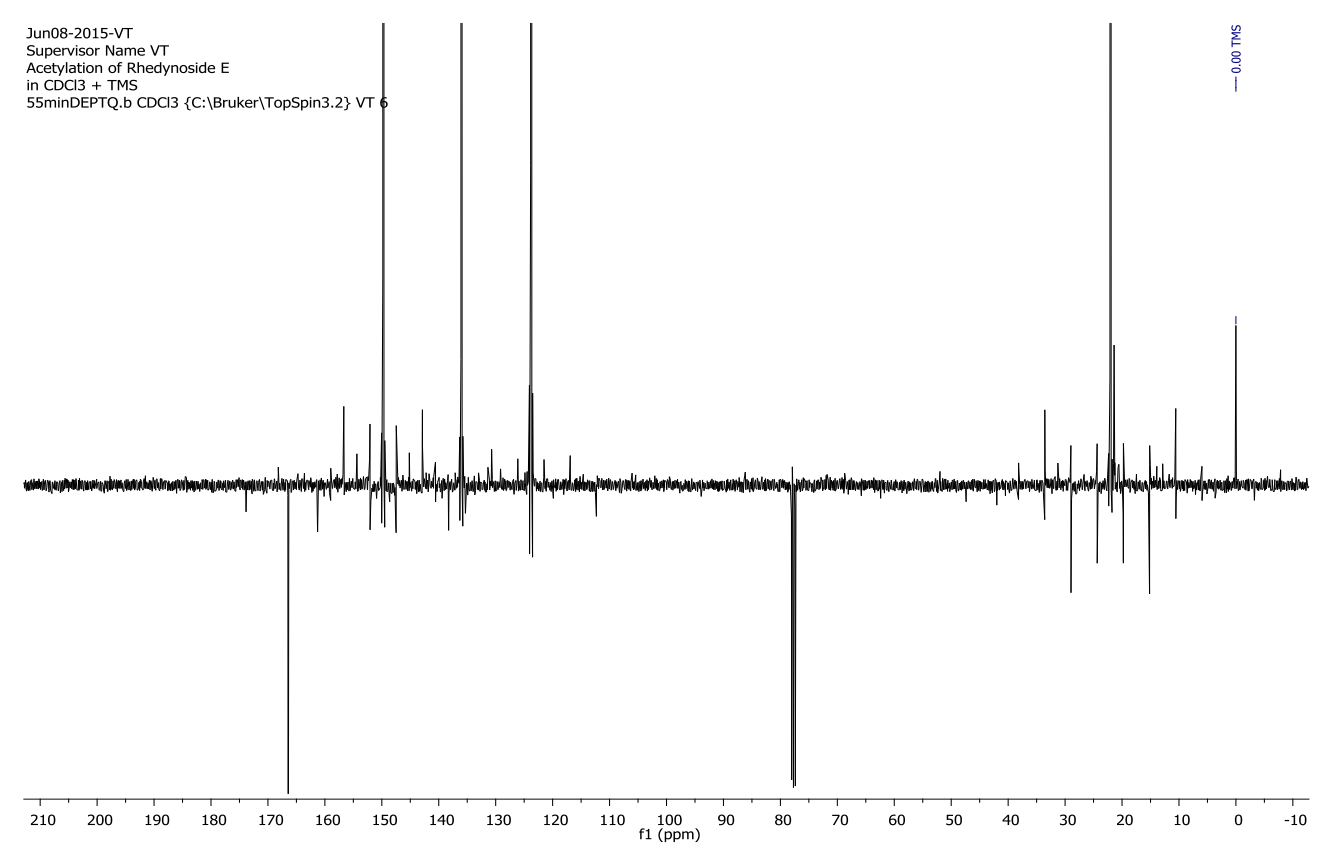

Figure S119. DEPTQ NMR $\left(\mathrm{CDCl}_{3}, 100 \mathrm{MHz}\right)$ spectrum of compound 13 after acetylation reaction

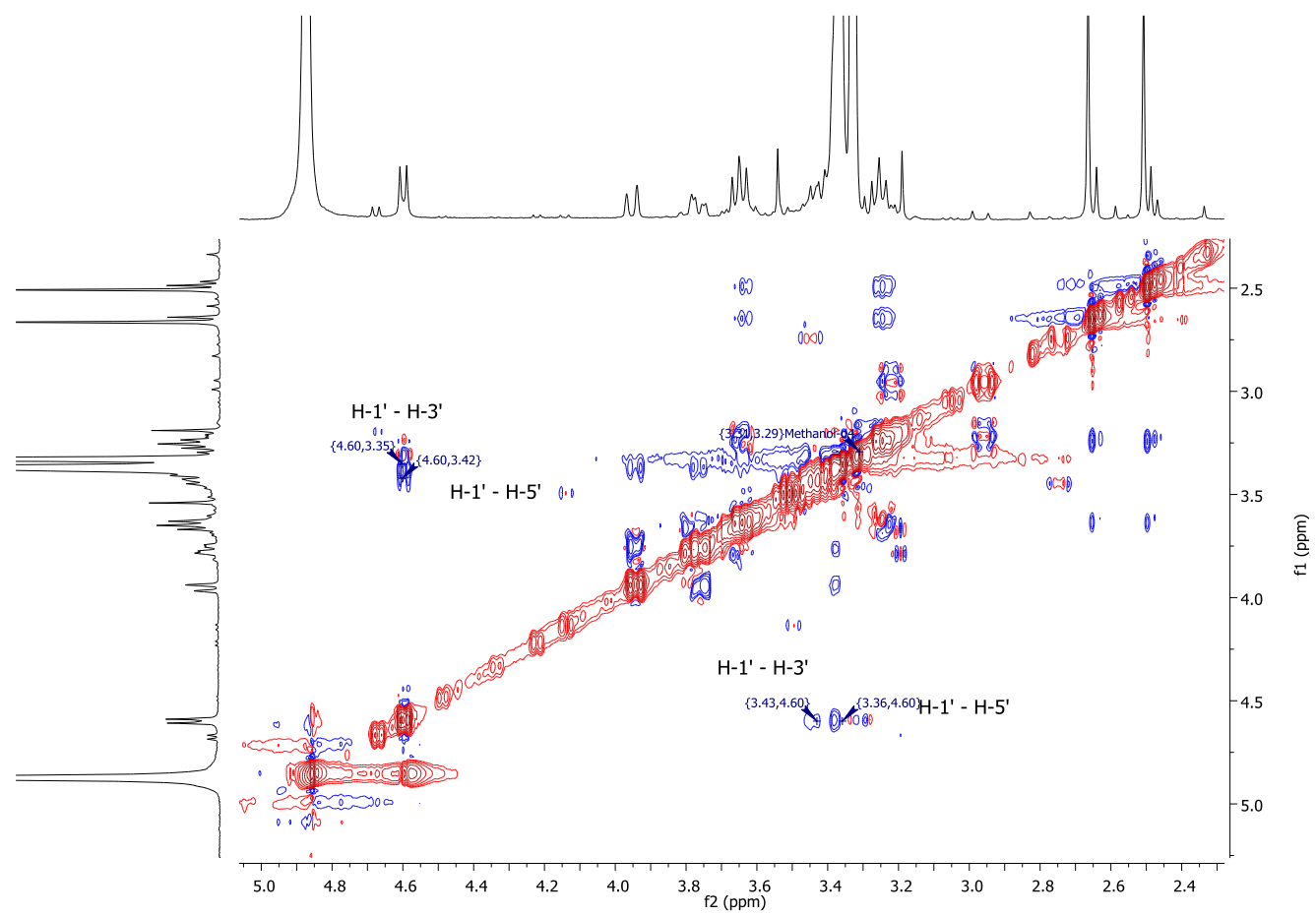

Figure S120. ${ }^{1} \mathrm{H}-{ }^{1} \mathrm{H}$ NOESY NMR $\left(\mathrm{CD}_{3} \mathrm{OD}, 400 \mathrm{MHz}\right)$ spectrum of compound 13. 


\section{Acetylation of compounds 2 and 10-13}

Accurately $1 \mathrm{mg}$ of each compound was dissolved with $100 \mu \mathrm{L}$ of dry pyridine in a HPLC vial and then $50 \mu \mathrm{L}$ of acetic anhydride was added. The vial was immersed and sonicated for 1 hour and left overnight. The reaction mixture was diluted with $400 \mu \mathrm{L}$ of $\mathrm{CDCl}_{3}$ containing tetramethylsilane (TMS) as an internal standard. ${ }^{1} \mathrm{H}$ NMR and COSY were recorded in the range of 3.0-6.0 ppm. DEPTQ was recorded from -50 to $250 \mathrm{ppm}$. 

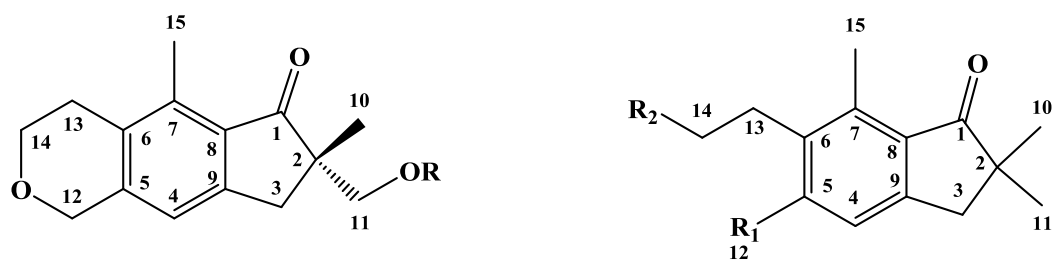

\begin{tabular}{ll} 
& \multicolumn{1}{c}{$\mathbf{R}$} \\
(1) & $\mathbf{H}$ \\
(2) $\beta$-D-Glc
\end{tabular}

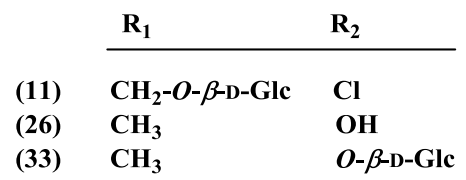<smiles>Cc1cc2c(c(C)c1CC(=O)O)C(=O)C(C)(C)[C@H]2O</smiles>

(6)<smiles>CCO[C@H]1c2cc(C)c(CCCl)c(C)c2C(=O)C1(C)C</smiles>

(13)<smiles>[R3]CCc1c([R4])cc2c(c1C)C(=O)[C@@]([Y3])(C)C2</smiles>

\begin{tabular}{|c|c|c|c|}
\hline & $\mathbf{R}_{\mathbf{3}}$ & $\mathbf{R}_{\mathbf{4}}$ & $\mathbf{R}_{5}$ \\
\hline (5) & OH & $\mathrm{CH}_{2} \mathrm{OH}$ & Cl \\
\hline (9) & $\mathbf{H}$ & $\mathrm{CH}_{3}$ & $\mathrm{OSO}_{3} \mathrm{H}$ \\
\hline (12) & $\mathbf{H}$ & $\mathrm{CH}_{2}-O-\beta$-D-Glc & Cl \\
\hline
\end{tabular}<smiles>Cc1c2c(cc3c1C(=O)[C@](C)(O)C3)C(=O)OCC2</smiles>

(3)<smiles>Cc1cc2c(c(C)c1[C@H](O)CCl)C(=O)[C@@](C)(CO)C2</smiles>

(7)<smiles>Cc1c2c(cc3c1C(=O)[C@](C)(O)C3)COC(=O)C2</smiles>

(4)<smiles>Cc1cc2c(c(C)c1[C@H](O)CCl)C(=O)[C@@](C)(O)C2</smiles>

(8)<smiles>Cc1cc2c(c(C)c1CC(=O)O)C(=O)[C@H](C)[C@H]2O</smiles>

(28)

Fig. 1. Chemical structures of isolated novel and known compounds from bracken rhizomes where compounds 1-9 \& 11-13 represent new natural products. 


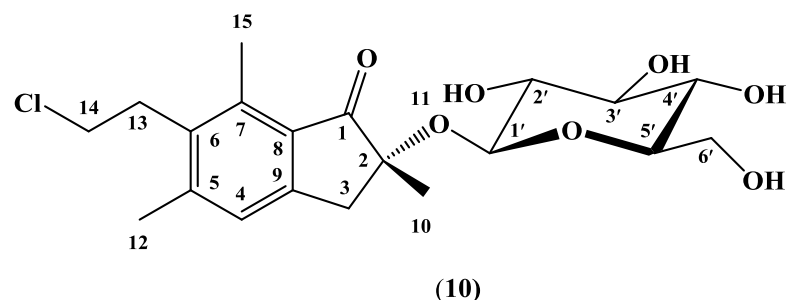

(2R)-rhedynoside B

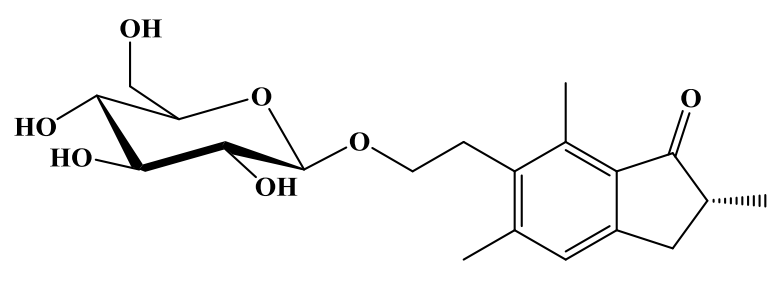

(31)

(2R)-pteroside B

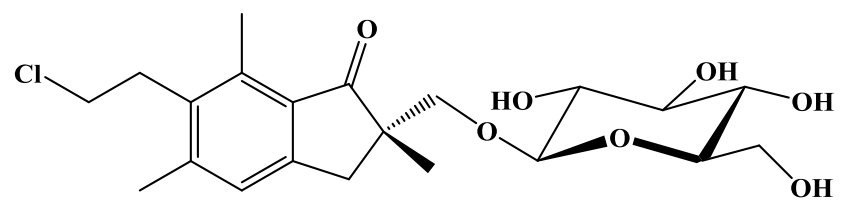

(35)

(2S)-pteroside K

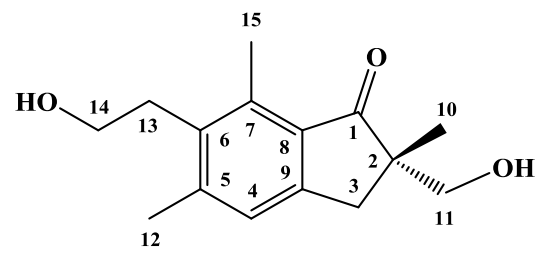

(15)

(2S)-pterosin A<smiles>Cc1cc2c(c(C)c1CCO)C(=O)[C@H](C)[C@H]2O</smiles>

(17)

trans-pterosin C

$(2 R, 3 R)$

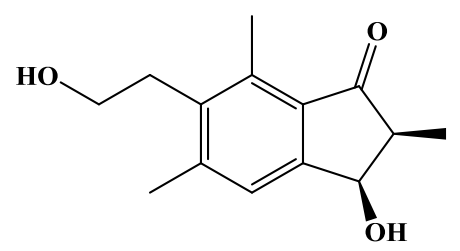

(18)

cis-pterosin C

$(2 S, 3 R)$

Fig. 2. The absolute stereochemistry of compounds $10,15,17,18,31$ and 35 obtained from bracken rhizomes, as established by X-ray crystallography (Figs. 5, 6 and SI2). Compound 10 represent a new natural product. The aglycone moiety is numbered $1-15$; the sugar moiety is numbered 1'-6'. 
<smiles>[R]Cc1c(C)cc2c(c1C)C(=O)[C@H](C)C2</smiles>

$$
\begin{array}{ll} 
& \multicolumn{1}{c}{\mathrm{R}} \\
\cline { 2 - 2 } \text { (16) } & \mathrm{CH}_{2} \mathrm{OH} \\
\text { (20) } & \mathrm{COOH} \\
\text { (21) } & \mathrm{CH}_{2} \mathrm{Cl}
\end{array}
$$<smiles>Cc1cc2c(c(C)c1CCCl)C(=O)[C@H](C)[C@H]2O</smiles>

(22)<smiles>[R]CCc1c(C)cc2c(c1C)C(=O)C(C)(C)[C@H]2O</smiles>

$$
\begin{array}{ll} 
& \multicolumn{1}{c}{\mathrm{R}_{1}} \\
\text { (19) } & \mathrm{OH} \\
\text { (32) } & O-\beta \text {-D-Glc }
\end{array}
$$

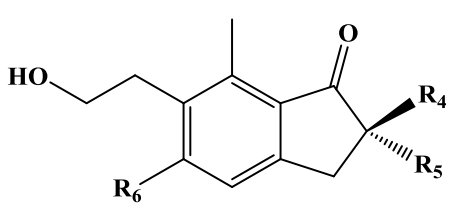

$$
\begin{array}{llll} 
& \mathbf{R}_{4} & \mathbf{R}_{5} & \mathbf{R}_{6} \\
\cline { 2 - 4 } \text { (24) } & \mathrm{OH} & \mathrm{CH}_{3} & \mathrm{CH}_{3} \\
\text { (25) } & \mathrm{CH}_{3} & \mathbf{H} & \mathrm{CH}_{2} \mathrm{OH} \\
\text { (34) } & \mathrm{CH}_{3} & \mathrm{CH}_{2}-O-\beta \text {-D-Glc } & \mathrm{CH}_{3}
\end{array}
$$
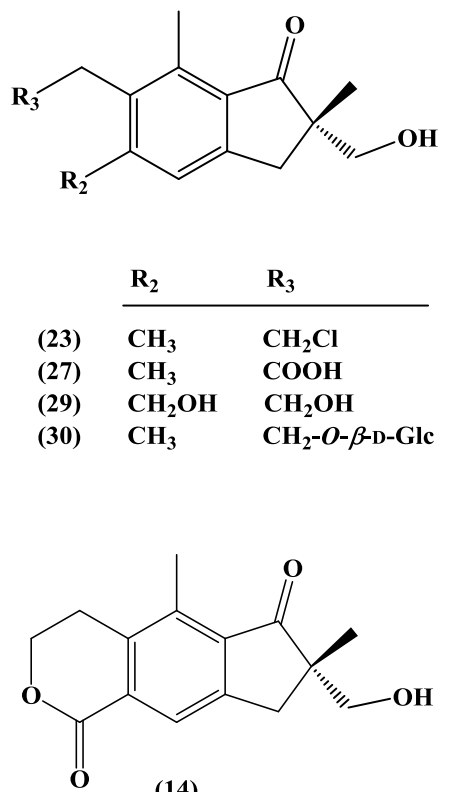

(14)

Fig. 3. Chemical structures of pterosins and pterosides 14, 27, 29 (Lee et al., 2012), 16, 30, 32 (Kuroyanagi et al., 1979), 19-25 (Fukuoka et al., 1978) and 34 (Castillo et al., 2003) obtained from bracken rhizomes with their absolute stereochemistry. 


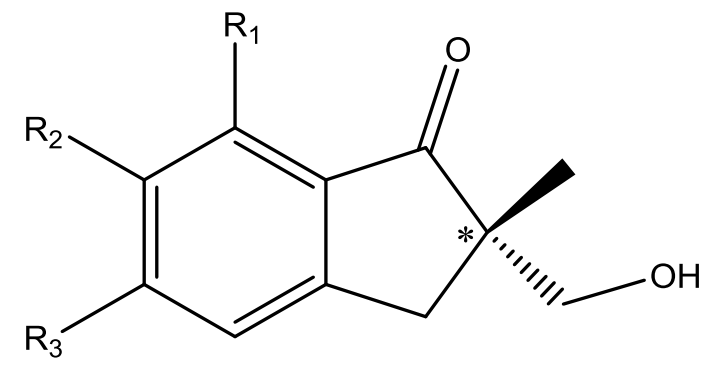

Fig. 4. Chromophore core in compounds 1, 2, 7, 14, 15, 23, 27, 29 and 30, 


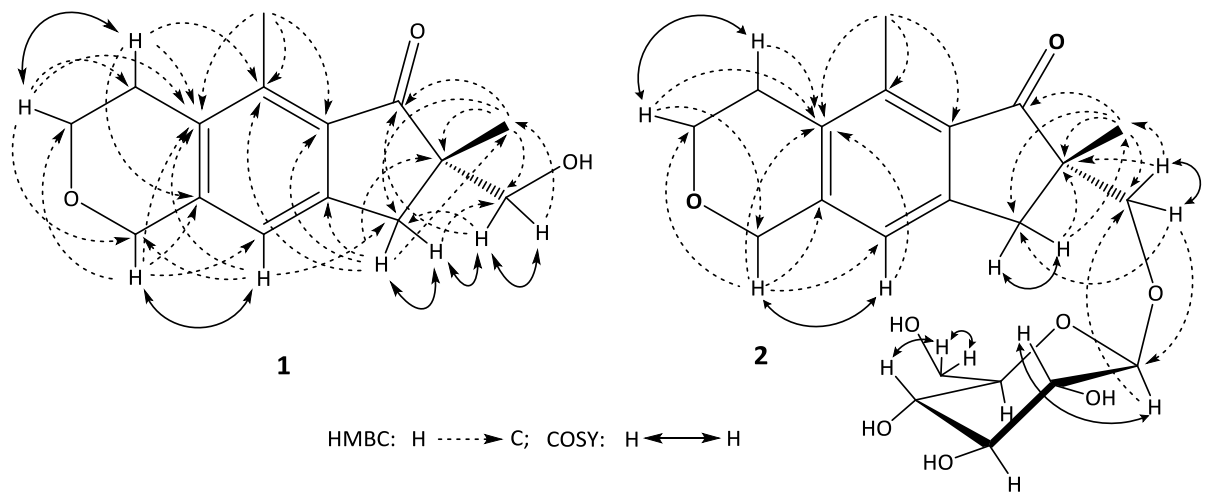

Fig. 5. Key HMBC and COSY correlations of compounds 1 and 2. 


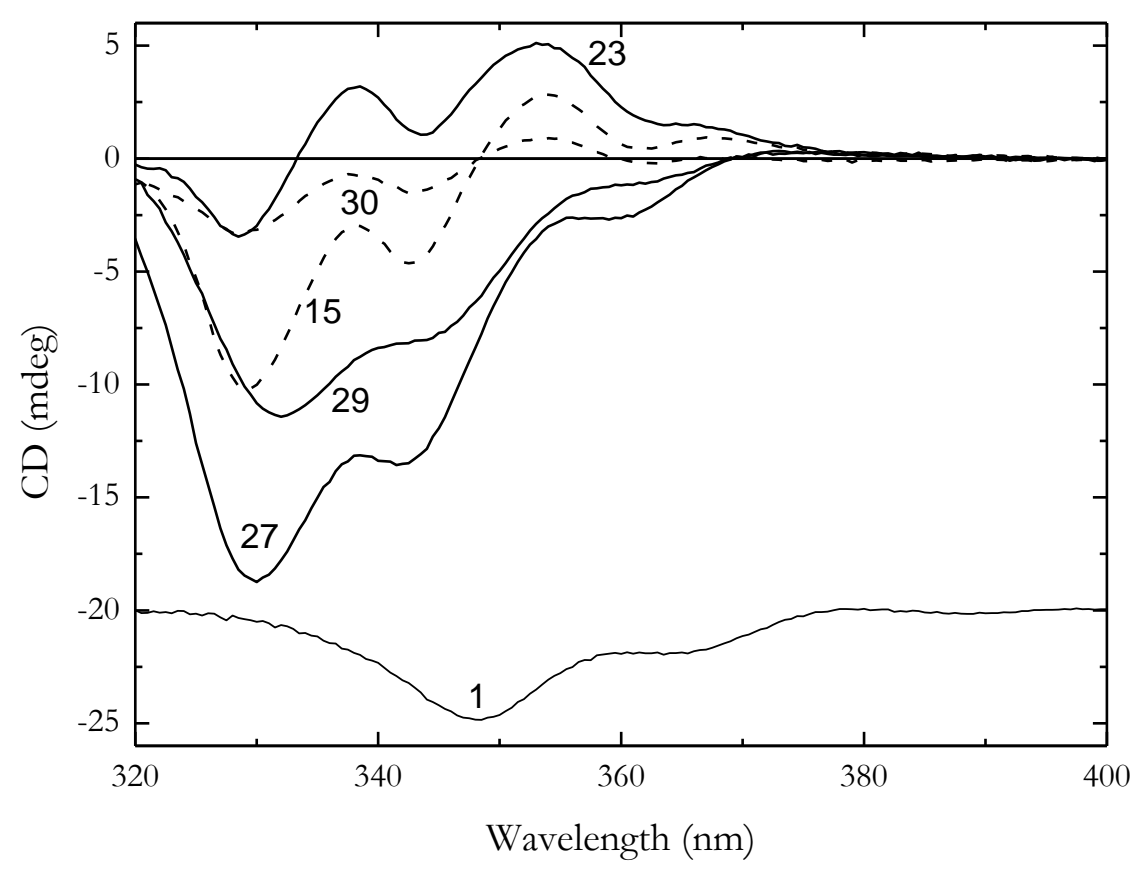

Fig. 6. The CD spectra of $\mathbf{1}, \mathbf{1 5}, \mathbf{2 3}, \mathbf{2 7}, \mathbf{2 9}$, and $\mathbf{3 0}$ in methanol illustrating the superposition of a longer wavelength positively signed vibronic progression and a shorter wavelength negatively signed vibronic progression. The CD of $\mathbf{1}$ has been offset by -20 mdeg to indicate the overall shift to longer wavelength of the $n \rightarrow \pi^{*}$ as the compound is tricyclic. 


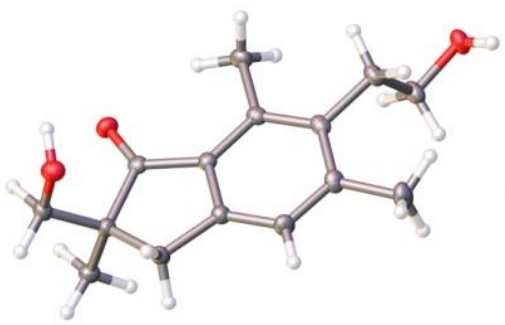

(15)

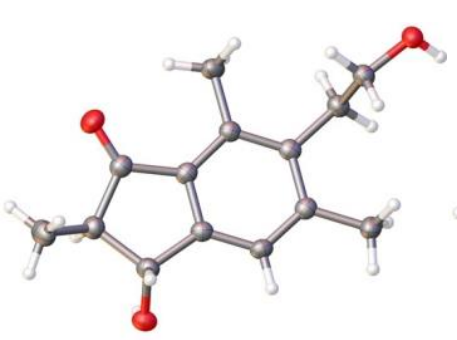

(17)

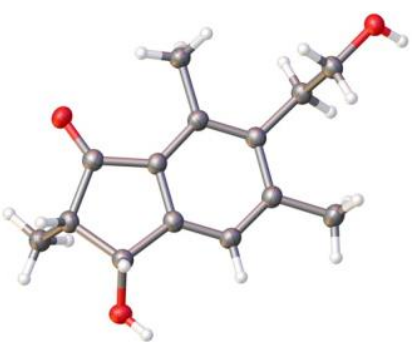

(18)

(2S)-pterosin A

trans-pterosin C

cis-pterosin C

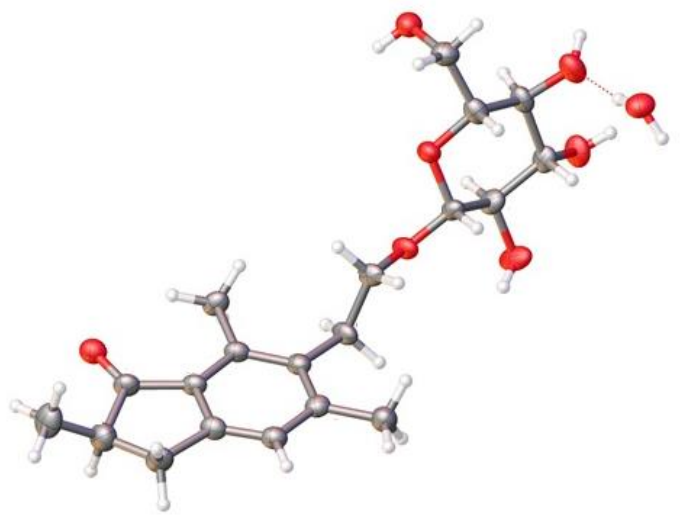

(31)

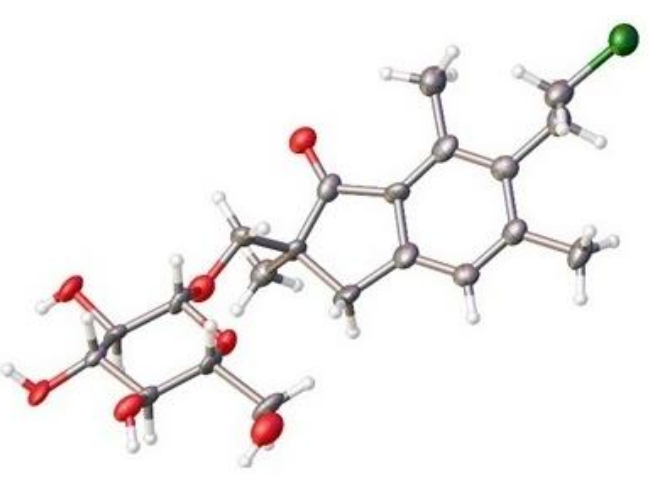

(35)

$(2 R)$-pteroside B

(2S)-pteroside K

Fig. 7. X-ray crystal structures showing absolute configurations of 15, 17, 18, 31 and 35. 


\section{Note:}

In Fig. 7, thermal ellipsoid plots of four crystal structures (cis-pterosin C, trans-pterosin C, $(2 S)$ pterosin A, $(2 R)$-pteroside B and (2S)-pteroside $\mathrm{K})$ with ellipsoids shown at $50 \%$ probability. N.B. pteroside $\mathrm{K}$ crystallises as a hemihydrate with four molecules of pteroside $\mathrm{K}$ and two molecules of water in the asymmetric unit. Only one molecule of the pteroside $\mathrm{K}$ structure is shown here for clarity.

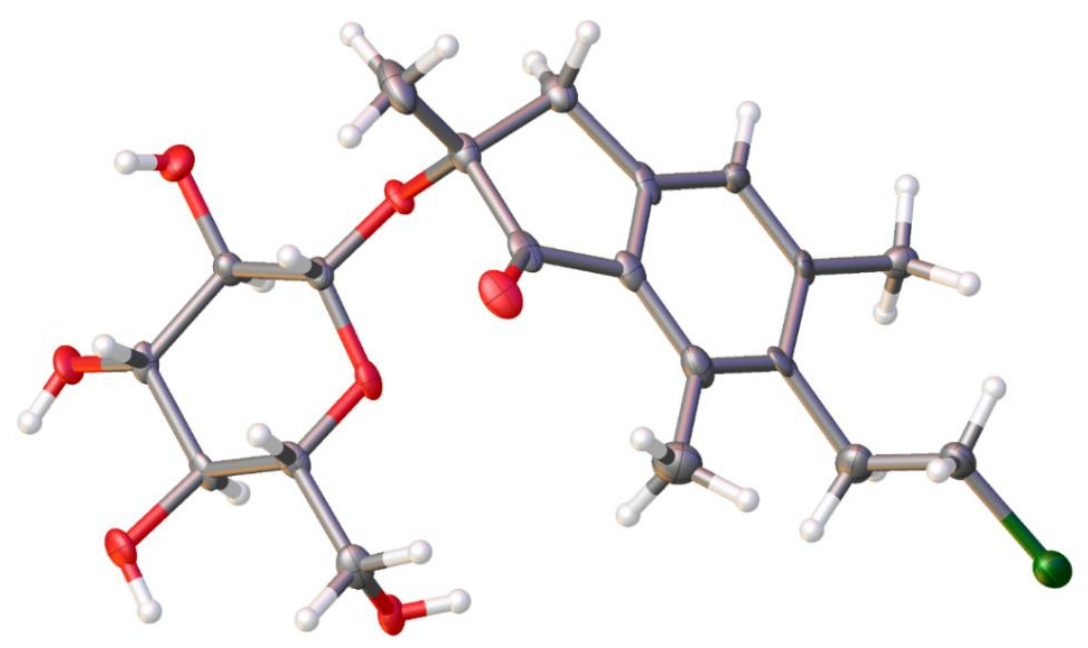

Fig. 8. Thermal ellipsoid plot of rhedynoside B (10) with ellipsoids shown at $50 \%$ probability. N.B. rhedynoside B crystallises as a hemihydrate with four molecules of rhedynoside B and two molecules of water in the asymmetric unit. Only one molecule of the rhedynoside B structure is shown here for clarity. 


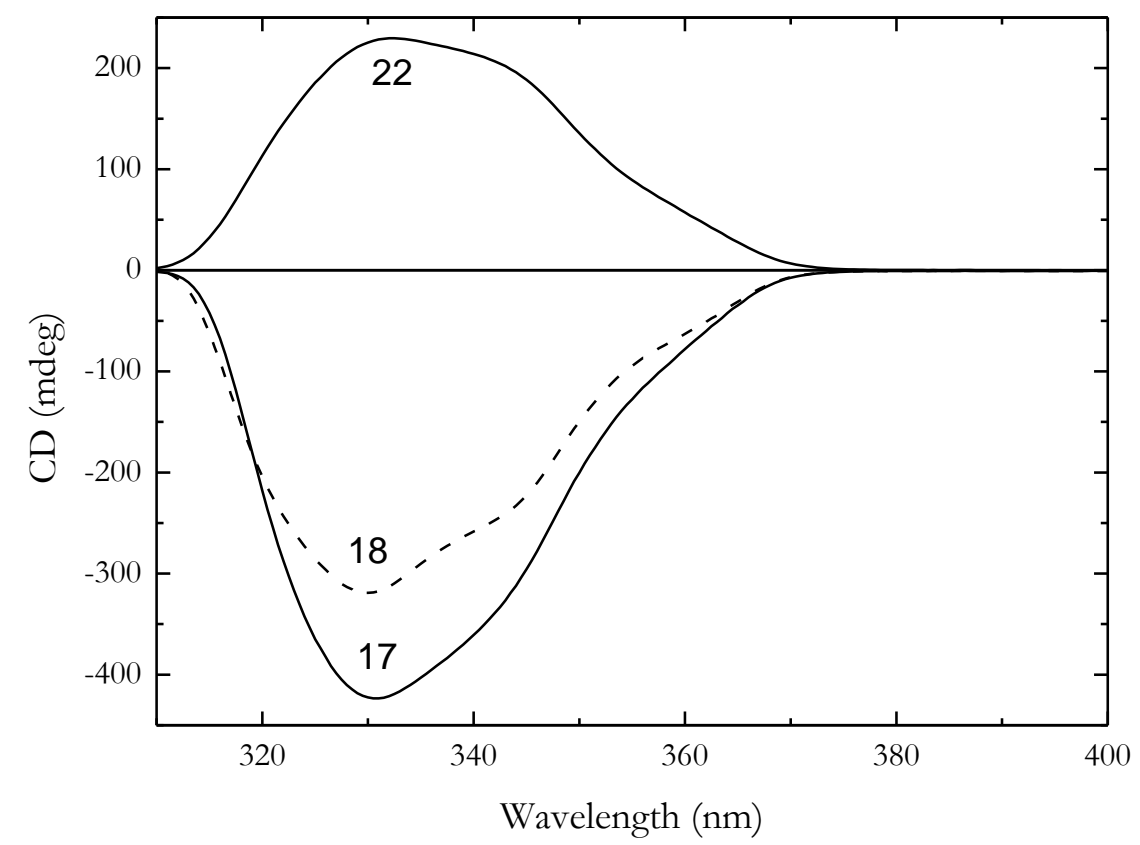

Fig. 9. The CD spectra of $\mathbf{1 7}, \mathbf{1 8}$, and $\mathbf{2 2}$ recorded in methanol. 


\section{Table 1}

${ }^{1} \mathrm{H}$ NMR (400 MHz) spectral data ${ }^{ \pm}$of compounds $\mathbf{1}, \mathbf{3} \& \mathbf{5}$ in $\mathrm{CDCl}_{3}$ and $\mathbf{2} \& \mathbf{4}$ in $\mathrm{CD}_{3} \mathrm{OD}(\delta$ in ppm,

\begin{tabular}{|c|c|c|c|c|c|}
\hline No. & $\begin{array}{l}\mathbf{1} \\
\delta_{\mathrm{H}} \\
\end{array}$ & $\begin{array}{l}2 \\
\delta_{\mathrm{H}}\end{array}$ & $\begin{array}{l}\mathbf{3} \\
\delta_{\mathrm{H}} \\
\end{array}$ & $\begin{array}{l}4 \\
\delta_{\mathrm{H}}\end{array}$ & $\begin{array}{l}\mathbf{5} \\
\delta_{\mathrm{H}} \\
\end{array}$ \\
\hline 1 & - & - & - & - & - \\
\hline 2 & - & - & - & - & - \\
\hline 3 & $\begin{aligned} & 3.06,2.77(\mathrm{~d}, J \\
= & 17.5)\end{aligned}$ & $\begin{array}{l}3.45,2.75(\mathrm{~d}, J= \\
17.4)\end{array}$ & $3.22(\mathrm{~s})$ & $\begin{array}{l}3.19,3.10(\mathrm{~d}, \\
J=17.0)\end{array}$ & $\begin{aligned} & 3.15(\mathrm{~d}, J \\
= & 2.8)\end{aligned}$ \\
\hline 4 & $6.93(\mathrm{~s})$ & $7.01(\mathrm{~s})$ & $8.05(\mathrm{~s})$ & $7.29(\mathrm{~s})$ & $7.39(\mathrm{~s})$ \\
\hline 5 & - & - & - & - & - \\
\hline 6 & - & - & - & - & - \\
\hline 7 & - & - & - & - & - \\
\hline 8 & - & - & - & - & - \\
\hline 9 & - & - & - & - & - \\
\hline 10 & $1.23(\mathrm{~s})$ & $1.14(\mathrm{~s})$ & $1.42(\mathrm{~s})$ & $1.36(\mathrm{~s})$ & $1.40(\mathrm{~s})$ \\
\hline 11 & $\begin{array}{l}3.78,3.62 \\
(\mathrm{~d}, J=10.8)\end{array}$ & $\begin{array}{l}4.13,3.48 \\
(\mathrm{~d}, J=9.4)\end{array}$ & - & - & - \\
\hline 12 & $4.80(\mathrm{~s})$ & $4.79(\mathrm{~s})$ & - & $5.40(\mathrm{~s})$ & $4.84(\mathrm{~s})$ \\
\hline 13 & $2.76(\mathrm{t}, J=5.9)$ & $2.77(\mathrm{t}, J=5.9)$ & $\begin{array}{l}3.05(\mathrm{t}, J= \\
6.0)\end{array}$ & $3.83(\mathrm{~s})$ & $\begin{aligned} & 3.21(\mathrm{t}, J \\
= & 8.0)\end{aligned}$ \\
\hline 14 & $\begin{array}{l}4.01(\mathrm{td}, \quad J= \\
1.3,5.9,11.8)\end{array}$ & $4.00(\mathrm{t}, J=5.9)$ & $\begin{array}{l}4.55(\mathrm{t}, J= \\
6.0)\end{array}$ & - & $\begin{aligned} & 3.62(\mathrm{t}, J \\
= & 8.0)\end{aligned}$ \\
\hline 15 & $2.56(\mathrm{~s})$ & $2.54(\mathrm{~s})$ & $2.64(\mathrm{~s})$ & $2.62(\mathrm{~s})$ & $2.67(\mathrm{~s})$ \\
\hline $1^{\prime}$ & & $4.21\left(\mathrm{~d}, J_{1^{\prime}, 2^{\prime}}=7.8\right)$ & & & \\
\hline $2^{\prime}$ & & $3.03\left(\mathrm{dd}, J_{2^{\prime}, 3^{\prime}}=8.9\right)$ & & & \\
\hline $3^{\prime}$ & & $3.29(\mathrm{~m})$ & & & \\
\hline $4^{\prime}$ & & $3.24(\mathrm{~m})$ & & & \\
\hline $5^{\prime}$ & & $3.20(\mathrm{~m})$ & & & \\
\hline 6'a & & $\begin{array}{l}3.78\left(\mathrm{dd}, \quad J_{5^{\prime}, 6^{\prime} \mathrm{a}}=\right. \\
\left.1.5, J_{6^{\prime} \mathrm{a}, 6^{\prime} \mathrm{b}}=12.0\right)\end{array}$ & & & \\
\hline $6^{\prime} \mathrm{b}$ & & $3.61\left(\mathrm{dd}, J_{5^{\prime}, 6 \mathrm{~b}}=4.6\right)$ & & & \\
\hline
\end{tabular}

Assignments were confirmed by coupling constants, COSY, DEPTQ, HSQC and HMBC experiments.

$J$ in $\mathrm{Hz}$ ). 


\section{Table 2}

${ }^{1} \mathrm{H}$ NMR spectral data ${ }^{ \pm} \ddagger$ of compounds $6 \& 9$ in $\mathrm{CD}_{3} \mathrm{OD}, 7$ in $\mathrm{CDCl}_{3}$ and 8 in $\left(\mathrm{CD}_{3}\right)_{2} \mathrm{CO}(\delta$ in ppm, $J$ in $\mathrm{Hz}$ ).

\begin{tabular}{|c|c|c|c|c|}
\hline No. & $\begin{array}{l}6 \\
\delta_{\mathrm{H}} \\
\end{array}$ & $\begin{array}{l}7 \\
\delta_{\mathrm{H}} \\
\end{array}$ & $\begin{array}{l}8 \\
\delta_{\mathrm{H}} \\
\end{array}$ & $\begin{array}{l}9 \\
\delta_{\mathrm{H}} \\
\end{array}$ \\
\hline 1 & - & - & - & - \\
\hline 2 & - & - & - & $2.63(\mathrm{~m})$ \\
\hline 3 & (s) ${ }^{4.76}$ & $3.08,2.74(\mathrm{~d}, J=17.3)$ & $3.05(\mathrm{~d}, J=9.5)$ & $\begin{array}{ll}3.27, & 2.59 \\
(\mathrm{~m}) & \end{array}$ \\
\hline 4 & $(\mathrm{~s})^{7.39}$ & $7.11(\mathrm{~s})$ & $7.13(\mathrm{~s})$ & $7.16(\mathrm{~s})$ \\
\hline 5 & - & - & - & - \\
\hline 6 & - & - & - & - \\
\hline 7 & - & - & - & - \\
\hline 8 & - & - & - & - \\
\hline 9 & - & - & - & - \\
\hline 10 & $(\mathrm{~s})^{1.19}$ & $1.20(\mathrm{~s})$ & $1.32(\mathrm{~s})$ & $\frac{1.23}{7.5)}(\mathrm{d}, J=$ \\
\hline 11 & (s) 1.05 & $3.79,3.59(\mathrm{~d}, J=10.7)$ & - & - \\
\hline 12 & $(\mathrm{~s})^{2,44}$ & $2.53(\mathrm{~s})$ & 2.55 & $2.46(\mathrm{~s})$ \\
\hline 13 & (s) 3.78 & $5.41(\mathrm{dd}, J=3.5,10.0)$ & $5.45(\mathrm{dd}, J=5.2,8.7)$ & $\begin{array}{l}3.15(\mathrm{t}, J= \\
8.0)\end{array}$ \\
\hline 14 & - & $\begin{array}{l}3.98\left(\mathrm{dd}, J_{13,14 \mathrm{a}}=10.2\right. \\
\left.J_{14 \mathrm{a}, 14 \mathrm{~b}}=11.4\right) \\
3.65\left(\mathrm{dd}, J_{13,14 \mathrm{~b}}=3.7\right)\end{array}$ & $\begin{array}{l}3.98\left(\mathrm{dd}, J_{13,14 \mathrm{a}}=8.7\right. \\
\left.J_{14 \mathrm{a}, 14 \mathrm{~b}}=11.2\right) \\
3.81\left(\mathrm{dd}, J_{13,14 \mathrm{~b}}=5.2\right)\end{array}$ & $\begin{array}{l}4.05(\mathrm{t}, J= \\
8.0)\end{array}$ \\
\hline 15 & $(\mathrm{~s})^{2.61}$ & $2.77(\mathrm{~s})$ & $2.75(\mathrm{~s})$ & $2.67(\mathrm{~s})$ \\
\hline
\end{tabular}

Assignments were confirmed by coupling constants, COSY, DEPTQ, HSQC and HMBC experiments.

${ }^{\ddagger}{ }^{1} \mathrm{H}$ NMR data measured at $400 \mathrm{MHz}$ for compounds $\mathbf{6}, 7 \& \mathbf{8}$, and at $500 \mathrm{MHz}$ for compound 9. 
Table 3

\begin{tabular}{|c|c|c|c|c|}
\hline No. & $\begin{array}{l}\mathbf{1 0} \\
\delta_{\mathrm{H}} \\
\end{array}$ & $\begin{array}{l}\mathbf{1 1} \\
\delta_{\mathrm{H}} \\
\end{array}$ & $\begin{array}{l}\mathbf{1 2} \\
\delta_{\mathrm{H}} \\
\end{array}$ & $\begin{array}{l}13 \\
\delta_{\mathrm{H}} \\
\end{array}$ \\
\hline 1 & - & - & - & - \\
\hline 2 & - & - & $2.66(\mathrm{~m})$ & - \\
\hline 3 & $\begin{array}{l}3.45,3.08(\mathrm{~d}, J= \\
17.4)\end{array}$ & $2.93(\mathrm{~s})$ & $3.33,2.64(\mathrm{~m})$ & $4.85(\mathrm{~s})$ \\
\hline 4 & $7.17(\mathrm{~s})$ & $7.50(\mathrm{~s})$ & $7.51(\mathrm{~s})$ & $7.56(\mathrm{~s})$ \\
\hline 5 & - & - & - & - \\
\hline 6 & - & - & - & - \\
\hline 7 & - & - & - & - \\
\hline 8 & - & - & - & - \\
\hline 9 & - & - & - & - \\
\hline 10 & $1.44(\mathrm{~s})$ & $1.17(\mathrm{~s})$ & $1.25(\mathrm{~d}, J=7.2)$ & $1.28(\mathrm{~s})$ \\
\hline 11 & - & $1.17(\mathrm{~s})$ & - & $1.09(\mathrm{~s})$ \\
\hline 12 & $2.45(\mathrm{~s})$ & $\begin{array}{l}4.78,5.11(\mathrm{~d}, J= \\
12.4)\end{array}$ & $\begin{array}{l}4.78,5.10(\mathrm{~d}, J= \\
12.3)\end{array}$ & $2.49(\mathrm{~s})$ \\
\hline 13 & $3.22(\mathrm{t}, J=8.0)$ & $3.26(\mathrm{~m})$ & $3.26(\mathrm{t}, J=8.0)$ & $3.24(\mathrm{t}, J=8.0)$ \\
\hline 14 & $3.63(\mathrm{t}, J=8.0)$ & $3.63(\mathrm{~m})$ & $3.70(\mathrm{t}, J=8.0)$ & $3.63(\mathrm{t}, J=8.0)$ \\
\hline 15 & $2.65(\mathrm{~s})$ & $2.66(\mathrm{~s})$ & $2.66(\mathrm{~s})$ & $2.65(\mathrm{~s})$ \\
\hline $1^{\prime}$ & $4.42\left(\mathrm{~d}, J_{1^{\prime}, 2^{\prime}}=7.8\right)$ & $4.40(\mathrm{~d}, J=7.7)$ & $4.39(\mathrm{~d}, J=7.7)$ & $4.58(\mathrm{~d}, J=7.7)$ \\
\hline $2^{\prime}$ & $\begin{array}{l}3.16\left(\mathrm{dd}, J_{2^{\prime}}, 3^{\prime}=\right. \\
8.0)\end{array}$ & $3.29(\mathrm{~m})$ & $3.26(\mathrm{~m})$ & $3.30(\mathrm{~m})$ \\
\hline $3^{\prime}$ & $3.32^{++}$ & $3.31(\mathrm{~m})$ & $3.31(\mathrm{~m})$ & $3.36(\mathrm{~m})$ \\
\hline $4^{\prime}$ & $\begin{array}{l}3.28\left(\mathrm{dd} \sim \mathrm{t}, J_{3^{\prime}, 4^{\prime}}=\right. \\
8.9)\end{array}$ & $3.31(\mathrm{~m})$ & $3.31(\mathrm{~m})$ & $3.36(\mathrm{~m})$ \\
\hline $5^{\prime}$ & $3.12(\mathrm{~m})$ & $3.36(\mathrm{~m})$ & $3.36(\mathrm{~m})$ & $3.42(\mathrm{~m})$ \\
\hline $6^{\prime} \mathrm{a}$ & $\begin{array}{l}3.70\left(\mathrm{dd}, J_{5^{\prime},}, 6^{\prime} \mathrm{a}=\right. \\
\left.2.5, J_{6^{\prime} \mathrm{a}, 6^{\prime} \mathrm{b}}=12.0\right)\end{array}$ & $\begin{array}{l}3.92\left(\mathrm{dd}, J_{5^{\prime},}, 6^{\prime} \mathrm{a}=\right. \\
\left.2.0, J_{6^{\prime} \mathrm{a}, 6^{\prime} \mathrm{b}}=12.0\right)\end{array}$ & $\begin{array}{l}3.92\left(\mathrm{dd}, J_{5^{\prime},} 6^{\prime} \mathrm{a}=\right. \\
\left.1.5, J_{6^{\prime} \mathrm{a}, 66^{\prime} \mathrm{b}}=11.5\right)\end{array}$ & $\begin{array}{l}3.93\left(\mathrm{dd}, J_{5^{\prime}, 6^{\prime} \mathrm{a}}=\right. \\
\left.1.5, J_{6^{\prime} \mathrm{a}, 6^{\prime} \mathrm{b}}=11.8\right)\end{array}$ \\
\hline $6^{\prime} b$ & $\begin{array}{l}3.60\left(\mathrm{dd}, J_{5^{\prime}}, 6^{\prime} \mathrm{b}\right. \\
5.0)\end{array}$ & $\begin{array}{l}3.70\left(\mathrm{dd}, J_{5^{\prime}, 6 \mathrm{~b}}=\right. \\
4.0)\end{array}$ & $\begin{array}{l}3.69\left(\mathrm{dd}, J_{5^{\prime}}, 6^{\prime} \mathrm{b}=\right. \\
3.0)\end{array}$ & $\begin{array}{l}3.75\left(\mathrm{dd}, J_{5^{\prime}, 6^{\prime} \mathrm{b}}=\right. \\
4.0)\end{array}$ \\
\hline
\end{tabular}

${ }^{ \pm}$Assignments were confirmed by coupling constants, COSY, DEPTQ, HSQC and HMBC experiments.

${ }^{++}$Signal under solvent, confirmed by HSQC experiment.

${ }^{1} \mathrm{H}$ NMR (400 MHz) spectral data ${ }^{ \pm}$of compounds 10-13 in $\mathrm{CD}_{3} \mathrm{OD}(\delta$ in ppm, $J$ in $\mathrm{Hz}$ ). 


\section{Table 4}

\begin{tabular}{|c|c|c|c|c|c|c|c|c|c|c|c|c|c|}
\hline${ }_{0 .}^{\mathrm{N}}$ & $\begin{array}{l}\mathbf{1}^{+} \\
\delta_{\mathrm{C}}\end{array}$ & $\begin{array}{r}\mathbf{2}^{+} \\
+\quad \delta_{\mathrm{C}}\end{array}$ & $\begin{array}{l}\mathbf{3}^{+} \\
\delta_{\mathrm{C}}\end{array}$ & $\begin{array}{r}\mathbf{4}^{+} \\
+\quad \delta_{\mathrm{C}}\end{array}$ & $\begin{array}{l}\mathbf{5}^{+} \\
\delta_{\mathrm{C}}\end{array}$ & $\begin{array}{r}6 \\
+\quad \\
\end{array}$ & $\partial_{\mathrm{C}}$ & $\begin{array}{l}\mathbf{8}^{\dagger} \\
\delta_{\mathrm{C}}\end{array}$ & $\begin{array}{r}9^{+} \\
+\quad \delta_{\mathrm{C}}\end{array}$ & $\begin{array}{l}\mathbf{1 0} \\
\delta_{\mathrm{C}}\end{array}$ & $\begin{array}{l}11 \\
\delta_{\mathrm{C}}\end{array}$ & $\begin{array}{r}12 \\
+\quad \begin{array}{l}12 \\
\delta_{\mathrm{C}}\end{array}\end{array}$ & $\begin{array}{r}13 \\
++ \\
\delta_{\mathrm{C}}\end{array}$ \\
\hline
\end{tabular}

\begin{tabular}{|c|c|c|c|c|c|c|c|c|c|c|c|c|c|}
\hline 1 & 21 & 21 & 20 & 20 & 20 & 21 & 21 & 20 & 20 & 20 & 21 & 21 & 21 \\
\hline & 0.5 & 2.4 & 9.2 & 9.7 & 8.9 & 1.6 & 1.7 & 8.5 & 8.8 & 7.3 & 1.2 & 2.5 & 1.2 \\
\hline & 50 & 51 & 78 & 78 & 77 & 52 & 51 & 77 & 43 & 84 & 46 & 43 & 52 \\
\hline & .9 & .5 & .0 & .1 & .8 & .5 & .0 & .4 & .7 & .1 & .9 & .9 & .6 \\
\hline & 37 & 37 & 41 & 42 & 41 & 77 & 36 & 42 & 34 & 40 & 42 & 34 & 86 \\
\hline & .1 & .7 & .4 & .9 & .4 & .6 & .8 & .2 & .6 & .9 & .7 & .9 & .1 \\
\hline 4 & 12 & 12 & 12 & 12 & 12 & 12 & 12 & 12 & 12 & 12 & 12 & 12 & 12 \\
\hline & 0.0 & 1.2 & 6.3 & 1.9 & 4.0 & 6.0 & 7.5 & 8.0 & 6.9 & 7.3 & 6.5 & 6.4 & 7.0 \\
\hline 5 & 14 & 14 & 13 & 14 & 14 & 14 & 14 & 14 & 14 & 14 & 14 & 14 & 14 \\
\hline$J$ & 2.1 & .6 & 8.2 & 0.5 & 6.9 & 6.6 & 4.8 & 5.7 & 6.8 & 7.2 & 4.9 & 4.7 & 6.0 \\
\hline 6 & 13 & 13 & 13 & 13 & 13 & 13 & 13 & 13 & 13 & 13 & 13 & 13 & 13 \\
\hline U & 1.8 & 2.9 & .6 & 6.9 & 4.7 & 6.0 & 5.4 & 4.6 & 5.3 & 6.7 & 6.5 & 6.4 & 6.8 \\
\hline 7 & 13 & 13 & 13 & 13 & 13 & 13 & 13 & 13 & 13 & 13 & 13 & 13 & 13 \\
\hline$t$ & 8.2 & 9.0 & 7.3 & 7.8 & 9.3 & 8.9 & 9.0 & 8.5 & 9.0 & 9.6 & 9.6 & 9.1 & 8.2 \\
\hline 8 & 13 & 12 & 13 & 13 & 13 & 13 & 13 & 13 & 13 & 13 & 13 & 13 & 13 \\
\hline & 1.3 & 7.3 & 0.7 & .3 & 1.0 & 1.1 & 2.4 & 1.1 & 2.5 & 1.5 & 3.4 & 4.4 & 1.0 \\
\hline 0 & 15 & 15 & 14 & 15 & 15 & 15 & 15 & 15 & 15 & 15 & 15 & 15 & 15 \\
\hline 7 & 1.0 & 3.1 & 9.7 & 2.1 & 1.0 & 4.3 & 4.0 & 1.9 & 5.0 & 2.3 & 3.4 & 4.7 & 2.5 \\
\hline 1 & 21 & 22 & 26 & 25 & 26 & 23 & 21 & 25 & 16 & 23 & 25 & 16 & 22 \\
\hline & .1 & .0 & .0 & .2 & .2 & .5 & .2 & .5 & .9 & .7 & .8 & .7 & .8 \\
\hline 1 & 68 & 75 & & & & 20 & 68 & & & & 25 & & 22 \\
\hline 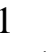 & .3 & .0 & & & & .7 & .1 & & & & .8 & & .0 \\
\hline 1 & 68 & 69 & 16 & 71 & 63 & 21 & 22 & 22 & 21 & 21 & 70 & 70 & 21 \\
\hline 2 & .8 & .6 & 5.0 & .1 & .8 & .6 & .2 & .0 & .4 & .3 & .2 & .2 & .3 \\
\hline 1 & 25 & 26 & 24 & 32 & 31 & 35 & 71 & 71 & 29 & 33 & 32 & 32 & 33 \\
\hline 3 & & .6 & .6 & & .7 & .1 & .5 & .4 & .3 & .0 & .5 & .5 & .1 \\
\hline 1 & 65 & 66 & 66 & 17 & 42 & 17 & 47 & 48 & 67 & 43 & 43 & 43 & 43 \\
\hline 4 & & .5 & .9 & 3.5 & & 5.3 & & & .4 & .1 & .8 & .8 & .0 \\
\hline 1 & 13 & 13 & 13 & 13 & 14 & 14 & 14 & 14 & 13 & 14 & 13 & 13 & \\
\hline 5 & .1 &.${ }^{.0}$ & .7 & .0 & .0 & .2 & .8 & .6 & .9 & .110 & $.7{ }_{10}$ & $.7{ }_{10}$ & .1 \\
\hline & & 4.7 & & & & & & & & 0.5 & 3.5 & 3.5 & .9 \\
\hline 2 & & 74 & & & & & & & & 75 & 75 & 75 & 75 \\
\hline & & .9 & & & & & & & & .1 & .2 & .2 & .3 \\
\hline 3 & & 78 & & & & & & & & 78 & 78 & 78 & 78 \\
\hline & & .1 & & & & & & & & .0 & .2 & .2 & .0 \\
\hline 4 & & 71 & & & & & & & & 71 & 71 & 71 & 71 \\
\hline & & .5 & & & & & & & & .3 & .8 & .8 & .7 \\
\hline 5 & & 77 & & & & & & & & 77 & 78 & 78 & 78 \\
\hline & & .9 & & & & & & & & .7 & .2 & .2 & .3 \\
\hline & & 62 & & & & & & & & 62 & 62 & 62 & \\
\hline & & .7 & & & & & & & & .5 & .9 & .9 & .9 \\
\hline
\end{tabular}

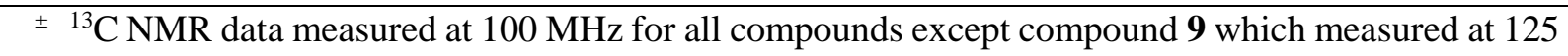
$\mathrm{MHz}$

$+{ }^{13} \mathrm{C}$ NMR data were taken in $\mathrm{CDCl}_{3}$

${ }^{++}{ }^{13} \mathrm{C}$ NMR data were taken in $\mathrm{CD}_{3} \mathrm{OD}$ 
${ }^{\dagger}{ }^{13} \mathrm{C}$ NMR data were taken in $\left(\mathrm{CD}_{3}\right)_{2} \mathrm{CO}$

${ }^{13} \mathrm{C}$ NMR spectral data ${ }^{ \pm}$of compounds $\mathbf{1 - 1 3}$ in ( $\delta$ in ppm). 